\title{
REMR Management Systems-Navigation and Flood Control Structures, Condition Rating Procedures for Lock and Dam Operating Equipment
}

by James H. Stecker, Lowell F. Greimann, Scott Mellema, and Kevin Rens Department of Civil and Construction Engineering lowa State University

and

Stuart D. Foltz

U.S. Army Construction Engineering Research Laboratories 


\section{REMR Management Systems- \\ Navigation and Flood Control Structures \\ Condition Rating Procedures \\ for Lock and Dam Operating Equipment}

by James H. Stecker, Lowell F. Greimann, Scott Mellema, and Kevin Rens

Department of Civil and Construction Engineering

lowa State University

Ames, IA 50011

and

Stuart D. Foltz

US Army Construction Engineering Research Laboratories

PO Box 9005

Champaign, IL 61826-9005

Approved for public release; distribution is unlimited

$\begin{array}{ll}\text { Prepared for } & \text { US Army Corps of Engineers } \\ & \text { Washington, DC 20314-1000 }\end{array}$

Under $\quad$ Civil Works Research Work Unit 32672

Monitored by Maintenance Management and Preservation Division US Army Construction Engineering Research Laboratories

PO Box 9005, Champaign, IL 61826-9005 


\section{Contents}

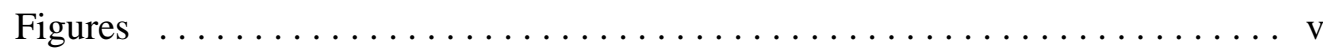

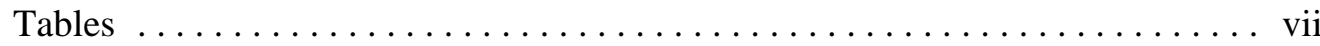

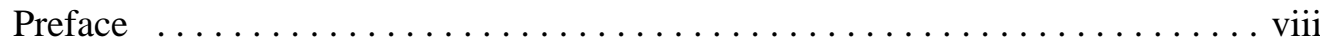

Conversion Factors, Non-SI to SI Units of Measurement $\ldots \ldots \ldots \ldots \ldots \ldots$ ix

$1 \quad$ Introduction $\ldots \ldots \ldots \ldots \ldots \ldots \ldots \ldots \ldots \ldots \ldots \ldots \ldots \ldots \ldots \ldots \ldots \ldots$

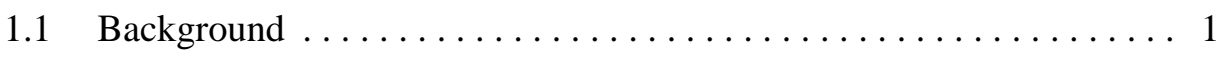

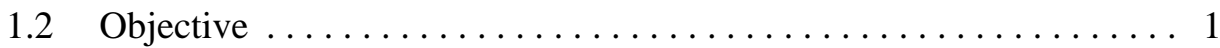

1.3 Mode of Technology Transfer $\ldots \ldots \ldots \ldots \ldots \ldots \ldots \ldots \ldots$

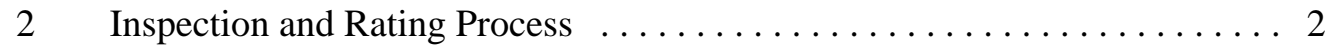

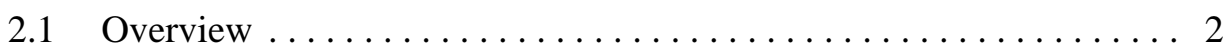

2.2 Inspection and Rating Procedure $\ldots \ldots \ldots \ldots \ldots \ldots \ldots \ldots \ldots$

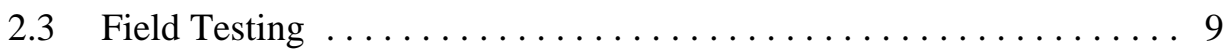

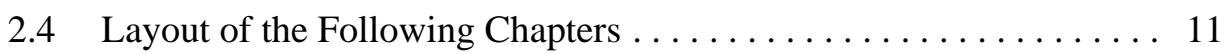

3 Inspection Form: Historical Information $\ldots \ldots \ldots \ldots \ldots \ldots \ldots \ldots$

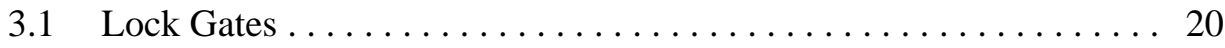

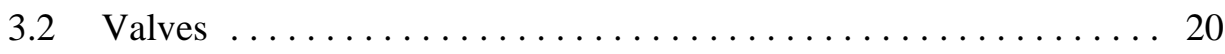

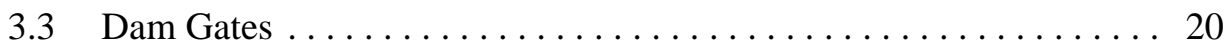

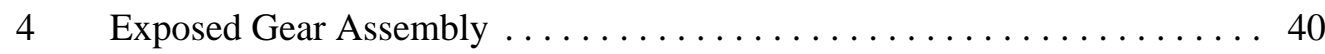

4.1 Component Identification $\ldots \ldots \ldots \ldots \ldots \ldots \ldots \ldots \ldots \ldots$

4.2 Inspection Form With Comments $\ldots \ldots \ldots \ldots \ldots \ldots \ldots \ldots \ldots$

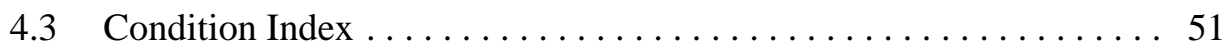

4.4 Field Test .......................... 57

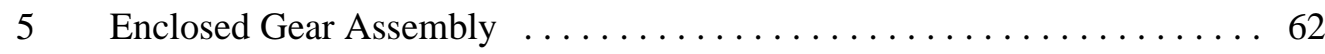

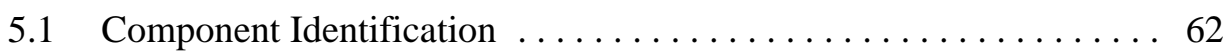

5.2 Inspection Form With Comments $\ldots \ldots \ldots \ldots \ldots \ldots \ldots \ldots \ldots \ldots \ldots \ldots$

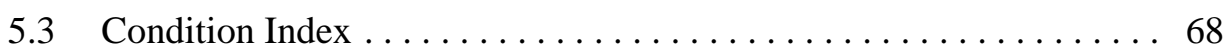

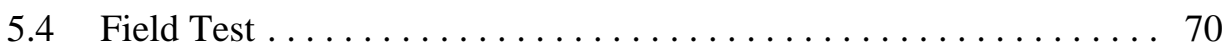


Gear Rack Assembly . . . . . . . . . . . . . . . . . . 76

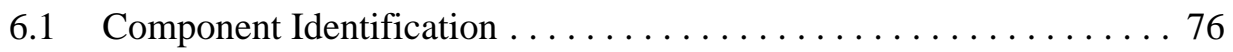

6.2 Inspection Form With Comments $\ldots \ldots \ldots \ldots \ldots \ldots \ldots \ldots$

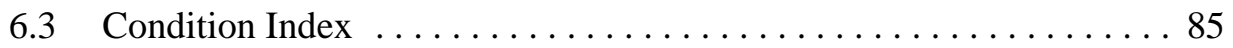

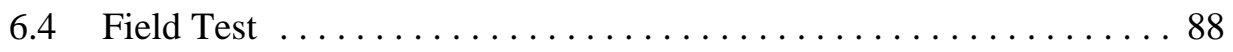

$7 \quad$ Strut Arm Assembly ............................. 93

7.1 Component Identification $\ldots \ldots \ldots \ldots \ldots \ldots \ldots \ldots \ldots \ldots \ldots$

7.2 Inspection Form With Comments $\ldots \ldots \ldots \ldots \ldots \ldots \ldots \ldots$

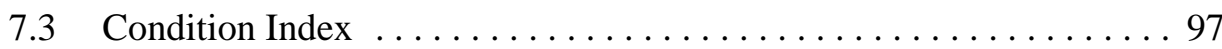

7.4 Field Test ............................. 99

$8 \quad$ Rocker Arm Assembly . . . . . . . . . . . . . . . . . . . . . . . . 103

8.1 Component Identification . . . . . . . . . . . . . . . . . . 103

8.2 Inspection Form With Comments $\ldots \ldots \ldots \ldots \ldots \ldots \ldots \ldots$

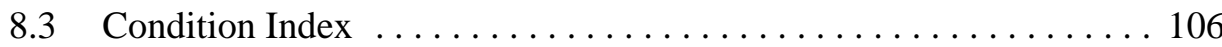

8.4 Field Tests . . . . . . . . . . . . . . . . . . . . . . . . 107

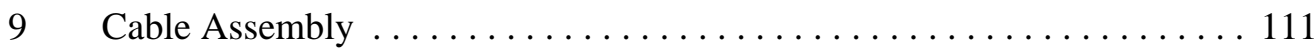

9.1 Component Identification . . . . . . . . . . . . . . . . . 111

9.2 Inspection Form With Comments $\ldots \ldots \ldots \ldots \ldots \ldots \ldots \ldots \ldots$

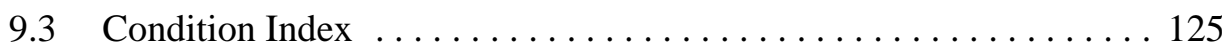

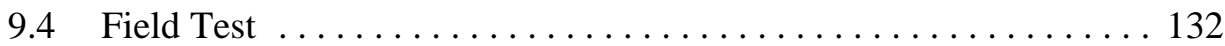

10 Chain Assembly . . . . . . . . . . . . . . . . . . . . . 138

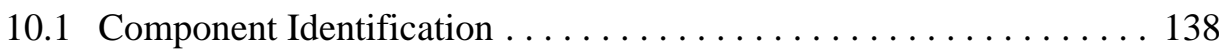

10.2 Inspection Form With Comments . . . . . . . . . . . . . . . 140

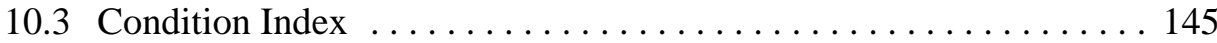

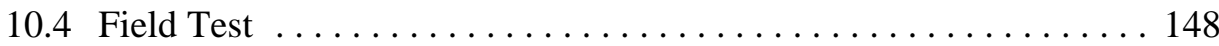

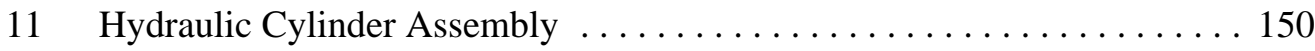

11.1 Component Identification $\ldots \ldots \ldots \ldots \ldots \ldots \ldots \ldots \ldots \ldots \ldots \ldots \ldots \ldots \ldots$

11.2 Inspection Form With Comments $\ldots \ldots \ldots \ldots \ldots \ldots \ldots \ldots \ldots$

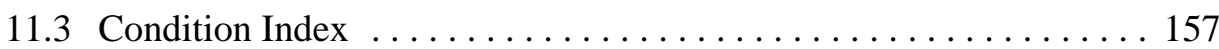

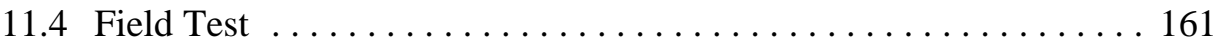

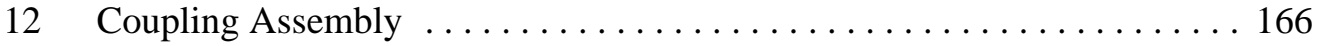

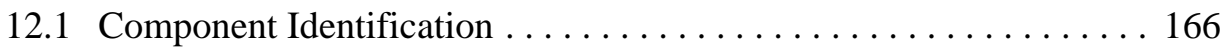

12.2 Inspection Form With Comments $\ldots \ldots \ldots \ldots \ldots \ldots \ldots$

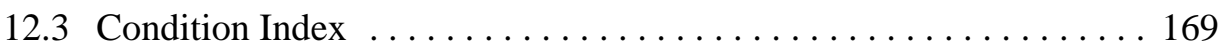

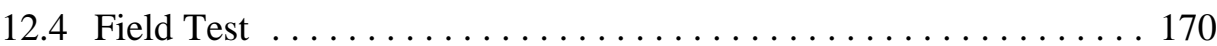


References ....................................... 174

Appendix A Bushing Wear Jacking Procedure . . . . . . . . . . . . 175

Appendix B Gear Tooth Wear Measuring Procedures . . . . . . . . . . . . . 179 


\section{Figures}

Figure 1. Inspection and rating procedure $\ldots \ldots \ldots \ldots \ldots \ldots \ldots \ldots \ldots \ldots$

Figure 2. Condition index related to $\mathrm{X} / \mathrm{X}_{\mathrm{MAX}} \ldots \ldots \ldots \ldots \ldots \ldots \ldots \ldots \ldots \ldots \ldots \ldots \ldots$

Figure 3. Weight adjustment factor for condition index $\ldots \ldots \ldots \ldots \ldots$

Figure 4. Lock and dam schematic . . . . . . . . . . . . . . . . . 19

Figure 5. Plan view of miter lock gate operating equipment $\ldots \ldots \ldots \ldots \ldots 25$

Figure 6. Side view of tainter valve operating equipment $\ldots \ldots \ldots \ldots \ldots \ldots$

Figure 7. Plan view of dam gate operating equipment $\ldots \ldots \ldots \ldots \ldots \ldots \ldots 4$

Figure 8. Plan view of sector lock gate operating equipment (gear and rack) .... 41

Figure 9. Reduction gear schematic $\ldots \ldots \ldots \ldots \ldots \ldots \ldots \ldots \ldots \ldots \ldots \ldots$

Figure 10. Gear anchorage movement/deterioration measurement $\ldots \ldots \ldots \ldots 50$

Figure 11. Tooth contact location $\ldots \ldots \ldots \ldots \ldots \ldots \ldots \ldots \ldots \ldots \ldots \ldots \ldots \ldots \ldots \ldots \ldots \ldots \ldots$

Figure 12. Anchorage movement/deterioration:. exposed gear assembly . . . . . 58

Figure 13. Bearing/bushing wear: exposed gear assembly ............ 58

Figure 14. Reduced tooth contact: exposed gear assembly . . . . . . . . . . . 59

Figure 15. Exposed gear assembly CI $\ldots \ldots \ldots \ldots \ldots \ldots \ldots \ldots \ldots \ldots \ldots \ldots \ldots \ldots$

Figure 16. Noise, jumping, and vibration: enclosed gear assembly . . . . . . 71

Figure 17. Anchorage movement/deterioration: enclosed gear assembly . . . . . 71

Figure 18. Damaged teeth: enclosed gear assembly $\ldots \ldots \ldots \ldots \ldots \ldots \ldots 72$

Figure 19. Temperature rise of oil: enclosed gear assembly $\ldots \ldots \ldots \ldots \ldots 72$

Figure 20. Oil leakage: enclosed gear assembly $\ldots \ldots \ldots \ldots \ldots \ldots \ldots \ldots$

Figure 21. Oil contamination: enclosed gear assembly $\ldots \ldots \ldots \ldots \ldots \ldots 73$

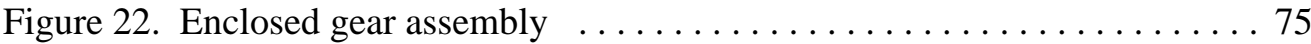

Figure 23. Gear/rack displacement measurement . . . . . . . . . . . . . 75

Figure 24. Reduced tooth contact: gear rack assembly . . . . . . . . . . . . 89

Figure 25. Gear/rack displacement: gear rack assembly . . . . . . . . . . 89

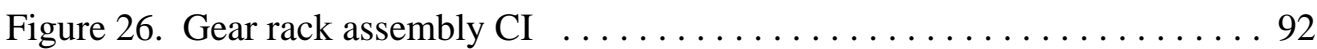

Figure 27. End connection movement distress $\ldots \ldots \ldots \ldots \ldots \ldots \ldots \ldots \ldots \ldots \ldots \ldots$

Figure 28. End connection movement: strut arm assembly . . . . . . . . 100

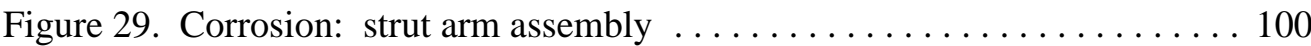

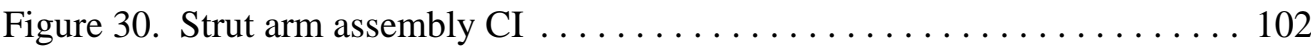

Figure 31. Rocker arm distress measurements $\ldots \ldots \ldots \ldots \ldots \ldots \ldots \ldots$

Figure 32. Pivot point anchorage movement/deterioration:

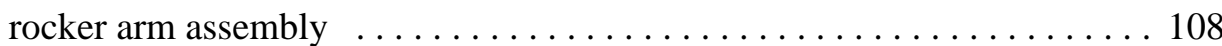

Figure 33. Pivot point pin movement: rocker arm assembly . . . . . . . . 108

Figure 34. Rocker arm assembly CI . . . . . . . . . . . . . . . . . 110

Figure 35. Plan view of sector lock gate operating equipment $\ldots \ldots \ldots \ldots 11$

Figure 36. Side view of tainter dam gate operating equipment $\ldots \ldots \ldots \ldots 112$ 
Figure 37. Vertical lift gate operating equipment $\ldots \ldots \ldots \ldots \ldots \ldots \ldots \ldots$

Figure 38. Cable schematic . . . . . . . . . . . . . . . . . . . . 113

Figure 39. Plan view of tainter gate operating equipment $\ldots \ldots \ldots \ldots \ldots . \ldots 114$

Figure 40. Location identification for cable and chain distresses . . . . . . . . 124

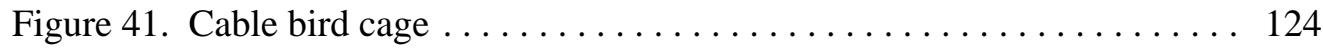

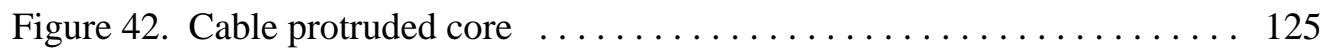

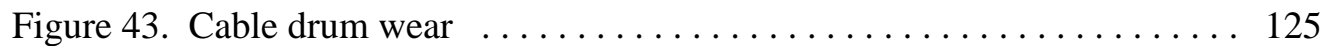

Figure 44. Outer wire wear: cable assembly $\ldots \ldots \ldots \ldots \ldots \ldots \ldots \ldots \ldots . \ldots \ldots$

Figure 45. Wire breakage: cable assembly . . . . . . . . . . . . . 133

Figure 46. Cable assembly CI . . . . . . . . . . . . . . . . . . 137

Figure 47. Side view of roller dam gate operating equipment $\ldots \ldots \ldots \ldots . . \ldots 138$

Figure 48. Chain link schematic . . . . . . . . . . . . . . . . . . 139

Figure 49. Chain linkage wear . . . . . . . . . . . . . . . . . 144

Figure 50. Hydraulic cylinder assembly distress measurements . . . . . . . . 156

Figure 51. Anchorage movement/deterioration: hydraulic cylinder assembly . 162

Figure 52. Corrosion/pitting of rod: hydraulic cylinder assembly . . . . . . . 162

Figure 53. Oil leakage: hydraulic cylinder assembly $\ldots \ldots \ldots \ldots \ldots \ldots \ldots$

Figure 54. Drift: hydraulic cylinder assembly $\ldots \ldots \ldots \ldots \ldots \ldots \ldots \ldots$

Figure 55. Hydraulic cylinder assembly CI . . . . . . . . . . . . . . 165

Figure 56. Coupling relative movement measurement . . . . . . . . . . 169

Figure 57. Input shaft and hub movement: coupling assembly . . . . . . . 171

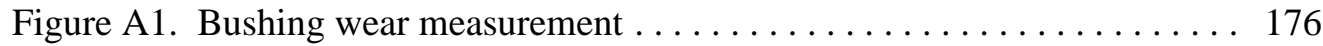

Figure A2. Vertical displacements when jacked on Side $1 \ldots \ldots \ldots \ldots \ldots$

Figure A3. Vertical displacements when jacked on Side $2 \ldots \ldots \ldots \ldots$. . . . 177

Figure A4. Displaced shape of gear (bowed and unbowed) . . . . . . . 178

Figure B1. Gear tooth dimensions and wear measurement . . . . . . . . . . 179

Figure B2. Gear tooth wear measurement: Procedure $1 \ldots \ldots \ldots \ldots \ldots . \ldots 182$ 


\section{Tables}

Table 1. List of operating equipment assemblies. $\ldots \ldots \ldots \ldots \ldots \ldots \ldots \ldots$

Table 2. Condition index scales and zones. $\ldots \ldots \ldots \ldots \ldots \ldots \ldots \ldots \ldots \ldots \ldots$

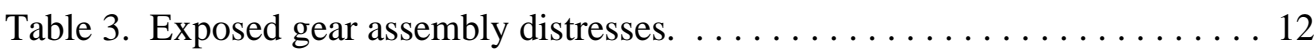

Table 4. Enclosed gear assembly distresses. $\ldots \ldots \ldots \ldots \ldots \ldots \ldots \ldots \ldots \ldots \ldots \ldots$

Table 5. Gear rack assembly distresses. . . . . . . . . . . . . . . 12

Table 6. Strut arm assembly distresses. $\ldots \ldots \ldots \ldots \ldots \ldots \ldots \ldots \ldots \ldots \ldots$

Table 7. Rocker arm assembly distresses. . . . . . . . . . . . . . 13

Table 8 . Cable assembly distresses. . . . . . . . . . . . . . . . 13

Table 9. Chain assembly distresses. . . . . . . . . . . . . . . . 14

Table 10. Hydraulic cylinder assembly distresses. . . . . . . . . . . . 14

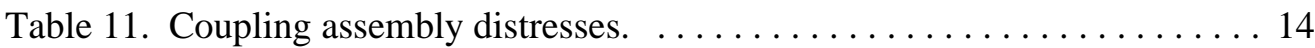

Table 12. Weighting factors for the exposed gear assembly. ........... 15

Table 13. Weighting factors for the enclosed gear assembly. . . . . . . . 15

Table 14. Weighting factors for the gear rack assembly (sector gate racks). . . . 15

Table 15. Weighting factors for the gear rack Assembly (other applications). . . 16

Table 16. Weighting factors for the strut arm assembly. . . . . . . . . . 16

Table 17. Weighting factors for the rocker arm assembly. .......... 16

Table 18. Weighting factors for the cable assembly. . . . . . . . . . 17

Table 19. Weighting factors for the chain assembly. ............. 17

Table 20. Weighting factors for the hydraulic cylinder assembly. . . . . . . 18

Table 21 . Weighting factors for the coupling assembly. ............ 18

Table B1. Gear tooth relationships. $\ldots \ldots \ldots \ldots \ldots \ldots \ldots \ldots \ldots \ldots \ldots \ldots \ldots$ 


\section{Preface}

The study reported herein was authorized by Headquarters, U.S. Army Corps of Engineers (HQUSACE), as part of the Operations Management problem area of the Repair, Evaluation, Maintenance, and Rehabilitation (REMR) Research Program. The work was performed under Civil Works Research Work Unit 32672, “Development of Uniform Evaluation for Procedures/Condition Index for Deteriorated Structures and Equipment," for which Stuart Foltz is the Principal Investigator. Mr. James E. Crews (CECW-O) is the REMR Technical Monitor for this work.

Mr. David B. Mathis (CERD-C) is the REMR Coordinator at the Directorate of Research and Development, HQUSACE; Mr. James Crews and Dr. Tony C. Liu (CEEC-ED) serve as the REMR Overview Committee; Mr. William F. McCleese, U.S. Army Engineer Waterways Experiment Station, is the REMR Program Manager; Mr. David T. McKay is the Problem Area Leader for the Operations Management problem area.

This study was performed by the Department of Civil and Construction Engineering, Iowa State University, under contract to the U.S. Army Construction Engineering Research Laboratories (USACERL). Principal Investigators for Iowa State University were Lowell Greimann, James Stecker, and Timothy Kraal. The study was conducted under the general supervision of Dr. Simon S. Kim, Chief of the Maintenance Management and Preservation Division (FL-P), Infrastructure Laboratory (FL), USACERL. The USACERL technical editor was Linda L. Wheatley, Technical Resources Center.

Special thanks are extended to the following Corps experts who participated in the development of this study: Mr. Fred Joers and Mr. Jim Bartek (Rock Island District), Mr. Allen Matherne (New Orleans District), Mr. Ross Woodbury (Louisville District), and Mr. Joe Britton and Mr. Steven Schneider (Jacksonville District).

COL James T. Scott was Commander and Acting Director of USACERL, and Dr. Michael J. O'Connor was Technical Director. 


\section{Conversion Factors, Non-SI to SI Units of Measurement}

Non-SI units of measurement used in this report can be converted to SI (metric) units as follows:

\begin{tabular}{lll} 
Multiply & \multicolumn{1}{c}{ By } & To Obtain \\
feet & 0.3048 & meters \\
inches & 0.0254 & meters \\
square ft & 0.0929 & square meters
\end{tabular}




\section{Introduction}

\subsection{Background}

Demand for new construction of civil works projects is frequently overridden by the need to maintain existing projects. Many existing civil works structures are nearing the end of their design life, yet service to the public must be maintained. The U.S. Army Corps of Engineers (USACE) Repair, Evaluation, Maintenance, and Rehabilitation (REMR) program was designed to focus attention on maintenance and to record and build baseline data to monitor deterioration rates of these structures.

This REMR project addressed equipment used to operate lock, valve, and dam structures, which include assemblies such as: exposed gear assemblies, enclosed gear assemblies, gear rack assemblies, strut arm assemblies, rocker arm assemblies, cable assemblies, chain assemblies, hydraulic cylinder assemblies, and coupling assemblies. Not included in this evaluation of operating equipment are hydraulic motors, pumps, hoses, or valves, limit switches, brakes, electric wiring, and electric motors.

\subsection{Objective}

A research team, applying the REMR project objectives to lock and dam operating equipment, has developed an inspection program to detect problems in operating equipment at an early stage. The objective of this project is to develop an inspection and rating procedure to describe the overall condition of operating equipment assemblies accurately. Such a rating will also flag a potential problem for the engineer.

\subsection{Mode of Technology Transfer}

It is recommended that the inspection procedures developed in this study for operating equipment be incorporated into Engineer Regulation (ER) 1110-2-100, Periodic Inspection and Continuing Evaluation of Completed Civil Works Structures. 


\section{Inspection and Rating Process}

\subsection{Overview}

The concepts and ideas presented here for the maintenance management of operating equipment rely heavily on work in similar projects for steel sheet pile structures (Greimann and Stecker 1990), miter lock gate structures (Greimann, Stecker, and Rens 1990), sector gate structures (Greimann, Stecker, and Rens 1993), tainter and butterfly valves (Greimann, Stecker, and Veenstra 1994), and tainter dam and lock gates (Greimann, Stecker, and Nop 1995). During that earlier work, basic ideas such as structural considerations, condition indexes, safety and serviceability, quantification of distresses by field measurements, and limiting values of distresses began to evolve. As these concepts were applied to lock and dam operating equipment, several enhancements and some new ideas became apparent.

During the course of this project, the research team has met with Corps personnel and conducted site visits and field investigations at many lock and dam facilities. These meetings led to the identification of several basic considerations for operating equipment. Corps experts expressed their opinions as to the critical components of lock and dam operating equipment, suggested means of quantifying the condition of these components, and related them to the overall condition of the operating equipment assemblies. The project team then formulated the experts' comments into an inspection procedure and a tentative set of rating rules. Field tests of the inspection form and rating rules were conducted at 16 lock and dam facilities. At each test site, experts suggested improvements to the rules and inspection process. Insofar as possible, the suggestions have been incorporated into this work except for cases of conflicting expert opinion. Software will be written to store the inspection data and calculate the condition rating.

\subsection{Inspection and Rating Procedure}

The inspection and rating procedure is illustrated schematically in Figure 1. The entire process is based on a field inspection of the operating equipment. 


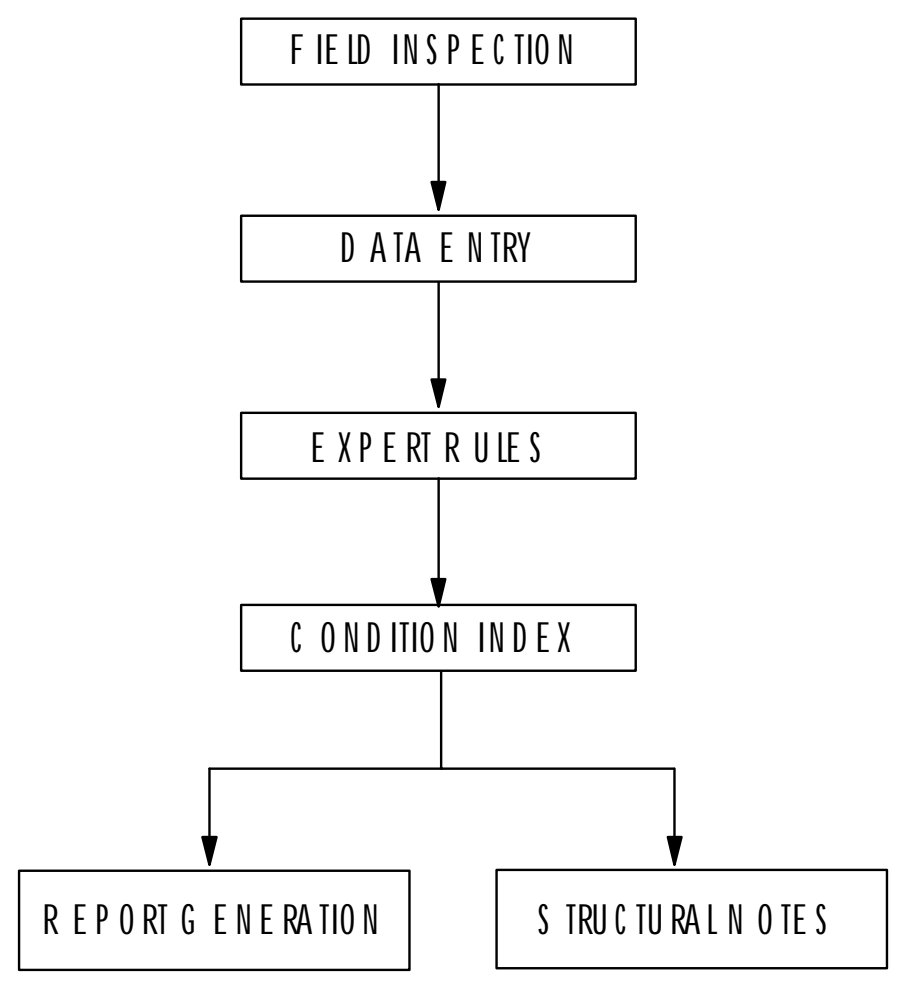

Figure 1. Inspection and rating procedure

\section{Field Inspection Procedure}

Simplicity and adaptability form the basis of the inspection procedure.

Conforming to these guidelines, the inspection program had to be applicable to a wide variety of operating equipment yet relatively straightforward for Corps personnel to implement in the field.

For rating systems previously developed by the research team, the field inspection was based on easily obtainable data. All data were measured with a tape measure, a level, a ruler, dial gages, or by subjective observation (poor, average, good, excellent). The procedure was kept as simple as possible, while still obtaining quantitative and applicable information to assess the structure. The lock and dam may remain in operation during the procedure. In general, the level of inspection for operating equipment is at a somewhat lower level of inspection than for previously 
inspected structures (e.g., dam gates). Hence, some rules involve more subjective questions to quantify the condition.

In addition to simplicity, the other goal was to develop a general inspection procedure that was adaptable to many types of operating equipment. The equipment covered in this report include lock, valve, and dam operating equipment. Within each of these structures are numerous designs and combinations of assemblies. For example, dam gates can be operated by various combinations of exposed gears, enclosed gears, gear racks, struts, cables, chains, hydraulic cylinders, and couplings. To accommodate these variations, separate inspection forms were developed for each assembly comprised in the operating equipment.

\section{Inspection Form}

The inspection forms for lock gate, valve, and dam gate operating equipment were designed to be flexible in documenting a variety of field conditions. The first two pages of the form address location of the equipment, historical information, inspection and maintenance history, and the current operating characteristics. These pages should be completed before the field inspection. Pages beyond the first two provide space for entering field measurements such as anchorage movements, cracks, and corrosion and should be completed in the field. These measurements are used directly to rate the condition of the operating equipment. The following paragraphs briefly outline the inspection form.

General Information. General information related to the structure is recorded on pages 1 and 2 of the inspection form, which are shown and described in detail in Chapter 3. Separate page 1 and 2 sets were developed for the operating equipment for: (1) lock structures, (2) valve structures, and (3) dam structures. Recorded information includes project reference data to identify and locate the specific structure. Further questions categorize the structure into a particular type and function. In particular, the path of power transfer through the assemblies, from the power source to the structure, is itemized on page 1 . The assemblies identified on page 1 constitute the basis for selecting the inspection forms that will be used to inspect the condition of the operating equipment assemblies within the structure. Historical descriptions of maintenance, modifications, and inspections are recorded on page 2 for reference only.

Field measurements. The remaining pages of the inspection form are used to describe the condition of each assembly that makes up the operating equipment. The inspection forms that describe the condition of each assembly consist of one to three pages, which are identified as Parts 1,2, and 3. The complete inspection form set 
for a structure will consist of one page 1, one page 2, and a number of pages to describe the condition of the assemblies, depending on the type and number of 8 assemblies in the operating equipment. Separate sets of inspection forms exist for each of the nine assemblies listed in Table 1. Several simple measurements and observations concerning problems or distresses in each assembly are recorded. The inspection forms corresponding to the separate assemblies are in Chapters 4 through 12.

Table 1. List of operating equipment assemblies.

\begin{tabular}{|l|l|}
\hline \multicolumn{1}{|c|}{ Assembly } & Inspection and Rating Procedure \\
\hline Exposed Gear & Chapter 4 \\
\hline Enclosed Gear & Chapter 5 \\
\hline Gear Rack & Chapter 6 \\
\hline Strut Arm & Chapter 7 \\
\hline Rocker Arm & Chapter 8 \\
\hline Cable & Chapter 9 \\
\hline Chain & Chapter 10 \\
\hline Hydraulic Cylinder & Chapter 11 \\
\hline Coupling & Chapter 12 \\
\hline
\end{tabular}

\section{Condition Index}

The field observations are used in the expert rules to determine the condition index (CI) for each operating equipment assembly. A condition index is the numerical measure used to rate the current state of the operating equipment. The purpose of the CI is twofold. First, the CI values serve as a planning tool meant to focus management attention on operating equipment most likely to warrant immediate repair or further evaluation. Second, the CI values can be used to monitor changes in the general condition over time and can serve as an approximate comparison of the condition of operating equipment at different locations.

A common definition of CI was developed during previous REMR work done by the research team (Table 2). The REMR CI is a numerical scale, ranging from a low of 0 to a high of 100 . The numbers indicate the relative need to perform REMR work because of deteriorating characteristics of the operating equipment. For management purposes, the CI scale is also calibrated to group operating equipment into three basic categories or zones, as listed in Table 2. If a structure is designed and constructed properly, it has an initial CI of 100. As time passes and the structure is exposed to varying environmental and operational situations, its condition will deteriorate. The CI will degrade as various distresses are incurred. 
Table 2. Condition index scales and zones.

\begin{tabular}{|c|c|c|c|}
\hline Zone & $\begin{array}{l}\text { Condition } \\
\text { Index }\end{array}$ & Condition Description & $\begin{array}{l}\text { Recommended } \\
\text { Action }\end{array}$ \\
\hline \multirow[t]{2}{*}{1} & 85 to 100 & $\begin{array}{l}\text { Excellent: No noticeable } \\
\text { defects. Some aging or wear } \\
\text { may be visible. }\end{array}$ & \multirow[t]{2}{*}{$\begin{array}{l}\text { Immediate action is } \\
\text { not required. }\end{array}$} \\
\hline & 70 to 84 & $\begin{array}{l}\text { Good: Only minor deterioration } \\
\text { or defects are evident. }\end{array}$ & \\
\hline \multirow{2}{*}{2} & 55 to 69 & $\begin{array}{l}\text { Fair: Some deterioration or } \\
\text { defects are evident, but function } \\
\text { is not significantly affected. }\end{array}$ & \multirow{2}{*}{$\begin{array}{l}\text { Economic analysis of } \\
\text { repair alternatives is } \\
\text { recommended to } \\
\text { determine appropriate } \\
\text { action. }\end{array}$} \\
\hline & 40 to 54 & $\begin{array}{l}\text { Marginal: Moderate } \\
\text { deterioration. Function is still } \\
\text { adequate. }\end{array}$ & \\
\hline \multirow{3}{*}{3} & 25 to 39 & $\begin{array}{l}\text { Poor: Serious deterioration in at } \\
\text { least some portions of the } \\
\text { structure. Function is } \\
\text { inadequate. }\end{array}$ & \multirow{3}{*}{$\begin{array}{l}\text { Detailed evaluation is } \\
\text { required to determine } \\
\text { the need for repair, } \\
\text { rehabilitation, or } \\
\text { reconstruction. } \\
\text { Safety evaluation } \\
\text { recommended. }\end{array}$} \\
\hline & 10 to 24 & $\begin{array}{l}\text { Very Poor: Extensive } \\
\text { deterioration. Barely functional. }\end{array}$ & \\
\hline & 0 to 9 & $\begin{array}{l}\text { Failed: No longer functions. } \\
\text { General failure or complete } \\
\text { failure of a major structural } \\
\text { component. }\end{array}$ & \\
\hline
\end{tabular}

Because the CI involves engineering judgment and depends on the experience of the person making the evaluation, some aspects of the CI were difficult to capture. Experts in the area of operating equipment were interviewed, and discussion continued until a consensus began to develop. A set of "expert opinion" rules are embedded in the evaluation that constitutes the CI. The rules have been designed to interpret straightforward, visual observation data in much the same manner that a seasoned engineer would interpret field observations.

Two general structural criteria for evaluating the CI were considered: safety and serviceability. Safety relates to the performance of a structure beyond normal service conditions, for example, under excessive load. It relates to the probability of failure. Serviceability relates to the performance of operating equipment under normal service conditions (e.g., hydraulic cylinder drift). The CI for each distress includes aspects of both safety and serviceability. Compared to other structural components at a lock and dam facility, few safety aspects are associated with operating equipment.

A series of critical measurements and observations are made on each operating equipment assembly to quantify the CI. Experts were asked to interpret these measurements in light of the serviceability and safety of the operating equipment and to assign the limiting values to the measurements. 
Distress $\boldsymbol{C I}$. Each assembly in this project has between five and fifteen distresses that affect the assembly CI. Each distress can detract from the safety and the serviceability of that assembly. Tables 3 through $11^{*}$ contain a brief description of the distresses for each of the nine assemblies listed in Table 1. Many distresses are quantified by a measurement $\mathrm{X}$. For example, hydraulic cylinder drift is a distress quantified by the motion of the cylinder rod when the oil valves are closed. In this case, the CI is calculated by:

$$
C 1=100(0.4)^{\frac{x}{x_{\max }}}
$$

where $X_{\mathrm{MAX}}$ is some limiting value of $\mathrm{X}$. Figure 2 illustrates the equation and the previously mentioned zones (Table 2). Experts selected $X_{\text {MAX }}$ to be the point at which the operating equipment requires immediate repair or at least a more detailed inspection and CI evaluation. In other words, it corresponds to a CI of 40 and is a potentially hazardous situation.

In Chapters 4 through 12, the definition and measurement of $X$ and $X_{\mathrm{MAX}}$ values are described for each assembly. Illustrated examples and potential causes of each distress that must be addressed in the maintenance and repair of the operating equipment are also included. Diagnosing causes for each distress is a complex issue. Many times a distress may have several possible causes, and a combination of distresses often must be present before a certain cause can be identified.

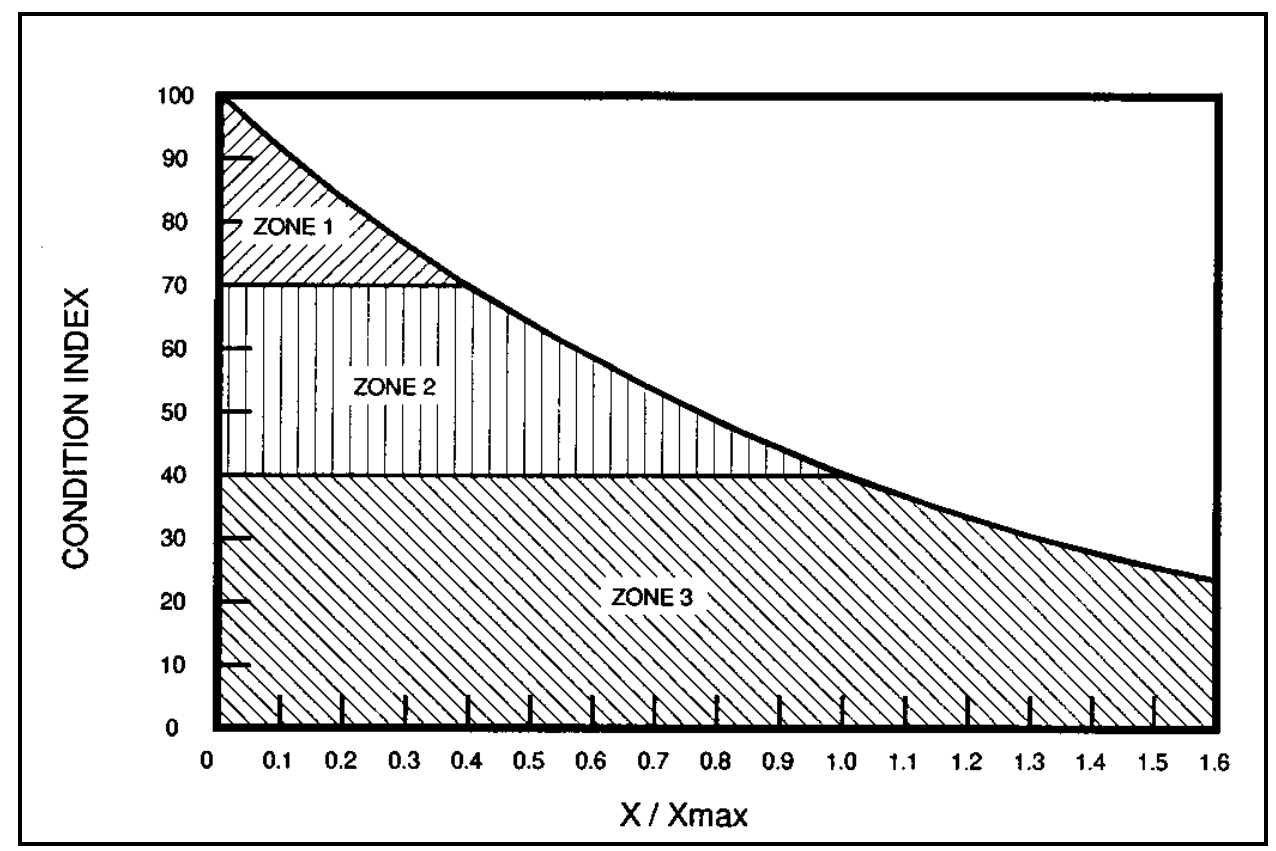

Figure 2. Condition index related to $\mathrm{X} / \mathrm{X}_{\mathrm{MAX}}$.

Tables 3 through 21 are placed at the end of the chapter. 
Assembly CI. The calculation of the assembly CI is also a complicated task. Although all of the individual $\mathrm{CI}_{\mathrm{i}} \mathrm{s}$ (where I refers to an individual distress) contribute to the assembly $\mathrm{CI}$, some are more significant in evaluating the overall condition of the assembly. To account for this varying significance, weighting factors, $\mathrm{w}_{\mathrm{i}}$, were obtained for each $\mathrm{CI}_{\mathrm{i}}$. Weighting factors were obtained by averaging the subjective weighting factors given by five operating equipment experts from the Army Corps of Engineers: Fred Joers (Rock Island District), Jim Bartek (Rock Island District), Ross Woodbury (Louisville District), Allen Matherne (New Orleans District), and Joe Britton (Jacksonville District).

Before the weighting factors were established by the experts, each expert was sent a letter and rating form that asked the experts to identify the importance of each distress and to determine whether it should be considered (1) critical to the structural stability of the assembly or (2) noncritical. The CI of a critical distress can control the assembly CI, which is the minimum of the CI for the critical distresses and weighted average of all the noncritical distresses.

$$
C 1=M \text { in im um }\left\{C I_{j}(s), \quad c i_{w}\right\}
$$

where $\mathrm{CI}_{\mathrm{j}} \mathrm{s}$ are the CIs of the critical distresses (j refers to critical distresses) and $\mathrm{CI}_{\mathrm{w}}$ is the weighted average of the noncritical distresses (discussed in the following paragraph). Eight of the nine assemblies have at least one distress that is considered critical. None of the distresses are critical in the hydraulic cylinder assembly.

After analyzing the responses to the first letter, The experts were sent a second letter and rating form - this time asking for the relative weights, $\mathrm{w}_{\mathrm{i}}$, of each distress that they considered noncritical. The weighting factors were normalized with the following equation:

$$
w_{1}=\frac{w_{i}}{\sum_{w}}\left(\begin{array}{lll}
1 & 0 & 0
\end{array}\right)
$$

such that

$$
\Sigma_{w},=100
$$

Tables 12 through 21 list the experts' average weighting factors and the normalized weighting factors for each of the nine assemblies with the exception of the gear rack 
assembly for which there are two tables (one for the sector gate application and one for the other gear rack applications). The normalized weighting factors are used to calculate the weighted average $\mathrm{CI}_{\mathrm{w}}$ for the noncritical distresses

$$
c I_{w}=w_{1} c I_{1}+w_{2} c I_{2}+\ldots+w_{n} c I_{n}
$$

where $\mathrm{n}$ is the number of noncritical distresses for that assembly.

As the $\mathrm{CI}_{\mathrm{i}}$ of an individual distress approaches Zone 3, it becomes more significant in the calculation of the weighted $\mathrm{CI}_{\mathrm{w}}$. In previous work, an adjustment factor (AF) was applied to the weighting factors of distresses for which the individual $\mathrm{CI}_{\mathrm{i}}$ was less than 70 (or in Zones 2 or 3). The AF has a maximum value of eight when the individual $\mathrm{CI}_{\mathrm{i}}$ is in Zone 3 and is obtained by the following linear equation when the individual $\mathrm{CI}_{\mathrm{i}}$ is in Zone 2 :

$$
A F_{i}=8-7 * \frac{(C 1,-40)}{30}
$$

Figure 3 shows the value of the adjustment factor versus the $\mathrm{CI}_{\mathrm{i}}$.

\subsection{Field Testing}

The performance of the rating rules was evaluated by comparing the calcu-

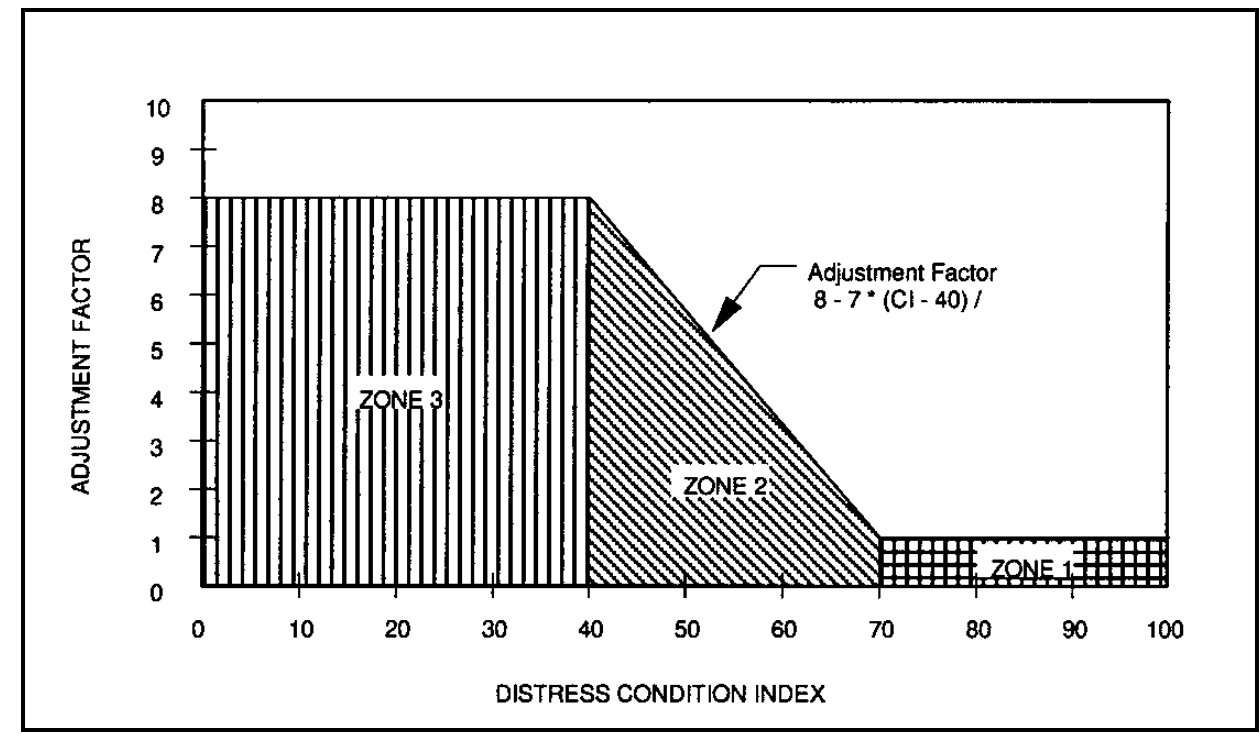

Figure 3. Weight adjustment factor for condition index. 
lated CI values based on the rules with the CI values subjectively determined by Corps operating equipment experts. During several site visits, Corps experts were interviewed to establish an initial set of CI rules. In January 1995, several field tests of operating equipment were performed in the Jacksonville District. The lock and dam sites for the tests were: (1) W.P. Franklin Lock and Dam, (2) Ortona Lock and Dam, (3) Moore Haven Lock and Dam, and (4) St. Lucie Lock and Dam. The Corps personnel who participated were: Fred Joers (Rock Island District), Jim Bartek (Rock Island District), Ross Woodbury (Louisville District), Allen Matherne (New Orleans District), Joe Britton (Jacksonville District), and Steve Schneider (Jacksonville District). Each expert was asked to rate subjectively the individual distresses for various operating equipment assemblies by assigning a CI to each distress. The experts were also asked to assess a combined assembly CI. After the field test, the inspection procedure and inspection forms were changed significantly in response to recommendations by the experts.

Field tests were conducted in March 1995 in the Louisville District at: (1) Cannelton Lock and Dam, (2) Green River 1 Lock and Dam, (3) Green River 2 Lock and Dam, and (4) Newburgh Lock and Dam. The participating Corps operating equipment experts were Joers, Bartek, Matherne, Woodbury, and Britton. The same calibration procedure was used to further refine and improve the inspection process, form, and rules.

Bar charts in Chapters 4 through 12 compare the experts' subjective CIs to the calculated individual and assembly CIs. In each chart, the individual bars represent:

! the average expert $\mathrm{CI}$

! the highest expert $\mathrm{CI}$

! the lowest expert CI

! the CI calculated by rating rules.

Some distresses were not observed in the tested assemblies during field testing. In these cases, the calculated $\mathrm{CI}_{\mathrm{i}} \mathrm{s}$ were 100 and the experts' average $\mathrm{CI}_{\mathrm{i}} \mathrm{s}$ were at least 90. Therefore, these cases are not presented in the bar charts. An expert adjusted average CI (the average of the experts' CIs excluding the highest and the lowest) was calculated and compared with the experts' average CI. The two averaging methods yielded approximately the same results; therefore, only the average of the experts' CI is shown.

Operating equipment was observed in June 1995 at the following Illinois lock and dam sites: (1) T.J. O'Brien Lock and Dam, (2) Chicago Lock, (3) Lockport Lock and Dam, (4) Brandon Road Lock and Dam, (5) Dresden Island Lock and Dam, (6) Marseilles Lock and Dam, (7) Starved Rock Lock and Dam, and (8) 
Mississippi River Lock and Dam \#16. Joers and Bartek participated in these visits. The inspection procedures for several of the assembly distresses were performed at the above sites in an effort to (1) fine tune the procedures, (2) make format changes to the inspection form, and (3) adjust the CI calculation rules. The visits were beneficial in reformatting the inspection form and finalizing the inspection procedure and rules for some of the distresses.

\subsection{Layout of the Following Chapters}

One of the nine operating equipment assemblies listed in Table 1 is described in each of the Chapters 4 through 12. In addition to component identification, these chapters include the inspection forms pertaining to the nine assemblies. The rules for evaluating the individual $\mathrm{CI}_{i} \mathrm{~s}$ and combined assembly CIs with example illustrations showing the calculations of these $\mathrm{CI}_{i} \mathrm{~s}$ are also included. The final section of each chapter compares the CIs calculated from the rules assembled by the research team with the subjective CIs given by the experts for assembly and combined distresses. 
Table 3. Exposed gear assembly distresses.

\begin{tabular}{|l|l|}
\hline Distress & Brief Description \\
\hline Noise, jump, vibration & Abnormal noise, jumping, or vibration during operation \\
\hline Anchorage movement, deterioration & Movement of embedded anchorage system and damaged components \\
\hline Bearing/bushing wear & Excessive play in the exposed reduction gear bearing or bushing \\
\hline Roller support wear/damage & Freezing or wear of the roller bearings or bushings \\
\hline Cracks & Breaks in the steel components \\
\hline Tooth wear & Wearing of the gear teeth \\
\hline Reduced tooth contact & Improper engagement of the teeth \\
\hline Damaged teeth & Chipped, deformed, pitted, gouged, or corroded teeth \\
\hline
\end{tabular}

Table 4. Enclosed gear assembly distresses.

\begin{tabular}{|l|l|}
\hline Distress & Brief Description \\
\hline Noise, jump, vibration & Abnormal noise, jumping, or vibration during operation \\
\hline Anchorage movement, deterioration & Movement of embedded anchorage system and damaged components \\
\hline Cracks & Breaks in the steel components \\
\hline Damaged teeth & Chipped, deformed, pitted, gouged, or corroded teeth \\
\hline Temperature rise of gear box & Temperature change in the gear box oil \\
\hline Oil leakage & Leakage of oil \\
\hline Oil contamination & Contamination of oil \\
\hline
\end{tabular}

Table 5. Gear rack assembly distresses.

\begin{tabular}{|l|l|}
\hline Distress & Brief Description \\
\hline Noise, jump, vibration & Abnormal noise, jumping, or vibration during operation \\
\hline Cracks & Breaks in the steel components \\
\hline Rack attachment deterioration & Deterioration of bolts which anchor the rack to the gate \\
\hline Reaction roller wear/damage & Wear and freezing of reaction roller bearings and bushings \\
\hline $\begin{array}{l}\text { Reaction roller anchorage } \\
\text { movement /deterioration }\end{array}$ & $\begin{array}{l}\text { Movement of embedded anchorage system and } \\
\text { damaged components }\end{array}$ \\
\hline Gear/rack displacement & $\begin{array}{l}\text { Relative displacement between the gear and rack perpendicular to the } \\
\text { rack }\end{array}$ \\
\hline Rack wear & Edge and bottom wear of the rack \\
\hline Tooth wear & Wearing of the gear teeth \\
\hline Reduced tooth contact & Improper engagement of the teeth \\
\hline Damaged teeth & Chipped, deformed, pitted, gouged, or corroded teeth \\
\hline
\end{tabular}


Table 6. Strut arm assembly distresses.

\begin{tabular}{|l|l|}
\hline Distresses & Brief Description \\
\hline Noise, jump, vibration & Abnormal noise, jumping, or vibration during operation \\
\hline Strut connection movement & Displacement between pin and bushing \\
\hline Compression spring movement & Abnormal functioning of the compression spring \\
\hline Corrosion & Loss of steel due to interaction with the environment \\
\hline Cracks & Breaks in the steel components \\
\hline
\end{tabular}

Table 7. Rocker arm assembly distresses.

\begin{tabular}{|l|l|}
\hline Distresses & Brief Description \\
\hline Noise, jump, vibration & Abnormal noise, jumping, or vibration during operation \\
\hline $\begin{array}{l}\text { Rocker and connecting rod } \\
\text { connection movement }\end{array}$ & Movement between the rocker arm and the connecting rod \\
\hline $\begin{array}{l}\text { Pivot point anchorage } \\
\text { movement/deterioration }\end{array}$ & $\begin{array}{l}\text { Movement of embedded anchorage system and damaged } \\
\text { components }\end{array}$ \\
\hline Pivot point pin movement & Movement between the rocker arm the pivot point anchorage system \\
\hline Corrosion & Loss of steel due to interaction with the environment \\
\hline Cracks & Breaks in the steel components \\
\hline
\end{tabular}

Table 8. Cable assembly distresses.

\begin{tabular}{|c|c|}
\hline Distresses & Brief Description \\
\hline Noise, jump, and vibration & Abnormal noise, jumping, or vibration during operation \\
\hline Outer wire wear & Reduction in the diameter of the cable wires \\
\hline Reduction in rope diameter & A reduced rope diameter \\
\hline Corrosion & Loss of steel due to interaction with the environment \\
\hline $\begin{array}{l}\text { Bird cages, kinks, and protruding } \\
\text { core }\end{array}$ & $\begin{array}{l}\text { Deformation of the rope by either bird cages, kinks in the rope, or } \\
\text { a core which is protruding from the rope }\end{array}$ \\
\hline Unlayed strands & Cable strands which are unlayed \\
\hline Wire breakage & The number of broken wires in any one cable lay \\
\hline Unequal tension & Improper cable tension \\
\hline Drum wear & Wear on cable guides and drum groove \\
\hline $\begin{array}{l}\text { Drum anchorage } \\
\text { movement/deterioration }\end{array}$ & $\begin{array}{l}\text { Movement of embedded anchorage system and damaged } \\
\text { components }\end{array}$ \\
\hline Sheave wear & Wear on the sheave groove \\
\hline Sheave bearing/bushing wear & Excessive play in the sheave bearing or bushing \\
\hline $\begin{array}{l}\text { Sheave anchorage } \\
\text { movement/deterioration }\end{array}$ & $\begin{array}{l}\text { Movement of embedded anchorage system and damaged } \\
\text { components }\end{array}$ \\
\hline Idler/roller wear & Improper operation of idlers and rollers \\
\hline Gate or valve connection movement & $\begin{array}{l}\text { Relative movement at the connection between the cable and the } \\
\text { lifting bracket }\end{array}$ \\
\hline
\end{tabular}


Table 9. Chain assembly distresses.

\begin{tabular}{|l|l|}
\hline Distresses & Brief Description \\
\hline Noise, jump, vibration & Abnormal noise, jumping, or vibration during operation \\
\hline Linkage wear/elongation & Wear and elongation of the chain links, pins, and bearings \\
\hline Cracks & Breaks in the steel components \\
\hline Frozen links & Links will not rotate or displace relative to each other \\
\hline Corrosion & Loss of steel due to interaction with the environment \\
\hline $\begin{array}{l}\text { Sprocket anchorage } \\
\text { movement/deterioration }\end{array}$ & Movement of embedded anchorage system and damaged components \\
\hline Sprocket wear & Wear of the sprocket \\
\hline Gate connection movement & Relative movement between the chain and the lifting bracket \\
\hline
\end{tabular}

Table 10. Hydraulic cylinder assembly distresses.

\begin{tabular}{|l|l|}
\hline Distresses & Brief Description \\
\hline Noise, jump, vibration & Abnormal noise, jumping, or vibration during operation \\
\hline Anchorage movement, deterioration & Movement of embedded anchorage system and damaged components \\
\hline Rod end connection movement & Relative movement between the hydraulic rod and the strut \\
\hline Corrosion/pitting of rod & $\begin{array}{l}\text { Corrosion and possibly pitting of hydraulic rod due to interaction with the } \\
\text { environment }\end{array}$ \\
\hline Damage of rod & Scoring, nicking, or other damage on the rod \\
\hline Oil leakage & Leakage of oil from the rod end of the hydraulic cylinder \\
\hline Drift & Movement of hydraulic rod with respect to the cylinder with load \\
\hline Damaged guide & Corrosion and/or attachment movement of the guides \\
\hline
\end{tabular}

Table 11. Coupling assembly distresses.

\begin{tabular}{|l|l|}
\hline Distress & Brief Description \\
\hline Noise, jump, vibration & Abnormal noise, jumping, or vibration during operation \\
\hline Cracks & Breaks in the steel components \\
\hline Corrosion & Loss of steel due to interaction with the environment \\
\hline Input shaft and hub movement & Relative movement between the input shaft and the hub \\
\hline Output shaft and hub movement & Relative movement between the output shaft and the hub \\
\hline
\end{tabular}


Table 12. Weighting factors for the exposed gear assembly.

\begin{tabular}{|l|l|}
\multicolumn{1}{|c|}{ Distress } & $\mathbf{W}_{\mathbf{i}}$ \\
\hline Noise, jump, and vibration & 27.5 \\
\hline Anchorage movement/deterioration & 26.8 \\
\hline Bearing/bushing wear & 12.3 \\
\hline Roller supports wear/damage* & 7.0 \\
\hline Cracks & critical \\
\hline Tooth wear & 2.6 \\
\hline Reduced tooth contact & 9.0 \\
\hline Damaged teeth & 14.8 \\
\hline
\end{tabular}

* If not applicable, $w_{i}$ for this distress is zero.

Table 13. Weighting factors for the enclosed gear assembly.

\begin{tabular}{|l|c|}
\hline \multicolumn{1}{|c|}{ Distress } & $\mathbf{W}_{\mathbf{i}}$ \\
\hline Noise, jump, and vibration & 24.1 \\
\hline Anchorage movement/deterioration & 21.5 \\
\hline Cracks* $^{*}$ & critical \\
\hline Damaged teeth* & 23.3 \\
\hline Temperature rise of gear box & 17.2 \\
\hline Oil leakage & 2.3 \\
\hline Oil contamination & 11.6 \\
\hline
\end{tabular}

* If not observable, $\mathrm{w}_{\mathrm{i}}$ for this distress is zero.

Table 14. Weighting factors for the gear rack assembly (sector gate racks).

\begin{tabular}{|l|c|}
\hline \multicolumn{1}{|c|}{ Distress } & $\mathbf{W}_{\mathbf{i}}$ \\
\hline Noise, jump, and vibration & 34.3 \\
\hline Cracks & critical \\
\hline Rack attachment deterioration & 25.1 \\
\hline Tooth wear & 6.4 \\
\hline Reduced tooth contact & 14.3 \\
\hline Damaged teeth & 19.9 \\
\hline
\end{tabular}


Table 15. Weighting factors for the gear rack Assembly (other applications).

\begin{tabular}{|l|c|}
\hline \multicolumn{1}{|c|}{ Distress } & $\mathbf{W}_{\mathbf{i}}$ \\
\hline Noise, jump, and vibration & 29.0 \\
\hline Cracks & critical \\
\hline Reaction roller wear/damage & 10.2 \\
\hline Reaction rollers anchorage movement/deterioration & 15.4 \\
\hline Gear/rack displacement & 9.0 \\
\hline Rack wear & 3.2 \\
\hline Tooth wear & 4.9 \\
\hline Reduced tooth contact & 11.4 \\
\hline Damaged teeth & 16.9 \\
\hline
\end{tabular}

Table 16. Weighting factors for the strut arm assembly.

\begin{tabular}{|l|c|}
\hline \multicolumn{1}{|c|}{ Distress } & W $_{\mathbf{i}}$ \\
\hline Noise, jump, and vibration & 44.5 \\
\hline Strut connection movement & 20.6 \\
\hline Compression spring movement & 27.7 \\
\hline Corrosion & 7.2 \\
\hline Cracks & critical \\
\hline
\end{tabular}

Table 17. Weighting factors for the rocker arm assembly.

\begin{tabular}{|l|c|}
\hline \multicolumn{1}{|c|}{ Distress } & $\mathbf{W}_{\mathbf{i}}$ \\
\hline Noise, jump, and vibration & 27.7 \\
\hline Rocker and connecting rod connection movement & 19.3 \\
\hline Pivot point anchorage movement/deterioration & 38.9 \\
\hline Pivot point pin movement & 4.9 \\
\hline Corrosion & 9.2 \\
\hline Cracks & critical \\
\hline
\end{tabular}


Table 18. Weighting factors for the cable assembly.

\begin{tabular}{|l|c|}
\hline \multicolumn{1}{|c|}{ Distress } & $\mathbf{W}_{\mathbf{i}}$ \\
\hline Noise, jump, and vibration & 9.1 \\
\hline Outer wire wear & 7.5 \\
\hline Reduction in rope diameter & 14.1 \\
\hline Corrosion & 8.8 \\
\hline Bird cages, kinks, and protruding core & critical \\
\hline Unlayed strands & 10.5 \\
\hline Wire breakage & critical \\
\hline Unequal tension & 7.0 \\
\hline Drum wear & 1.3 \\
\hline Drum anchorage movement/deterioration & 10.6 \\
\hline Sheave wear* & 2.7 \\
\hline Sheave bearing/bushing wear* & 4.1 \\
\hline Sheave anchorage movement/deterioration* & 10.6 \\
\hline Idlers/rollers wear* & 3.4 \\
\hline Gate or valve connection movement** & 10.5 \\
\hline If not applicable, ${ }^{*}$ for this distrss is zero. & \\
\hline
\end{tabular}

* If not applicable, $\mathrm{w}_{\mathrm{i}}$ for this distress is zero.

** If not observable, $\mathrm{w}_{\mathrm{i}}$ for this distress is zero.

Table 19. Weighting factors for the chain assembly.

\begin{tabular}{|l|c|}
\multicolumn{1}{|c|}{ Distress } & $\mathbf{W}_{\mathbf{i}}$ \\
\hline Noise, jump, and vibration & 16.3 \\
\hline Linkage wear/elongation & 12.3 \\
\hline Cracks & critical \\
\hline Frozen links & 23.6 \\
\hline Corrosion/pitting & 9.7 \\
\hline Sprocket anchorage movement/deterioration & 21.8 \\
\hline Sprocket wear & 2.9 \\
\hline Gate connection movement ${ }^{* *}$ & 13.4 \\
\hline
\end{tabular}

** If not observable, $\mathrm{w}_{\mathrm{i}}$ for this distress is zero. 
Table 20. Weighting factors for the hydraulic cylinder assembly.

\begin{tabular}{|l|c|}
\hline \multicolumn{1}{|c|}{ Distress } & $\mathbf{W}_{\mathbf{i}}$ \\
\hline Noise, jump, and vibration & 18.1 \\
\hline Anchorage movement/deterioration & 21.0 \\
\hline Rod end connection movement & 13.1 \\
\hline Corrosion/pitting of rod & 12.3 \\
\hline Damage of rod & 14.8 \\
\hline Oil leakage & 7.4 \\
\hline Drift & 11.2 \\
\hline Damaged guide & 2.1 \\
\hline
\end{tabular}

* If not applicable, $\mathrm{w}_{\mathrm{i}}$ for this distress is zero.

Table 21. Weighting factors for the coupling assembly.

\begin{tabular}{|l|c|}
\hline \multicolumn{1}{|c|}{ Distress } & $\mathbf{W}_{\mathbf{i}}$ \\
\hline Noise, jump, and vibration & 89.3 \\
\hline Cracks & critical \\
\hline Corrosion & 10.7 \\
\hline Input shaft and hub movement & critical \\
\hline Output shaft and hub movement & critical \\
\hline
\end{tabular}




\section{Inspection Form: Historical Information}

This chapter contains pages 1 and 2 of the inspection forms for: (1) lock gate, (2) valve, and (3) dam gate operating equipment. The side-by-side arrangement of the opposing pages displays specific explanations (right side) adjacent to the entry on the inspection form (left side). The chapter begins with a brief description of lock gates, valves, and dam gates. An overall view of a lock and dam facility is shown in Figure 4, in which various operating equipment areas are highlighted.

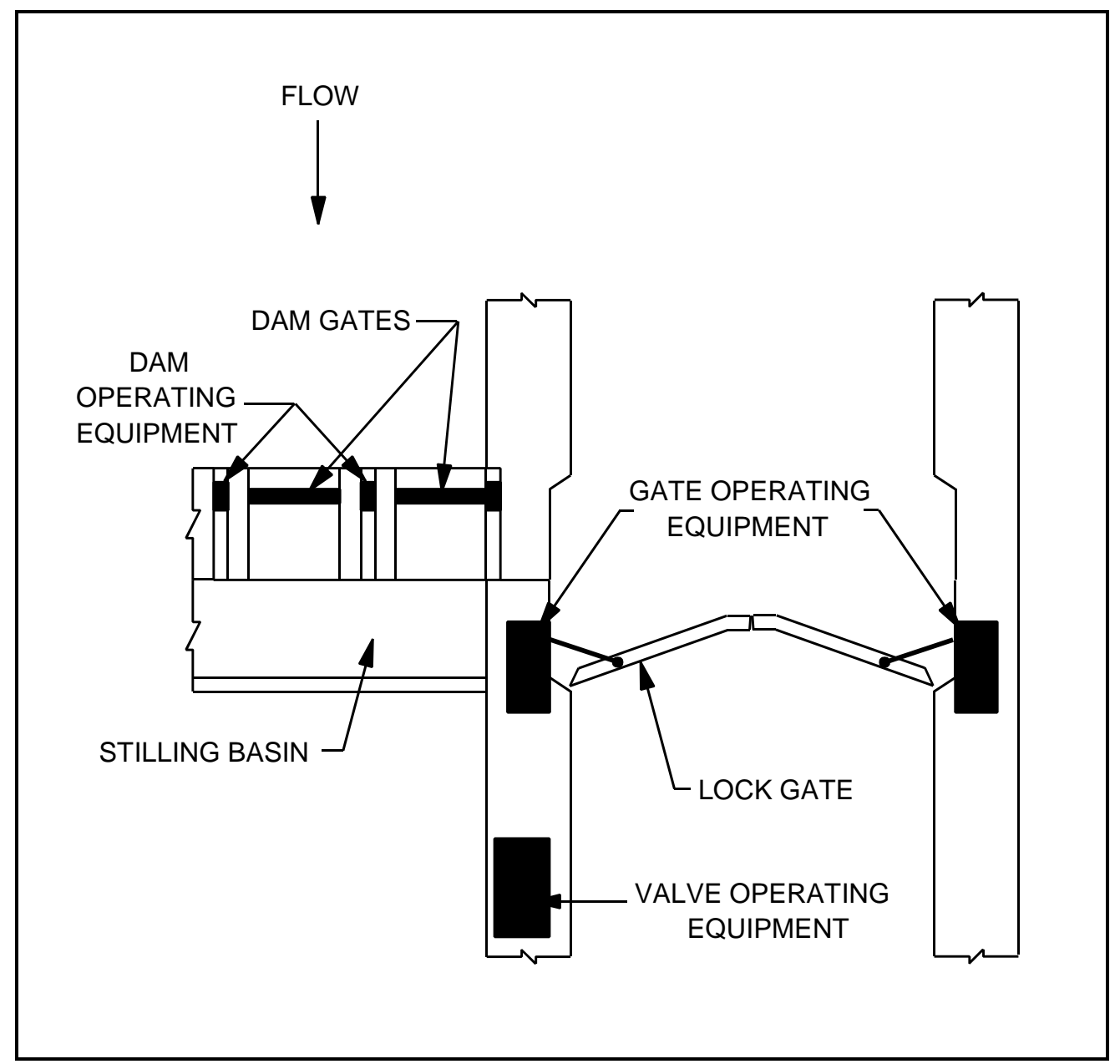

Figure 4. Lock and dam schematic. 


\subsection{Lock Gates}

Lock gates can be miter, sector, tainter, or vertical lift lock gates. Miter gates rotate on hinges that are attached to the concrete monolith wall and resist forces similar to a three-hinged arch. Sector gate structures have skin plates that are sectors of a circle. Sector gates can resist water pressure on either side of the skin plate; whereas miter gates can have net water pressure only on the upstream side. Tainter lock gates sometimes serve as upper gates in a lock chamber and are usually submersible. Vertical lift gates are comprised of skin plates that are framed with horizontal and vertical girders.

\subsection{Valves}

Valves are used inside the culverts of the filling and emptying systems of lock structures. At least two valves are necessary in each longitudinal culvert. A filling valve is located between the upper pool intake and the chamber intake ports. An emptying valve is located between the chamber outlet ports and the lower pool discharge. Some of the most common valve types are tainter, vertical lift, and butterfly.

\subsection{Dam Gates}

Dam gates are used at the top of a dam spillway to control the upper pool elevation by holding back or passing water. The types of dam gates currently used are tainter, vertical lift, and roller. 
Intentionally Blank 
U. S. ARMY CORPS OF ENGINEERS

LOCK GATE LEAF OPERATING EQUIPMENT INSPECTION

PAGE 1

NAME OF CIVIL WORKS PROJECT:

LOCATION OF CIVIL WORKS PROJECT: (1. Body of water, 2. Nearest town)

1.

2.

INSPECTION DATE:

INSPECTED BY:

GATE IDENTIFICATION: (circle the correct gate, leaf, and type of gate)
Upper Gate
1. Left Leaf
2. Right Leaf
Lower Gate
1. Left Leaf
2. Right Leaf

GATE TYPE

1. Miter

2. Sector

3. Tainter

4. Vertical Lift

ASSEMBLY LIST AND ORDER OF POWER TRANSFER

COMMON LEFT RIGHT

Exposed gear

Enclosed gear

Gear rack

Strut arm

Rocker arm

Cable

Chain

Hydraulic cylinder
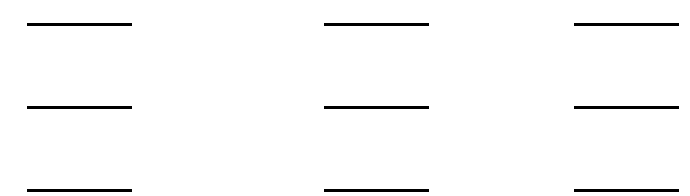

Coupling 


\section{Page 1. Comments: Recordkeeping Data}

Completed before the site inspection and verified or changed during the site inspection.

Enter the NAME of the Corps of Engineer Project Title.

Indicate the BODY OF WATER and NEAREST TOWN.

Indicate GATE IDENTIFICATION. Circle the gate that will be inspected and the TYPE of gate. The orientation of the gate, left or right, is determined by looking downstream.

Select ASSEMBLIES that exist in the operating equipment and number them in order of POWER TRANSFER from source of the power to the structure. If the equipment splits into a LEFT and RIGHT set of equipment, place the power transfer number in the columns labeled left and right, respectively. Place an L behind the number if it is on the left side and an $\mathrm{R}$ behind the number if it is on the right side. If the assembly is common to (shared by) both sides or if there is no power split, place the numbers in the COMMON column. Left and right are determined when facing downstream.

Example: One Page 1 can be used for the inspection of any combination of assemblies in a lock gate. If the upper right gate leaf is inspected, RIGHT LEAF should be circled in the row labeled UPPER GATE. The gate type should also be indicated by circling the appropriate type. The order of power transfer of the assemblies in the structure should be numbered; for example, in Figure 5 the order is (1) Hydraulic Cylinder, (2) Rack, (3) Exposed gear, and (4) Strut. The numbering for this example is shown below.

ASSEMBLY LIST AND ORDER OF POWER TRANSFER

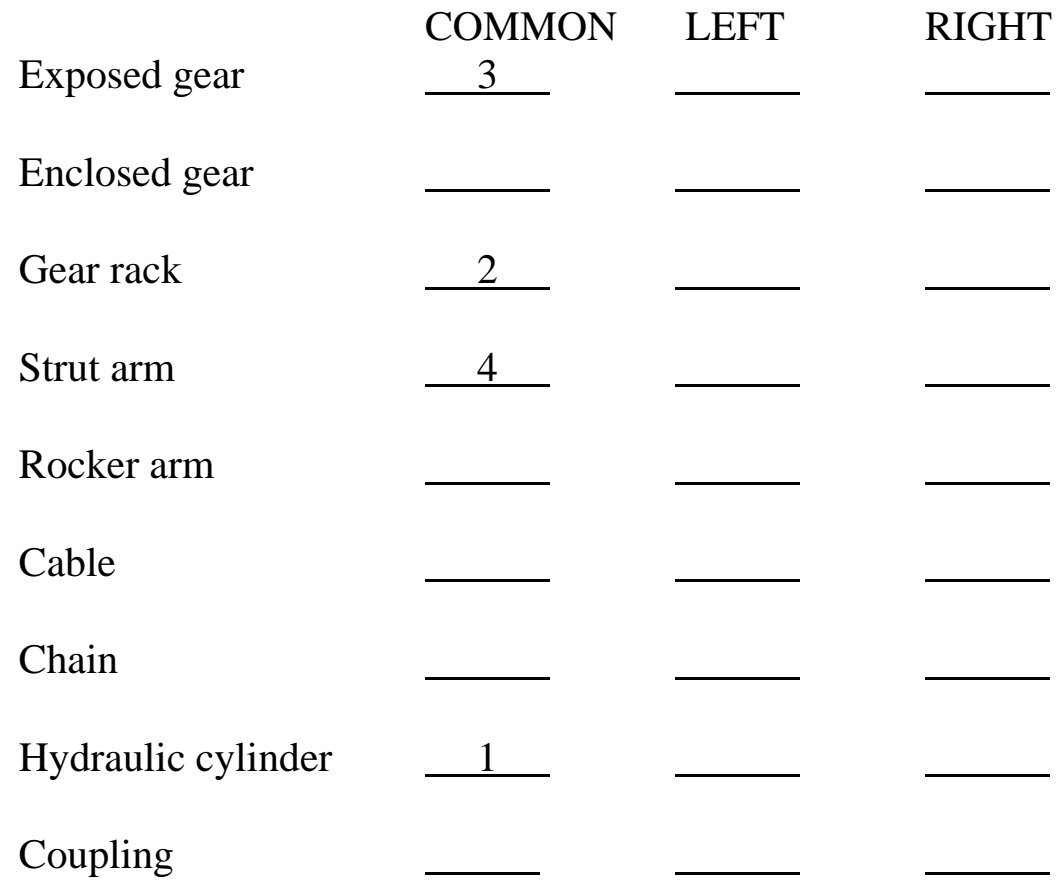


U. S. ARMY CORPS OF ENGINEERS

LOCK GATE LEAF OPERATING EQUIPMENT INSPECTION

PAGE 1

NAME OF CIVIL WORKS PROJECT:

LOCATION OF CIVIL WORKS PROJECT: (1. Body of water, 2. Nearest town)

1.

2.

INSPECTION DATE:

INSPECTED BY:

GATE IDENTIFICATION: (circle the correct gate, leaf, and type of gate)
Upper Gate
1. Left Leaf
2. Right Leaf
Lower Gate
1. Left Leaf
2. Right Leaf

GATE TYPE

1. Miter

2. Sector

3. Tainter

4. Vertical Lift

ASSEMBLY LIST AND ORDER OF POWER TRANSFER

COMMON LEFT RIGHT

Exposed gear

Enclosed gear

Gear rack

Strut arm

Rocker arm

Cable

Chain

Hydraulic cylinder
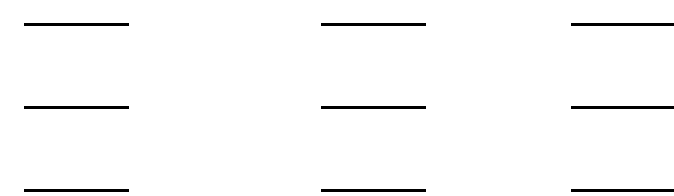

Coupling 


\section{Page 1. Comments: Recordkeeping Data (continued)}

The appropriate inspection Parts 1 and 2 for the selected assemblies will then be completed and combined with pages 1 and 2 for a complete set of inspection forms. If the gate shown in Figure 5 were inspected, one hydraulic cylinder Parts 1 and 2, one gear rack Parts 1 and 2, one exposed gear Parts 1 and 2, and one strut page must be added to the pages 1 and 2 for a complete set.

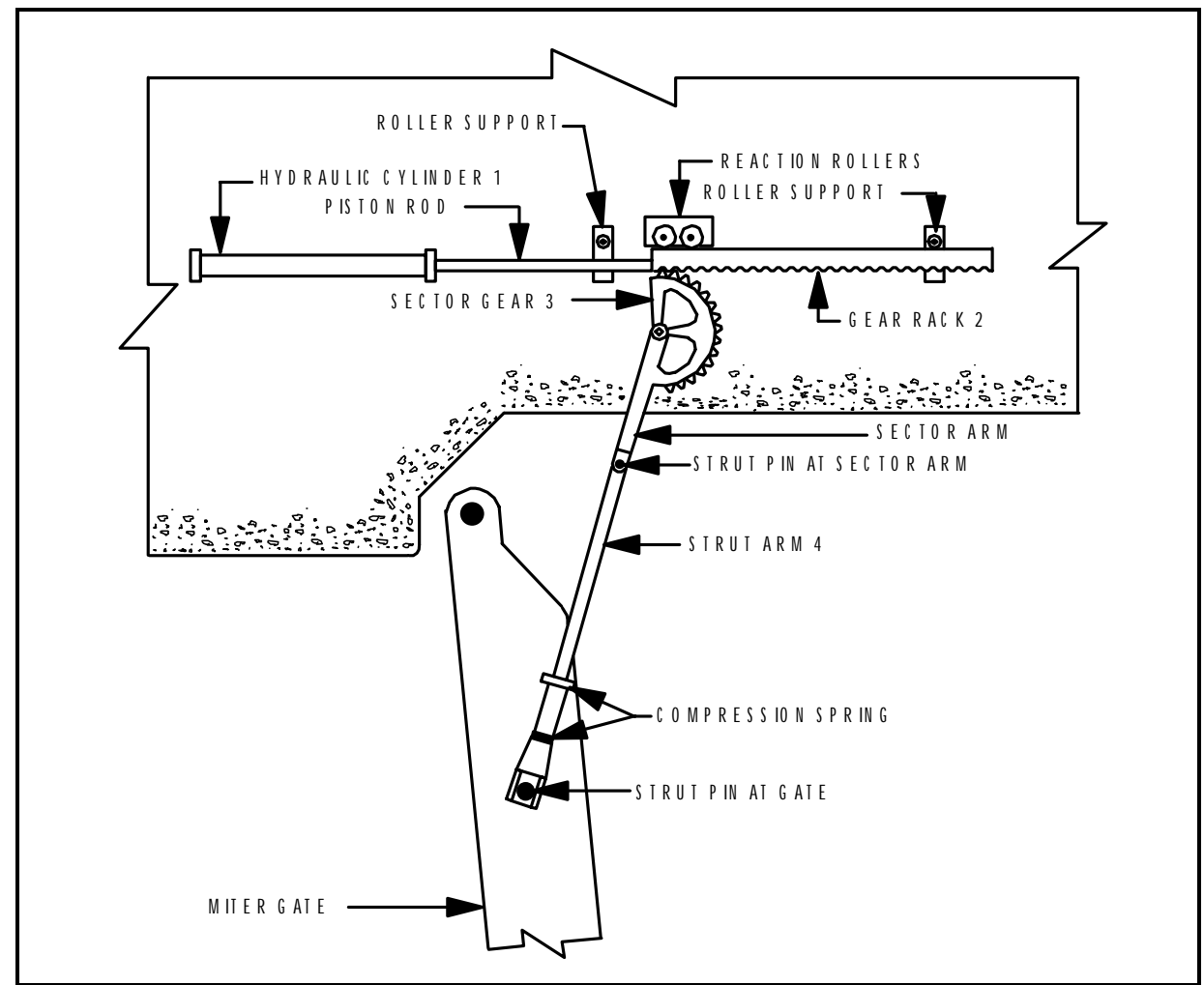

Figure 5. Plan view of miter lock gate operating equipment. 
U. S. ARMY CORPS OF ENGINEERS

LOCK GATE LEAF OPERATING EQUIPMENT INSPECTION

PAGE 2

IS ORIGINAL OPERATION EQUIPMENT IN PLACE? $\underline{(\mathrm{Y} / \mathrm{N})}$

IF NOT, IDENTIFY CURRENT OPERATION EQUIPMENT HISTORY:

ARE DRAWINGS AVAILABLE FOR EQUIPMENT IN PLACE? (Y/N)

ARE THE DRAWINGS INCLUDED WITH THIS FILE? (Y/N)

PAST 10 YEAR HISTORY

MAJOR MAINTENANCE, REPAIRS, OR OTHER MODIFICATIONS

DATE DESCRIPTION

(1):

(2):

(3):

(4):

PREVIOUS INSPECTIONS OR STRUCTURAL REVIEWS (attach available copies)

DATE DESCRIPTION

(1):

(2):

(3):

(4):

OTHER COMMENTS: 
Page 2 comments: Historical or General Data.

Completed before the site inspection and verified or changed during the site inspection.

Operating equipment components are sometimes replaced or removed during rehabilitation. It is important for later reference to record the history of the in-place structure.

Enter major MAINTENANCE, REPAIRS, OR OTHER MODIFICATIONS performed on the operating equipment within the past 10 years.

Enter PREVIOUS INSPECTION information for reference purposes. 
U. S. ARMY CORPS OF ENGINEERS

VALVE OPERATING EQUIPMENT INSPECTION

PAGE 1

NAME OF CIVIL WORKS PROJECT:

LOCATION OF CIVIL WORKS PROJECT: (1. Body of water, 2. Nearest town)

1.

2.

INSPECTION DATE:

INSPECTED BY:

VALVE IDENTIFICATION: (circle the correct valve and type of valve)
Filling Valve
1. Left Valve
2. Right Valve

Emptying Valve

1. Left Valve

2. Right Valve

VALVE TYPE

1. Tainter

2. Butterfly

3. Vertical lift

ASSEMBLY LIST AND ORDER OF POWER TRANSFER

$$
\text { COMMON LEFT RIGHT }
$$

Exposed gear

Enclosed gear

Gear rack

Strut arm

Rocker arm

Cable

Chain

Hydraulic cylinder

Coupling 
Page 1. Comments: Recordkeeping Data

Completed before the site inspection and verified or changed during the site inspection.

Enter the NAME of the Corps of Engineer Project Title.

Indicate the BODY OF WATER and NEAREST TOWN.

Indicate VALVE IDENTIFICATION. Circle the valve that will be inspected and the TYPE of VALVE. The orientation of the valve, left or right, is determined by looking downstream.

Select ASSEMBLIES that exist in the operating equipment and number them in order of POWER TRANSFER from source of the power to the structure. If the operating equipment splits into a LEFT and RIGHT set of equipment, place the power transfer number in the columns labeled left and right, respectively. Place an L behind the number if it is on the left side and an $\mathrm{R}$ behind the number if it is on the right side. If the assembly is common to (shared by) both sides or if there is no power split, place the numbers in the COMMON column. Left and right are determined when facing downstream.

Example: One Page 1 can be used for the inspection of any combination of assemblies in a valve. If the right filling valve is inspected, the RIGHT VALVE of the FILLING VALVE should be circled. The valve type should also be indicated by circling the appropriate type. The order of power transfer of the assemblies in the structure should be numbered; for example, the order in Figure 6 is (1) Hydraulic cylinder, (2) Rocker arm, and (3) Strut. The numbering for this example is shown below.

ASSEMBLY LIST AND ORDER OF POWER TRANSFER

Exposed gear

COMMON LEFT RIGHT

Enclosed gear

Gear rack

Strut arm

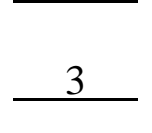

Rocker arm

2

Cable

Chain

Hydraulic cylinder

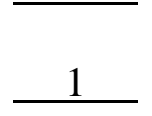

Coupling 
U. S. ARMY CORPS OF ENGINEERS

VALVE OPERATING EQUIPMENT INSPECTION

PAGE 1

NAME OF CIVIL WORKS PROJECT:

LOCATION OF CIVIL WORKS PROJECT: (1. Body of water, 2. Nearest town)

1.

2.

INSPECTION DATE:

INSPECTED BY:

VALVE IDENTIFICATION: (circle the correct valve and type of valve)
Filling Valve
1. Left Valve
2. Right Valve

Emptying Valve

1. Left Valve

2. Right Valve

VALVE TYPE

1. Tainter

2. Butterfly

3. Vertical lift

ASSEMBLY LIST AND ORDER OF POWER TRANSFER

$$
\text { COMMON LEFT RIGHT }
$$

Exposed gear

Enclosed gear

Gear rack

Strut arm

Rocker arm

Cable

Chain

Hydraulic cylinder

Coupling 
Page 1. Comments: Recordkeeping Data (continued)

The appropriate inspection pages for the selected assemblies will then be completed and combined with pages 1 and 2 for a complete set of inspection forms. If the valve shown in Figure 6 were inspected, one hydraulic cylinder Parts 1 and 2, one rocker arm page, and one strut arm page must be added to pages 1 and 2 for a complete set.

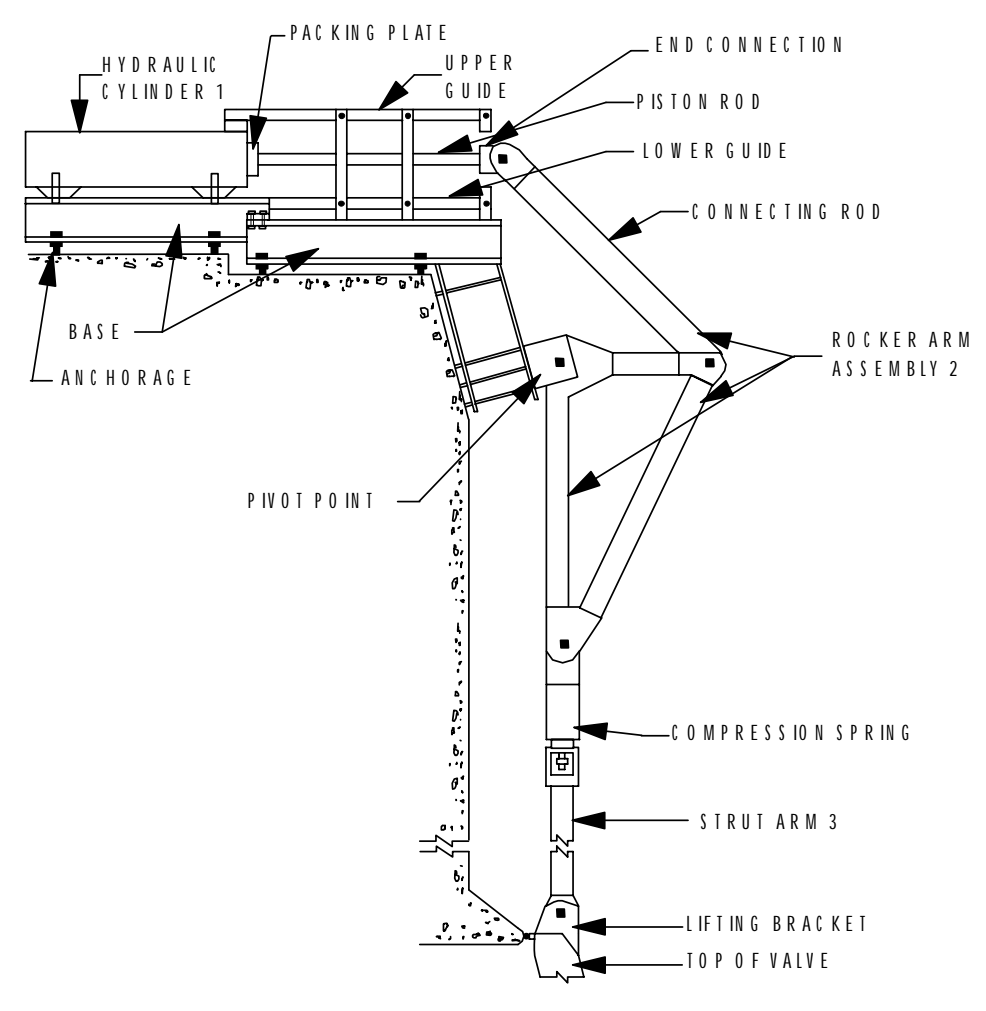

Figure 6. Side view of tainter valve operating equipment. 
U. S. ARMY CORPS OF ENGINEERS

PAGE 2

VALVE OPERATING EQUIPMENT INSPECTION

IS ORIGINAL OPERATION EQUIPMENT IN PLACE? $\underline{(\mathrm{Y} / \mathrm{N})}$

IF NOT, IDENTIFY CURRENT OPERATION EQUIPMENT HISTORY:

ARE DRAWINGS AVAILABLE FOR EQUIPMENT IN PLACE? (Y/N)

ARE THE DRAWINGS INCLUDED WITH THIS FILE? (Y/N)

PAST 10 YEAR HISTORY

MAJOR MAINTENANCE, REPAIRS, OR OTHER MODIFICATIONS

DATE DESCRIPTION

(1):

(2):

(3):

(4):

$\underline{\text { PREVIOUS INSPECTIONS OR STRUCTURAL REVIEWS (attach available copies) }}$

DATE DESCRIPTION

(1):

(2):

(3):

(4):

OTHER COMMENTS: 
Page 2 comments: Historical or General Data.

Completed before the site inspection and verified or changed during the site inspection.

Operating equipment components are sometimes replaced or removed during rehabilitation. It is important for later reference to record the history of the in-place structure.

Enter major MAINTENANCE, REPAIRS, OR OTHER MODIFICATIONS performed on the operating equipment within the past 10 years.

Enter PREVIOUS INSPECTION information for reference purposes. 
NAME OF CIVIL WORKS PROJECT:

LOCATION OF CIVIL WORKS PROJECT: (1. Body of water, 2. Nearest town) 1 .

2.

INSPECTION DATE: INSPECTED BY:

GATE IDENTIFICATION(circle the appropriate gate)

1. Tainter

2. Vertical lift

3. Roller

ASSEMBLY LIST AND ORDER OF POWER TRANSFER

COMMON LEFT RIGHT

Exposed gear

Enclosed gear

Gear rack

Strut arm

Rocker arm

Cable

Chain

Hydraulic cylinder

Coupling

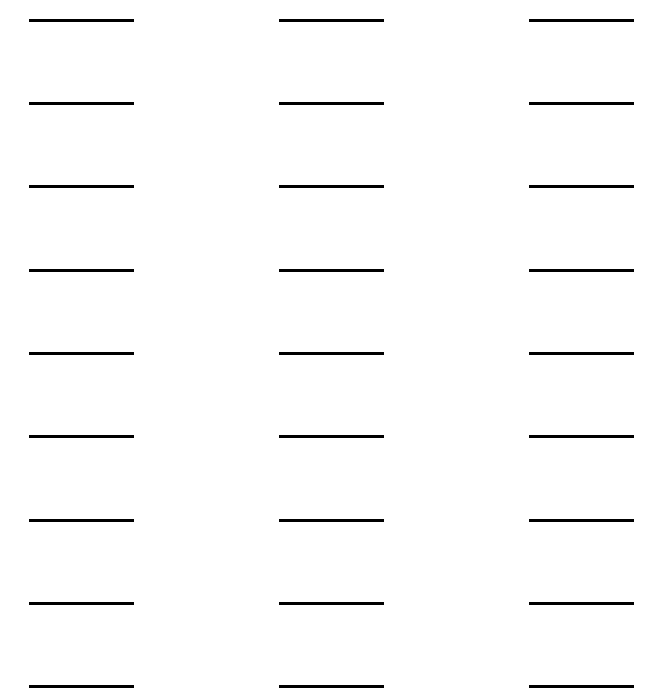


Page 1. Comments: Recordkeeping Data

Completed before the site inspection and verified or changed during the site inspection.

Enter the NAME of the Corps of Engineer Project Title.

Indicate the BODY OF WATER and NEAREST TOWN.

Indicate type of gate for the GATE IDENTIFICATION.

Select ASSEMBLIES that exist in the operating equipment and number them in order of POWER TRANSFER from source of power to the structure. If the equipment splits into a LEFT and RIGHT set of equipment, place the power transfer number in the columns labeled left and right, respectively. Place an L behind the number if it is on the left side and an $\mathrm{R}$ behind the number if it is on the right side. If the assembly is common to (shared by) both sides or if there is no power split, place the numbers in the COMMON column. Left and right are determined when facing downstream.

Example: One Page 1 can be used for any combination of assemblies used to operate a dam gate. The gate type should be indicated by circling the appropriate type. The order of power transfer of the assemblies in the structure should be numbered; for example, the order in Figure 7 is: (1) Coupling, (2) Enclosed gears, (3) Coupling, (4) Enclosed gears, (5) Coupling, (6L) Exposed gears, (6R) Coupling, (7L) Cable, (7R) Coupling, (8R) Exposed gears, and (9R) Cable. The numbering for this example is shown below.

ASSEMBLY LIST AND ORDER OF POWER TRANSFER

COMMON LEFT RIGHT

\begin{tabular}{|c|c|c|}
\hline Exposed gear & & $6 \mathrm{~L}$ \\
\hline Enclosed gear & 2,4 & \\
\hline Gear rack & & \\
\hline Strut arm & & \\
\hline Rocker arm & & \\
\hline Cable & & $7 \mathrm{~L}$ \\
\hline Chain & & \\
\hline Hydraulic cylinder & & \\
\hline Coupling & $1,3,5$ & \\
\hline
\end{tabular}


NAME OF CIVIL WORKS PROJECT:

LOCATION OF CIVIL WORKS PROJECT: (1. Body of water, 2. Nearest town) 1 .

2.

INSPECTION DATE: INSPECTED BY:

GATE IDENTIFICATION(circle the appropriate gate)

1. Tainter

2. Vertical lift

3. Roller

ASSEMBLY LIST AND ORDER OF POWER TRANSFER

$$
\text { COMMON LEFT RIGHT }
$$

Exposed gear

Enclosed gear

Gear rack

Strut arm

Rocker arm

Cable

Chain

Hydraulic cylinder

Coupling

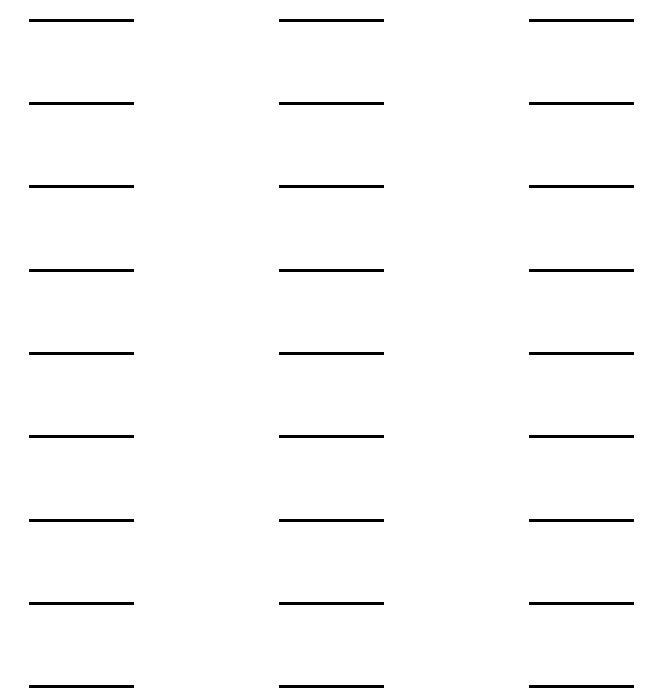




\section{Page 1. Comments: Recordkeeping Data}

The appropriate inspection Parts 1 and 2 for the selected assemblies will then be completed and combined with pages 1 and 2 for a complete set of inspection forms. If the dam gate operating equipment shown in Figure 7 were inspected, five coupling pages, two enclosed gear Parts 1 and 2, two exposed gear Parts 1 and 2, and two cable Parts 1 and 2 must be added to pages 1 and 2 for a complete set.

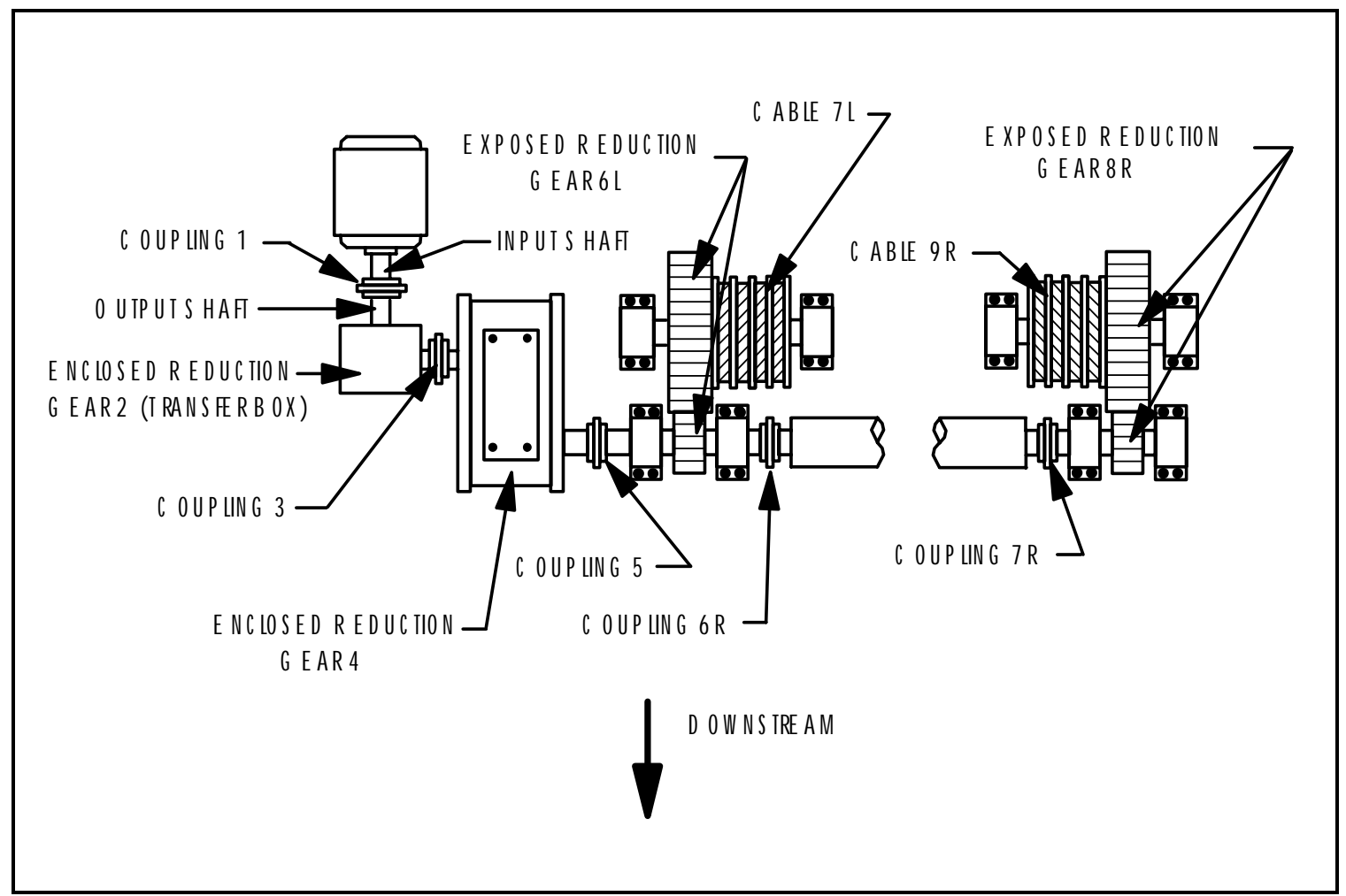

Figure 7. Plan view of dam gate operating equipment. 
IS ORIGINAL OPERATION EQUIPMENT IN PLACE? $\underline{(\mathrm{Y} / \mathrm{N})}$

IF NOT, IDENTIFY CURRENT OPERATION EQUIPMENT HISTORY:

ARE DRAWINGS AVAILABLE FOR EQUIPMENT IN PLACE? (Y/N)

ARE THE DRAWINGS INCLUDED WITH THIS FILE? (Y/N)

$\underline{\text { PAST } 10 \text { YEAR HISTORY }}$

MAJOR MAINTENANCE, REPAIRS, OR OTHER MODIFICATIONS

DATE DESCRIPTION

(1):

(2):

(3):

(4):

PREVIOUS INSPECTIONS OR STRUCTURAL REVIEWS (attach available copies)

(1):
(2):
(3):
(4):
DESCRIPTION

OTHER COMMENTS: 
Page 2 comments: Historical or General Data.

Completed before the site inspection and verified or changed during the site inspection.

Operating equipment components are sometimes replaced or removed during rehabilitation. It is important for later reference to record the history of the in-place structure.

Enter major MAINTENANCE, REPAIRS, OR OTHER MODIFICATIONS performed on the operating equipment within the past 10 years.

Enter PREVIOUS INSPECTION information for reference purposes. 


\section{Exposed Gear Assembly}

\subsection{Component Identification}

Definitions and sketches for components of the exposed gear assembly are presented in the following paragraphs. Sector gears and bull gears, which are used with the rack assembly on lock and dam gates, are included in this assembly. The inspection form and rules for racks are presented in Chapter 6.

\section{Sector Gear}

A sector gear is a large gear in the shape of a partial circle. The gear transfers force from the roller rack to a linkage arm through rotation (Figure 5). The linkage arm is secured to and rotates with the sector gear, which rotates on either a bushing or bearing system. Sector gears often have counter weights or are supported by a roller system to account for eccentric loads on the bushings or bearings.

\section{Bull Gear}

The bull gear consists of teeth arranged in a circular fashion and transfers force from the reduction gear set to the rack on a sector gate (Figure 8). The gear rotates on either a bushing or a bearing system.

\section{Reduction Gears}

Reduction gears are a series of gears used to lessen the torque required to open and close or raise and lower gate or valve structures, respectively. As a result, the structure moves at a slower rate of speed then the motor rotates (Figures 7, 8, and 9).

\section{Gear and Pinion}

The gear and pinion are a set of reduction gears, with the pinion substantially smaller than the gear. 


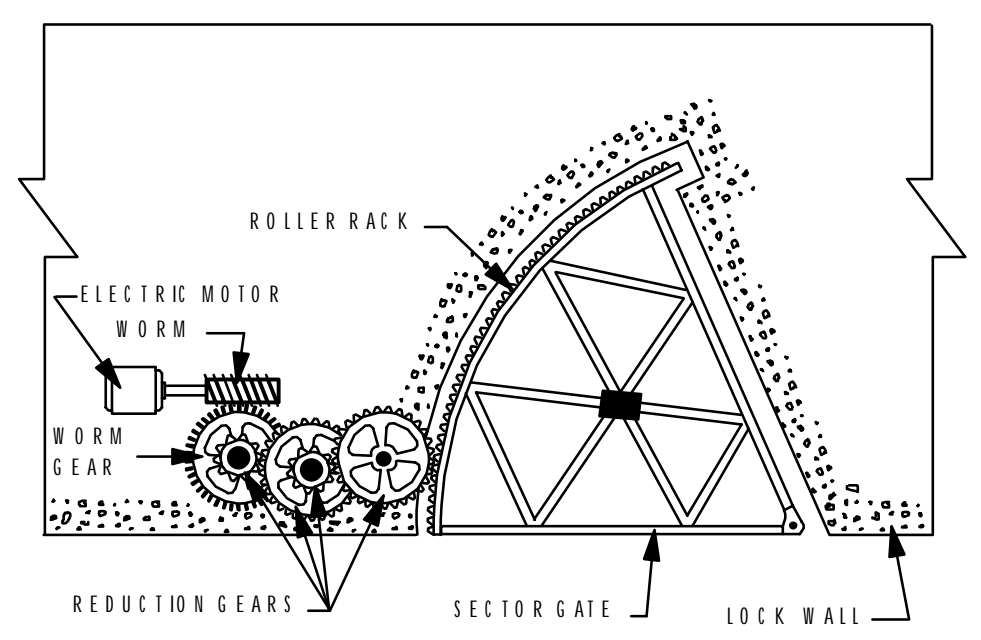

LOCKCHAMBER

Figure 8. Plan view of sector lock gate operating equipment (gear and rack).

\section{Roller Support}

Large horizontal gears are often supported with roller systems.

\subsection{Inspection Form With Comments}

The following pages present Parts 1 and 2 of the field inspection forms for an exposed gear assembly. The side-by-side arrangement of the opposing pages displays specific explanations (right side) adjacent to the entry on the inspection form (left side). 


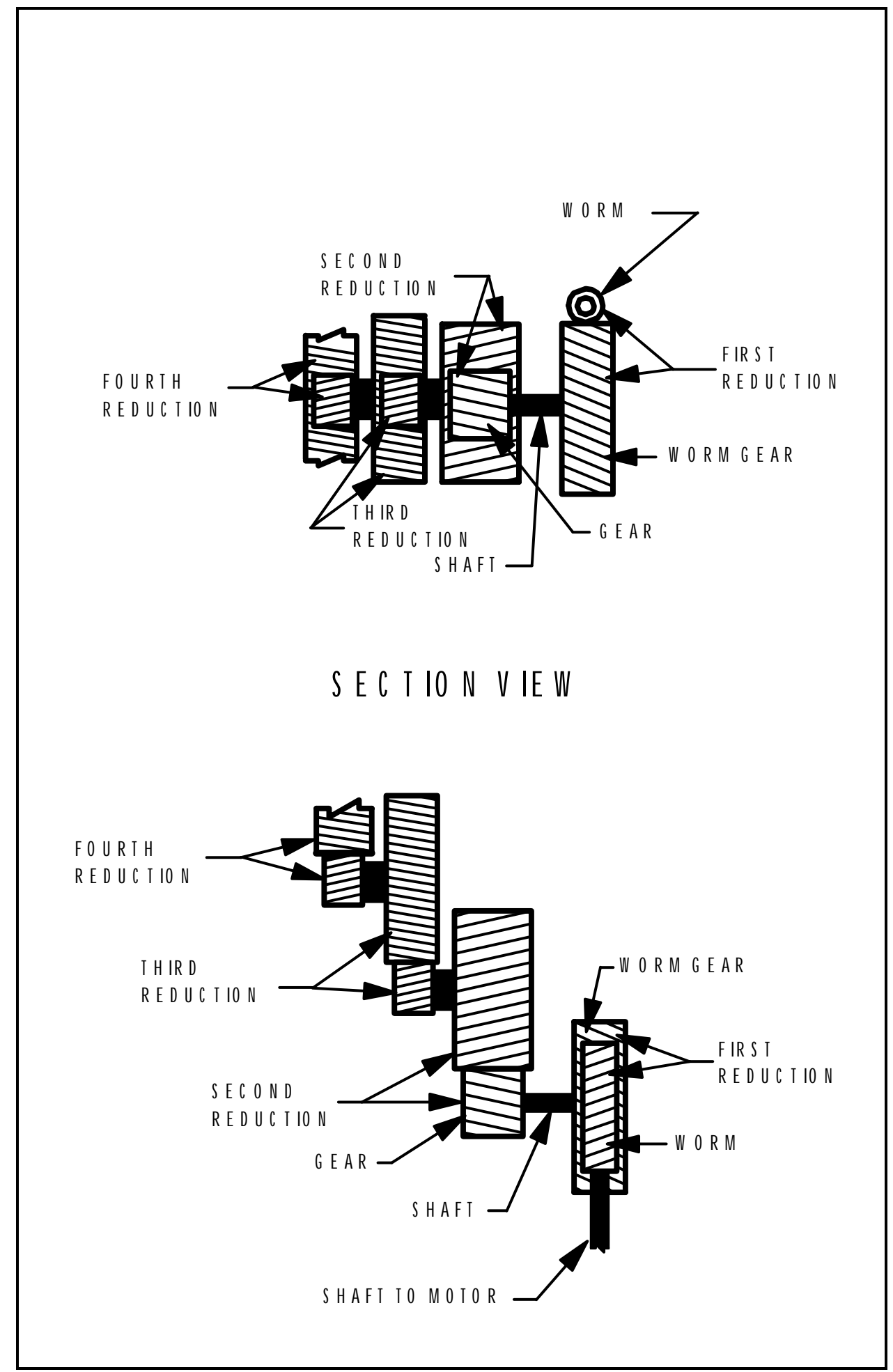

Figure 9. Reduction gear schematic. 
Intentionally Blank 


\section{EXPOSED GEAR INSPECTION PART 1}

PROJECT NAME:

DATE:

GATE IDENTIFICATION: (identify the appropriate lock gate, valve, or dam gate)

Lock Gate
Upper
Lower
1. Left Leaf
2. Right Leaf

Valve

$\begin{array}{lll}\text { Emptying } & \text { 1. Left } & \text { 2. Right } \\ \text { Filling } & \text { 1. Left } & \text { 2. Right }\end{array}$

Dam Gate

Number

NOISE, JUMPING, \& VIBRATION

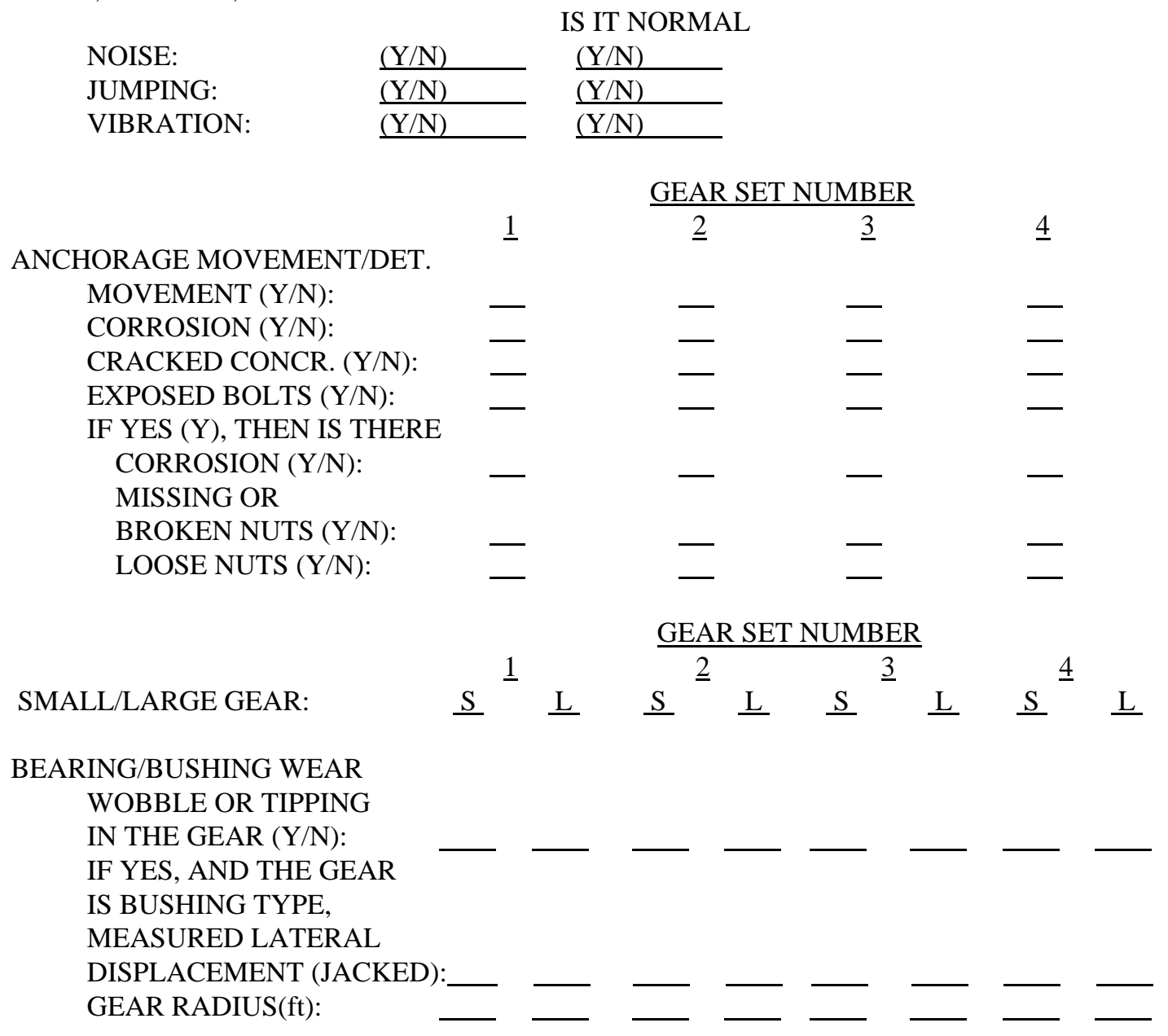

COMMENTS: 
PART 1 Comments: Field data

Enter the PROJECT NAME for this inspection, the DATE of the inspection, and, for the GATE IDENTIFICATION, identify which gate leaf or valve is being inspected. Also enter the power transfer number (P.T.\#), which can be found on Page 1 of the inspection form.

Observation of the exposed gear during gate movement is a good indicator of problems. Record any indication of NOISE, JUMPING, and/or VIBRATION during operation and then indicate whether this noise, jumping, and/or vibration is NORMAL.

Record the evidence of MOVEMENT of the gear ANCHORAGE system base as the gate is opened and closed. Evidence of movement can be observed visually or enhanced by placing a dial gage to monitor any movement (Figure 10). ${ }^{*}$ A dial gage change greater than 0.002 in. is considered movement. Excessive concrete spalling may indicate a displacement occurred at this location at some time. Also, record the presence of any CORROSION (10\% volume loss) of the steel portion or any CRACKED CONCRETE at the interface of the embedment (Figure 10). Small hairline cracks, probably caused by thermal expansion or contraction of the concrete, should be ignored. Indicate if there are any CORRODED (10\% volume loss), MISSING OR BROKEN, or LOOSE NUTS at the gear anchorage if the BOLTS are EXPOSED (Figure 10).

The presence of BEARING/BUSHING WEAR for the gear is determined by observing whether there is WOBBLE or TIPPING of the gear. Record whether there is wobbling or tipping of the gear. To check for wobble, watch the gear as it is operated. If the gear is not too large, bearing/bushing wear can also be checked by prying the gear while it is not being operated. Tipping of large horizontal gears can be observed by measuring the vertical distance from a gear tooth to a reference point on the concrete floor, rotating the gear to a closed position if it was open (or to an open position if it was closed) and measuring from the reference point on the concrete floor to the corresponding tooth directly above the reference point. For vertical gears, a horizontal reference point should be established to determine if wobbling occurs. When using this method to determine whether tipping occurs, the maximum lateral displacement in a bushing type gear is 1/16 in. per foot of radius and 1/16 in. per $3 \mathrm{ft}$ of radius in a bearing type system. If the measured vertical displacement is greater than these maximums, record a yes $(Y)$ for bearing/bushing wear. If the gear rotates on a BUSHING TYPE system and tipping is evident, record the MEASURED LATERAL DISPLACEMENT found by JACKING the gear. A detailed procedure for jacking the gear can be found in Appendix A. Also record the GEAR RADIUS in feet.

* This figure is on p 50 . 


\section{EXPOSED GEAR INSPECTION PART 2}

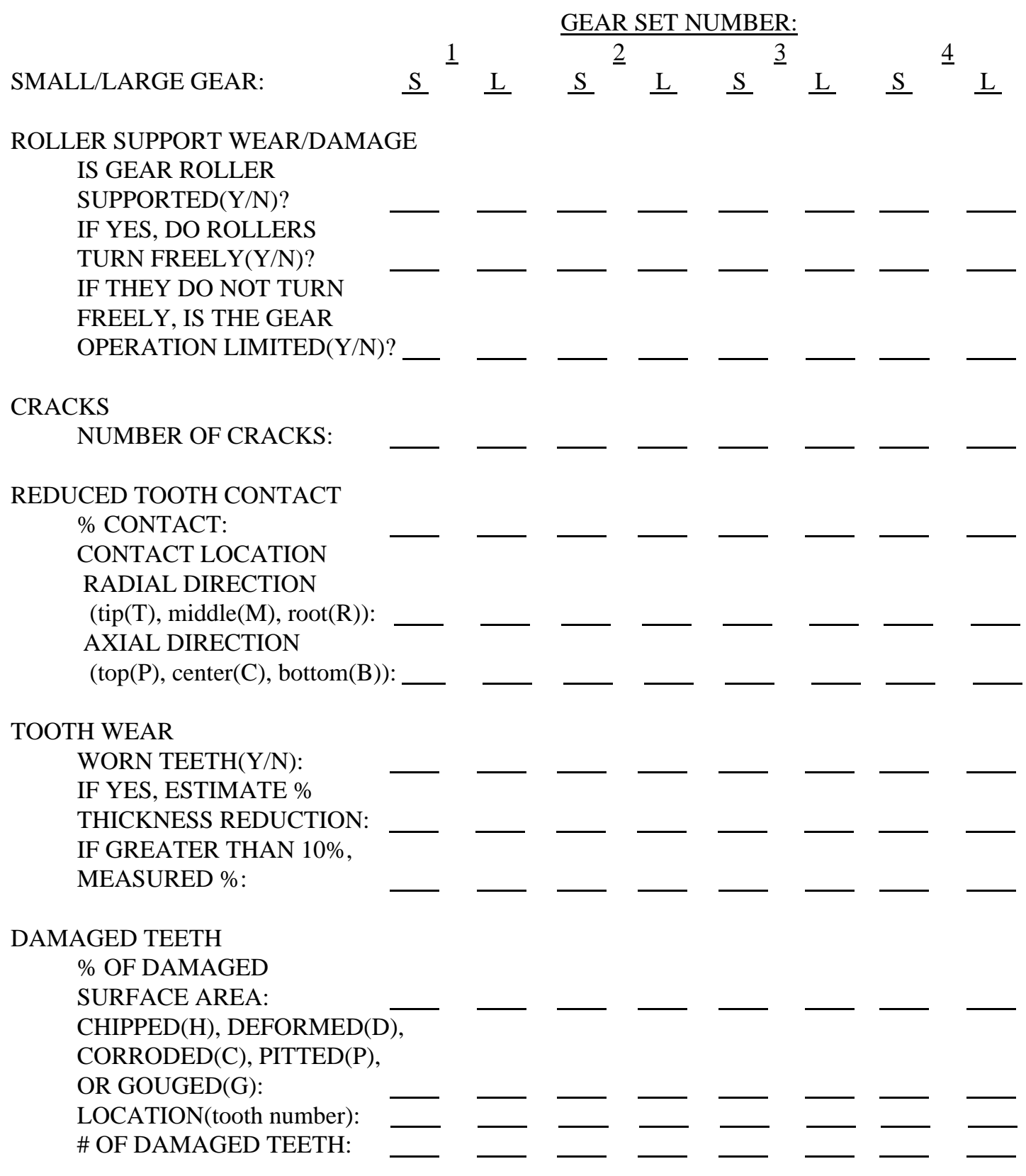

COMMENTS: 
Record a yes (Y) if the gear is ROLLER SUPPORTED. If the gear is roller supported, record if the ROLLERS TURN FREELY. If the rollers do not turn freely, record if the GEAR OPERATION IS LIMITED.

The presence of CRACKS on the gear is usually not tolerated. Record the NUMBER OF CRACKS found on the gear by visual observation. Many times a crack will show up as corrosion underneath the painted surface. Also record the location of the cracks in the COMMENT section.

Record the average percentage of TOOTH CONTACT in the five teeth with the least contact area. The contact area is usually associated with an area where the grease film is noticeably thinner. Wear patterns may also help to identify the contact area. Once the contact area has been identified, the \% CONTACT is recorded as the percentage of the total tooth area which is contacted area. Also, record where the CONTACT area LOCATION is, relative to the total tooth area. In the RADIAL DIRECTION, the location is recorded as occurring primarily at the tip $(\mathrm{T})$, middle $(\mathrm{M})$, root $(\mathrm{R})$, or any combination of the three (Figure 11). ${ }^{*}$ In the AXIAL DIRECTION, the location is recorded as occurring primarily on the top $(\mathrm{P})$, center $(\mathrm{C})$, bottom $(\mathrm{B})$ or any combination of the three (Figure 11). On horizontal gears, the top of the tooth is on the top side of the gear. To determine the side of the tooth designated as the top on vertical gears, observe the gear from both sides as the gate or valve is being closed. The side from which the gear is turning counter-clockwise is the top side of the gear.

Pick the TOOTH with the worst WEAR and look at the wear at the pitch line. Record if there is TOOTH WEAR. If the pitch line is not scribed on the teeth, a good estimate of the pitch line location is slightly towards the tip from the mid-depth of the tooth. If tooth wear is visible, estimate the PERCENTAGE of TOOTH THICKNESS REDUCTION. The percentage of thickness reduction can be estimated a number of ways. One technique is to measure both a worn tooth and a tooth that has infrequent contact with a ruler or tape measure and compare the tooth thicknesses. A second technique to estimate the thickness reduction of tooth thickness on meshing gears with different widths is to check for a worn ledge on the wider tooth, with the depth of the ledge being the estimate of reduction in thickness. A third technique is to observe the curvature of a worn tooth and a tooth that has infrequent contact. As the tooth wears, the tooth edge may become flat. If the estimated percentage is greater than $10 \%$, record the MEASURED percentage using wear measurement techniques in Appendix B.

Pick the worst DAMAGED TOOTH for each type of damage on each gear and record the percentage of SURFACE AREA that is missing due to CHIPPING, DEFORMATION, PITTING, CORROSION, or GOUGING. If damage has occurred indicate the TYPE of DAMAGE. Chipping of the tooth is the breaking off of steel pieces, which usually results in jagged edges and high stress concentrations in the tooth. Deformation of the tooth is the changing of the shape of the tooth, usually the result of excessive forces or something becoming lodged between teeth during operation. Pitting of the tooth is the severe

\footnotetext{
* This figure is on $p 50$.
} 


\section{EXPOSED GEAR INSPECTION PART 2}

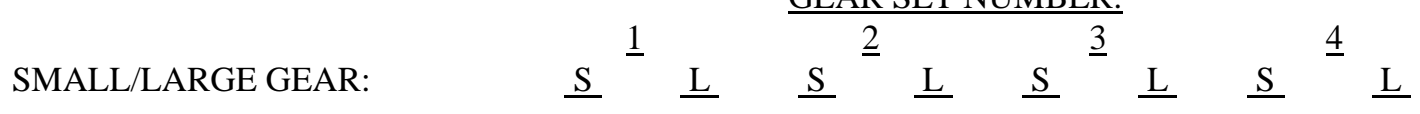

ROLLER SUPPORT WEAR/DAMAGE

IS GEAR ROLLER

SUPPORTED(Y/N)?

IF YES, DO ROLLERS

TURN FREELY(Y/N)?

IF THEY DO NOT TURN

FREELY, IS THE GEAR

OPERATION LIMITED(Y/N)?

\section{CRACKS}

NUMBER OF CRACKS:

REDUCED TOOTH CONTACT

$\%$ CONTACT:

CONTACT LOCATION

RADIAL DIRECTION

(tip(T), middle(M), $\operatorname{root}(\mathrm{R}))$ :

AXIAL DIRECTION

(top $(\mathrm{P})$, center(C), bottom $(\mathrm{B}))$ :

TOOTH WEAR

WORN TEETH(Y/N):

IF YES, ESTIMATE \%

THICKNESS REDUCTION:

IF GREATER THAN 10\%,

MEASURED \%:

DAMAGED TEETH

$\%$ OF DAMAGED

SURFACE AREA:

CHIPPED(H), DEFORMED(D),

CORRODED(C), PITTED(P),

OR GOUGED $(\mathrm{G})$ :

LOCATION(tooth number):

\# OF DAMAGED TEETH:

COMMENTS: 
PART 2 Comments: Field data (continued)

localized corrosion of the tooth that results in small cavities in the tooth surface. Corrosion is the loss of steel in the tooth due to interaction with the environment. Gouging of the tooth is the occurrence of smooth grooves or holes in the tooth surface. Record the LOCATION of the damaged teeth. The location of the tooth is described by a number. On a sector gear, the first tooth on the side where the sector arm is connected is tooth number one and will be numbered from there. For bull gears that engage the sector gate rack, the gear tooth that is fully in contact with the rack when the gate is in the open position is numbered one and the remaining teeth will be numbered in counter-clockwise direction from tooth one. For exposed reduction gears, the meshing tooth between the gears that are fully in contact when the gate or valve is in the open position is numbered one. The remaining teeth are numbered in order starting at tooth one and going in the direction the gear turns as the gate or valve is being closed. 


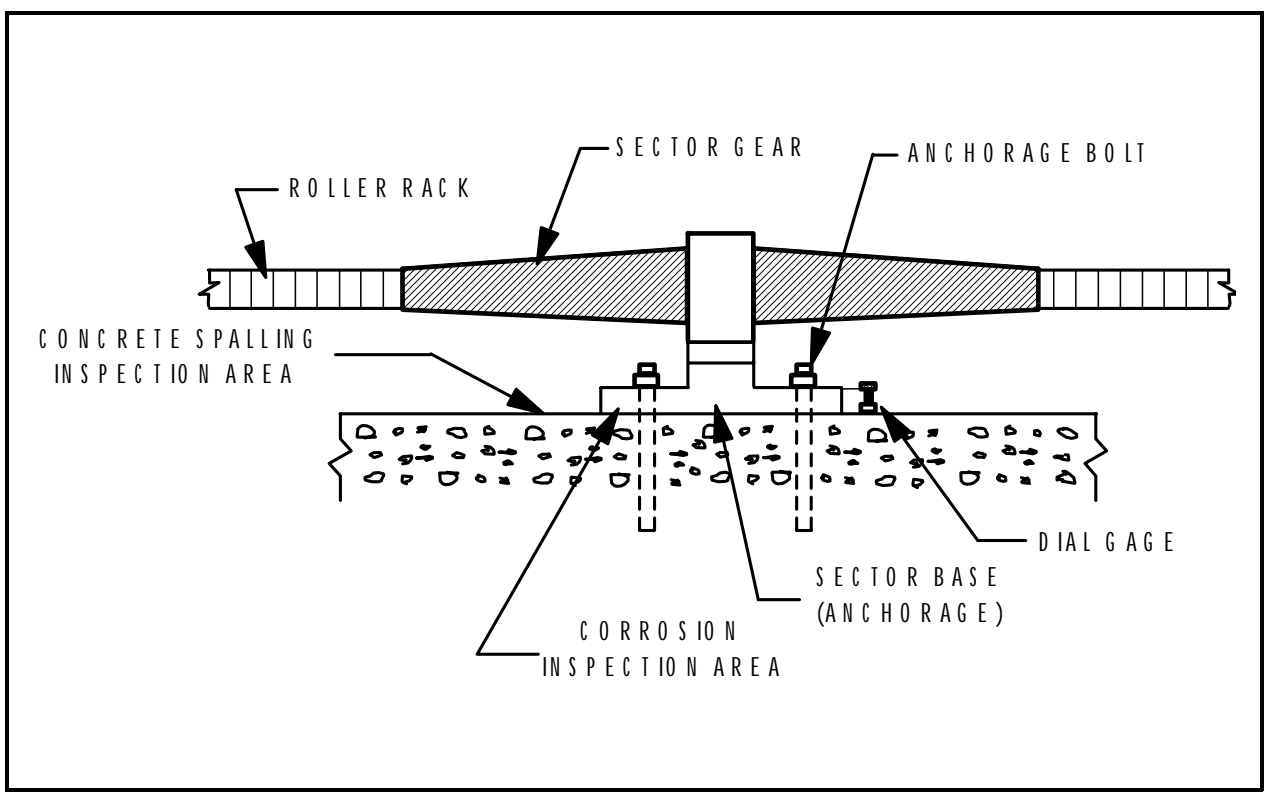

Figure 10. Gear anchorage movement/deterioration measurement.

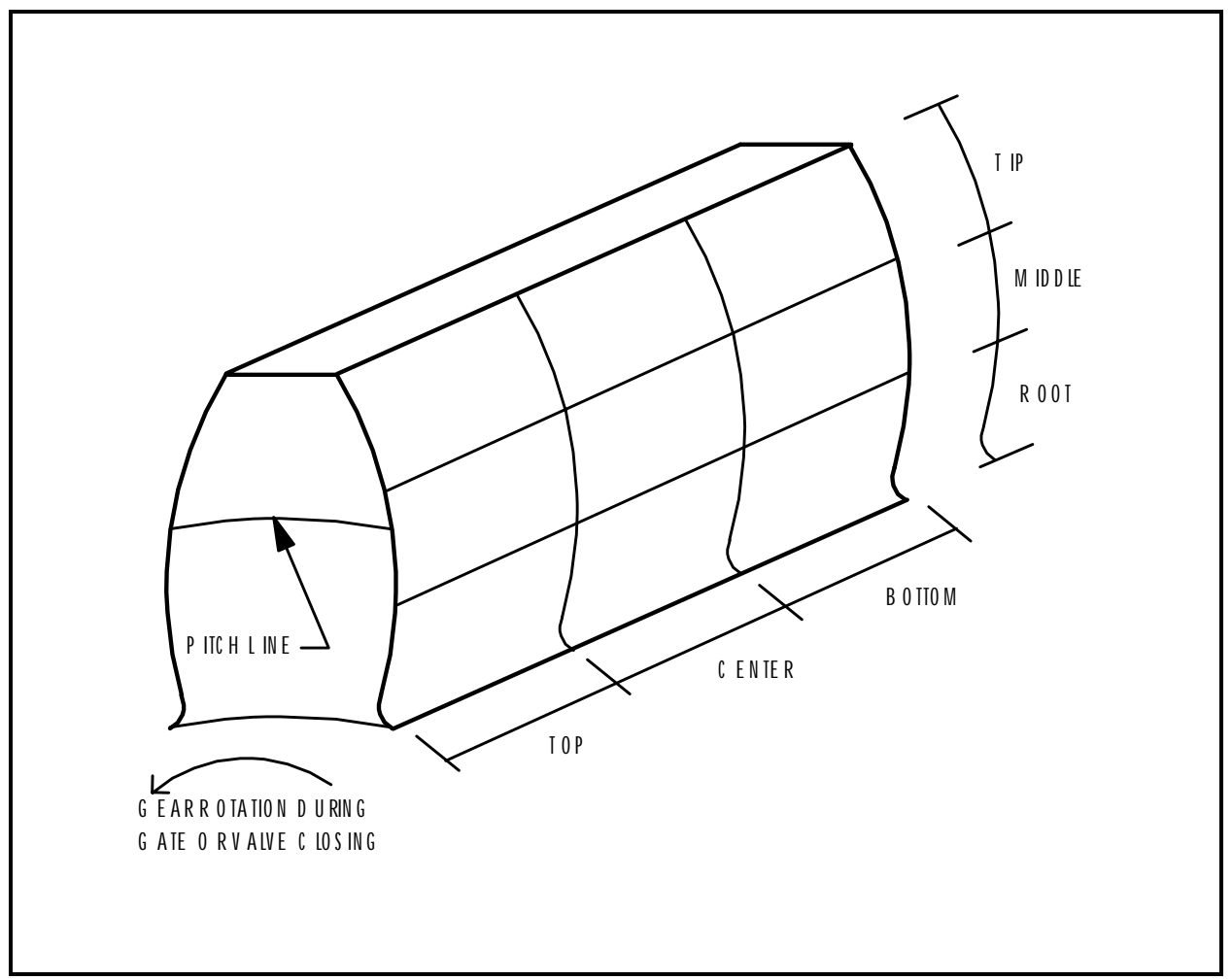

Figure 11. Tooth contact location. 


\subsection{Condition Index}

The following section contains the rules for calculating the individual $\mathrm{CI}_{\mathrm{i}} \mathrm{s}$ and the assembly CIs for the exposed gear assembly. Distress descriptions and example illustrations are also provided.

\section{Noise, Jumping, and Vibration}

Definition and causes. This distress represents abnormal sounds and motions of the exposed gear assembly during operation. Although a noise is often difficult to isolate and diagnose, abnormal noises should not be ignored because they commonly indicate a problem. Abnormal noises, jumping, and vibrations are caused by several factors including improper lubrication and misalignment of the exposed gear assembly. Obviously, this distress is more subjective and less quantifiable than many distresses; however, its importance should not be minimized. Jumping, for example, can indicate the presence of an assembly problem. Abnormal noises almost always indicate behavior that should be investigated.

Measurement and Limits. The noise, jumping, and vibration distress is recorded when it occurs at any point in the operation sequence. The CI for the possible combinations is:

$\begin{array}{ll}\text { Noise, Jumping, or Vibration } & \text { CI } \\ \text { None } & 100 \\ \text { Yes for any one of the three } & 70 \\ \text { Yes for any two of the three } & 40 \\ \text { Yes for all three } & 30\end{array}$

Example: During the operation of an exposed gear assembly, a grinding sound could be heard. The CI for the noise, jumping, and vibration distress is:

$$
c 1=70
$$

because the grinding sound is abnormal for an exposed gear assembly. Table 2 shows this CI to be Good.

\section{Anchorage Movement/Deterioration}

Definition and causes. Anchorage movement and deterioration represents the displacement of the embedded anchorage system and the current condition of the assembly components, especially the gear casting and anchorage bolts. Movement 
can occur during opening and closing of the gate or valve structure. The anchorage system is the only mechanism that connects the gear to the concrete. Hence, anchorage movement may indicate a significant structural problem, or it could eventually introduce structural problems into other parts of the operating equipment power transfer setup. In addition, corroded, loose, or missing casting and anchorage bolts can cause irregular movement of the equipment introducing functional and structural problems into various components.

Measurement and limits. If anchorage movement is detected visually or if a movement of 0.002 in. or greater is registered on the dial gage, the movement is considered significant. Any movement reduces the CI to 40. Any structural cracking or spalling of the concrete in this area will reduce the $\mathrm{CI}$ by a factor of 0.85 (Figure 10). This is also the case for a corroded embedment at this location (e.g., an additional 0.85 reduction). In addition, if any of the exposed bolts or nuts are significantly corroded, the $\mathrm{CI}$ is decreased by a factor of 0.70 . If any of the anchor or casting nuts are loose, the $\mathrm{CI}$ is decreased by a factor of 0.55 . If any bolts or nuts are broken or missing, the $\mathrm{CI}$ is decreased by a factor of 0.40 . If an assembly has multiple gear sets, the anchorage movement/deterioration CI for the assembly is the minimum of the anchorage movement/deterioration CIs of the gear sets making up that assembly.

Example: The anchorage for an exposed gear assembly had cracked concrete around the anchorage base. In addition, some of the exposed bolts were significantly corroded. No movement was detectable; therefore, the

$$
c_{1}=\left[\begin{array}{lll}
1 & 0 & 0
\end{array}\right]\left[\begin{array}{lll}
0.8 & 5
\end{array}\right]\left[\begin{array}{lll}
0.7 & 0
\end{array}\right]=60
$$

Table 2 describes this CI as Fair.

\section{Bearing/Bushing Wear}

Definition and causes. A bearing or bushing separates the axle and the gear. The axle casting is rigidly attached to the anchorage system, while the bearing or bushing is free to rotate. Bearing/bushing wear refers to the total relative movement of the gear with respect to the axle. This wear can be caused by normal use, excessive forces, improperly aligned gears, or inadequate lubrication.

Measurement and limits. Wear in the bearing or bushing is determined by observing the wobbling or tipping in the gear. If significant wobbling or tipping in a gear is recorded (1/16 in. per foot of gear radius in a bushing system and 1/16 in. per $3 \mathrm{ft}$ in a bearing system), the CI can be no higher than 70. If a "yes" is recorded for wobbling or tipping and the gear rotates on a bushing type system, a vertical 
displacement, $\mathrm{X}$, is recorded by a jacking procedure, as described in Appendix A. The limiting value for this vertical displacement is:

$$
x_{\text {MAX }}=5 / 32 \text { in. per foot of radius }
$$

If an assembly has multiple gears, the bearing/bushing wear CI for the assembly is the minimum of the CIs for bearing/bushing wear of the gears making up that assembly.

Example: Tipping of a bushing type gear was detected. A vertical displacement of

$$
x=5 / 16 \text { in } .
$$

was measured. The gear has a radius of $3 \mathrm{ft}$. The limiting value of the vertical displacement for this gear is

$$
x_{M A X}=15 / 32 \text { in } .
$$

The CI for bushing wear is

$$
C I=100(0.4)^{(5 / 16) /(15 / 32)}=54
$$

The CI is Marginal.

\section{Roller Support Wear/Damage}

Definition and causes. The roller support distress refers to the wear or corrosion of the bearing or bushing system for the gear roller supports, if they exist. Wear or corrosion of the roller bearing or bushing can cause the roller to freeze and become incapable of rolling. This distress can be caused by normal use, improper alignment, or interaction with the environment.

Measurement and limits. Wear or corrosion in the rollers is determined by observing whether the rollers turn freely during the operation of the equipment. If the rollers do not turn freely, the $\mathrm{CI}$ is 70 . If the roller damage affects the operation of the gear, the CI is 40 . If the exposed gear is not roller supported, no CI will be calculated, and the CI for the exposed gear assembly will not be affected by the roller support distress. If an assembly has multiple gears, the roller support wear/ 
damage CI for the assembly is the minimum of the roller support wear/damage CIs of the gears making up that assembly.

Example: During the operation of a roller supported exposed gear, the rollers did not turn freely. The CI for the roller support distress is

$$
c 1=70
$$

The CI is rated Marginal.

\section{Cracks}

Definition and causes. Cracks usually represent a narrow opening, break, or discontinuity in the steel members. Cracks are caused by fatigue, brittle fracture, or overstressed steel components. Obviously, cracks have significant structural implications because they can continue to grow if the cause of the overstress still exists or if the remaining steel cross section cannot carry the normal loads.

Measurement and limits. The number of cracks on the teeth and frame of the gear are recorded on the inspection form. The limiting value for a exposed gear is one crack:

$$
x_{M A X}=1
$$

which is considered critical. A crack on the gear reduces the CI to 40. If an assembly has multiple gears, the cracks CI for the assembly is the minimum of the cracks CIs of the gears making up that assembly.

Example: One crack was found on an exposed gear during an inspection. The CI for this distress is:

$$
C 1=100(0.4)^{1 / 1}=40
$$

The CI is rated Marginal. 


\section{Reduced Tooth Contact}

Definitions and causes. The tooth contact distress is the reduction in contact area or engagement surface between meshing teeth. This distress can be caused by normal wear, uneven wear, or misalignment of gears.

Measurements and limits. The percent of contact, $\mathrm{X}_{1}$, is found by observing the grease on the face of the gear teeth. The percent of tooth not in contact is:

$$
x=100 \%-x_{1}
$$

The limiting value for the percentage of noncontact on gear teeth is:

$$
x_{\text {MAX }}=75 \%
$$

If an assembly has multiple gears, the reduced tooth contact CI for the assembly is the minimum of the reduced tooth contact CIs of the gears making up that assembly.

Example: The percentage of contact on a gear tooth was:

$$
x_{1}=40 \%
$$

The percentage of the tooth not in contact was:

$$
x=100 \%-40 \%=60 \%
$$

The CI for tooth contact is:

$$
\left.c I=\left[1000(0.4)^{(60 / 75)}\right)\right]=48
$$

The $\mathrm{CI}$ is rated Fair.

\section{Tooth Wear}

Definition and causes. Tooth wear is the deterioration of gear teeth as corresponding teeth engage. The causes of this distress can be attributed to normal wear, inadequate lubrication, excessive loads, and improper gear alignment. Appendix B describes gear tooth wear measuring procedures. 
Measurement and limits. Gear tooth wear will be measured by recording the estimated or measured percentage of tooth thickness loss at the pitch line, $X$. The limiting value is:

$$
x_{M A X}=25 \%
$$

If an assembly has multiple gears, the tooth wear CI for the assembly is the minimum of the tooth wear CIs of the gears making up that assembly.

Example: The percentage of lost thickness of a gear tooth at the pitch line measured during an inspection was:

$$
x=15 \%
$$

The CI (from Equation 2.1) is:

$$
c 1=\left[100\left(0.4^{15 / 25}\right]=58\right.
$$

The CI is rated Fair.

\section{Damaged Teeth}

Definitions and causes. Stress in gear teeth increases as the surface area is decreased or stress concentrations are introduced. Damage to teeth may lead to failure because of the reduction in surface area and the introduction of stress concentrations. This distress could be caused by factors including improper lubrication, excessive force on teeth, or misalignment of teeth.

Measurements and limits. The percentage of lost surface area on gear teeth, $\mathrm{X}$, is recorded in the inspection process. The limiting value for damaged teeth depends on the type of damage. In cases where the tooth has been chipped or deformed, the limiting value is:

$$
x_{M A X}=20 \%
$$

If the tooth is corroded, pitted, or gouged, the stress concentrations will be lower and the limiting value is:

$$
x_{M A X}=40 \%
$$


If an assembly has multiple gears, the damaged teeth CI for the assembly is the minimum of the damaged teeth CIs of the gears making up that assembly.

Example: The percent of contact area that was chipped on a gear tooth was:

$$
x=15 \%
$$

The CI for damaged gear teeth is:

$$
c_{1}=\left[\begin{array}{llll}
1 & 0 & 0 & (0.4)^{15 / 20}
\end{array}\right]=50
$$

The $\mathrm{CI}$ is rated Marginal.

\section{Assembly Cl}

The assembly CI will be calculated with Equations 2.2, 2.5, and 2.6 (see Chapter 2, Assembly Distress). The lone critical distress in the exposed gear assembly is the cracks distress. The $\mathrm{CI}_{i} \mathrm{~s}$ from the remaining seven distresses will be used to calculate the weighting factor assembly $\mathrm{CI}_{\mathrm{w}}$ (Equation 2.5). The weighting factors for those seven distresses are in Table 12.

\subsection{Field Test}

Twenty exposed gear assemblies were observed during the field tests. The bar charts in Figures 12, 13, and 14 compare the experts' subjective CI during the various field tests with the CI calculated from the rules in Section 4.3 for three exposed gear distresses. Assemblies with no distresses are not plotted. Comparisons between the calculated and experts' CIs are summarized in the remainder of this chapter. 


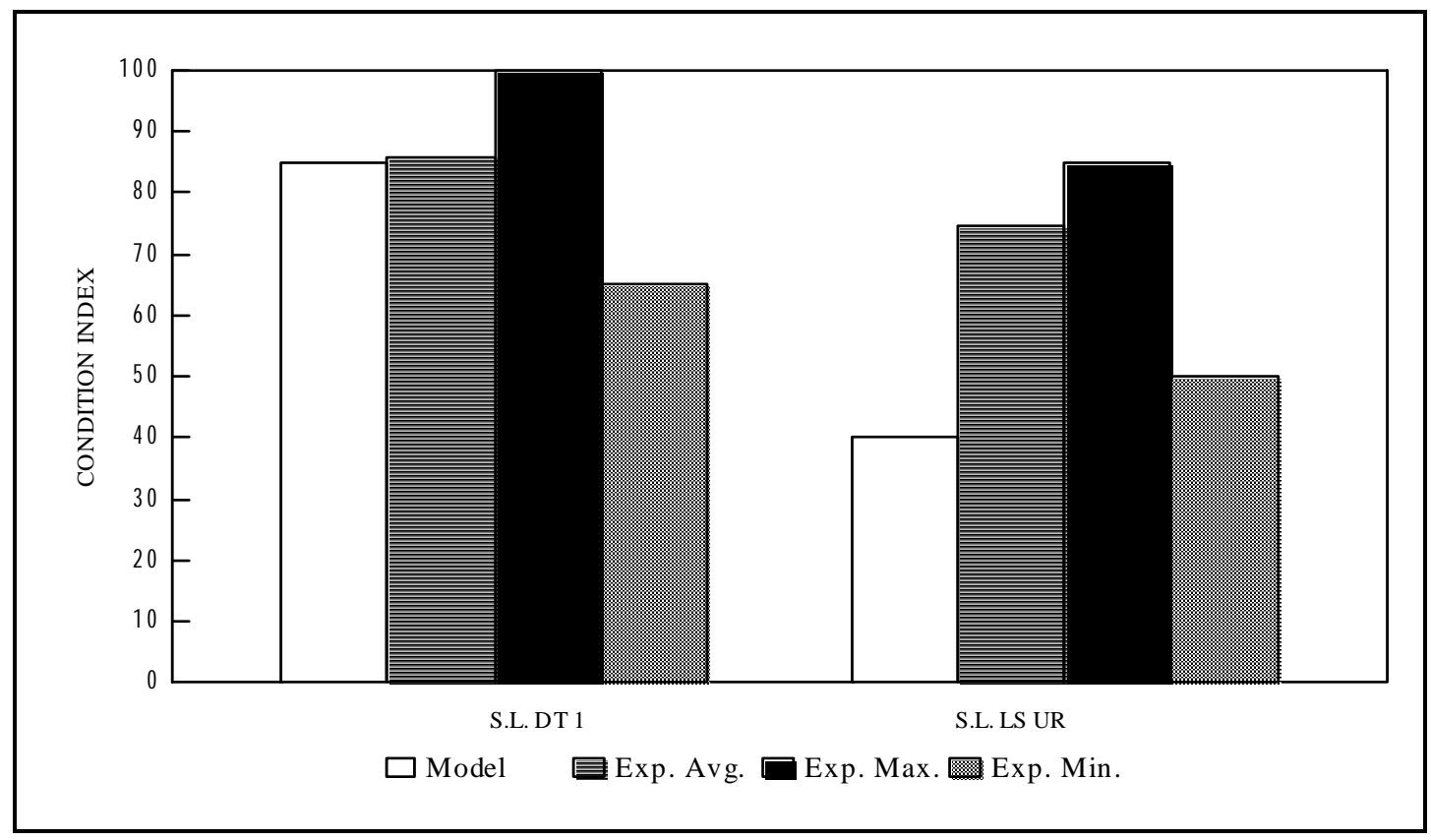

Figure 12. Anchorage movement/deterioration: exposed gear assembly.

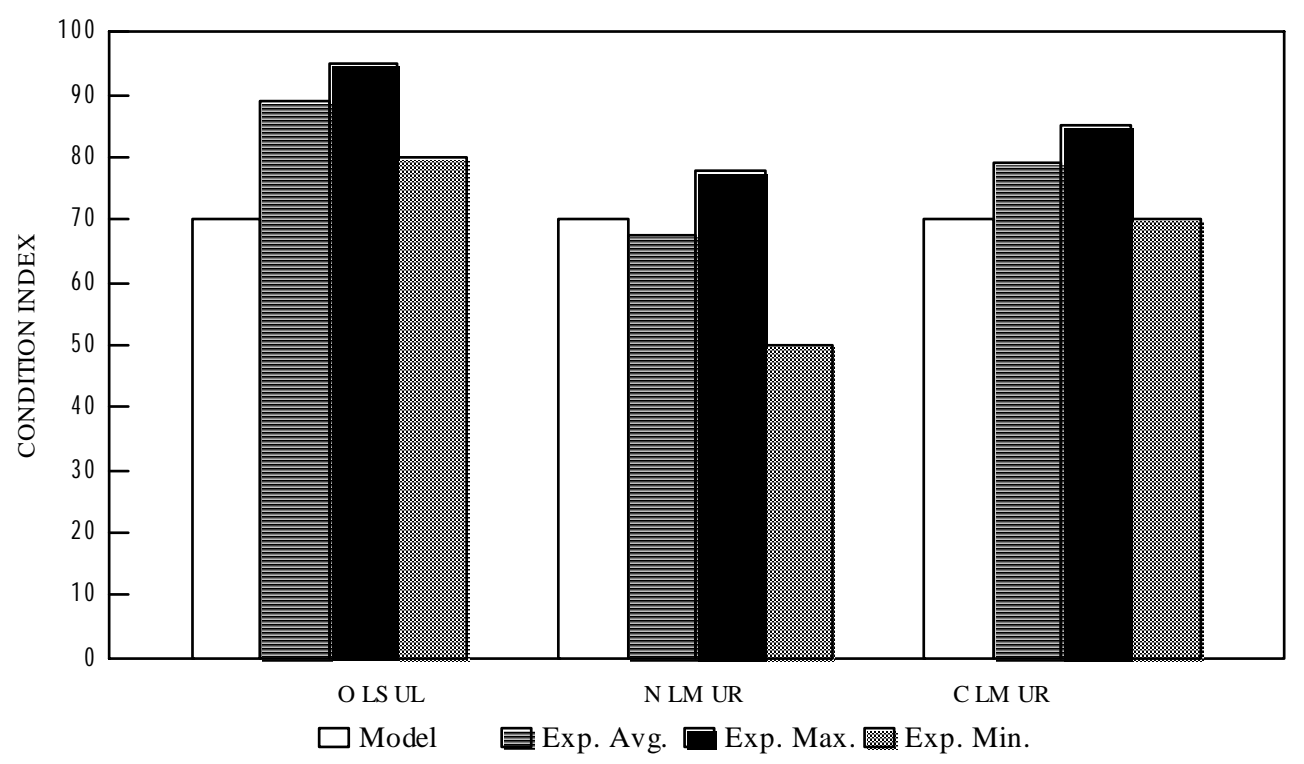

Figure 13. Bearing/bushing wear: exposed gear assembly. 


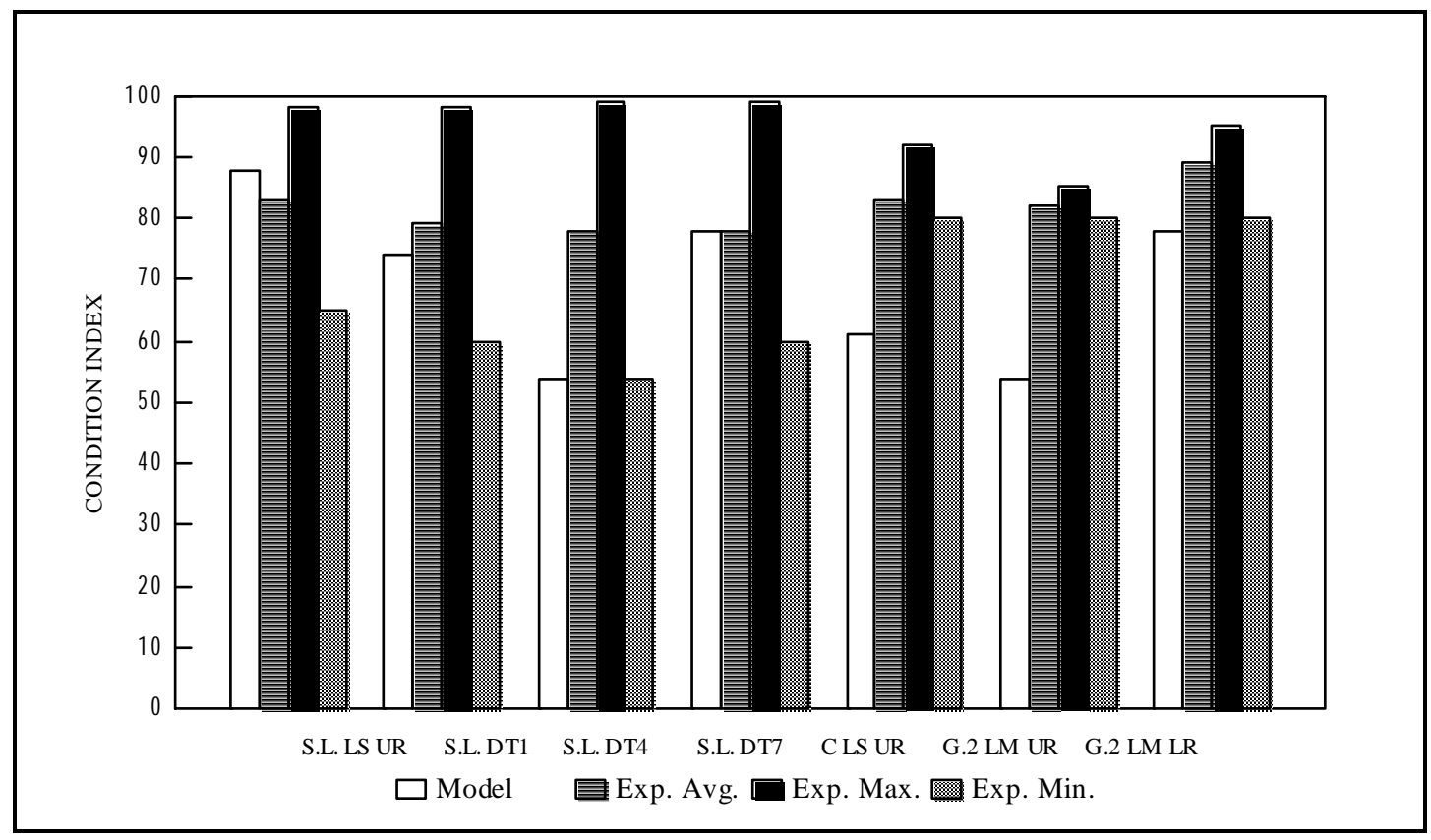

Figure 14. Reduced tooth contact: exposed gear assembly.

\section{Noise, Jumping, and Vibration}

Because no abnormal noise, jumping, or vibration was recorded, the calculated CI values were 100. Although this distress was not recorded, the experts' average was below 90 on three of sixteen assemblies that were rated. However, in each of these three cases the experts' average was 85 or greater. The noise, jumping, and vibration distress was calibrated in the enclosed gear assembly and the calculated CIs closely approximated the experts' average CIs.

\section{Anchorage Movement/Deterioration: Figure 12}

The anchorage movement/deterioration distress was observed only twice on the operating equipment field tests in exposed gear assemblies. Corroded nuts were observed on an exposed reduction gear set (Tainter Dam Gate St. Lucie \#1), and anchorage movement was observed on a bull gear (Upper Right Sector Lock Gate St. Lucie). The calculated CI for a corroded nut (85) closely approximates the experts' average CI (86). The calculated CI for anchorage movement (40) is significantly lower than the experts' average (75) for the one observed case. In later conversation with the experts, some said they had not rated the distress lower because they felt it could be fixed by merely tightening the bolts. They did agree, however, that the CI should have been lower than 75 if the problem was not fixed. For the remainder of the exposed reduction gear assemblies that were observed, the calculated CIs were 100 and the experts' average CIs were above 90. 


\section{Bearing/Bushing Wear: Figure 13}

The bearing/bushing distress was observed once (Ortona Upper Left Lock Gate) during the field tests using the current rules. In this case, the calculated CI was 70 and the experts' average CI was 89. In two other cases bushing wear was observed using the jacking technique described in Appendix A (Newburgh Upper Right Miter Lock Gate and Cannelton Miter Lock Gate Main Chamber). For these cases, the calculated CIs (70 and 70), respectively, and the experts' average CIs (68 and 80 ), respectively, are in better agreement.

\section{Roller Support Wear/Damage}

The roller support wear/damage distress was not calibrated because no damage to any roller supports was observed in the exposed gears. Hence, the calculated CIs were all 100 and the experts' average CIs were 90 or above.

\section{Cracks}

The cracks distress was not calibrated because no cracks were observed in the exposed gears. Hence, the calculated CIs were all 100 and the experts' average CIs were 90 or above. Although this distress was not calibrated, the experts feel that cracks in the gear are critical and should be repaired, which corresponds well to Section 4.3.

\section{Reduced Tooth Contact: Figure 14}

The reduced tooth contact and tooth wear distresses were initially combined as one distress. Discussion with the experts near the end of the Louisville District field test resulted in separating the initial distress into two distinct distresses - tooth contact and tooth wear. Although no data was collected after the separation of the distresses, the data collected for the original combined distress was used to calibrate the tooth contact distress. This is appropriate for two reasons: (1) the observed wear of the gear teeth was relatively low, and (2) the weighting factor given by the experts for tooth contact was significantly higher than the weighting factor for tooth wear (Table 12). In three cases (Tainter Dam Gate \#4 St. Lucie, Miter Lock Gate Upper Right Cannelton, and Miter Gate Upper Right Green River \#2) where the tooth contact distress was observed, the calculated CIs were lower than the experts' average CIs. However, in all three cases the calculated CIs were in Zone 2. In the other four cases, the calculated CIs corresponded well with the expert averaged CIs. 


\section{Tooth Wear}

Discussion with the experts near the end of the Louisville District field test resulted in a separation of the tooth wear and tooth contact distresses (see previous paragraph). Therefore, while the tooth wear distress was observed, calibration of the new rules is not possible with the current data. The new rules for tooth wear have, however, been constructed using the experts' judgement and advice.

\section{Damaged Teeth}

The inspection form questions and rules for the damaged teeth distress have changed significantly since the first field test. The current questions and rules were formulated during discussion with experts following the second field test. Therefore, while damaged teeth were observed, calibration of the new rules is not possible with the current data. The new rules for damaged teeth have, however, been constructed using the experts' judgement and advice.

\section{Assembly $\mathrm{Cl}:$ Figure 15}

The assembly CI for exposed gear assembly was calibrated for three assemblies. In each case, the model CI was somewhat higher than the experts' average CI. Although the model CIs were higher, the experts' average CIs and the model CIs were all in Zone 1.

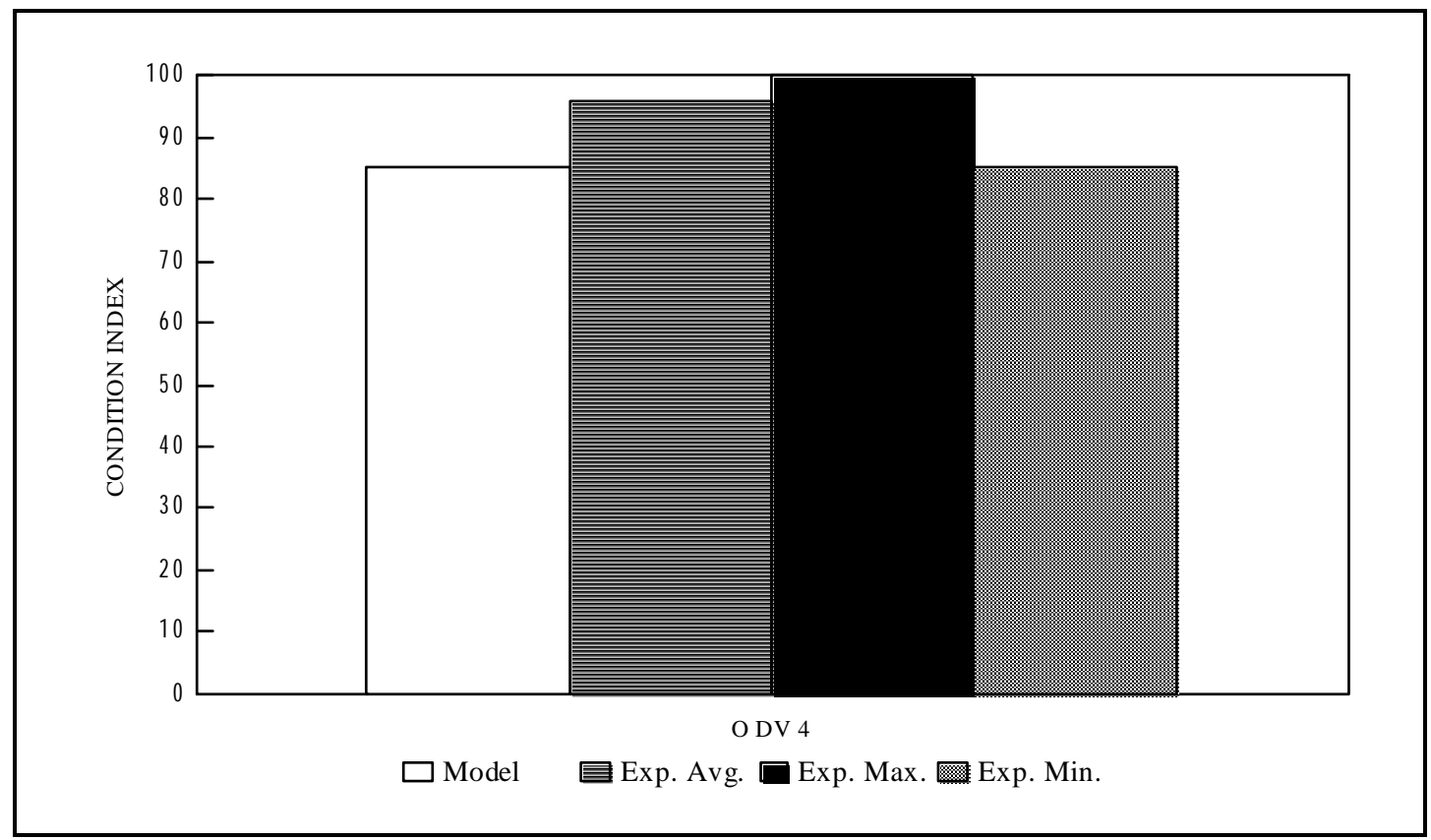

Figure 15. Exposed gear assembly $\mathrm{Cl}$. 


\section{Enclosed Gear Assembly}

\subsection{Component Identification}

Definitions and sketches for components of enclosed gear are presented in the following paragraphs.

\section{Reduction Gears}

Reduction gears are a series of gears used to lessen the torque required to open and close or raise and lower gate or valve structures, respectively. As a result, the structure moves at a slower rate of speed than the motor rotates (Figures 7 and 8). Enclosed reduction gears are in a gear box and can sometimes be seen by removing the cover plate. The gears in the gear box are lubricated with an oil or grease bath.

\section{Gear and Pinion}

The gear and pinion are a set of reduction gears, with the pinion substantially smaller than the gear.

\section{Transfer Box}

The transfer box is a set of reduction gears that redirects the rotating shaft by 90 degrees (Figure 7). This is accomplished with the use of a worm and a worm gear (Figure 9) or with bevel gears.

\subsection{Inspection Form With Comments}

The following pages are Parts 1 and 2 of the field inspection forms for an enclosed gear assembly. The side-by-side arrangement of the opposing pages displays specific explanations (right side) adjacent to the entry on the inspection form (left side). 
Intentionally blank 


\section{ENCLOSED GEAR INSPECTION PART 1}

P.T.\#:

PROJECT NAME:

DATE:

GATE IDENTIFICATION: (identify the appropriate lock gate, valve, or dam gate)

Lock Gate
Upper
Lower
1. Left Leaf
2. Right Leaf

Valve

$\begin{array}{lll}\text { Emptying } & \text { 1. Left } & \text { 2. Right } \\ \text { Filling } & \text { 1. Left } & \text { 2. Right }\end{array}$

Dam Gate

Number

NOISE, JUMPING, \& VIBRATION

NOISE

JUMPING

$(\mathrm{Y} / \mathrm{N})$

IS IT NORMAL

VIBRATION

$\underline{\underline{(\mathrm{Y} / \mathrm{N} / \mathrm{N})}}$

$(\mathrm{Y} / \mathrm{N})$

$(\mathrm{Y} / \mathrm{N})$

$\underline{(\mathrm{Y} / \mathrm{N})}$

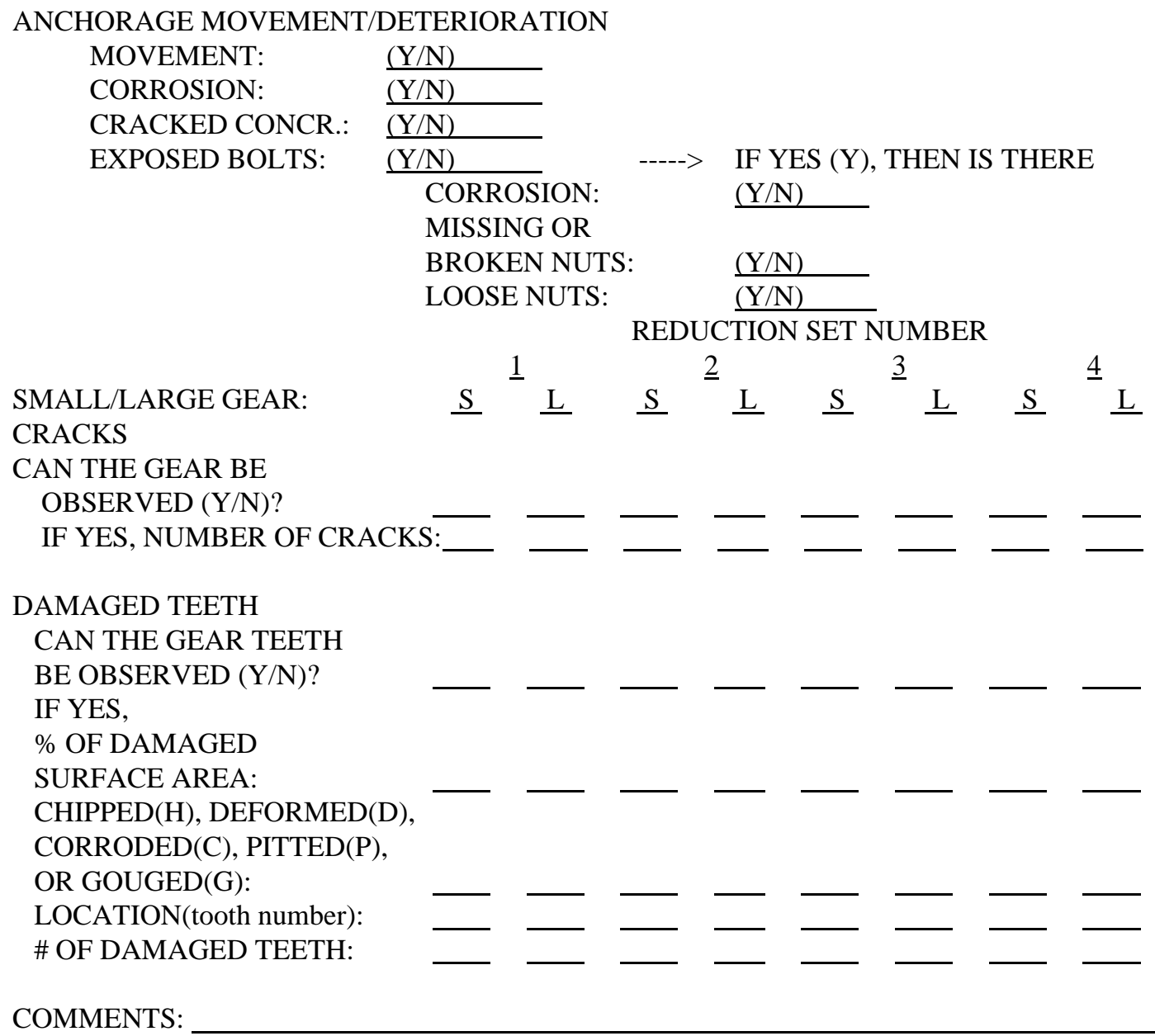

COMMENTS: 
PART 1 Comments: Field data

Enter the PROJECT NAME for this inspection, the DATE of the inspection, and, for the GATE IDENTIFICATION, identify which gate leaf or valve is being inspected. Also enter the power transfer number (P.T.\#), which can be found on Page 1 of the inspection form.

Observation of the enclosed gear during gate or valve movement is a good indicator of problems. Record any indication of NOISE, JUMPING, and/or VIBRATION during operation and then indicate whether this noise, jumping, and/or vibration is NORMAL.

Record the evidence of MOVEMENT of the gear ANCHORAGE system base of the gear as the gate is opened and closed. Evidence of movement can be observed visually or enhanced by placing a dial gage to monitor any movement (Figure 10). A dial gage change greater than 0.002 in. is considered movement. Excessive concrete spalling may indicate a displacement occurred at this location at some time. Also, record the presence of any CORROSION (10\% volume loss) of the steel portion or any CRACKED CONCRETE at the interface of the embedment (Figure 10). Small hairline cracks, probably caused by thermal expansion or contraction of the concrete, should be ignored. Indicate if there are any CORRODED (10\% volume loss), MISSING OR BROKEN, or LOOSE NUTS at the gear anchorage if the BOLTS are EXPOSED (Figure 10).

The presence of CRACKS on the gear is usually not tolerated. Sometimes a cover plate can be removed and the gears can be observed. If the GEARS CAN BE OBSERVED, record the NUMBER OF CRACKS found on the gear by visual observation. Many times a crack will show up as corrosion underneath the painted surface. Also record the location of the cracks in the COMMENT section.

Sometimes a cover plate on the gear box can be removed and the gear teeth can be observed. If the GEAR TEETH CAN BE OBSERVED, pick the worst DAMAGED TOOTH for each type of damage on each gear and record the percentage of SURFACE AREA, which is missing due to CHIPPING, DEFORMATION, PITTING, CORROSION, or GOUGING. If damage has occurred indicate the TYPE of DAMAGE. Chipping of the tooth is the breaking off of steel pieces, which usually results in jagged edges and high stress concentrations in the tooth. Deformation of the tooth is the changing of the shape of the tooth, usually the result of excessive forces or something becoming lodged in between teeth during operation. Pitting of the tooth is the severe localized corrosion of the tooth that results in small cavities in the tooth surface. Corrosion is the loss of steel in the tooth due to interaction with the environment. Gouging of the tooth is the making of smooth grooves or holes in the tooth surface. Record the LOCATION of the damaged teeth. The location of the tooth is described by a number. The meshing tooth between the gears that are fully in contact when the gate or valve is in the open position is numbered one. The remaining teeth are numbered in order starting at tooth one and going in the counter-clockwise direction. The counter-clockwise direction is determined as the gate or valve is being closed. 
U.S. ARMY CORPS OF ENGINEERS

P.T.\#:

\section{ENCLOSED GEAR INSPECTION PART 2}

OIL CONDITION

SLIGHT TEMPERATURE RISE OF GEAR BOX:

$(\mathrm{Y} / \mathrm{N})$

SIGNIFICANT TEMPERATURE RISE OF GEAR BOX:

$(\mathrm{Y} / \mathrm{N})$

EVIDENCE OF RECENT OIL LEAKAGE:

$(\mathrm{Y} / \mathrm{N})$

NUMBER OF OIL DROPS PER CYCLE:

WATER PRESENT IN OIL:

RUST/DIRT PRESENT IN OIL:

METAL PRESENT IN OIL:

HAS OIL SAMPLE BEEN TAKEN?

IF YES, DATE IT WAS TAKEN:

DOES THE OIL MEET SPECIFICATIONS:

$(\mathrm{Y} / \mathrm{N})$

$(\mathrm{Y} / \mathrm{N})$

$(\mathrm{Y} / \mathrm{N})$

$(\mathrm{Y} / \mathrm{N})$

$(\mathrm{Y} / \mathrm{N})$

COMMENTS: 
PART 2 Comments: Field data

Excessive TEMPERATURE RISE of THE GEAR BOX is often an indication that something is not operating properly. A temperature rise can be observed by placing a hand on the gear box during operation. Record if there is a SLIGHT or SIGNIFICANT TEMPERATURE RISE of THE GEAR BOX. Record if there is EVIDENCE OF RECENT LEAKAGE. Record the NUMBER of OIL DROPS that leak from the gear box during one operating CYCLE. One cycle for a lock gate or a valve is by opening and then closing the structure or vice-versa. For a dam gate, one cycle is completed by opening the gate $2 \mathrm{ft}$ and then closing it. Record if any WATER is PRESENT in the OIL. Many times water will appear as a milky ribbon throughout the oil. Record if any DIRT or RUST is PRESENT in the OIL. Also record if any METAL is PRESENT IN the OIL. This can be accomplished by taking a small sample of oil and subjectively observing its quality. Record if an OIL SAMPLE WAS TAKEN. If YES, record the DATE WHEN it was last tested and if the OIL MEETS manufacturer SPECIFICATIONS. 


\subsection{Condition Index}

The following section contains the rules for calculating the individual CIs for the enclosed gear assembly distresses and the assembly CI. Distress descriptions and example illustrations are also provided.

\section{Noise, Jumping, and Vibration}

See noise, jumping, and vibration for the exposed gear assembly (Chapter 4, p 51).

\section{Anchorage Movement/Deterioration}

See anchorage movement/deterioration for the exposed gear assembly (Chapter 4, p 51).

\section{Cracks}

See cracks for the exposed gear assembly (Chapter 4, p 54).

\section{Damaged Teeth}

See damaged teeth for the exposed gear assembly (Chapter 4, 56).

\section{Temperature Rise of Gear Box}

Definition and causes. Excessive temperature change often indicates that the enclosed gears are not operating properly. Excessive temperature change can be caused by inadequate lubrication, misaligned gear teeth, or excessive loads on the enclosed gear assembly.

Measurement and limits. The temperature change of the oil in the gear box that can be felt with the hand is recorded. If a slight temperature rise is observed, the CI is 70. If a significant temperature rise is observed, the CI is 40 .

Example: During the operation of an enclosed gear, a slight temperature rise was observed. The CI for the temperature rise of the gear box distress is:

$$
c_{1}=70
$$

The $\mathrm{CI}$ is rated Good. 


\section{Oil Leakage}

Definition and causes. Fresh oil stains, dripping oil, or standing oil are signs of oil leakage. Oil leakage can indicate other problems in the operating equipment or can be caused by worn seals or gaskets on the gear box.

Measurement and limits. The number of oil drips per operation cycle are recorded in the inspection form. One cycle of a lock gate or a valve is completed by opening and then closing the structure or vice-versa. For a dam gate, one cycle is completed by opening the gate $2 \mathrm{ft}$ and then closing it. If drops of oil are observed leaking during the operation of the enclosed gear, the limiting value of oil leakage per cycle is:

$$
X_{\text {MAX }}=3 \text { drops }
$$

The presence of any puddled oil or oil stains is also recorded. If there is evidence of recent oil leakage, the CI can be no higher than 85 .

Example: A sheet of paper was placed below an enclosed gear box during its operation. During one cycle, three drips of oil dropped to the paper. The CI for the oil leakage distress is:

$$
C_{1}=100(0.4)^{(3 / 3)}=40
$$

The $\mathrm{CI}$ is rated Marginal.

\section{Oil Contamination}

Definition and causes. All rotating equipment parts and machinery require lubrication to function properly. Over time the oil becomes contaminated and breaks down. The oil contamination distress is the reduction of the useful life of the lubrication oil. The contamination of the oil is caused by the collection of dirt, rust, water, and metal particles in the oil.

Measurement and limits. Oil distress is measured at two different levels. The first level involves visually checking the oil consistency for: (1) water, (2) dirt or rust, and (3) metal. If water is present, the CI is reduced by a factor of 0.85 . Likewise, if dirt or rust are present, a reduction factor of 0.85 is applied to the CI. If metal is in the oil, the CI is 40 . In the second level of inspection, a representative sample is examined in the laboratory for extended chemical analysis to check for particulates such as dirt, water, and rust on a more precise scale. The results of this test should be included in any inspection report that is 
generated. If the oil does not meet the specifications set by the manufacturer or laboratory, the $\mathrm{CI}$ is 40 .

Example: Upon inspection of a gear box, rust and water were found to be present in

the oil. The CI for oil contamination is:

$$
c I=\llbracket 100(.85)(.85)]=72
$$

Table 2 describes the CI as Good.

\section{Assembly Cl}

The assembly CI will be calculated with Equations 2.2, 2.5, and 2.6 (See Chapter 2, Assembly Distress). The lone critical distress in the enclosed gear assembly is the cracks distress. The CIs from the remaining six distresses will be used to calculate the weighted $\mathrm{CI}_{\mathrm{w}}$ (Equation 2.5). The weighting factors for those six distresses are in Table 13.

\subsection{Field Test}

Fifteen enclosed gear assemblies were observed during the field tests. The bar charts in Figures 16 to 21 compare the experts' subjective CI to the CI calculated from the rules in Section 5.3 for six enclosed gear distresses that were observed during field tests. Comparisons between the calculated and experts' CIs are summarized below.

\section{Noise, Jumping, and Vibration: Figure 16}

The calculated noise, jumping, and vibration CIs closely approximated the experts' averages. In 12 of the 15 observed exposed gear assemblies, this distress was not observed; therefore, the calculated CIs were 100 and the experts' average CIs were above 90. In one case (Upper Right Lock Gate Moore Haven), a thumping noise was heard in the gear box. The calculated CI was 70, while the experts' average CI was 80 . In another case, jumping was observed (Upper Right Lock Gate St. Lucie); therefore, the calculated CI was 70. The experts' average CI was 74. The enclosed gear used to operate Dam Gate \#1 on the St. Lucie Dam was observed to make a noise and vibrate. The calculated CI for noise and vibration is 40 . The experts' average CI dropped to 51. 


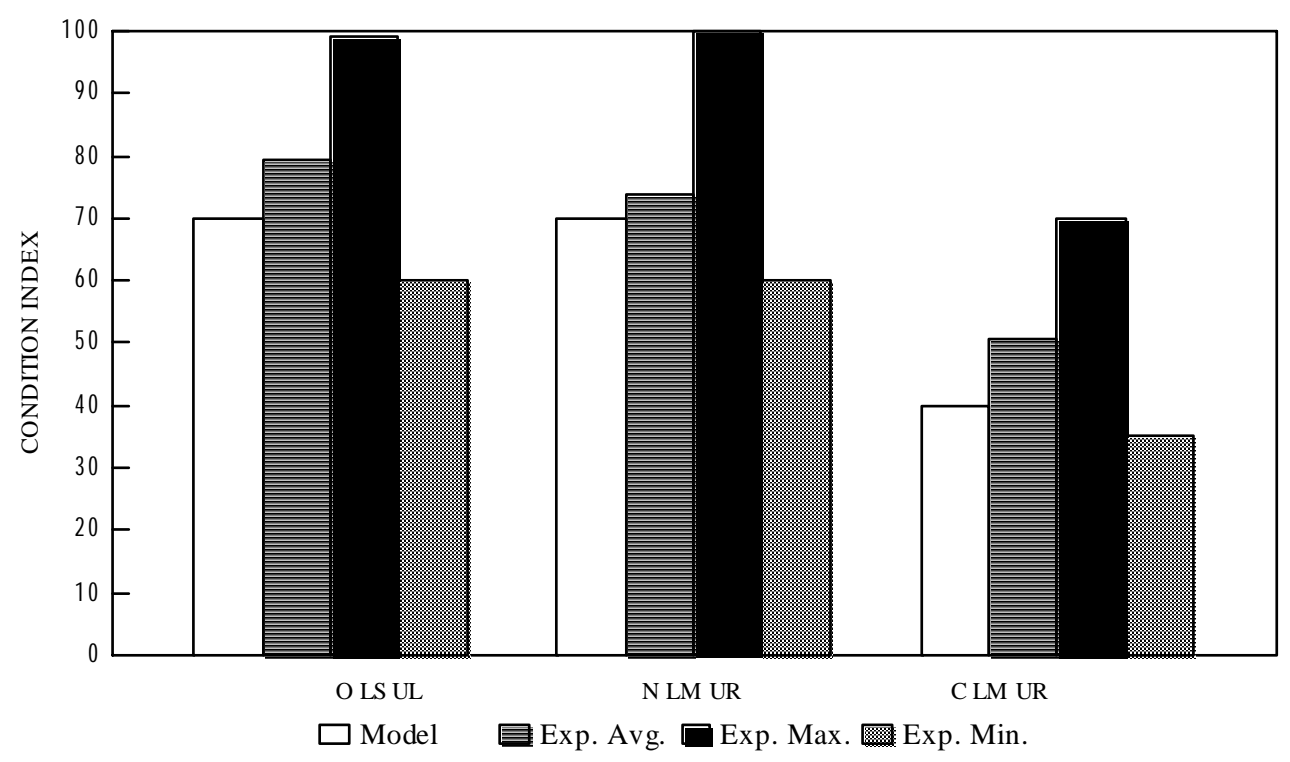

Figure 16. Noise, jumping, and vibration: enclosed gear assembly.

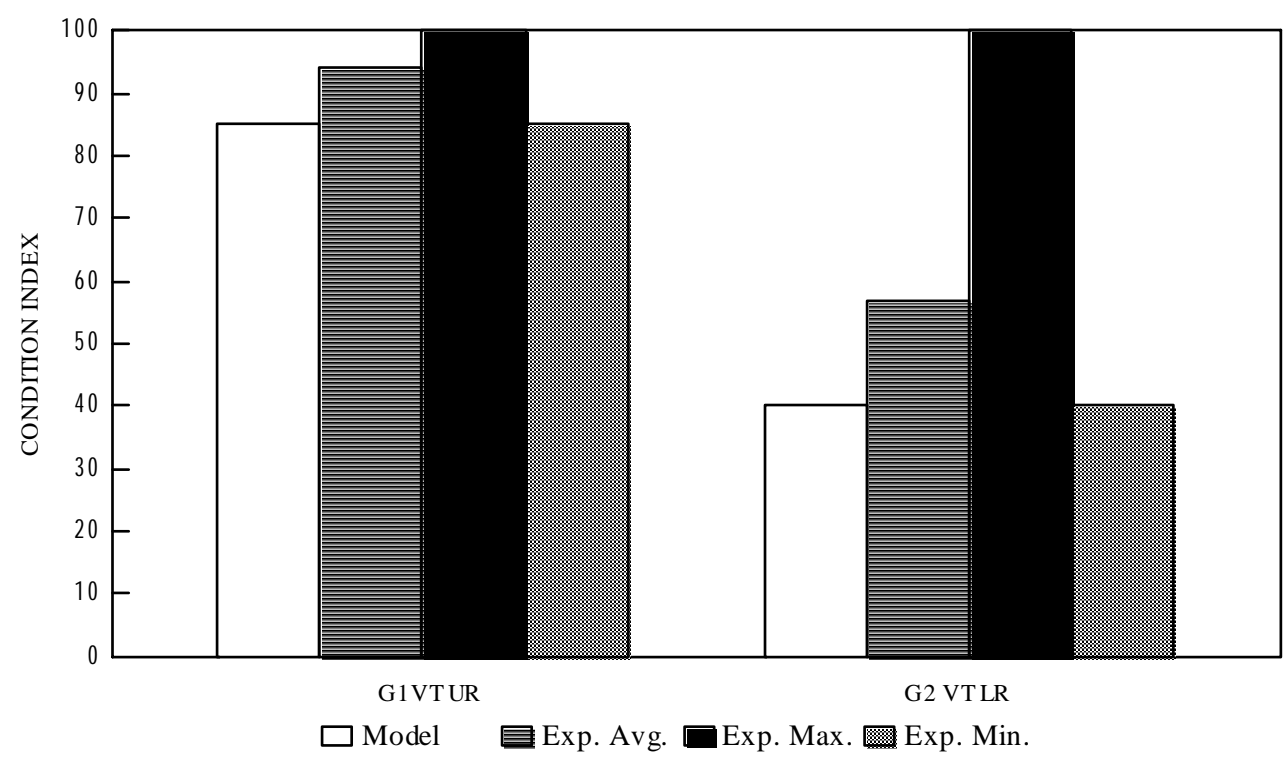

Figure 17. Anchorage movement/deterioration: enclosed gear assembly. 


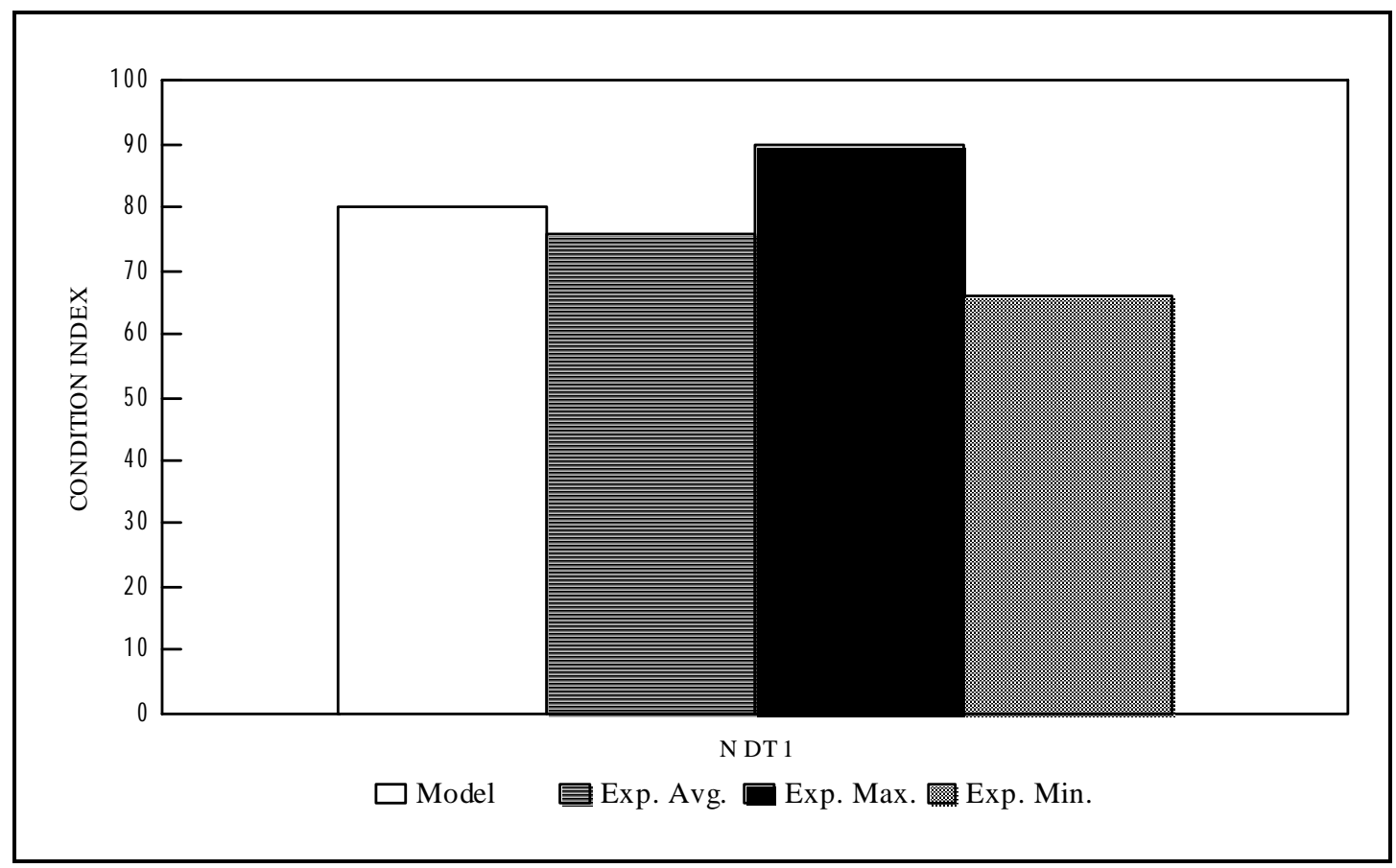

Figure 18. Damaged teeth: enclosed gear assembly.

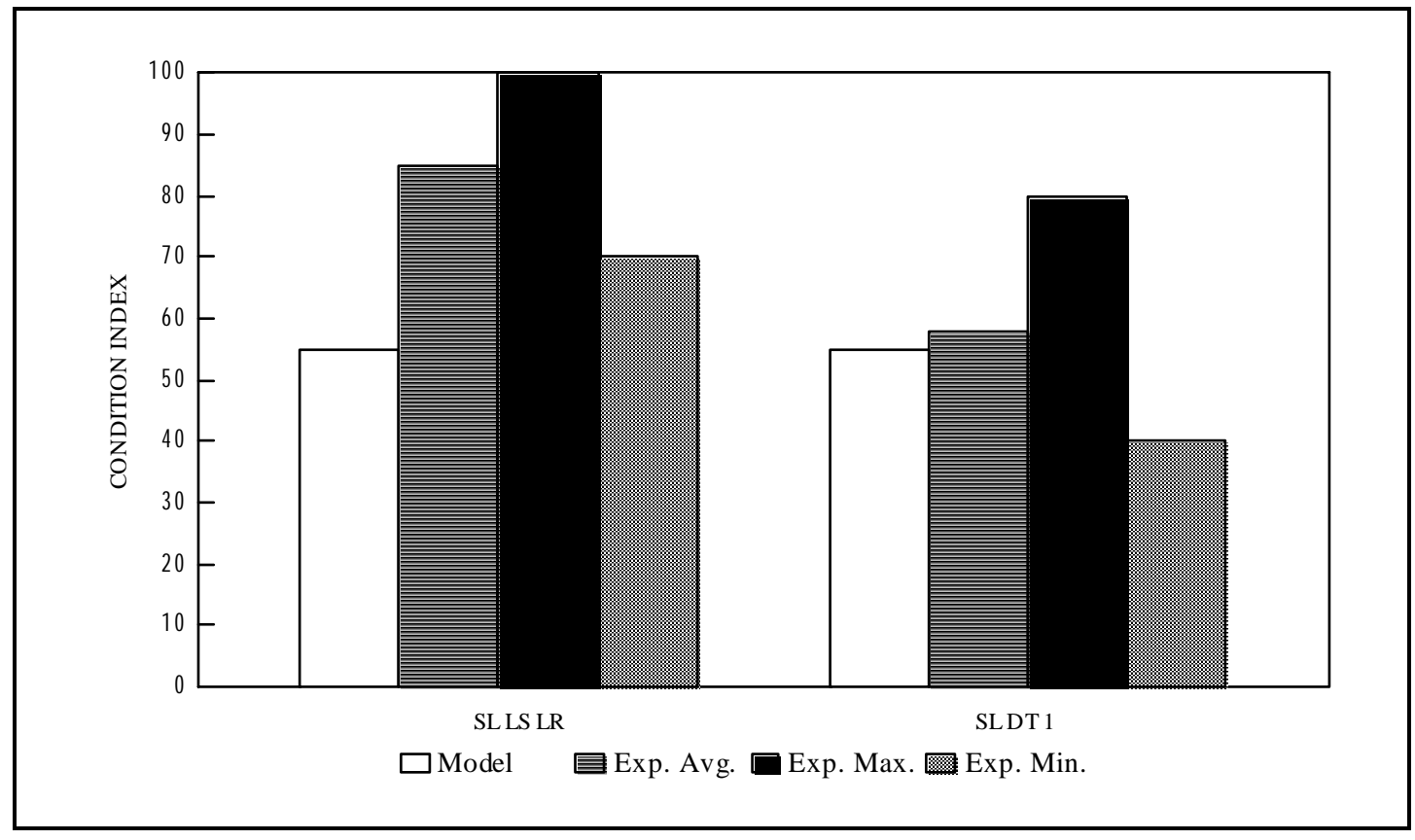

Figure 19. Temperature rise of oil: enclosed gear assembly. 


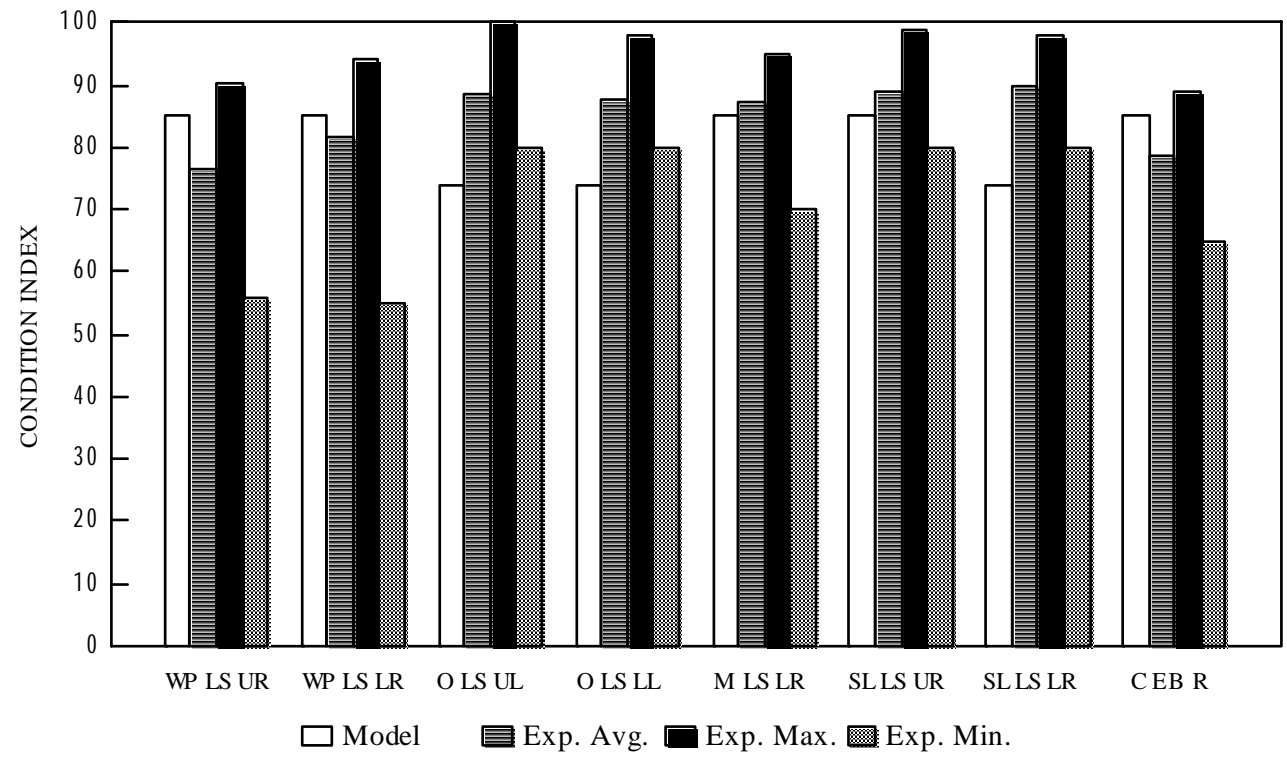

Figure 20. Oil leakage: enclosed gear assembly.

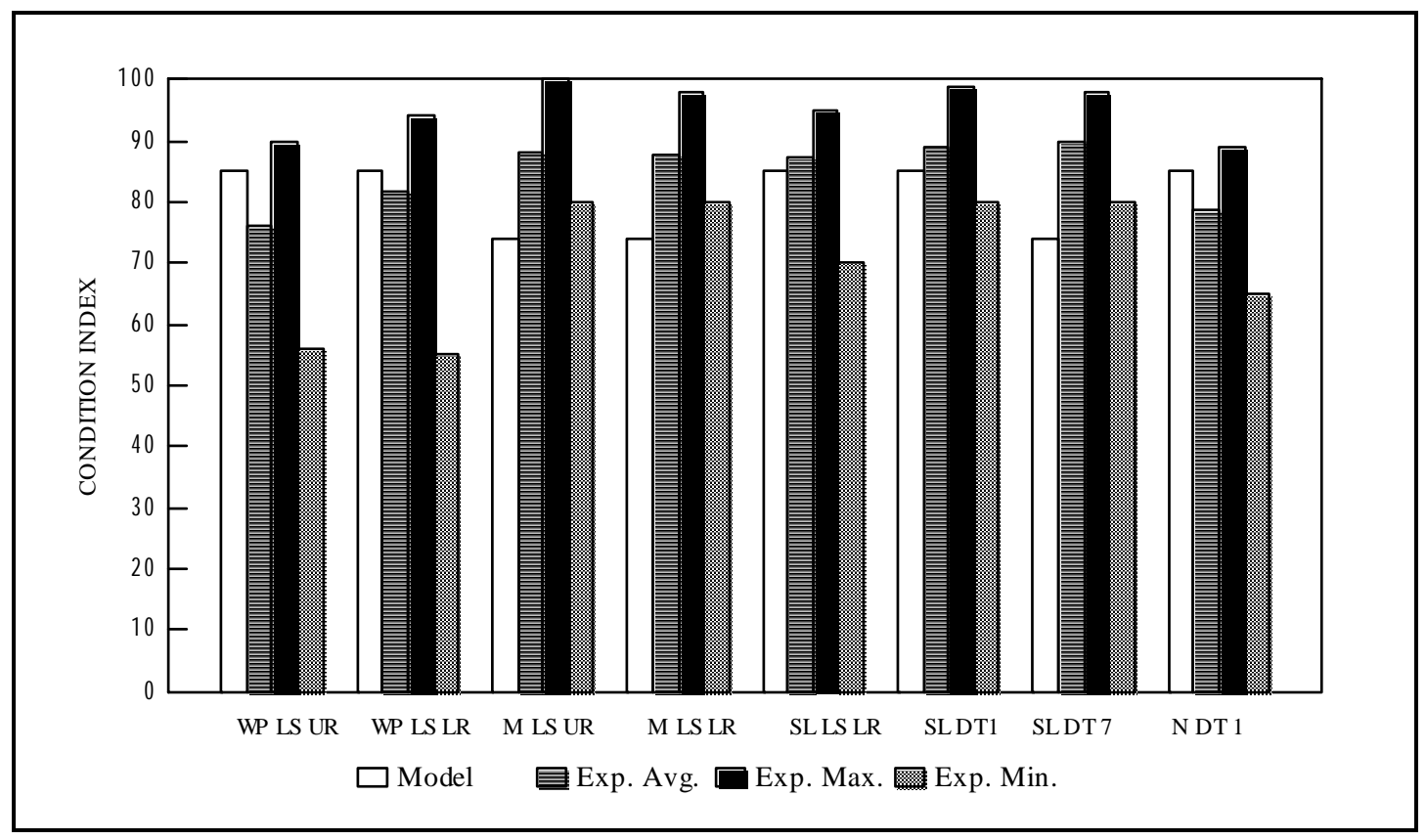

Figure 21. Oil contamination: enclosed gear assembly. 


\section{Anchorage Movement/Deterioration: Figure 17}

The anchorage movement/deterioration distress could be calibrated for only two enclosed gear assemblies during the field tests as the distress was not observed in the other assemblies during the field tests. Corroded anchorage nuts were observed at one location (Upper Right Lock Gate Moore Haven), where a CI of 85 was calculated. The experts did not seem to consider the corrosion significant, as their average CI was 94. Anchorage movement of a different anchorage system (Lower Right Lock Gate St. Lucie) was detected, and a CI of 40 was calculated. The experts' average CI of 57 was significantly lower than 100; however, it was still 17 points higher than the calculated CI.

\section{Cracks}

The cracks distress was not calibrated because no cracks were observed in the enclosed gears. Hence, the calculated CIs were all 100 and the experts' average CIs were 90 or above. Although this distress was not calibrated, the experts felt that cracks in an enclosed gear were critical and should be repaired, which corresponds well to Section 4.3 .

\section{Damaged Teeth: Figure 18}

Only one case of damaged teeth in enclosed gears was observed (Dam Gate \#1 Newburgh). In this case, the calculated CI of 80 closely approximated the experts' average of 76 .

\section{Temperature Rise Of Oil: Figure 19}

The temperature rise of oil was observed twice in the field testing of enclosed gear assemblies (Lower Right Lock Gate St. Lucie and Tainter Dam Gate \#1 St. Lucie). In both cases, the calculated CI is 70. The experts' average CI varied greatly in the two cases. With a slight temperature rise of the reduction gear box on the Lower Right Lock Gate, the experts' average was 85, while the experts' average was 58 when a temperature rise occurred in the gear box on Tainter Dam Gate \#1. The difference in the experts' CIs could be based on the difference in temperature change in the two cases; that is, the temperature change in the second case was greater.

\section{Oil Leakage: Figure 20}

The oil leakage distress was observed in eight of the 15 enclosed gear assemblies. The calculated CIs approximations to the experts' average CIs for this 
distress were fairly close. The experts' average CIs varied from 9 points below to 15 points above the calculated CIs.

\section{Oil Contamination: Figure 21}

The calculated CIs for the oil contamination distress closely approximated the experts' average CIs. Dirt or water was observed in eight of the 15 enclosed gear assemblies. The experts' average CIs varied from 10 points below to 6 points above the calculated CIs of 85. Metal filings were observed in one of the gear boxes (Tainter Dam Gate \#1 St. Lucie). In this case, the calculated CI was 40 and, the experts' average CI was 53. In the remaining seven cases, the distress was not observed, and the experts' average CIs were all 90 or higher.

\section{Assembly $\mathrm{Cl}$ : Figure 22}

The assembly CI for the enclosed gear assembly was calibrated for six assemblies. For four of the assemblies, the model CIs were above the experts' average CIs, and for the remaining two assemblies the model CIs were slightly lower. In only one case (Tainter Dam Gate \#1 Newburgh) was the model CI significantly different from the experts' average CI. The corresponding model CIs and experts' average CIs were in the same zone for each of the six calibrated assemblies.

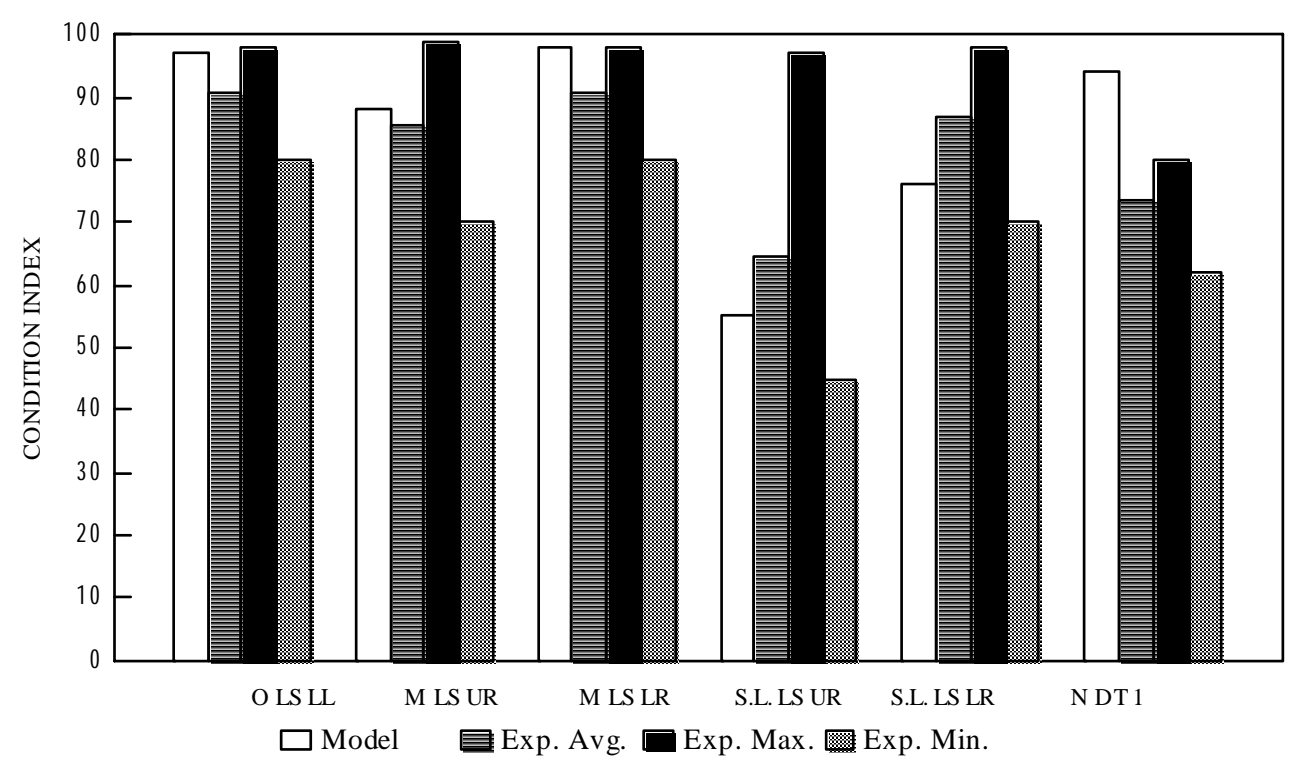

Figure 22. Enclosed gear assembly. 


\section{Gear Rack Assembly}

\subsection{Component Identification}

Definitions and sketches for components of the gear rack assembly are presented in the following paragraphs.

\section{Rack}

The rack consists of a set of teeth arranged in a linear or slightly curved fashion. Teeth on the rack mesh with matching teeth on the corresponding gear. The rack transfers force from the hydraulic cylinder to the sector gear when used to operate a miter gate (Figure 5). When used to operate a sector gate, the rack is attached rigidly to the top of the gate and transfers force from a gear to the gate (Figure 8). Racks are sometimes designed to perform as strut and rack assemblies simultaneously. These rack/strut members are used to operate sector lock gates and tainter dam gates.

\section{Reaction Rollers}

Reaction rollers resist the lateral load on the rack by the gear as the equipment is operated (Figure 5). This lateral force is caused by the transfer of force from the gear to the rack.

\section{Roller Supports}

Roller supports act as vertical and horizontal guides for the rack as it is operated (Figure 5). Roller supports, unlike reaction rollers, do not resist large forces. They are simply guides that ensure that the rack moves smoothly through the operation cycle.

\subsection{Inspection Form With Comments}

The following pages are Parts 1 and 2 of the field inspection forms for the rack assembly. The side-by-side arrangement of the opposing pages displays specific explanations (right side) adjacent to the entry on the inspection form (left side). 
Intentionally Blank 


\section{GEAR RACK INSPECTION PART 1}

PROJECT NAME:

DATE:

GATE IDENTIFICATION: (circle the appropriate gate)

Lock Gate
Upper
1. Left Leaf
2. Right Leaf

Lower

1. Left Leaf

2. Right Leaf

Valve
Emptying
1. Left
2. Right
Filling
1. Left
2. Right

Dam Gate

Number

NOISE, JUMPING, \& VIBRATION

NOISE

JUMPING

VIBRATION

CRACKS

NUMBER OF CRACKS:

REDUCED TOOTH CONTACT

$\%$ CONTACT:

CONTACT LOCATION

TOOTH DIRECTION(tip(T), middle(M), $\operatorname{root}(\mathrm{R}))$ :

LATERAL DIRECTION(top(P), center(C), bottom(B)):

TOOTH WEAR

WORN TEETH(Y/N):

IF YES, ESTIMATE \% OF WORN THICKNESS:

IF GREATER THAN 10\%, MEASURED \%:

DAMAGED TEETH

$\%$ OF DAMAGED SURFACE AREA:

CHIPPED(H), DEFORMED(D), CORRODED(C), PITTED(P), OR GOUGED(G):

LOCATION(tooth number):

NUMBER OF DAMAGED TEETH:

RACK ATTACHMENT DETERIORATION

CORROSION:

MISSING OR BROKEN NUTS:

LOOSE NUTS:

$(\mathrm{Y} / \mathrm{N})$

$(\mathrm{Y} / \mathrm{N})$

$(\mathrm{Y} / \mathrm{N})$

COMMENTS: 
Part 1 Comments: Field data

Enter the PROJECT NAME for this inspection, the DATE of the inspection, and, for the GATE IDENTIFICATION, identify which gate leaf or valve is being inspected. Also enter the power transfer number (P.T.\#), which can be found on Page 1 of the inspection form.

Observation of the rack during gate movement is a good indicator of problems. Record any indication of NOISE, JUMPING, and/or VIBRATION during operation and then indicate whether this noise, jumping, and/or vibration is NORMAL.

The presence of CRACKS on the RACK is usually not tolerated. Record the NUMBER OF CRACKS found by visual observation. Many times a crack will show up as corrosion underneath the painted surface. Also record the LOCATION of the cracks.

Record the average percentage of TOOTH CONTACT in the five teeth with the least contact area. The contact area is usually associated with an area where the grease film is noticeably thinner. Wear patterns may also help to identify the contact area. Once the contact area has been identified, the \% CONTACT is recorded as the percentage of the total tooth area that is contact area. Also, record where the CONTACT area LOCATION is relative to the total tooth area. In the TOOTH DIRECTION, the location is recorded as occurring primarily at the tip (T), middle $(\mathrm{M})$, root $(\mathrm{R})$, or any combination of the three (Figure 11). In the LATERAL DIRECTION, the location is recorded as occurring primarily on the top $(\mathrm{P})$, center $(\mathrm{C})$, bottom $(\mathrm{B})$ or any combination of the three (Figure 11). On a horizontal rack, the top of the tooth is on the top side of the rack. On a vertical rack, the side of the tooth defined as the top is identified by the gear with which it meshes. As described in Chapter 4, the top side of the vertical gear is the side that is turning counter-clockwise as the gate or valve is being closed. The top side of the rack tooth is the side that meshes with the top side of the meshing gear tooth.

Pick the TOOTH with the worst WEAR and look at the wear at the pitch line. Record if there is TOOTH WEAR. If the pitch line is not scribed on the teeth, a good estimate of the pitch line location is slightly towards the tip from the mid-depth of the tooth. If tooth wear is visible, estimate the PERCENTAGE of TOOTH THICKNESS REDUCTION. The percentage of thickness reduction can be estimated a number of ways. One technique is to measure both a worn tooth and a tooth that has infrequent contact at the pitch line with a ruler or tape measure and compare the tooth thicknesses. A second technique to estimate the thickness reduction of tooth thickness on meshing gear and rack with different widths is to check for a worn ledge on the wider tooth, with the depth of the ledge being the estimate of reduction in thickness. If the estimated percentage is greater than $10 \%$, record the MEASURED percentage using wear measurement techniques in Appendix B.

Pick the worst DAMAGED TOOTH for each type of damage on the rack and record the percentage of SURFACE AREA that is missing due to CHIPPING, DEFORMATION, PITTING, CORROSION, or GOUGING. If damage has occurred indicate the TYPE of DAMAGE. Chipping of the tooth is the breaking off of steel pieces, which usually results in 


\section{GEAR RACK INSPECTION PART 1}

PROJECT NAME:

DATE:

GATE IDENTIFICATION: (circle the appropriate gate)

Lock Gate
Upper
1. Left Leaf
2. Right Leaf

Lower

1. Left Leaf

2. Right Leaf

Valve
Emptying
1. Left
2. Right
Filling
1. Left
2. Right

Dam Gate

Number

NOISE, JUMPING, \& VIBRATION

NOISE

JUMPING

VIBRATION

CRACKS

NUMBER OF CRACKS:

REDUCED TOOTH CONTACT

$\%$ CONTACT:

CONTACT LOCATION

TOOTH DIRECTION(tip(T), middle(M), $\operatorname{root}(\mathrm{R}))$ :

LATERAL DIRECTION(top(P), center(C), bottom(B)):

TOOTH WEAR

WORN TEETH(Y/N):

IF YES, ESTIMATE \% OF WORN THICKNESS:

IF GREATER THAN 10\%, MEASURED \%:

DAMAGED TEETH

$\%$ OF DAMAGED SURFACE AREA:

CHIPPED(H), DEFORMED(D), CORRODED(C), PITTED(P), OR GOUGED(G):

LOCATION(tooth number):

NUMBER OF DAMAGED TEETH:

RACK ATTACHMENT DETERIORATION

CORROSION:

MISSING OR BROKEN NUTS:

LOOSE NUTS:

$(\mathrm{Y} / \mathrm{N})$

$(\mathrm{Y} / \mathrm{N})$

$(\mathrm{Y} / \mathrm{N})$

COMMENTS: 


\section{Part 1 Comments: Field data (continued)}

jagged edges and high stress concentrations in the tooth. Deformation of the tooth is the changing of the shape of the tooth, usually the result of excessive forces or something becoming lodged in between teeth during operation. Pitting of the tooth is the severe localized corrosion of the tooth that results in small cavities in the tooth surface. Corrosion is the loss of steel in the tooth surface due to interaction with the environment.

Record the evidence of RACK ATTACHMENT DETERIORATION. Record whether there are any CORRODED (10\% volume loss), MISSING OR BROKEN, or LOOSE NUTS. If a sector gate is being inspected, the bolts attach the rack to the gate. If a miter lock gate or dam gate is being inspected, the bolts connect the rack to the I-beam. 
U.S. ARMY CORPS OF ENGINEERS

P.T.\#:

GEAR RACK INSPECTION PART 2

IS THE RACK BEING INSPECTED BEING USED TO

OPERATE A MITER LOCK GATE OR DAM GATE(Y/N)?

IF YES, COMPLETE THE REMAINING QUESTIONS

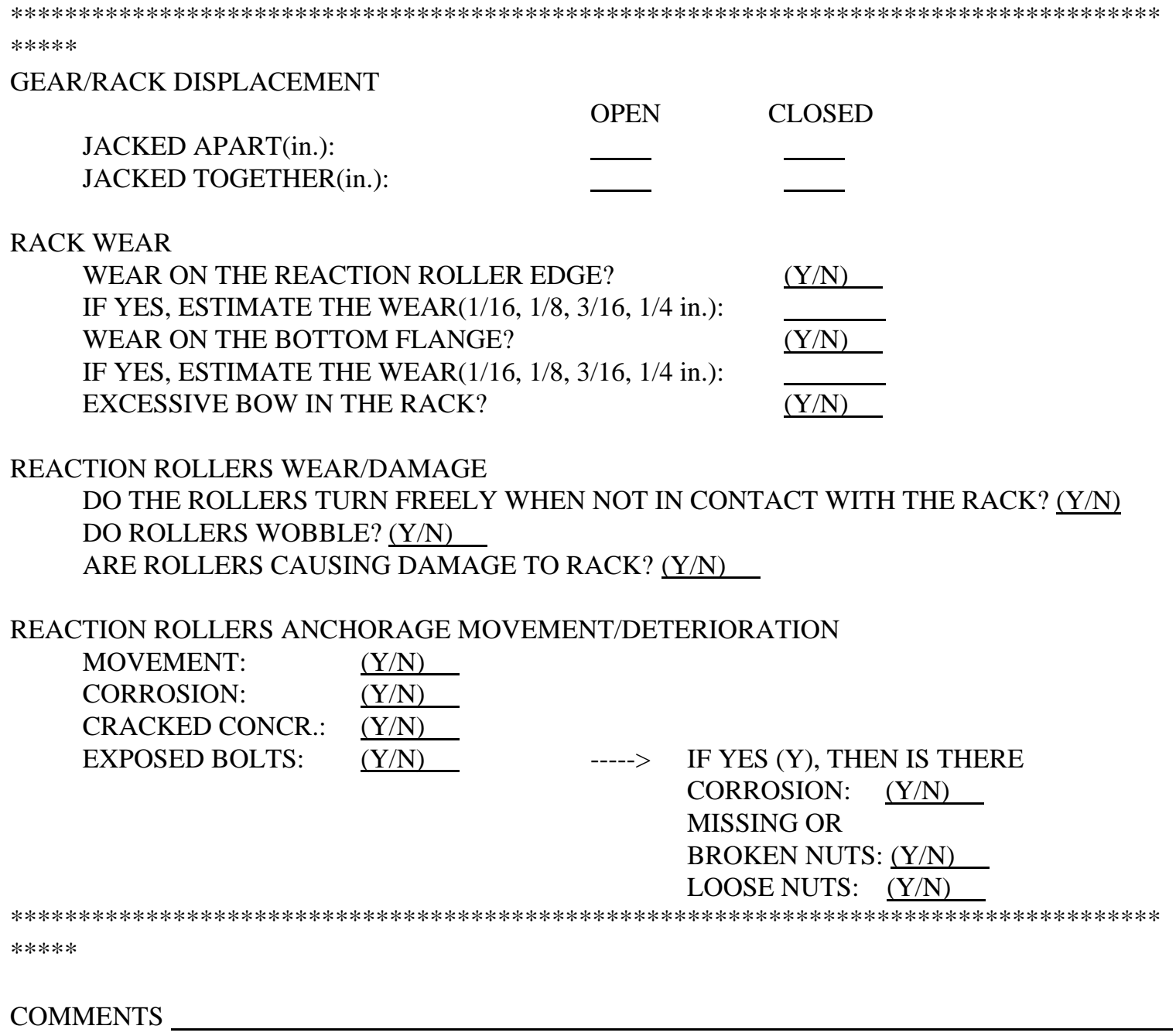

COMMENTS 
PART 2 Comments: Field data

Record whether the RACK BEING INSPECTED IS USED TO OPERATE A MITER LOCK GATE OR DAM GATE. If yes, the following questions should be answered.

Excessive lateral DISPLACEMENT of the ROLLER RACK is an indication that a problem is developing in the equipment. The movement can be quantified by placing permanent marks on the gear and rack (Figure 23). The distance between these two points is recorded when the gear and rack are JACKED or pried APART and when JACKED or pried TOGETHER. The pry bar is placed between the gear and the rack to force the roller rack and gear apart and the first measurement is taken (Figure 23). A jack can also be placed in a position to force the gear and roller rack apart. The second measurement is taken after the pry bar or jack are placed on the opposite side and used to force the gear and roller rack together. These measurements should be taken when the gate is OPEN and CLOSED. The difference between these two measurements indicates the "play" in the system. This measurement is not applicable to racks attached to sector gates.

Record the evidence of WEAR ON THE REACTION ROLLER EDGE of the rack. If there is wear, estimate the amount of wear to the nearest 1/16 in. Record the evidence of WEAR ON THE BOTTOM FLANGE of the rack. If there is wear, estimate the amount of wear to the nearest 1/16 in. Also record any evidence of BOW IN THE RACK.

Record whether the REACTION ROLLERS TURN FREELY by hand WHEN NOT IN CONTACT WITH the RACK. Indicate whether the reaction rollers WOBBLE. Also record if the reaction ROLLERS ARE CAUSING DAMAGE TO the RACK.

Record the evidence of MOVEMENT of the REACTION ROLLERS ANCHORAGE base as the gate is opened and closed. Evidence of movement can be observed visually or enhanced by placing a dial gage to monitor any movement. A dial gage change greater than 0.002 in. is considered movement. Excessive concrete spalling may indicate a displacement occurred at this location at some time. Also, record the presence of any CORROSION (10\% volume loss) of the steel portion or any CRACKED CONCRETE at the interface of the embedment. Small hairline cracks, probably caused by thermal expansion or contraction of the concrete, should be ignored. Indicate if there are any CORRODED (10\% volume loss), MISSING OR BROKEN, or LOOSE NUTS at the reaction rollers anchorage if the BOLTS are EXPOSED. 


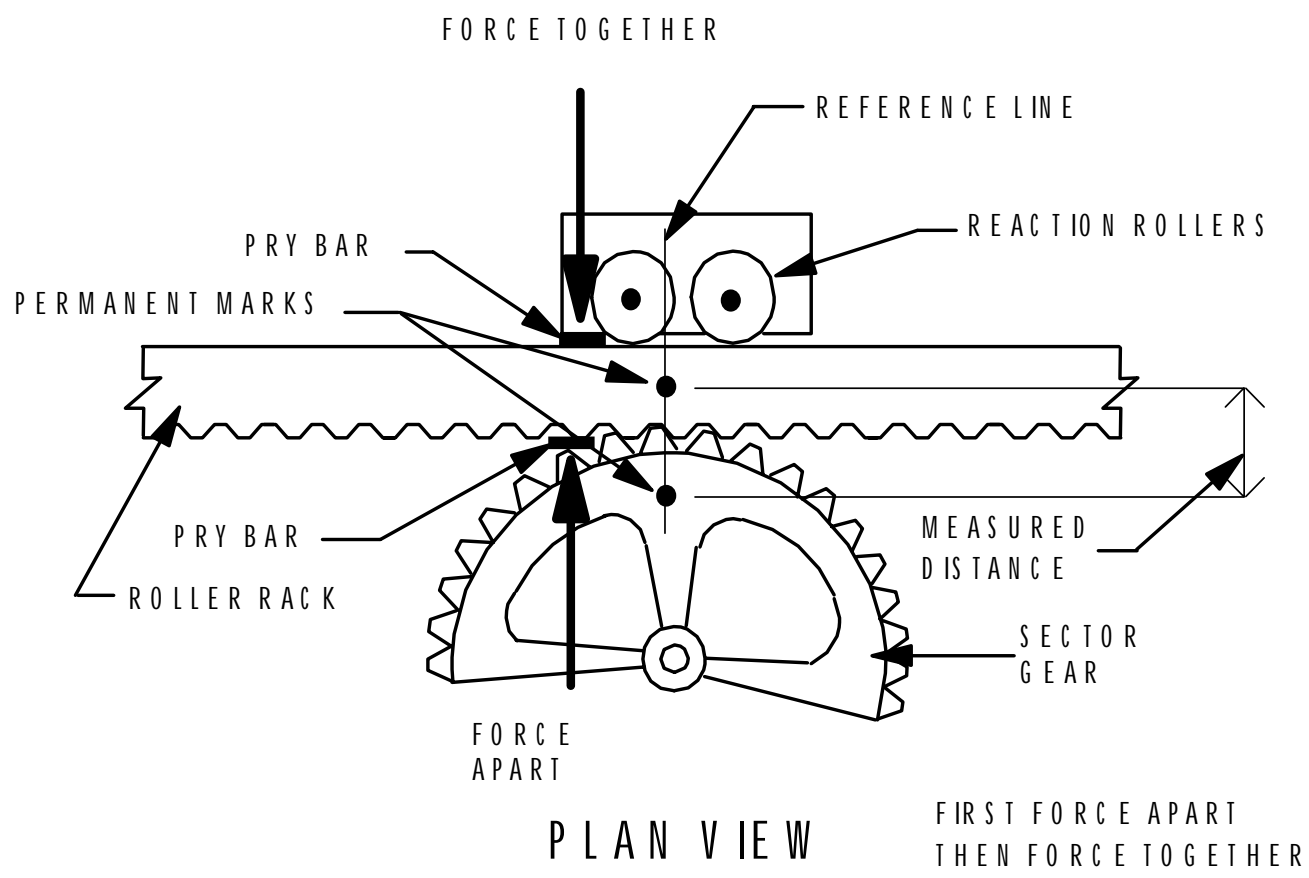

JACKOR PRY BAR

MAY BE USED

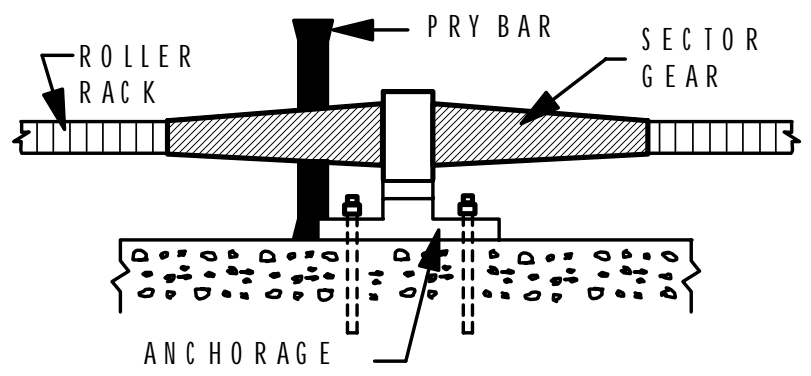

SECTION VIE W

Figure 23. Gear/rack displacement measurement. 


\subsection{Condition Index}

The following section contains the rules for calculating the individual CIs for the rack assembly distresses. Distress descriptions and example illustrations are also provided.

\section{Noise, Jumping, and Vibration}

See noise, jumping, and vibration for the exposed gear assembly (Chapter 4, p 51).

\section{Cracks}

See cracks for the exposed gear assembly (Chapter 4, p 54).

\section{Reduced Tooth Contact}

See reduced tooth contact for the exposed gear assembly (Chapter 4, p 55).

\section{Tooth Wear}

See tooth wear for the exposed gear assembly (Chapter 4, p 55).

\section{Damaged Teeth}

See damaged teeth for the exposed gear assembly (Chapter 4, p 56).

\section{Rack Attachment Deterioration}

See anchorage movement/deterioration for the exposed gear assembly (Chapter 4, p 51).

\section{Gear/Rack Displacement}

Definition and causes. Excessive lateral movement between the gear and the rack may cause the contact between gear teeth and rack teeth to decrease. With decreased contact, the stress on the teeth may increase significantly. The wear that causes this problem can be due to improper lubrication and jumping and vibration during operation of the assembly.

Measurement and limits. Measurements are recorded when the rack is moved to the right and left with a crow bar (pry bar) or a jack (Figure 23). 


$$
\begin{gathered}
X_{1}=\text { Measurement when jacked or pried apart } \\
X_{2}=\text { Measurement when jacked or pried together }
\end{gathered}
$$

The $\mathrm{X}$ movement is taken as the difference between these two measurements.

$$
x=\left|x_{2}-x_{1}\right|
$$

These measurements are taken twice, once with the gate opened and once with the gate closed, and the largest $\mathrm{X}$ is used. The limiting value for this movement is taken as:

$$
x_{M A X}=y / 2 \text { in } .
$$

Example: A gear and rack were pried apart. The measurement was:

$$
x_{1}=12.53 \mathrm{in} .
$$

The assembly was then pried together. This measurement was:

$$
x_{2}=12.00 \mathrm{in} .
$$

The displacement $\mathrm{X}$ is found by Equation 6.1.

$$
\begin{aligned}
& x=|12.53-12.0|=0.53 \quad \begin{array}{l}
\text { The CI for gear and rack } \\
\text { displacement is: }
\end{array} \\
& C 1=\left[100(0.4)^{0.53 / 0.50}\right]=38
\end{aligned}
$$

The $\mathrm{CI}$ is rated Poor.

\section{Rack Wear}

Definitions and causes. Rack damage can be in the form of loss of steel section or bowing of the rack. The loss of section can occur both on the reaction roller edge and on the bottom flange of the rack. This wear is caused by interaction with the rollers. Bowing of the rack can occur from excessive force being applied to the rack. 
Measurements and limits. The amount of wear, X, on either the roller edge or bottom flange of the roller rack is recorded in the inspection form. The maximum of the two $\mathrm{X}$ values is used to calculate the CI. The limiting value for rack wear is:

$$
x_{\text {MAX }}=1 / 8 \text { in }
$$

If bowing in the rack is evident, the CI shall be 70 .

The CI for rack wear is the minimum of the CIs for wear and for bowing of the rack.

Example: Wear on the bottom flange of a rack was

$$
x=1 / 16 \text { in } .
$$

There was no noticeable wear on the reaction roller edge nor was there any bowing of the rack. The CI for rack wear is

$$
C I=\left[\begin{array}{llll}
1 & 0 & 0 & \left.\left.(0.4)^{(1 / 16) /(1 / 8}\right)\right]
\end{array}=63\right.
$$

The $\mathrm{CI}$ is rated Fair.

\section{Reaction Roller Wear/Damage}

Definitions and causes. The bushings or bearings in reaction rollers can freeze and stop rotating or in some cases wear and cause the rollers to wobble. Inadequate lubrication and interaction with the environment can cause seizing of the bushings or bearings. Wobble in the reaction rollers can be caused by regular use or inadequate lubrication.

Measurements and limits. The reaction rollers are checked to see if they rotate freely when they are not in contact with the rack. If they do not rotate freely, the CI for reaction rollers is 70 . The rollers are also observed to see if they wobble. If they wobble, the $\mathrm{CI}$ is 70 . If the rollers are causing damage to the rack the $\mathrm{CI}$ is 40 . 
Example: Wobble was observed in a reaction roller; therefore:

$$
c I=70
$$

The CI is rated Good.

\section{Reaction Roller Anchorage Movement/Deterioration}

See anchorage movement/deterioration for the exposed gear assembly (Chapter 4, p 51).

\section{Assembly Cl}

The assembly CI will be calculated with Equations 2.2, 2.5, and 2.6 (See Chapter 2, Assembly Distress). The lone critical distress in the gear rack assembly is the crack distress. The CIs from the remaining distresses will be used to calculate the weighted assembly $\mathrm{CI}_{\mathrm{w}}$ (Equation 2.5). For a rack used to operate a sector lock gate, five distresses will be used to calculate the weighted assembly $\mathrm{CI}_{\mathrm{w}}$. The weighting factors for those distresses are in Table 14. For a rack used to operate a miter lock gate or a dam gate, eight distresses will be used to calculate the weighted assembly $\mathrm{CI}_{\mathrm{w}}$. The weighting factors for those distresses are in Table 15.

\subsection{Field Test}

The bar charts in Figures 24 and 25 compare the experts' subjective condition index during the field tests to the condition index calculated from the rules in Section 6.3 for two rack distresses. Only data from assemblies with observed distresses are plotted. Comparisons between the calculated and experts' CIs are summarized below.

\section{Noise, Jumping, and Vibration}

Because no abnormal noise, jumping, or vibration was recorded, the calculated CI values were 100. Although this distress was not recorded, the experts' average was below 90 on three of seven assemblies that were rated. However, in each of these cases, the experts' average CI was 85 or greater. The noise, jumping, and vibration distress was calibrated in Chapter 5 for the enclosed gear assembly and the calculated CIs closely approximated the experts' averages. 


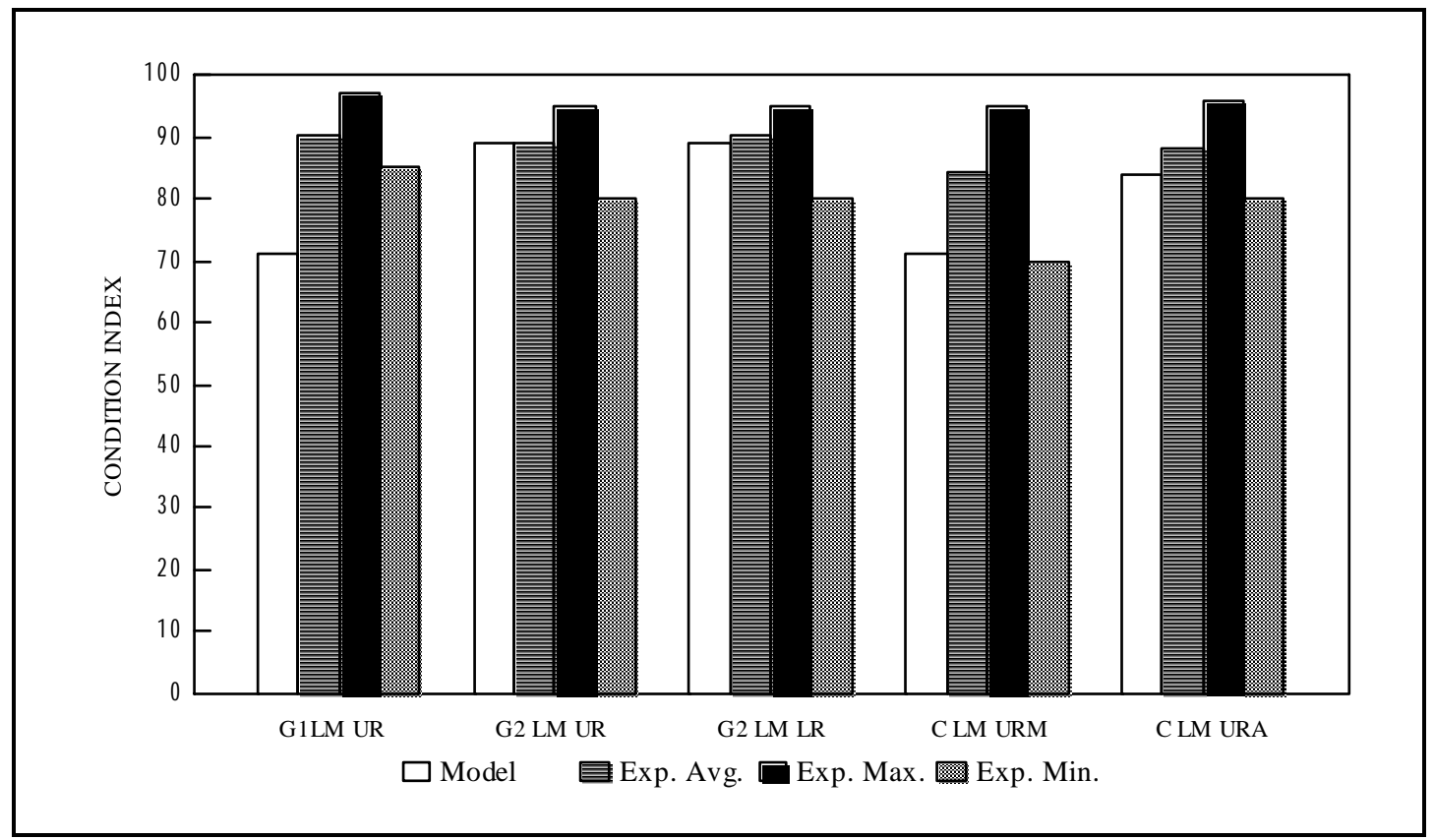

Figure 24. Reduced tooth contact: gear rack assembly.

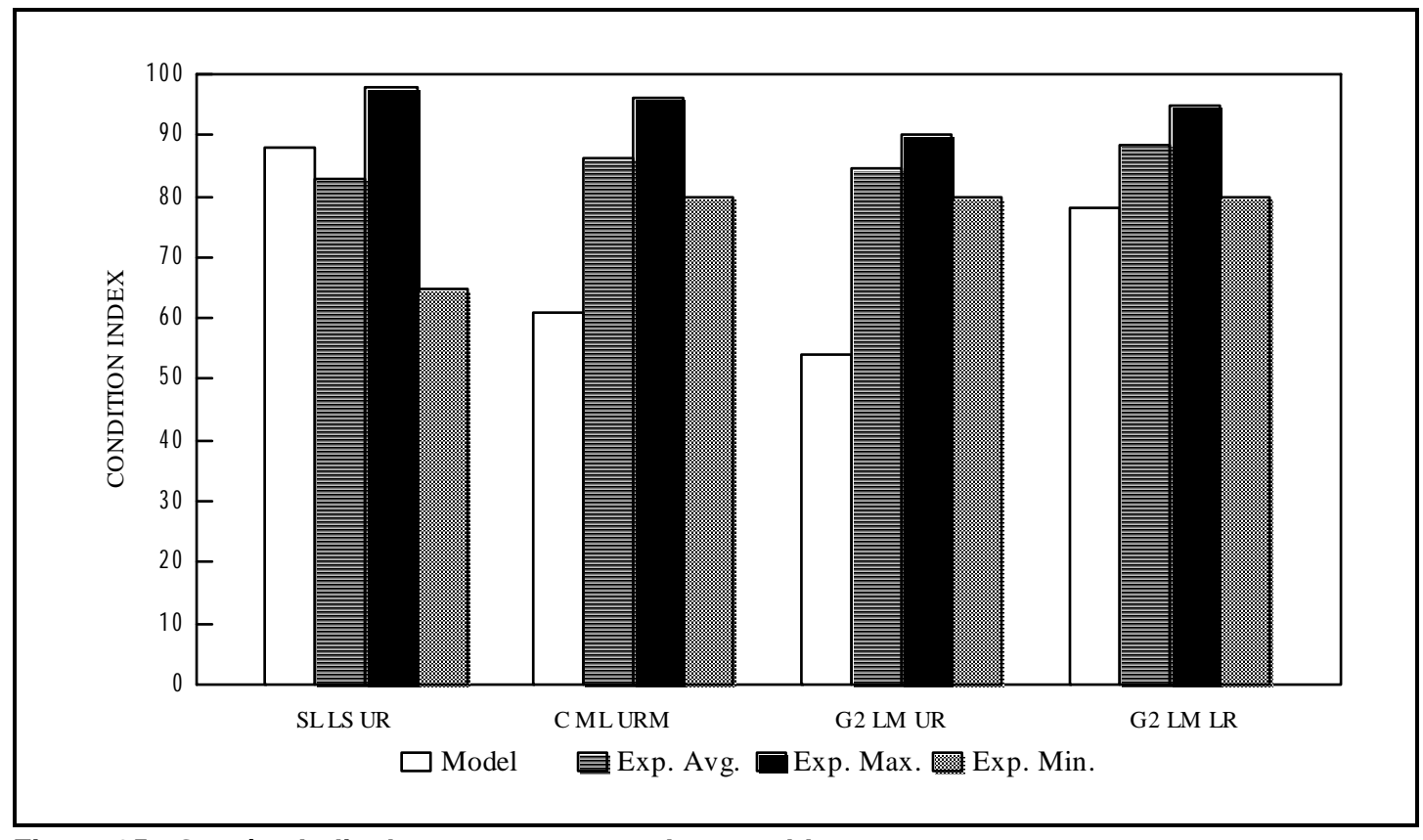

Figure 25. Gear/rack displacement: gear rack assembly. 


\section{Cracks}

The cracks distress was not calibrated because no cracks were observed in sector gears or racks. Hence, the calculated CIs were all 100 and the experts' average CIs were 90 or above. Although this distress was not calibrated, the experts felt that cracks in the gear or rack were critical and should be repaired, which corresponds well to Section 4.3.

\section{Reduced Tooth Contact: Figure 24}

The tooth contact and tooth wear distresses were initially combined as one distress. Discussion with the experts near the end of the Louisville District field test resulted in separating the original distress into two distinct distresses- tooth contact and tooth wear. Although no data were collected after the separation of the distresses, the data collected for the original combined distress was used to calibrate the tooth contact distress. This is appropriate for two reasons: (1) the observed wear of the rack teeth was relatively low on the observed gears, and (2) the weighting factor for tooth contact was significantly higher than the weighting factor for tooth wear (Tables 14 and 15). In two cases where the tooth contact/wear distress was observed (Miter Lock Gate Upper Right Cannelton and Miter Gate Upper Right Green River \#2), the calculated CIs were lower than the experts' average CIs. In these cases, the calculated CIs were in Zone 2. In two other cases, the calculated CIs corresponded well with the experts' average CIs.

\section{Tooth Wear}

During development, discussion with the experts resulted in a separation of the tooth wear and tooth contact distresses. Therefore, while the tooth wear distress was observed, calibration of the new rules was not possible with the current data used in the calibration of the tooth contact distress. The new rules for tooth wear were, however, constructed using the experts' judgement and advice.

\section{Damaged Teeth}

The damaged teeth distress was not calibrated because no damaged teeth were observed in the racks. Hence, the calculated CIs were all 100 and the experts' average CIs were 90 or above. The damaged teeth distress was calibrated for the enclosed gear assembly (Section 5.4) and the calculated CIs closely approximated the experts' average CIs. 


\section{Rack Attachment Deterioration}

The rack attachment deterioration distress was not calibrated because no deterioration was observed in the rack attachment for sector gates. Hence, the calculated CIs were all 100 and the experts' average CIs were 90 or above. The anchorage movement/deterioration distress was calibrated for the exposed gear assembly (Section 4.4) and the enclosed gear assembly (Section 5.4). In each case the calculated CIs closely approximated the experts' average CIs.

\section{Gear/Rack Displacement: Figure 25}

The calculated CIs closely approximated the experts' average on all but two (Upper Right Lock Gate Green River 1 and Upper Right Lock Gate Main Chamber Cannelton) of the sector gear and rack assemblies that were rated. In both of these cases, the measured displacements were 3/16 in., which were the largest displacements observed during the field tests. In both cases, the calculated CI was well below the experts' average CI. In each of the other sector gear and rack assemblies where the displacements were smaller, the calculated CIs matched well with the experts' averages.

\section{Rack Wear}

The rack wear distress was not calibrated because rack wear was not observed during the field tests. Hence, the calculated CIs were all 100 and the experts' average CIs were 90 or above.

\section{Reaction Roller Wear/Damage}

The reaction roller wear/damage distress was not calibrated because the distress was not observed during the field tests. Hence, the calculated CIs were all 100. The experts' average CIs ranged between 83 and 92. The experts were reluctant to rate the reaction rollers higher because they were not in perfect working condition. Although the reaction rollers did turn freely when not loaded, they were no longer in the condition they had been in when installed.

\section{Reaction Roller Anchorage Movement/Deterioration}

The reaction roller anchorage movement/deterioration distress was not calibrated because no movement or deterioration of the anchorage was observed. Hence, the calculated CIs were all 100 and the experts' average CIs were 90 or above. The anchorage movement/deterioration distress was calibrated for the exposed gear assembly (Section 4.4) and the enclosed gear assembly (Section 
5.4). In each case, the calculated CIs closely approximated the experts' average CIs.

\section{Assembly Cl: Figure 26}

The assembly CI for the rack assembly was calibrated for three assemblies. In each case the model CI was slightly higher than the experts' average CI. Although the model CIs were higher, the experts' average CIs and the model CIs were all in the upper part of Zone 1.

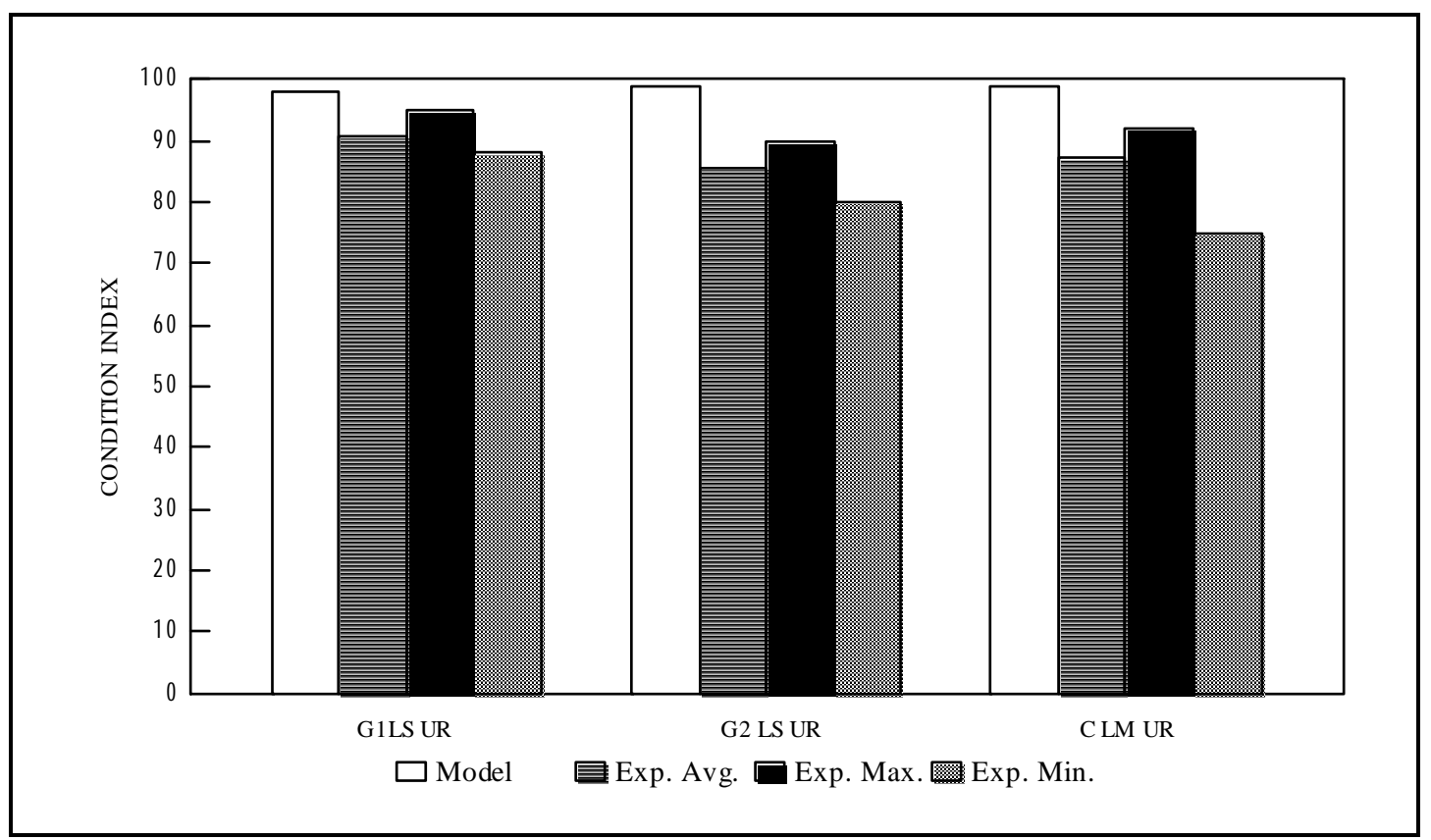

Figure 26. Gear rack assembly $\mathrm{Cl}$. 


\section{Strut Arm Assembly}

\subsection{Component Identification}

Definitions and sketches for components of the strut arm assembly are presented in the following paragraphs.

\section{Strut}

The strut transfers force from one component to another. Its function when used with a lock gate is to transfer force from the sector arm to the gate (Figure 5). The strut transfers force from the rocker arm assembly to the valve when used with a valve structure (Figure 6).

\section{Linkage Pin}

The linkage pin serves as a pivot point for the strut (Figure 5). For lock gates, one linkage pin serves as a pivot between the sector arm and the strut, and a second pin serves as a pivot between the strut and the gate. Valve struts also have pins on both ends.

\section{Compression Spring}

The compression spring is in the strut (Figures 5 and 6). Its function is to allow the strut to shorten or lengthen slightly when the gates or valves are closed or lowered, which provides a tight fit without damaging the structure. The compression spring also acts as a shock absorber between the gate and the operating equipment.

\section{End Connection}

The end connection is fixed to the gate, sector arm, or valve and transfers force from the strut to these structures or components (Figure 6).

\subsection{Inspection Form With Comments}

The following page is the field inspection form for the strut arm assembly. The side-by-side arrangement of the opposing pages displays specific explanations (right side) adjacent to the entry on the inspection form (left side). 
U.S. ARMY CORPS OF ENGINEERS

P.T.\#:

STRUT ARM INSPECTION

PROJECT NAME:

DATE:

GATE IDENTIFICATION: (indicate the appropriate gate)

Lock Gate

$\begin{array}{lll}\text { Upper } & \text { 1. Left Leaf } & \text { 2. Right Leaf } \\ \text { Lower } & \text { 1. Left Leaf } & \text { 2. Right Leaf }\end{array}$

Valve
Emptying
1. Left
2. Right
Filling
1. Left
2. Right

Dam Gate

Number

NOISE, JUMPING, \& VIBRATION

NOISE

JUMPING

VIBRATION

$\frac{(\mathrm{Y} / \mathrm{N})}{(\mathrm{Y} / \mathrm{N})} \frac{(\mathrm{Y} / \mathrm{N})}{\underline{ }}$

IS IT NORMAL

$(\mathrm{Y} / \mathrm{N})$

$(\mathrm{Y} / \mathrm{N})$

$(\mathrm{Y} / \mathrm{N})$

END CONNECTION MOVEMENT

(estimate movement (in.): $0,1 / 8,1 / 4,3 / 8,1 / 2): \quad$ OPEN $\quad$ CLOSED

POWER END:

OTHER END:

COMPRESSION SPRING MOVEMENT

DOES IT MOVE FREELY?

IF NO, COULD LACK OF MOVEMENT DAMAGE EQUIPMENT?

CORROSION

ORIGINAL SECTION THICKNESS(in.):

SIGNIFICANT CORROSION:

SEVERE PITTING OR GENERAL THICKNESS REDUCTION: CRACKS

NUMBER OF CRACKS:

LOCATION FROM POWER END (ft):

COMMENTS: 
Comments: Field data

Enter the PROJECT NAME for this inspection, the DATE of the inspection, and, for the GATE IDENTIFICATION, identify whether a lock gate, valve, or dam gate is being inspected. Also enter the power transfer number(P.T.\#), which can be found on Page 1 of the inspection form.

Observation of the strut arm assembly during gate and valve movement is a good indicator of problems. Record any indication of NOISE, JUMPING, and/or VIBRATION during operation, and then indicate whether this noise, jumping, and/or vibration is NORMAL.

Record the relative MOVEMENT in the END CONNECTION between the strut arm and the attached component or structure. Estimate the movement to the nearest $1 / 8$ in. To further enhance the visual observation, place a dial gage at this location. Record the readings while the operating equipment is in the OPEN and CLOSED positions. Movement should be recorded for both the POWER END and the OTHER END of the strut arm (Figure 27). The END CONNECTION MOVEMENT at the bottom of the valve strut is inspected during the valve inspection (leave OTHER END blank).

Record if the COMPRESSION SPRING is operating normally. Watch the structure as it is opened and closed. The spring should MOVE FREELY at the beginning and end of the stroke. During the closing of the structure, the compression spring should compress at least $1 / 2$ to $1 \mathrm{in}$. and should release when the force in the strut changes from compression to tension. The compression spring should act as a shock absorber to soften the loads transmitted to the operating machinery. If the compression spring does not move freely, record whether LACK OF MOVEMENT COULD DAMAGE EQUIPMENT or the structure.

The presence of excessive CORROSION on the strut arm is a potential problem. Record the WALL THICKNESS of the STRUT in order to better judge the corrosion. Obtain the wall thickness from construction drawings. Record YES if there is SIGNIFICANT CORROSION (more than general scaling). If yes, indicate if there is SEVERE PITTING (1/8 in. pits or greater) in a dense pattern or GENERAL THICKNESS REDUCTION of $10 \%$ or greater in local areas.

The presence of CRACKS on the strut arm is usually not tolerated. Record the NUMBER OF CRACKS found on these components by visual observation as well as the LOCATION of the cracks with respect to the POWER END. 


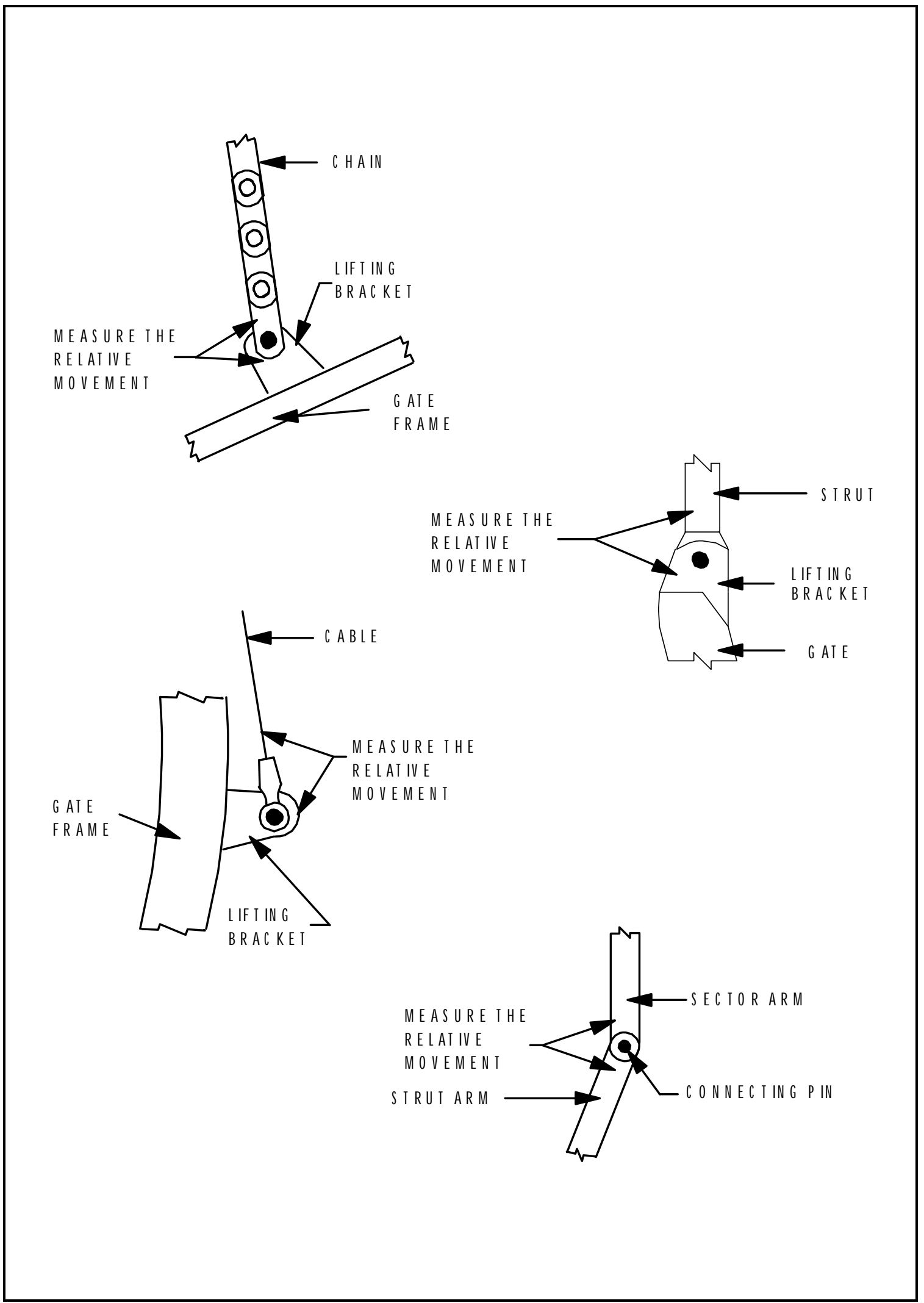

Figure 27. End connection movement distress. 


\subsection{Condition Index}

The following section contains the rules for calculating the individual CIs for the strut arm assembly distresses. Distress descriptions and example illustrations are also provided.

\section{Noise, Jumping, Vibration}

See noise, jumping, vibration for the exposed gear assembly (Chapter 4, p 51).

\section{End Connection Movement}

Definition and causes. The strut arms are connected to the sector gear or valve with linkage pins. Over time, the pins and bushings wear due to normal operation or improper lubrication. Relative movement is experienced due to the wear in the linkage pins and the bushings. In some cases, the connection is designed without a bushing. In this case, the wear occurs directly between the pin and the strut arm.

Measurement and limits. End connection movement at the opened and closed positions is visually observed and recorded to the nearest $1 / 8$ in. The $\mathrm{X}$ value for end connection movement is the relative movement between the end of the strut and the structure to which it is attached. The greater of $X_{1}$ and $X_{2}$ at the two ends of the strut arm is used to calculate the CI.

$$
x=\operatorname{Maxim} u m\left(x_{1}, x_{2}\right)
$$

For valves, the end of the strut arm connected to the valve is inspected during the valve inspection, in which case $\mathrm{X}$ is equal to the measurement at the power end. The limiting value for end connection movement is:

$$
x_{\text {MAX }}=1 / 4 \text { in } .
$$

Example: The relative movement of the strut arm end connection at End 1 was:

$$
x_{1}=1 / 8 \text { in } .
$$

and at End 2 was:

$$
x_{2}=1 / 4 \mathrm{in} .
$$


The value of $\mathrm{X}$ (by Equation 7.1) is:

$$
x=\text { Maximum }(1 / 8,1 / 4)=1 / 4 \text { in } .
$$

The CI for the strut arm end connection movement is:

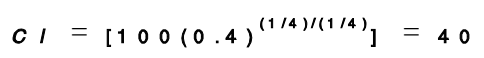

The CI is rated Marginal.

\section{Compression Spring Movement}

Definition and causes. The compression spring acts like a shock absorber as the gate opens into the recess or closes for emptying or filling of the chamber. Normal compression spring movement occurs near the end of the opening and closing cycles. Corrosion or other damage can cause the compression spring to lose flexibility.

Measurement and limits. If the compression spring is not working properly, but will not likely damage the other operating equipment, the $\mathrm{CI}$ is 70 . If, however, the compression spring is not working properly and could cause damage to the structure and other operating equipment, the $\mathrm{CI}$ is 40 .

Example: A compression spring did not move during the opening and closing of a lock gate. The lack of movement created the potential for damage to occur to other operating equipment. The $\mathrm{CI}$ for the compression spring is:

$$
c I=40
$$

The CI is rated Marginal.

\section{Corrosion}

Definitions and causes. Corrosion involves the loss of steel material on the strut arm assembly due to interaction with the environment. If this interaction continues, pitting occurs. Pitting is the minor loss of steel in localized areas. While light deterioration causes little structural problems, extensive corrosion can reduce the cross-sectional area of the assembly, thereby increasing the stresses.

Measurements and limits. Corrosion that is more intensive than general scaling is recorded. If corrosion is greater than scaling but pitting is less than $1 / 8$ in. and general thickness reductions are less than 10 percent, the $\mathrm{CI}$ is 70 . If pitting is 
$1 / 8$ in. or greater or a general thickness reduction of 10 percent or greater, the CI should be reduced to 40 .

Example: Corrosion of a strut arm was detected during an inspection. In several local areas the general thickness reduction of the arm was 15 percent of its original thickness.

The CI for corrosion is:

$$
c_{1}=40
$$

The $\mathrm{CI}$ is considered Marginal.

\section{Cracks}

See cracks for the exposed gear assembly (Chapter 4, p 54).

\section{Assembly Cl}

The assembly CI will be calculated with Equations 2.2, 2.5, and 2.6 (See

Chapter 2, Assembly Distress). The lone critical distress in the strut assembly is the crack distress. The CIs from the remaining four distresses will be used to calculate the weighted $\mathrm{CI}_{\mathrm{w}}$ (Equation 2.5). The weighting factors for those four distresses are in Table 16.

\subsection{Field Test}

The bar charts in Figures 28 and 29 compare the experts' subjective condition index from the field tests to the condition index calculated from the rules in Section 7.3 for two strut arm distresses. Only data from assemblies with observed distresses are plotted. Comparisons between the calculated and experts' condition indexes are summarized below.

\section{Noise, Jumping, Vibration}

The noise, jumping, and vibration distress was not calibrated because the distress was not observed in strut arms. Hence, the calculated CIs were all 100, and the experts' average condition indexes were 90 or above. The noise, jumping, and vibration distress was calibrated for the enclosed gear assembly, and the calculated CIs closely approximated the experts' averages. 


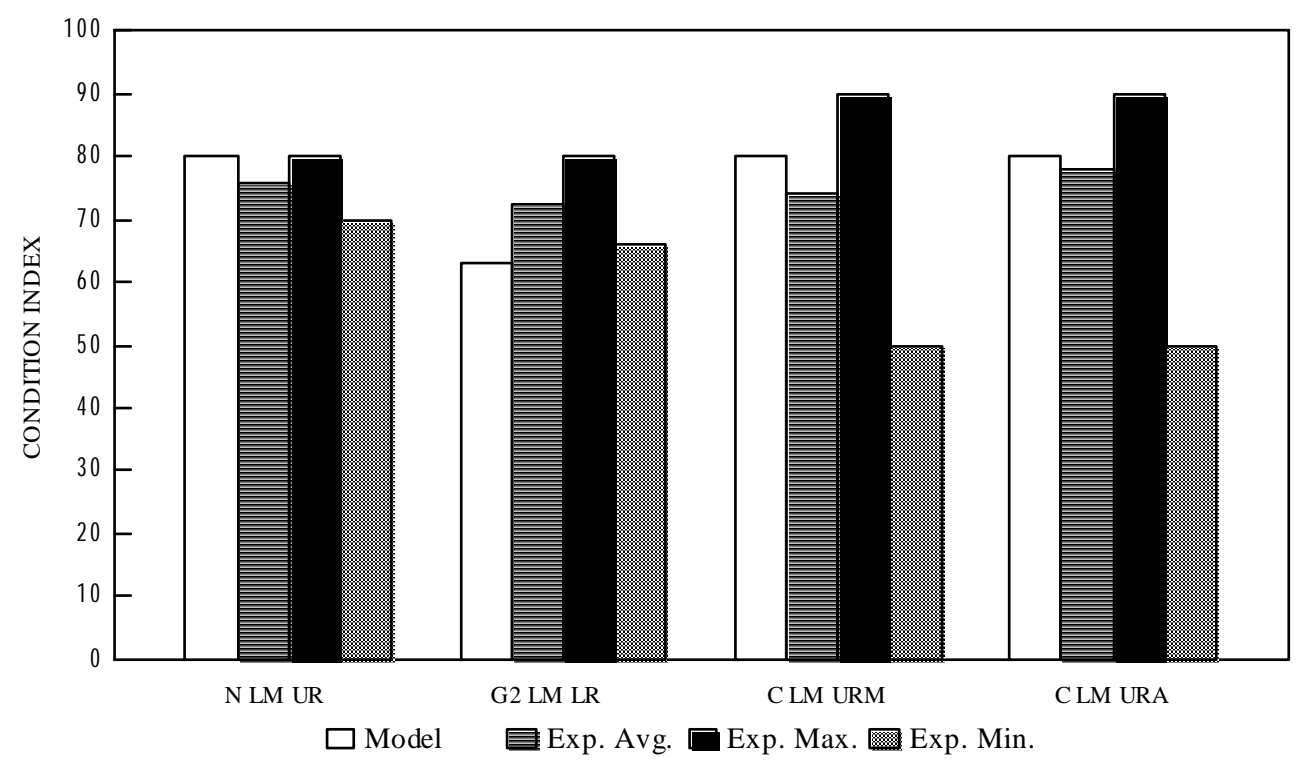

Figure 28. End connection movement: strut arm assembly.

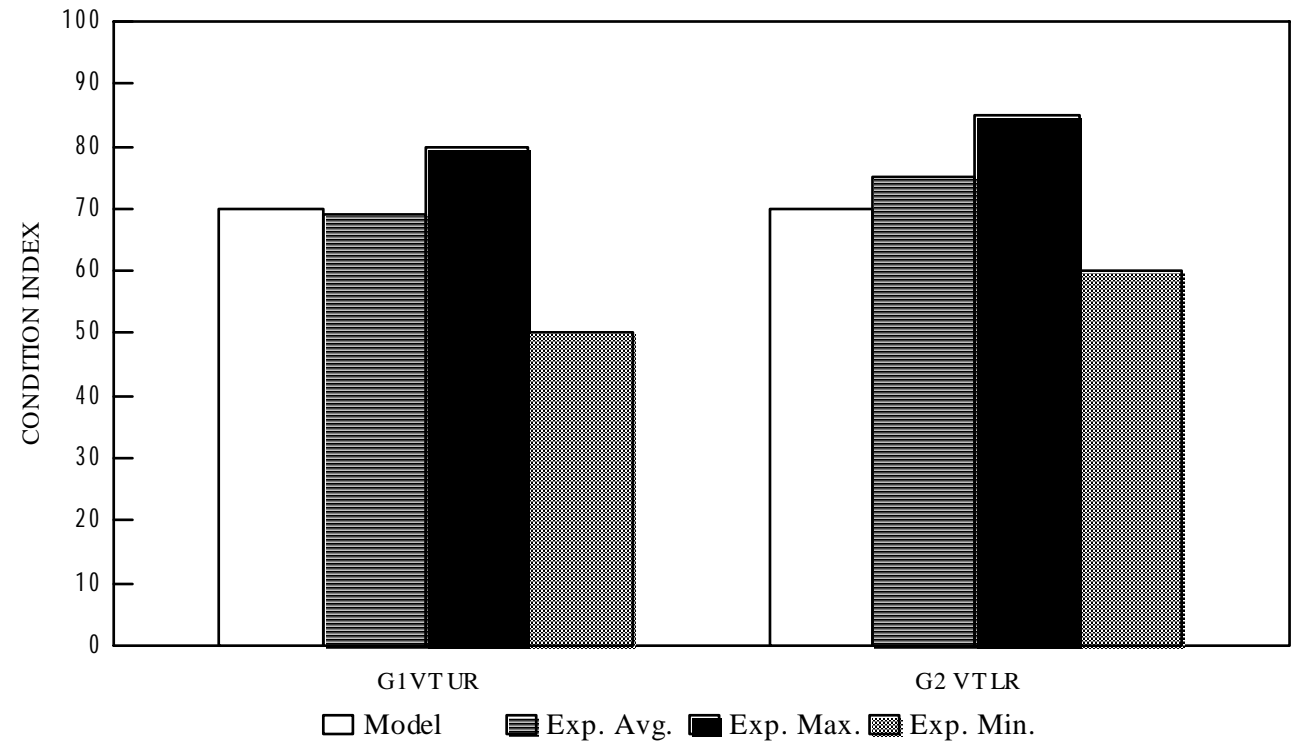

Figure 29. Corrosion: strut arm assembly. 


\section{End Connection Movement: Figure 28}

For the four strut arms for which movement was observed (Newburgh Upper Right Miter Lock Gate, Green River \#2 Lower Right Miter Lock Gate, Cannelton Upper Right Miter Lock Gate, and Cannelton Upper Left Miter Lock Gate) the calculated CIs closely approximated the experts' average, with the greatest difference being 9 points.

\section{Compression Spring Movement}

The compression spring movement distress was not calibrated because no strut arm compression spring movement problems were observed. Hence, the calculated CIs were all 100, and the experts' average condition indexes were 90 or above.

\section{Corrosion: Figure 29}

The calculated CIs closely approximated the experts' average CIs (within 5 points) for corrosion of the strut arms at the two locations (Green River \#1 Right Filling Valve and Green River \#2 Right Emptying Valve) where the corrosion distress was observed. Both of these struts were valve operating equipment. The corrosion distress for struts was not observed on any struts used to operate miter lock gates.

\section{Cracks}

The cracks distress was not calibrated because no cracks in strut arms were observed. Hence, the calculated CIs were all 100 and the experts' average CIs were 90 or above. Although this distress was not calibrated, the experts felt that cracks in the strut were critical and should be repaired, which corresponds well to Section 4.3.

\section{Assembly $\mathrm{Cl}$ : Figure 30}

The assembly CI for strut arms was calibrated for six assemblies. In each case, the model CI was higher than the experts' average CI. Although the model CIs were higher, the experts' average CIs and the model CIs were all in Zone 1. 


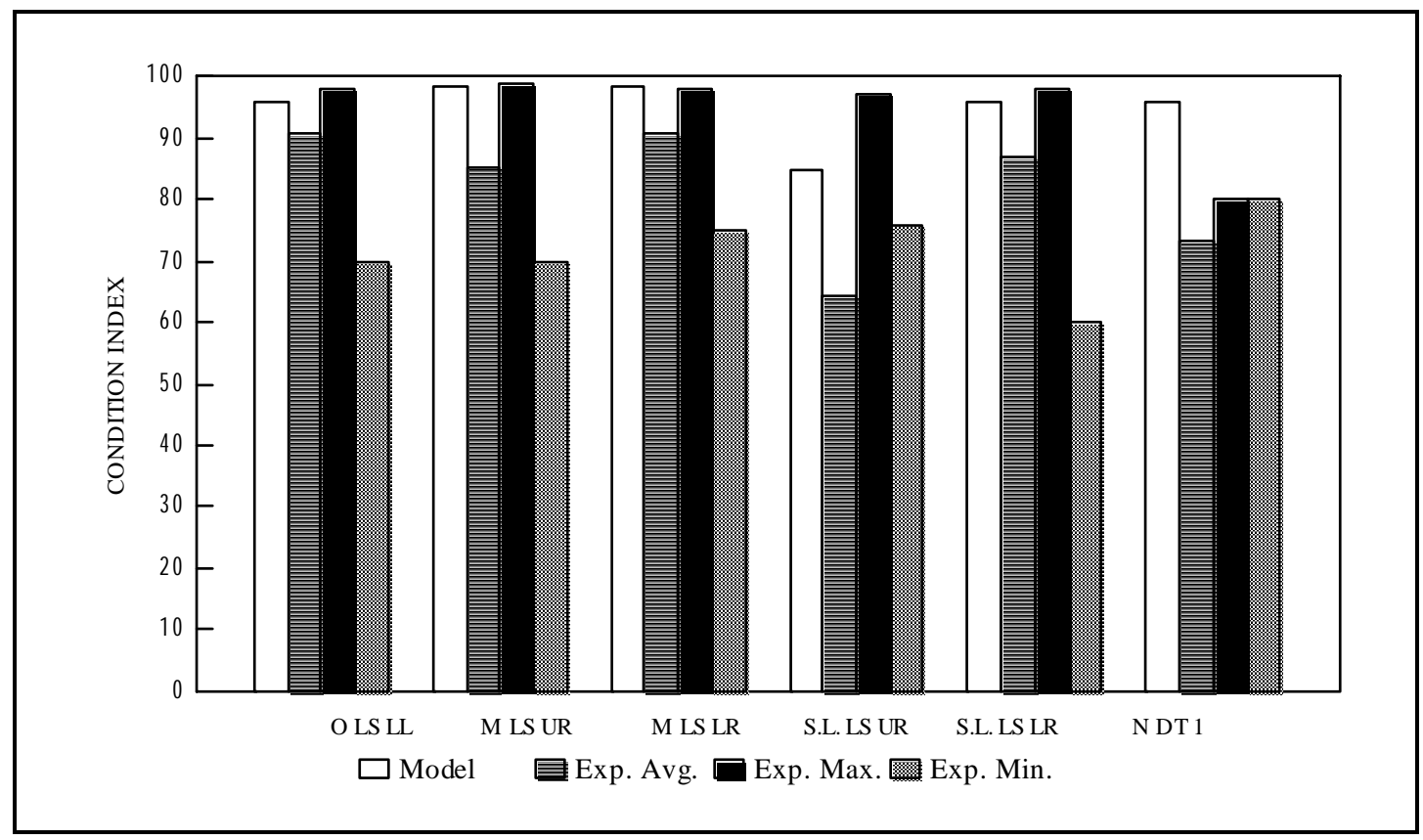

Figure 30. Strut arm assembly $\mathrm{Cl}$. 


\section{Rocker Arm Assembly}

\subsection{Component Identification}

Definitions and sketches for components of the rocker arm assembly are presented in the following paragraphs.

\section{Rocker}

The rocker consists of steel arms that are joined with connecting pins (Figure 6). It transfers and redirects the horizontal load produced by a hydraulic cylinder to a vertical strut arm assembly.

\section{Pivot Point}

The pivot point is the connecting pin on which the rocker rotates (Figure 6).

\section{Connecting Rod}

The connecting rod transfers force from the piston rod to the rocker (Figure 6). Not all rocker assemblies have connecting rods.

\subsection{Inspection Form With Comments}

The following page is the field inspection form for the rocker arm assembly. The side-by-side arrangement of the opposing pages displays specific explanations (right side) adjacent to the entry on the inspection form (left side). 


\section{ROCKER ARM INSPECTION}

P.T.\#:

PROJECT NAME:

DATE:

VALVE IDENTIFICATION: (circle the appropriate valve)

Valve
Emptying
1. Left
2. Right
Filling
1. Left
2. Right

NOISE, JUMPING, \& VIBRATION IS IT NORMAL

$\begin{array}{lll}\text { NOISE } & (\mathrm{Y} / \mathrm{N}) & (\mathrm{Y} / \mathrm{N}) \\ \text { JUMPING } & \underline{(\mathrm{Y} / \mathrm{N})} & \underline{(\mathrm{Y} / \mathrm{N})} \\ \text { VIBRATION } & \underline{(\mathrm{Y} / \mathrm{N})} & \end{array}$

PIVOT POINT ANCHORAGE MOVEMENT/DETERIORATION

MOVEMENT: $\quad(\mathrm{Y} / \mathrm{N})$

CORROSION: $\quad(\mathrm{Y} / \mathrm{N})$

CRACKED CONCR.: $\quad \underline{(\mathrm{Y} / \mathrm{N})}$

EXPOSED BOLTS: $\quad \underline{(\mathrm{Y} / \mathrm{N})}$

-------> IF YES(Y), THEN IS THERE

CORROSION:

MISSING OR

BROKEN NUTS:

LOOSE NUTS:

PIVOT POINT PIN MOVEMENT

OPEN

CLOSED

(estimate movement (in.): $0,1 / 8,1 / 4,3 / 8,1 / 2$ ):

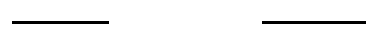

ROCKER AND CONNECTING ROD CONNECTION MOVEMENT OPEN CLOSED

(estimate movement(in.): $0,1 / 8,1 / 4,3 / 8,1 / 2$ ):

CORROSION

NEW SECTION THICKNESS (in.):

SIGNIFICANT CORROSION:

$(\mathrm{Y} / \mathrm{N})$

SEVERE PITTING OR GENERAL THICKNESS REDUCTION:

CRACKS

NUMBER OF CRACKS:

LOCATION FROM POWER END(ft):

COMMENTS: 
Comments: Field data

Enter the PROJECT NAME for this inspection, the DATE of the inspection, and, for the GATE IDENTIFICATION, identify which valve is being inspected. Also enter the power transfer number (P.T.\#), which can be found on Page 1 of the inspection form.

Observation of the rocker arm during gate movement is a good indicator of problems. Record any indication NOISE, JUMPING, and/or VIBRATION during operation. Also indicate whether this noise, jumping, and/or vibration is NORMAL.

Record any evidence of MOVEMENT at the ANCHORAGE of the PIVOT POINT as the valve is opened and closed. Evidence of movement can be observed visually or enhanced by placing a dial gage to monitor any movement (Figure 31). A dial gage change greater than 0.002 in. is considered movement. Excessive concrete spalling may indicate a displacement occurred at this location at some time. Also, record the presence of any CORROSION (10\% volume loss) of the steel portion or any CRACKED CONCRETE at the interface of the embedment. Small hairline cracks, probably caused by thermal expansion or contraction of the concrete, should be ignored. Indicate if there are any CORRODED (10\% volume loss), MISSING OR BROKEN, or LOOSE nuts at this connection if the BOLTS are EXPOSED.

Record the relative MOVEMENT at the PIVOT POINT PIN (Figure 31) between the rocker and the anchorage bracket by visual observation to the nearest $1 / 8 \mathrm{in}$. To further enhance the visual observation, place a dial gage at this location.

Record the relative CONNECTION MOVEMENT between the ROCKER AND CONNECTING ROD (Figure 31) by visual observation to the nearest $1 / 8$ in. To further enhance the visual observation, place a dial gage at this location.

The presence of excessive CORROSION on the rocker arm or connecting rod is a potential problem. Select the section of the rocker arm or connecting arm with the most corrosion. From construction drawings, record the NEW SECTION THICKNESS at this location. Record YES if there is SIGNIFICANT CORROSION (more than general scaling). If yes, indicate if there is SEVERE PITTING (1/8 in. pits or greater) in a dense pattern or GENERAL THICKNESS REDUCTION of $10 \%$ or greater in local areas.

The presence of CRACKS on the rocker arm assembly is usually not tolerated. Record the NUMBER OF CRACKS found by visual observation of the rocker and connecting rod. Many times a crack will show up as corrosion under the painted surface. Also record the LOCATION of any cracks.

Note: Wear at the connection of the rocker to the strut is recorded in the STRUT inspection, and wear at the connection of the rocker to the piston rod is recorded in the HYDRAULIC CYLINDER inspection. 


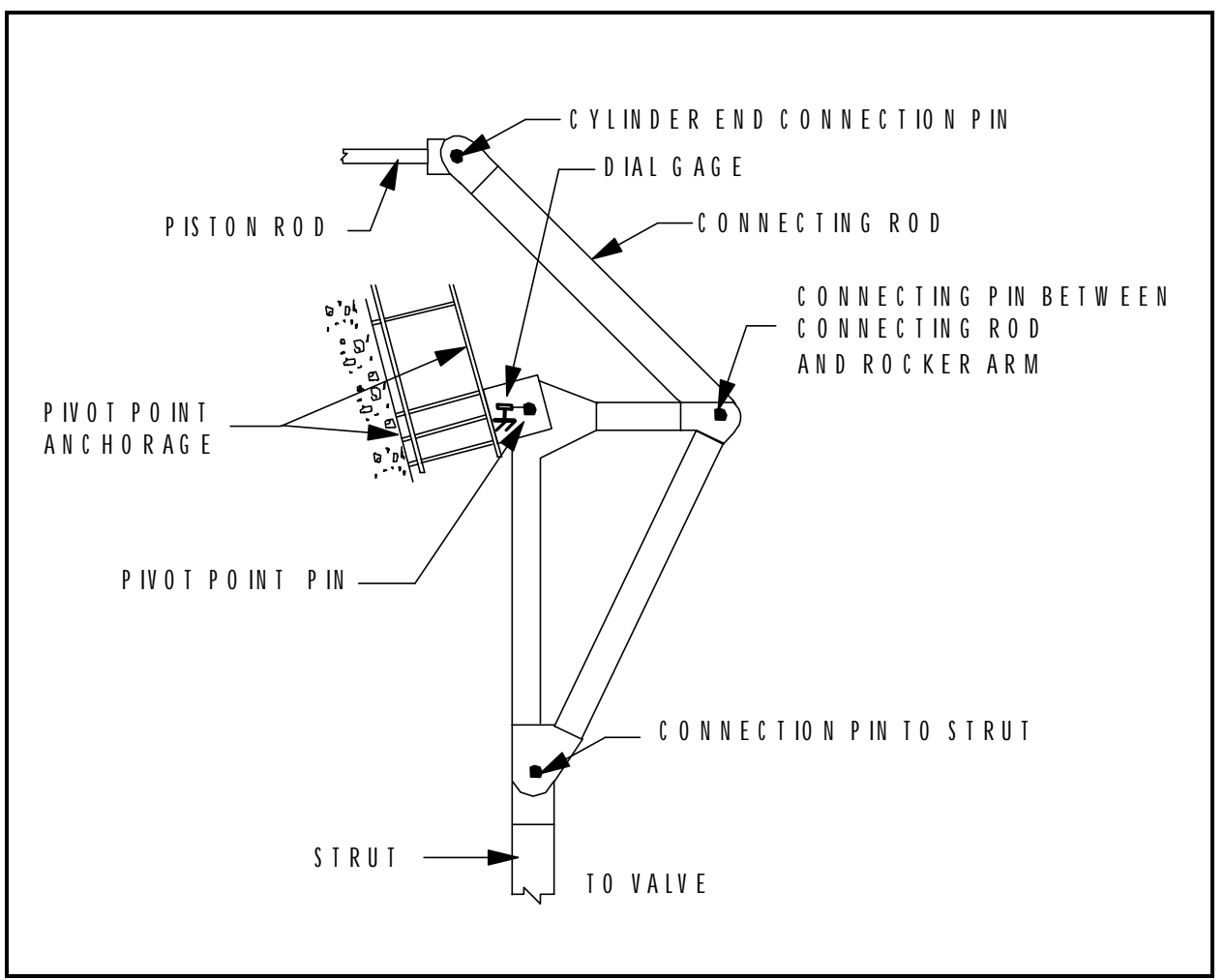

Figure 31. Rocker arm distress measurements.

\subsection{Condition Index}

The following section contains the rules for calculating the individual CIs for the rocker arm assembly distresses. Distress descriptions and example illustrations are also provided.

\section{Noise, Jumping, Vibration}

See noise, jumping, vibration for the exposed gear assembly (Chapter 4, p 51).

\section{Pivot Point Anchorage Movement/Deterioration}

See anchorage movement/deterioration for the exposed gear assembly (Chapter 4, p 51).

\section{Pivot Point Pin Movement}

See end connection movement for the strut arm assembly (Chapter 7, p 101). 


\section{Rocker and Connecting Rod Connection Movement}

See end connection movement for the strut arm assembly (Chapter 7, p 101).

\section{Corrosion}

See corrosion for the strut arm assembly (Chapter 7, p 101).

\section{Cracks}

See cracks for the exposed gear assembly (Chapter 4, p 54).

\section{Assembly Cl}

The assembly CI will be calculated with Equations 2.2, 2.5, and 2.6 (See Chapter 2, Assembly Distress). The lone critical distress in the rocker arm assembly is the crack distress. The CIs from the remaining five distresses will be used to calculate the weighted $\mathrm{CI}_{\mathrm{w}}$ (Equation 2.5). The weighting factors for those five distresses are in Table 17.

\subsection{Field Tests}

The bar charts in Figures 32 and 33 compare the experts' subjective condition index from the field tests with the CI calculated from the rules in Section 8.3 for two rocker arm distresses. Only data from assemblies with observed distresses are plotted. Comparisons between the calculated and experts' CIs are summarized below.

\section{Noise, Jumping, Vibration}

The noise, jumping, and vibration distress was not calibrated because no noise, jumping, or vibration in rocker arms was observed. Hence, the calculated CIs were all 100 and the experts' average CIs were 90 or above. The noise, jumping, and vibration distress was calibrated in the enclosed gear assembly, and the calculated CIs closely approximated the experts' averages.

\section{Pivot Point Anchorage Movement/Deterioration: Figure 32}

The pivot point anchorage movement/deterioration distress was observed on a filling valve at Green River \#1 Lock. The experts' average was 15 points higher than the calculated CI of 40 . 


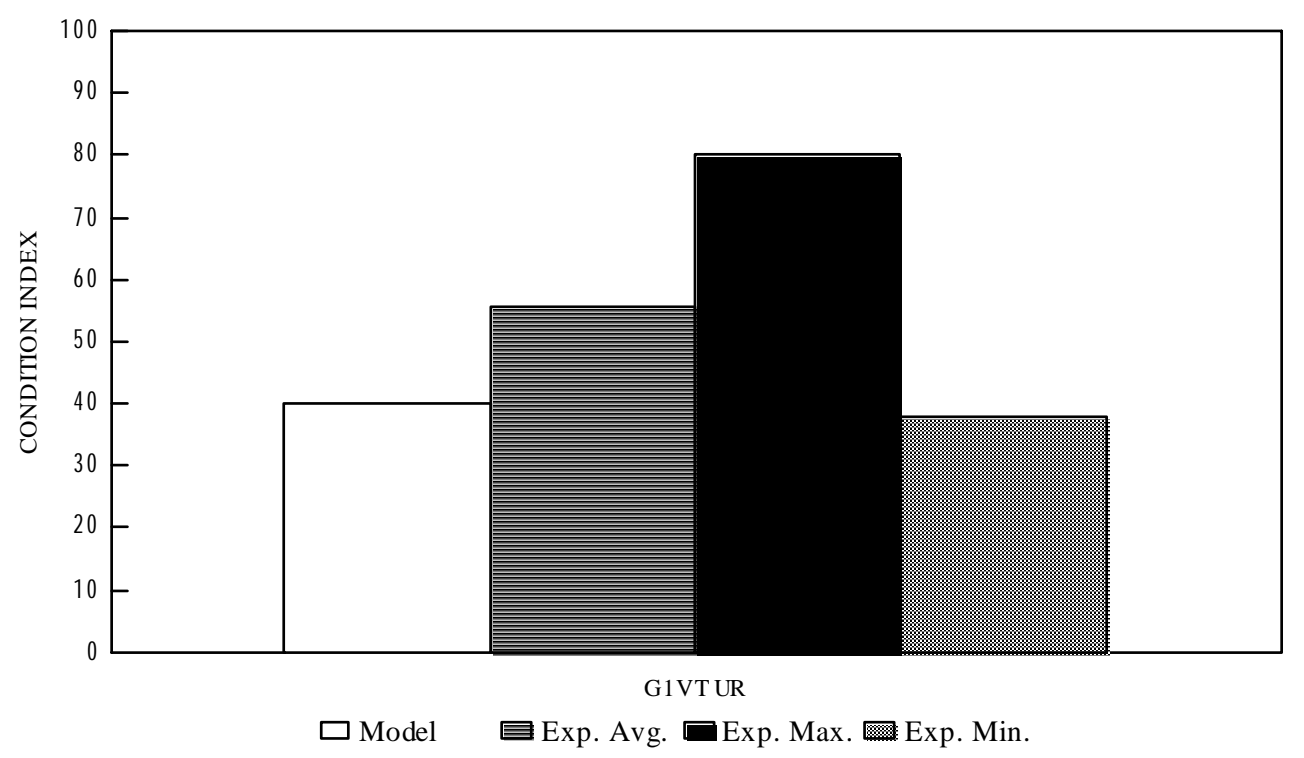

Figure 32. Pivot point anchorage movement/deterioration: rocker arm assembly.

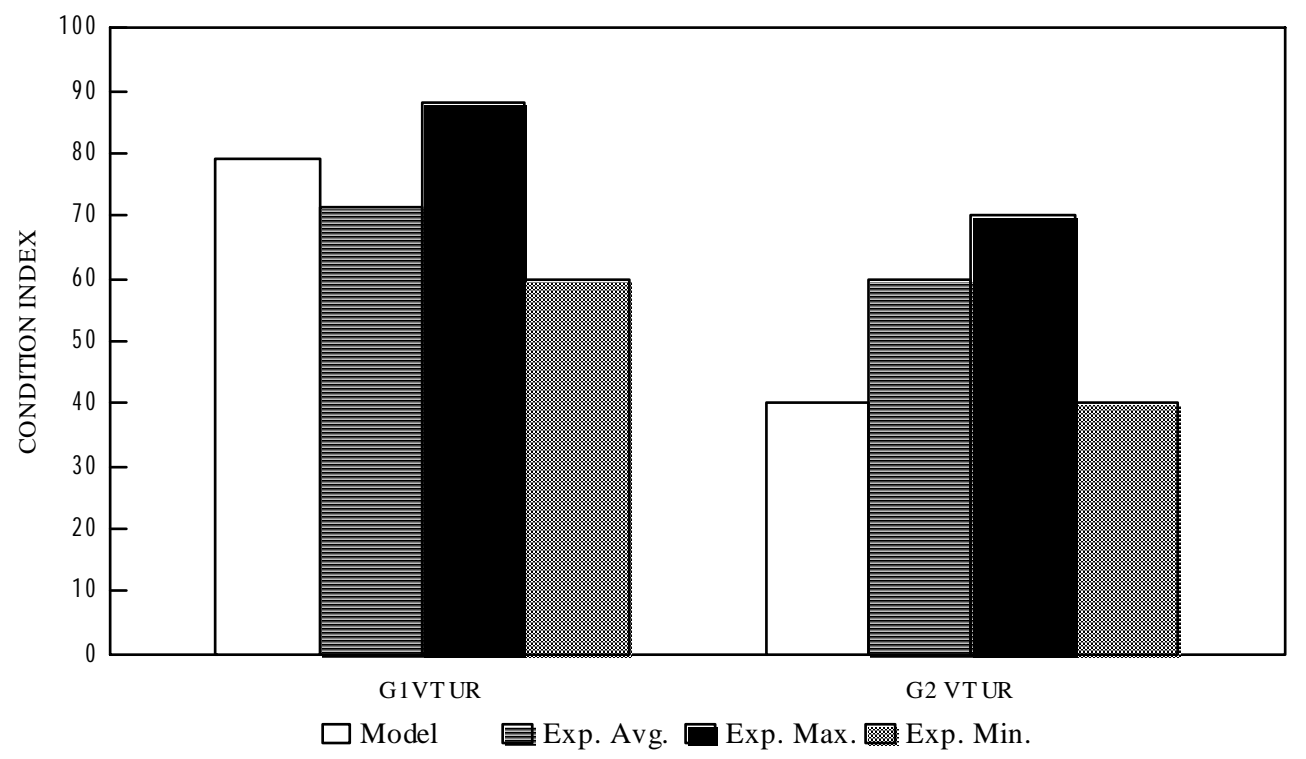

Figure 33. Pivot point pin movement: rocker arm assembly. 


\section{Pivot Point Pin Movement: Figure 33}

The pivot point pin movement distress was observed at two locations. At Green River \#1, the movement was 1/16 in. and the calculated CI was very close to the experts' average. Although the movement was four times larger at the second location (1/4 inch at Green River \#2), the experts lowered their average by only 12 points, from 72 to 60 . The calculated CI at the second location decreased by 39 points and was equal to the expert low (40).

\section{Movement Between Rocker and Connecting Rod}

The movement between rocker and connecting rod distress was not calibrated because no relative movement was observed between the rocker and the connecting rod in rocker arms. Hence, the calculated CIs were all 100, and the experts' average CIs were 90 or above.

\section{Corrosion}

The corrosion distress was not calibrated because no significant corrosion was observed in rocker arms. Hence, the calculated CIs were all 100, and the experts' average CIs were 90 or above. The rule for the corrosion distress was, however, calibrated for strut arms, and the calculated CIs closely approximated the experts' averages.

\section{Cracks}

The cracks distress was not calibrated because no rocker arms cracks were observed. Hence, the calculated CIs were all 100, and the experts' average CIs were 90 or above. Although this distress was not calibrated, the experts felt that cracks in the rocker arm were critical and should be repaired, which corresponds well to Section 4.3.

\section{Assembly $\mathrm{Cl}:$ Figure 34}

The assembly CI for rocker arms was calibrated for two assemblies. The model CI was slightly lower than the experts' average CI for the case in Zone 2 (Upper Right Valve Green River \#1), and was higher than the experts' average CI for the case in Zone 1 (Lower Right Valve Green River \#2). 


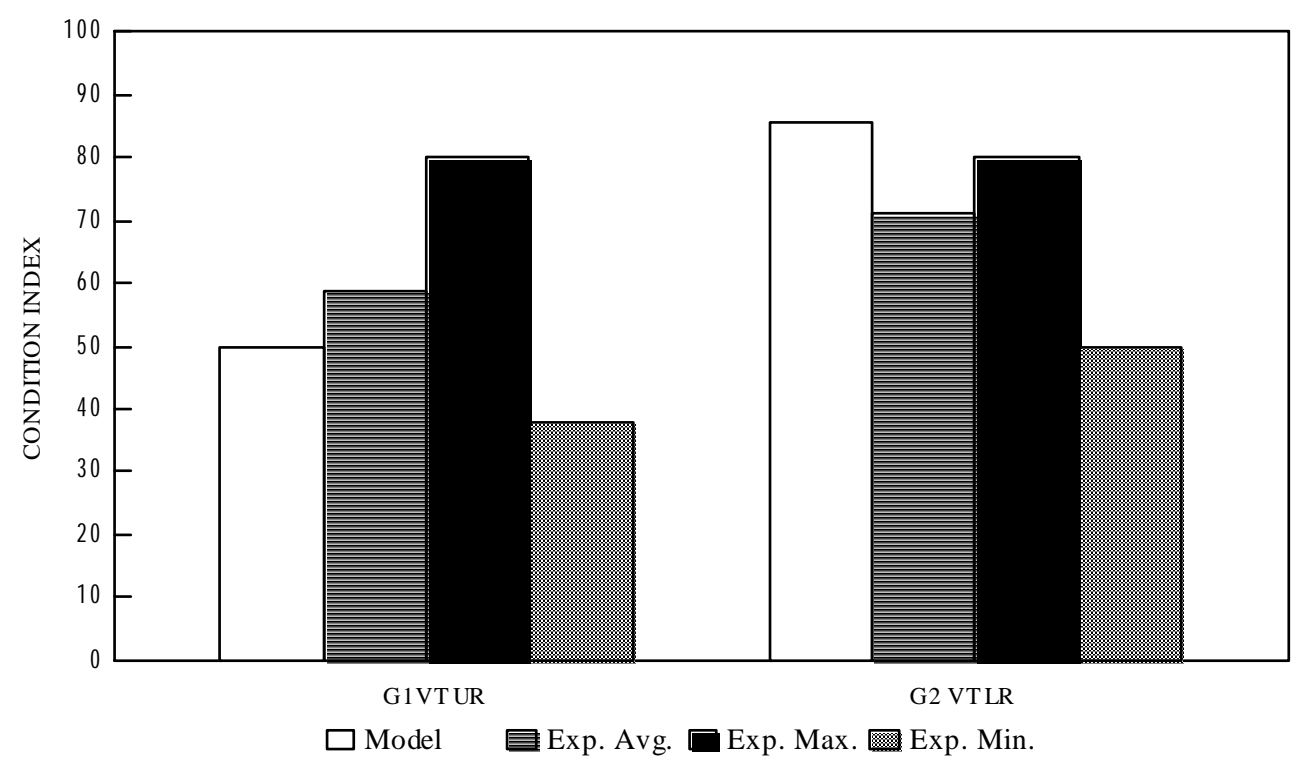

Figure 34. Rocker arm assembly $\mathrm{Cl}$. 


\section{Cable Assembly}

\subsection{Component Identification}

Definitions and sketches for components of the cable assembly are presented in the following paragraphs. Cable lifting systems are sometimes used to raise and lower or open and close the structures (Figures 35, 36, and 37).

\section{Cable (wire rope)}

The cable is made up of several strands (Figure 38) usually wound in one of two ways: regular or lang lay. The wires of a regular lay are twisted to make the strands, and the strands are then twisted in the opposite direction to make the rope. The wires in the regular lay end up running in the longitudinal direction. Figure 38 shows a lang lay, where the wires and strands are twisted in the same direction.

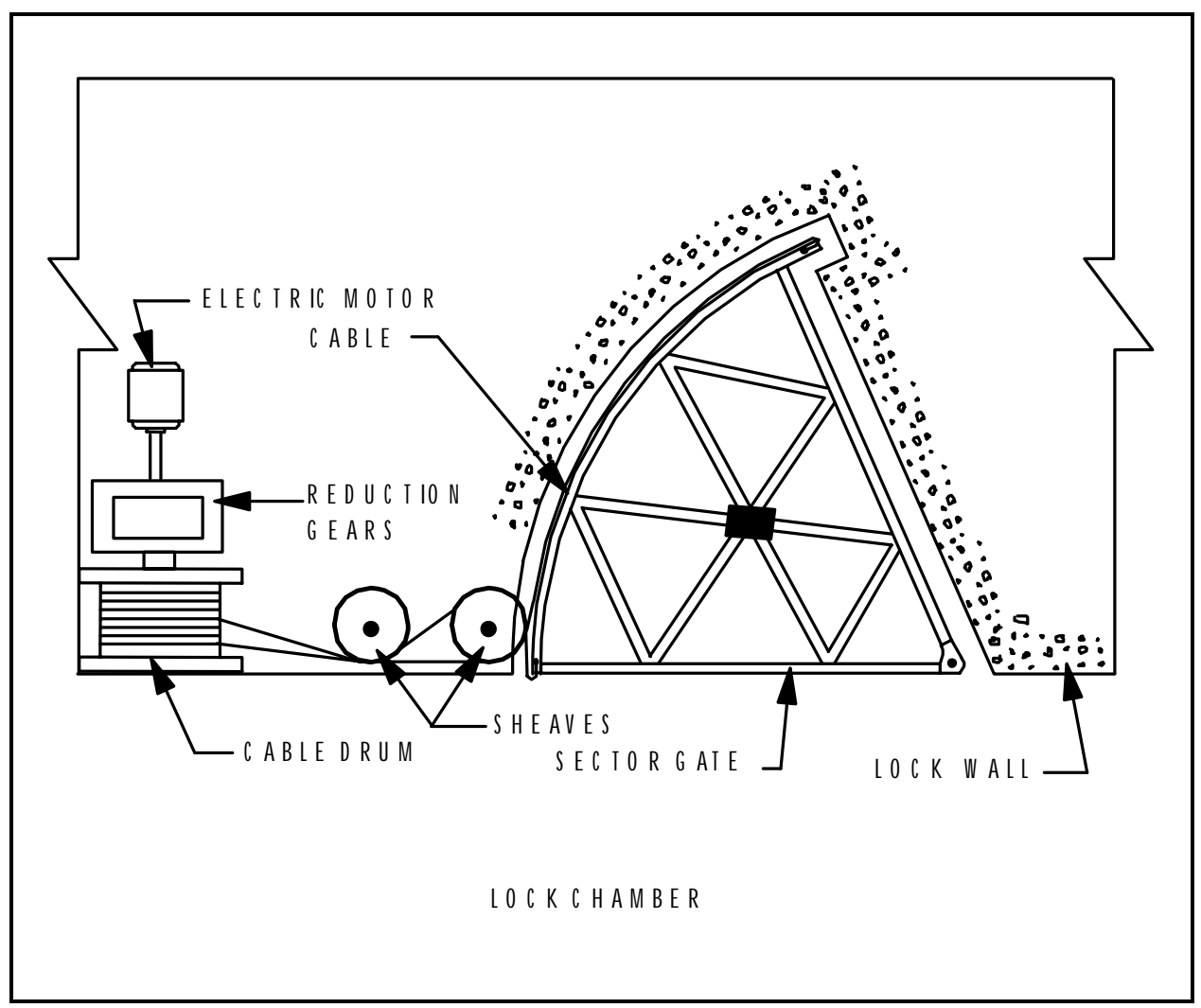

Figure 35. Plan view of sector lock gate operating equipment. 


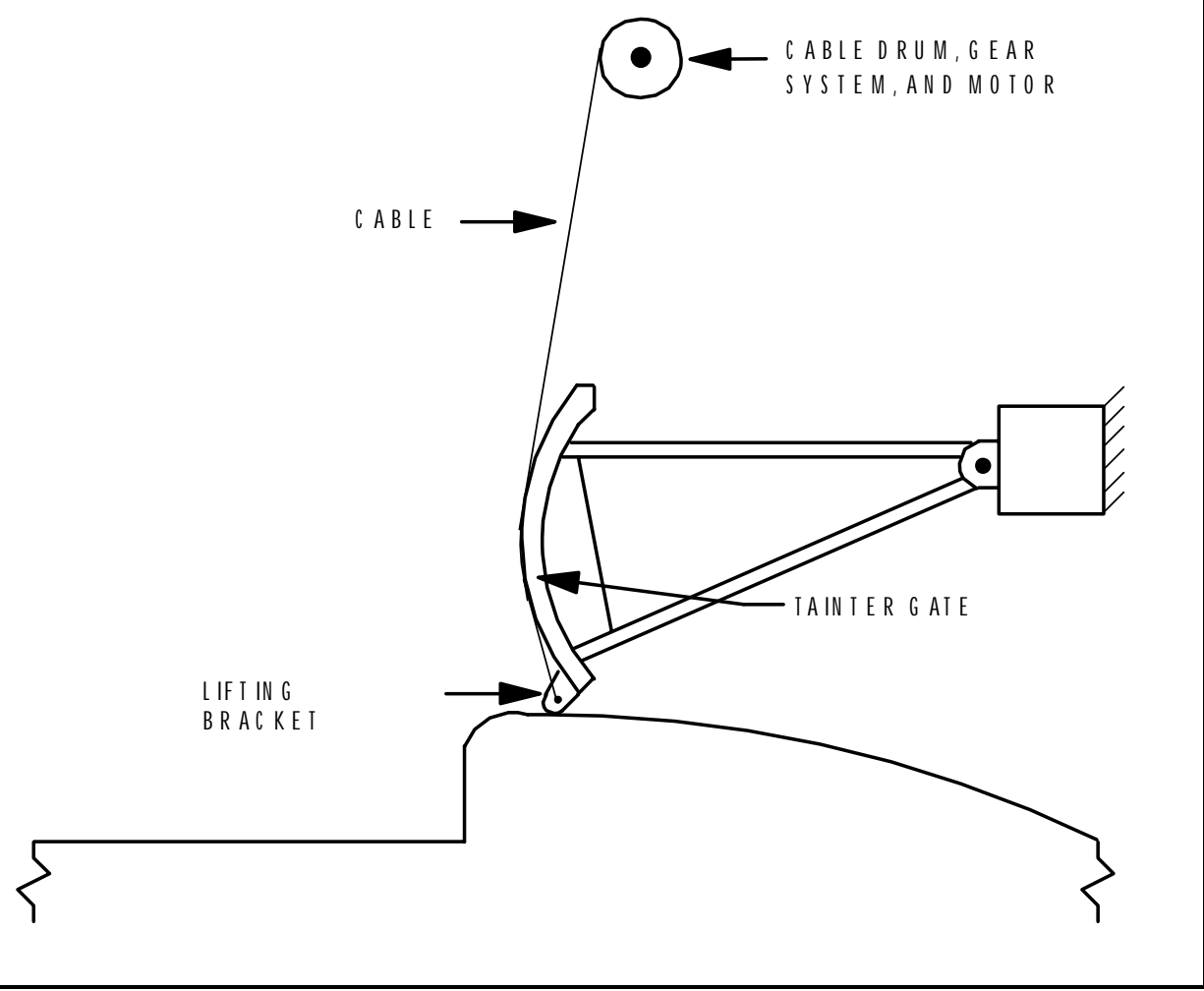

Figure 36. Side view of tainter dam gate operating equipment.

\section{Cable Strand}

The cable strand is composed of several wires wrapped together in various arrangements (Figure 38).

\section{Cable Wire}

The smallest component of the cable is the single steel wire (Figure 38).

\section{Cable Lay}

The cable lay is the length of cable in which a strand makes one complete revolution of the cable (Figure 38).

\section{Cable Drum}

The cable drum is the component around which the cable is wound as the valve structure is raised and lowered or the gate is moved (Figures 35 and 39). 


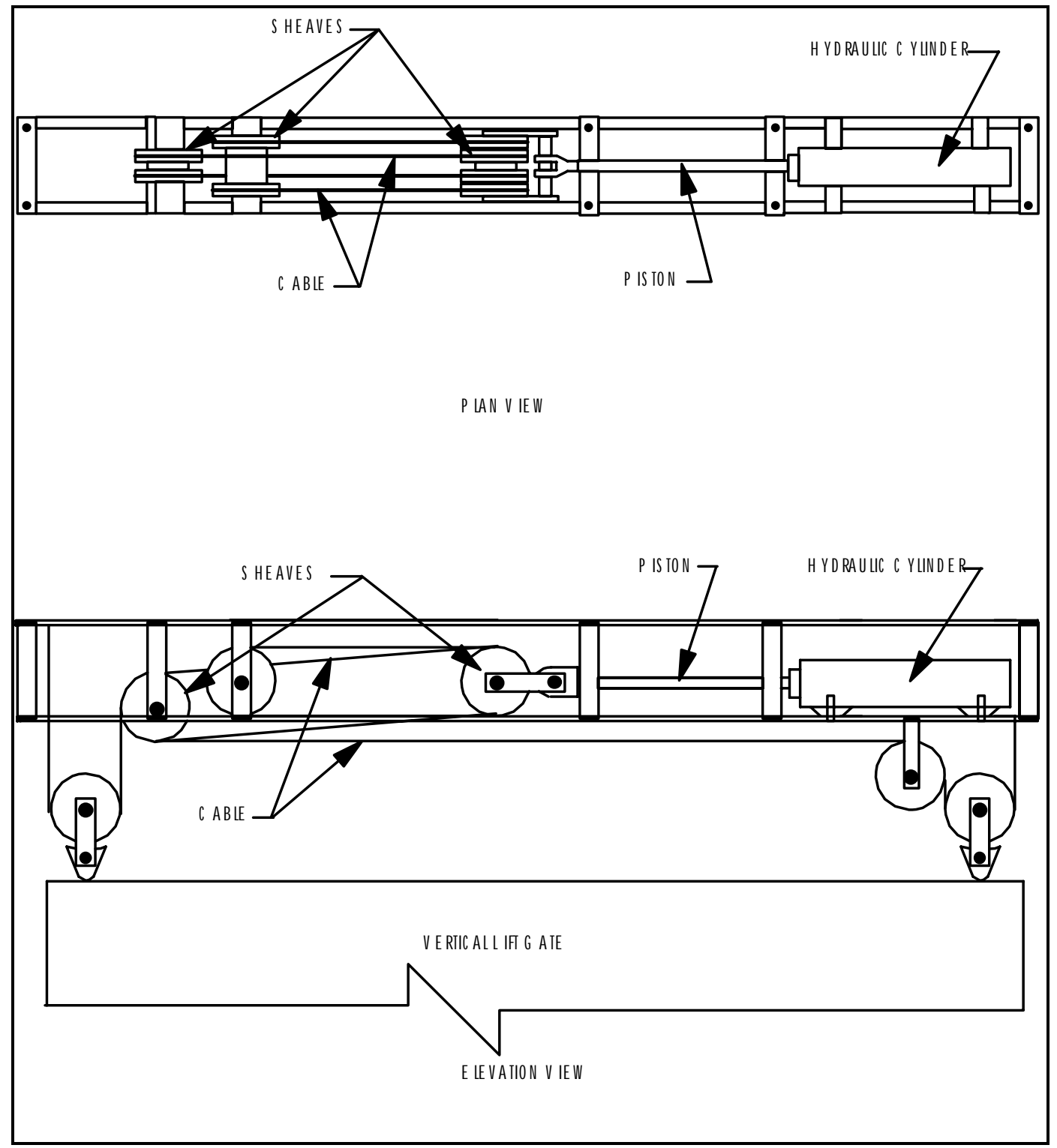

Figure 37. Vertical lift gate operating equipment.

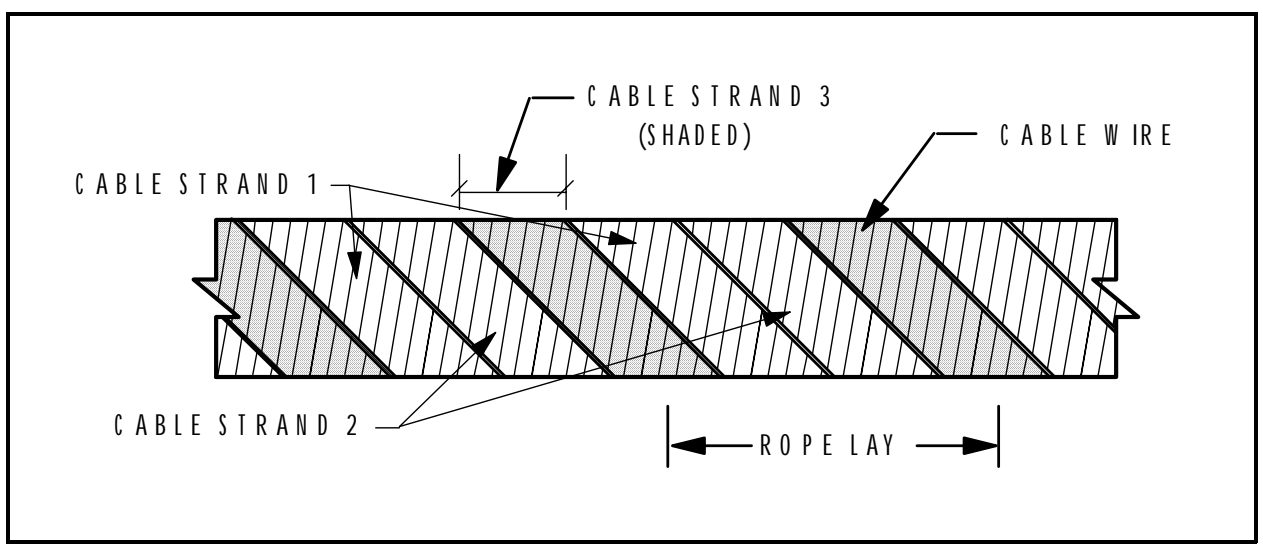

Figure 38. Cable schematic. 


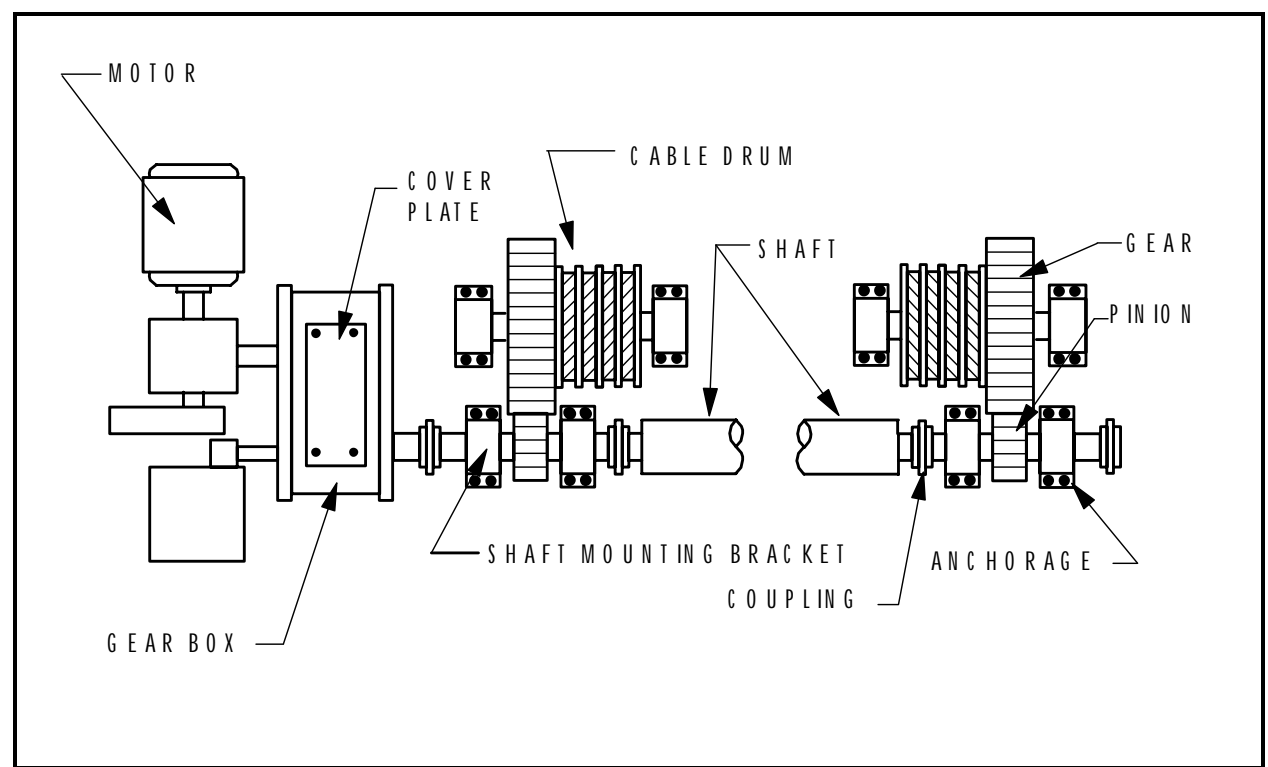

Figure 39. Plan view of tainter gate operating equipment.

\section{Sheave}

The sheave is a wheel with a grooved rim. It is used to redirect the cable (Figures 35 and 37).

Idler/Roller

The idler, or roller, is a pulley used to guide and take up slack in the cable.

\subsection{Inspection Form With Comments}

The following pages are Parts 1, 2, and 3 of the field inspection forms for a cable assembly. The side-by-side arrangement of the opposing pages displays specific explanations (right side) adjacent to the entry on the inspection form (left side). 
Intentionally Blank 


\section{CABLE INSPECTION PART 1}

PROJECT NAME:

DATE:

GATE IDENTIFICATION: (identify the appropriate structure)

Lock Gate
Upper
1. Left Leaf
2. Right Leaf
Lower
1. Left Leaf
2. Right Leaf

Valve
Emptying
1. Left
2. Right
Filling
1. Left
2. Right

Dam Gate

Number

CABLE \# FROM

LEFT

NUMBER OF CABLES IN THE CABLE SET:

FACING

DOWNSTREAM

NOISE, JUMPING, AND VIBRATION

IS IT

NOISE

$(\mathrm{Y} / \mathrm{N})$

JUMPING

$(\mathrm{Y} / \mathrm{N})$

NORMAL

VIBRATION

$\underline{(\mathrm{Y} / \mathrm{N})}$

$(\mathrm{Y} / \mathrm{N})$

$(\mathrm{Y} / \mathrm{N})$

OUTER WIRE WEAR

WORN PORTION?

PERCENTAGE OF WEAR:

LOCATION (from power end (ft)):

REDUCTION IN ROPE DIAMETER

DIAMETER REDUCTION?

$\underline{(\mathrm{Y} / \mathrm{N})}$

NEW DIAMETER (in.):

REDUCED DIAMETER (in.):

LOCATION (from power end (ft)):

$\underline{(\mathrm{Y} / \mathrm{N})}$

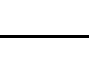

CORROSION

CORROSION?

IF YES, (1) SLIGHT(colored) OR (2) SEVERE (pitted):

LOCATION (from power end (ft)):

IS THE CABLE LUBRICATED PROPERLY:

IS THE CABLE CARBON STEEL(C),

GALVANIZED(G), OR STAINLESS(S):

YEARS SINCE LAST REPLACED:

COMMENTS: 
Part 1 Comments: Field data

Enter the PROJECT NAME for this inspection, the DATE of the inspection, and, for the GATE IDENTIFICATION, identify which gate or valve is being inspected. Also enter the power transfer number (P.T.\#), which can be found on Page 1 of the inspection form.

Indicate the NUMBER OF CABLES IN THE CABLE SET.

Observation of the cable assembly during gate and valve movement is a good indicator of problems. Record any indication of NOISE, JUMPING, and/or VIBRATION during the operation of the structure. Also indicate whether this noise, jumping, and/or vibration is NORMAL.

Record if a WORN PORTION of the outer cable WIRES is evident. If wear is evident, record the average PERCENTAGE of WEAR of the wire diameter on the outer wires. The wear would most likely occur near the drum when the gate is in the opened or closed position. Also indicate the LOCATION of the worn section from the power end (Figure $\left.40^{*}\right)$.

Record if a REDUCTION IN ROPE DIAMETER of the cable is evident. If there is evidence of a reduced diameter, record the NEW DIAMETER and the smallest REDUCED DIAMETER. Look closely at the cable that is near the drum when the gate is in the opened or closed position. The reduction in area of the cable would most likely occur at the point of smallest radius of cable bend. The reduced diameter of the cable can often be checked with cable templates or with the use of calipers. Indicate the LOCATION of the reduced area from the power end (Figure 40).

In steel cables, CORROSION of interior wires in the cable regularly occurs but is difficult to identify. Record any evidence of corrosion such as local discoloring or pitting of the wires. The splash zone is often a problem spot. Indicate whether the corrosion is SLIGHT (slight discoloration) or SEVERE (pitting and/or severe rusting). Indicate the LOCATION from the power end where the corrosion occurs (Figure 40). Record whether the CABLE is LUBRICATED PROPERLY. Indicate the type of cable (CARBON STEEL, GALVANIZED, or STAINLESS). Also record the number of YEARS SINCE the cable has LAST been REPLACED.

* Figures 40 through 43 are placed at the end of this section (beginning on p 124). 
BIRD CAGES, KINKS, AND PROTRUDING CORE

BIRD CAGES(B), KINKS(K), OR

PROTRUDING CORE(P): $\quad(\mathrm{Y} / \mathrm{N})$

IF YES WHICH ONE(S)?

LOCATION (from power end (ft)):

UNLAYED STRANDS

UNLAYED STRANDS:

LOCATION (from power end (ft)):

$\underline{(\mathrm{Y} / \mathrm{N})}$

WIRE BREAKAGE

NUMBER OF BROKEN WIRES IN ONE ROPE LAY:

LOCATION (from power end (ft)):

UNEQUAL TENSION

UNEQUAL CABLE TENSION:

NUMBER OF UNTENSIONED CABLES:

DRUM WEAR

VISIBLE GROOVE WEAR:

$\underline{(\mathrm{Y} / \mathrm{N})}$

IF YES, ESTIMATE DEPTH OF WORN GROOVE IN \% OF CABLE DIAMETER?

IF GREATER THAN 10\%, MEASURED DEPTH OF WORN GROOVE (\%):

SIDE WEAR:

$\underline{(\mathrm{Y} / \mathrm{N})}$

DRUM ANCHORAGE MOVEMENT/DETERIORATION

MOVEMENT:

CORROSION:

CRACKED CONCR.:

EXPOSED BOLTS:

IF YES (Y), THEN IS THERE ------->

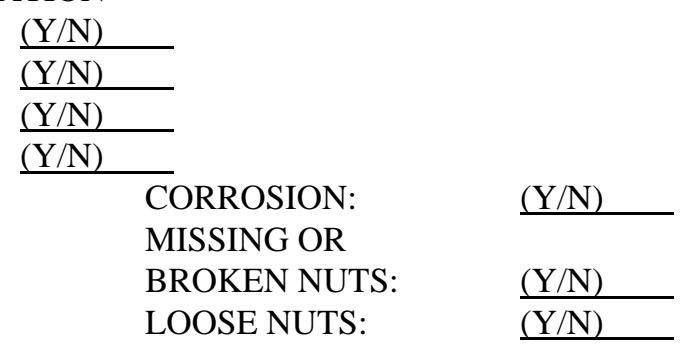

ARE THERE ANY SHEAVES IN THE CABLE ASSEMBLY(Y/N)?

IF YES, COMPLETE THE FOLLOWING QUESTIONS ON SHEAVES

SHEAVE WEAR SHEAVE NUMBER:

1

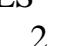

VISIBLE GROOVE WEAR(Y/N):

IF YES, ESTIMATE DEPTH OF WORN

GROOVE IN \% OF CABLE DIAMETER?

IF GREATER THAN 10\%,

MEASURED DEPTH OF WORN GROOVE (\%):

SIDE WEAR $(\mathrm{Y} / \mathrm{N})$ :

SHEAVE BEARING/BUSHING WEAR

DOES THE SHEAVE WOBBLE (Y/N):

LATERAL DISPLACEMENT OF SHEAVE

WHEN PRYING:

RADIUS OF SHEAVE(ft): 
Part 2 Comments: Field data

A BIRD CAGE is a local area of unraveled portion of the cable (Figure 41). Record the existence of BIRD CAGES, KINKS, OR PROTRUDING CORES (Figure 42) on the inspection form. Indicate the type of distress (a bird cage, a kink, or a protruding core) if one of the three exists. Also record the LOCATION from the power end that this distress occurs (Figure 40).

Record any existence of UNLAYED cable STRANDS. Unlayed strands occur when the cable rubs against an object. Unlayed strands are the strands displaced from the uniformly distributed manufactured position. Also indicate the LOCATION of the unlayed strands from the power end (Figure 40).

Record the maximum number of BROKEN WIRES in all strands of any ONE ROPE LAY (Figure 38). Also indicate the LOCATION of the broken wires from the power end of the cable (Figure 40).

For cable sets with more than one cable, observe the cable and indicate if UNEQUAL TENSION occurs in each CABLE. Cable tension can be tested by applying equal force perpendicular to the length of each cable and observing the displacement of the cable in the direction of the force. The displacements should be equal if the cable tension is equal. Cable tension can also be tested by observing the vibration in each cable as wind or other disturbance vibrates the cable. If the cable tension for a cable is unequal, the vibrations in the cables could occur at different frequencies. The tension can also be tested by striking each cable separately and listening to the frequency of each cable. Cables with equal tension will have the same frequency. Also record the NUMBER of CABLES that have no or little tension.

For DRUMS, record if there is VISIBLE GROOVE WEAR. Groove wear is the wearing of the bottom of the grooves. If there is groove wear, estimate the DEPTH OF the GROOVE WEAR in percentage of the CABLE DIAMETER. If the estimate of groove wear is GREATER THAN 10\% of the cable diameter, use an appropriate method to MEASURE the groove wear. Groove wear can be measured by placing a cable groove template into the groove and observing the gap between the bottom of the groove and the template. A similar procedure that can be used is to place a piece of new cable into the groove and to measure the gap. Indicate whether there is SIDE WEAR on the drum. If the cable is misaligned, the guide plates will show the imprint of the cable (Figure 43).

Record any evidence of MOVEMENT at the DRUM ANCHORAGE as the gate or valve is opened and closed. Evidence of movement can be observed visually or enhanced by placing a dial gage to monitor any movement. A dial gage change greater than 0.002 in. is considered movement. Excessive concrete spalling may indicate a displacement occurred at this location at some time. Also, record the presence of any CORROSION ( $10 \%$ volume loss) of the steel portion or any CRACKED CONCRETE at the interface of the embedment. Small hairline cracks, probably caused by thermal expansion or contraction of the concrete, should be ignored. Indicate if there are any CORRODED (10\% volume loss), MISSING OR BROKEN, or LOOSE nuts at this connection if the BOLTS are EXPOSED. 


\section{CABLE INSPECTION PART 2}

BIRD CAGES, KINKS, AND PROTRUDING CORE

BIRD CAGES(B), KINKS(K), OR

PROTRUDING CORE(P): $\quad(\mathrm{Y} / \mathrm{N})$

IF YES WHICH ONE(S)?
LOCATION (from power end (ft)):

UNLAYED STRANDS

UNLAYED STRANDS:

LOCATION (from power end (ft)):

$(\mathrm{Y} / \mathrm{N})$

WIRE BREAKAGE

NUMBER OF BROKEN WIRES IN ONE ROPE LAY:

LOCATION (from power end (ft)):

UNEQUAL TENSION

UNEQUAL CABLE TENSION:

NUMBER OF UNTENSIONED CABLES:

\section{$(\mathrm{Y} / \mathrm{N})$}

DRUM WEAR

VISIBLE GROOVE WEAR:

$\underline{(\mathrm{Y} / \mathrm{N})}$

- $\quad$ IF YES, ESTIMATE DEPTH OF WORN GROOVE IN \% OF CABLE DIAMETER?

IF GREATER THAN 10\%, MEASURED DEPTH OF WORN GROOVE (\%):

SIDE WEAR:

$\underline{(\mathrm{Y} / \mathrm{N})}$

DRUM ANCHORAGE MOVEMENT/DETERIORATION

$\begin{array}{lc}\text { MOVEMENT: } & \frac{(\mathrm{Y} / \mathrm{N})}{(\mathrm{Y} / \mathrm{N})} \\ \text { CORROSION: } & \frac{(\mathrm{Y} / \mathrm{N})}{\text { CRACKED CONCR.: }} \\ \text { EXPOSED BOLTS: } & \frac{(\mathrm{Y} / \mathrm{N})}{\text { IF YES (Y), THEN IS THERE -------> }}\end{array}$

CORROSION:

$\underline{(\mathrm{Y} / \mathrm{N})}$

MISSING OR

BROKEN NUTS:

LOOSE NUTS:

$(\mathrm{Y} / \mathrm{N})$

$\underline{(\mathrm{Y} / \mathrm{N})}$

ARE THERE ANY SHEAVES IN THE CABLE ASSEMBLY(Y/N)?

IF YES, COMPLETE THE FOLLOWING QUESTIONS ON SHEAVES

SHEAVE WEAR SHEAVE NUMBER:

12

VISIBLE GROOVE WEAR(Y/N):

IF YES, ESTIMATE DEPTH OF WORN

GROOVE IN \% OF CABLE DIAMETER?

IF GREATER THAN $10 \%$,

MEASURED DEPTH OF WORN GROOVE (\%):

SIDE WEAR (Y/N):

SHEAVE BEARING/BUSHING WEAR

DOES THE SHEAVE WOBBLE $(\mathrm{Y} / \mathrm{N})$ :

LATERAL DISPLACEMENT OF SHEAVE

WHEN PRYING:

SHEAVE RADIUS(ft):

Part 2 Comments: Field data (continued) 
The FOLLOWING QUESTIONS ON SHEAVES should be answered only if there ARE SHEAVES IN THE CABLE ASSEMBLY.

Record if there is VISIBLE GROOVE WEAR. Groove wear is the wearing of the bottom of the grooves. If there is groove wear, estimate the DEPTH OF the WORN GROOVE in percentage of the CABLE DIAMETER. If the estimate of groove wear is GREATER THAN $10 \%$ of the cable diameter, use an appropriate method to MEASURE the groove wear. Groove wear can be measured by placing a cable groove template into the groove and observing the gap between the bottom of the groove and the template. A similar procedure that can be used is to place a new cable into the groove and to measure the gap. Also indicate whether there is SIDE WEAR on the sheave.

Record if there is SHEAVE BEARING/BUSHING WEAR. Bearing and bushing wear can be observed by placing a pry bar between the sheave and a solid surface or watching the sheave during operation and checking for WOBBLE. Also record the LATERAL DISPLACEMENT observed when PRYING the SHEAVE. 


\section{CABLE INSPECTION PART 3}

SHEAVE ANCHORAGE MOVEMENT/DETERIORATION
SHEAVE NUMBER:
MOVEMENT(Y/N):

IDLERS/ROLLERS WEAR

ARE THERE ANY IDLERS OR ROLLERS IN THE CABLE ASSEMBLY(Y/N)?

IF YES, THEN ANSWER THE FOLLOWING QUESTIONS FOR IDLERS AND ROLLERS IDLER/ROLLER NUMBER:

$\begin{array}{llll}1 & \underline{3} & \underline{4}\end{array}$

ARE IDLERS/ROLLERS

WORKING PROPERLY $(\mathrm{Y} / \mathrm{N})$ :

IF NO, IS THE CABLE

BEING DAMAGED(Y/N):

GATE OR VALVE CONNECTION MOVEMENT

IS THE GATE OR VALVE CONNECTION OBSERVABLE(Y/N)?

IF YES, ESTIMATE THE MOVEMENT(in.):(0, 1/8, 1/4, 3/8, 1/2):

COMMENTS: 


\section{Part 3 Comments: Field data}

Record any evidence of MOVEMENT greater than 0.002 in. at the SHEAVE ANCHORAGE as the gate is opened and closed. Evidence of movement can be observed visually or enhanced by placing a dial gage to monitor any movement. Excessive concrete spalling may indicate a displacement occurred at this location at some time. Also, record the presence of any CORROSION (10\% volume loss) of the steel portion or any CRACKED CONCRETE at the interface of the embedment. Small hairline cracks, probably caused by thermal expansion or contraction of the concrete, should be ignored. Indicate if there are any CORRODED (10\% volume loss), MISSING OR BROKEN, or LOOSE nuts at this connection if the BOLTS are EXPOSED.

Record whether there ARE ANY IDLERS OR ROLLERS IN THE CABLE ASSEMBLY being inspected. IF YES, record whether the IDLERS and/or ROLLERS are WORKING PROPERLY. Idlers and rollers should rotate freely and should not wobble as the cable passes through them. If the idlers or rollers are not functioning properly, record if the CABLE is being DAMAGED by the malfunction of the idlers or rollers.

Record whether the GATE OR VALVE CONNECTION IS OBSERVABLE. IF YES, record the evidence of GATE OR VALVE CONNECTION MOVEMENT by estimating the relative movement to the nearest $1 / 8$ in. between the gate or valve and the end of the cable (Figure 27). 


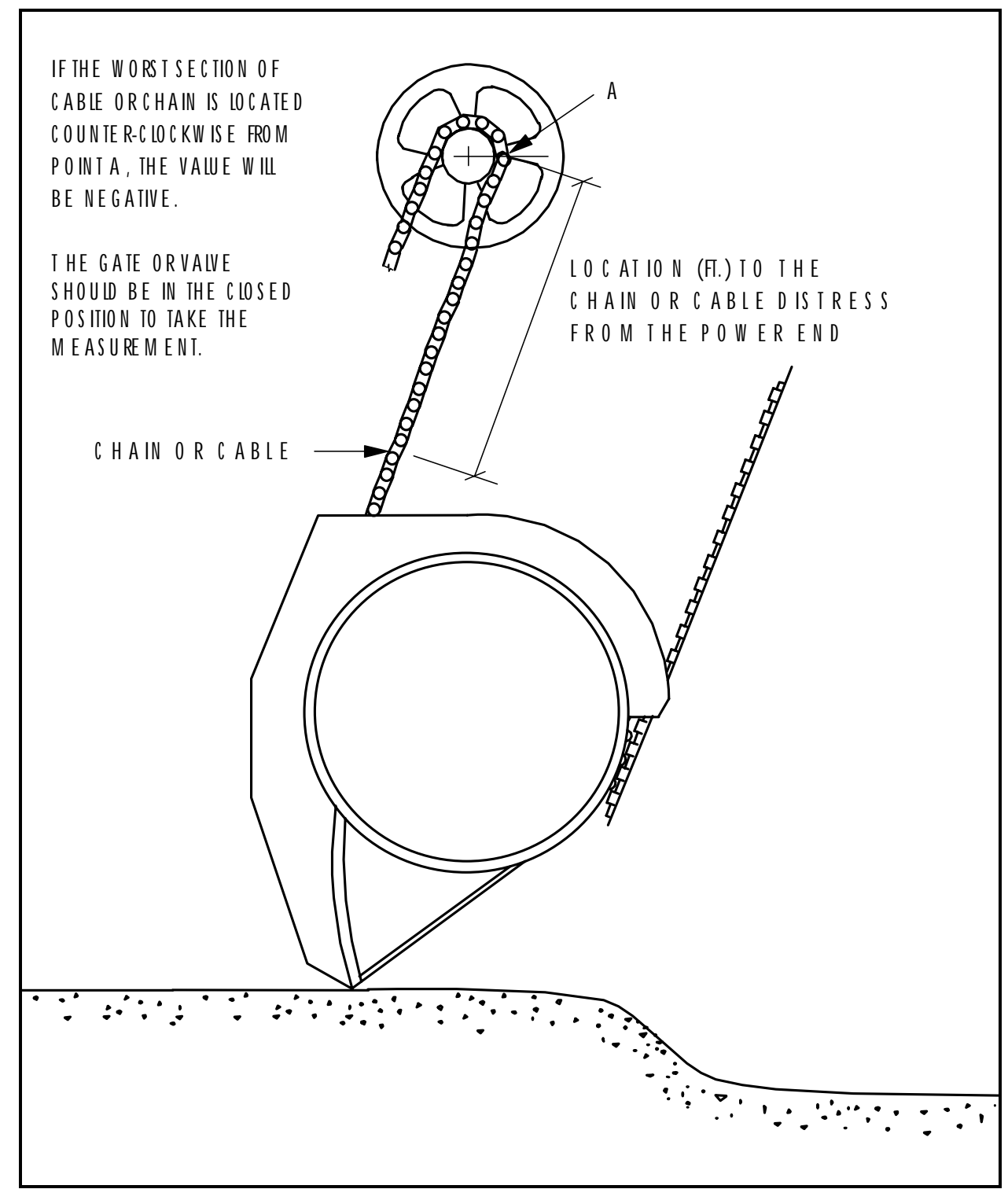

Figure 40. Location identification for cable and chain distresses.

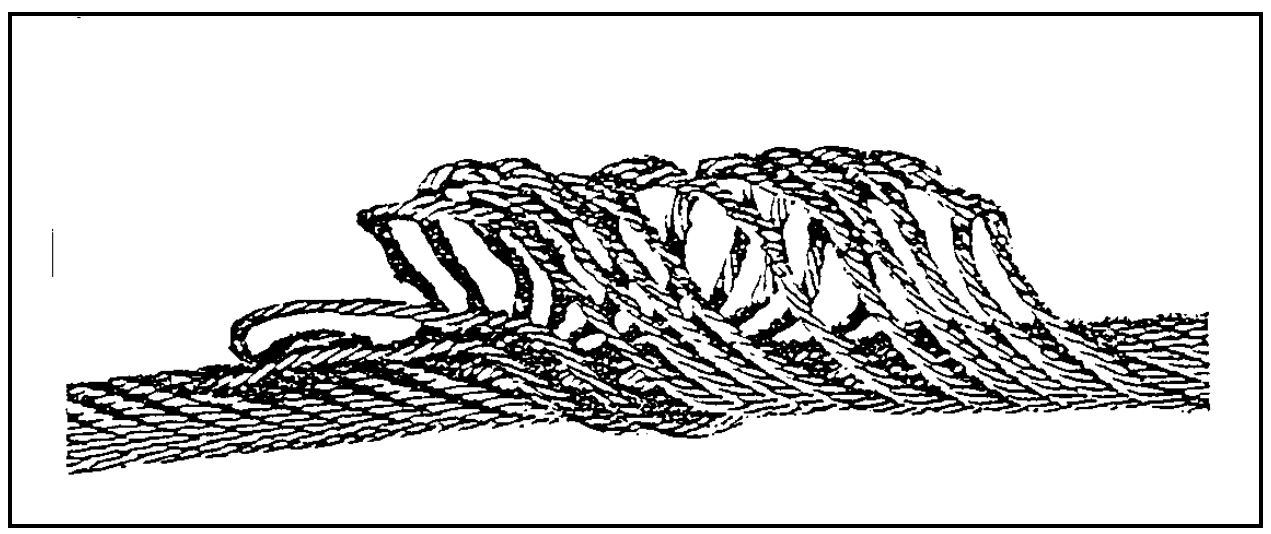

Figure 41. Cable bird cage. 


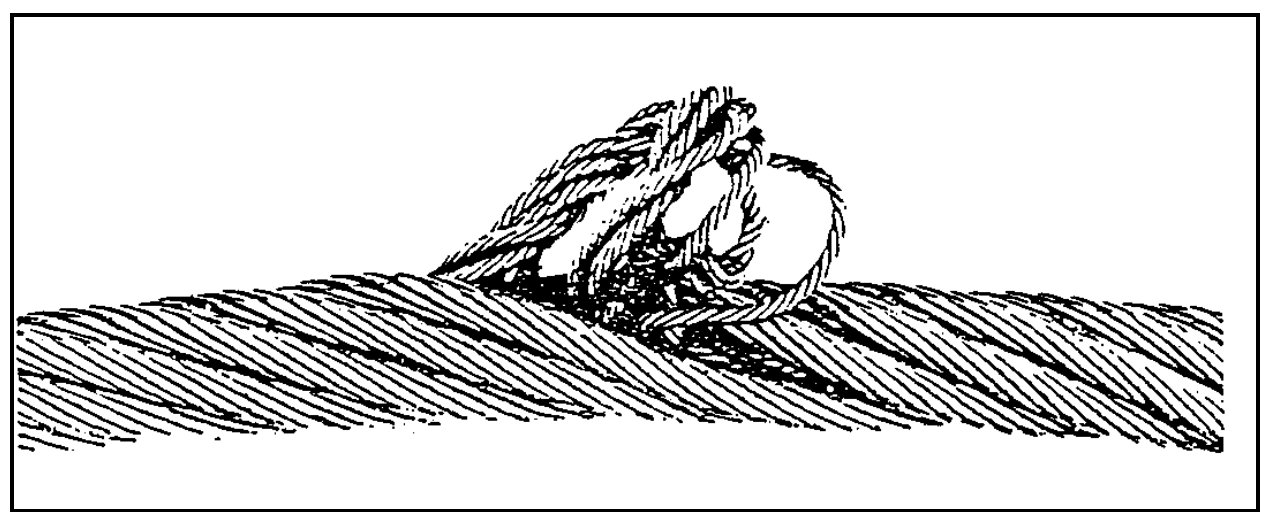

Figure 42. Cable protruded core.

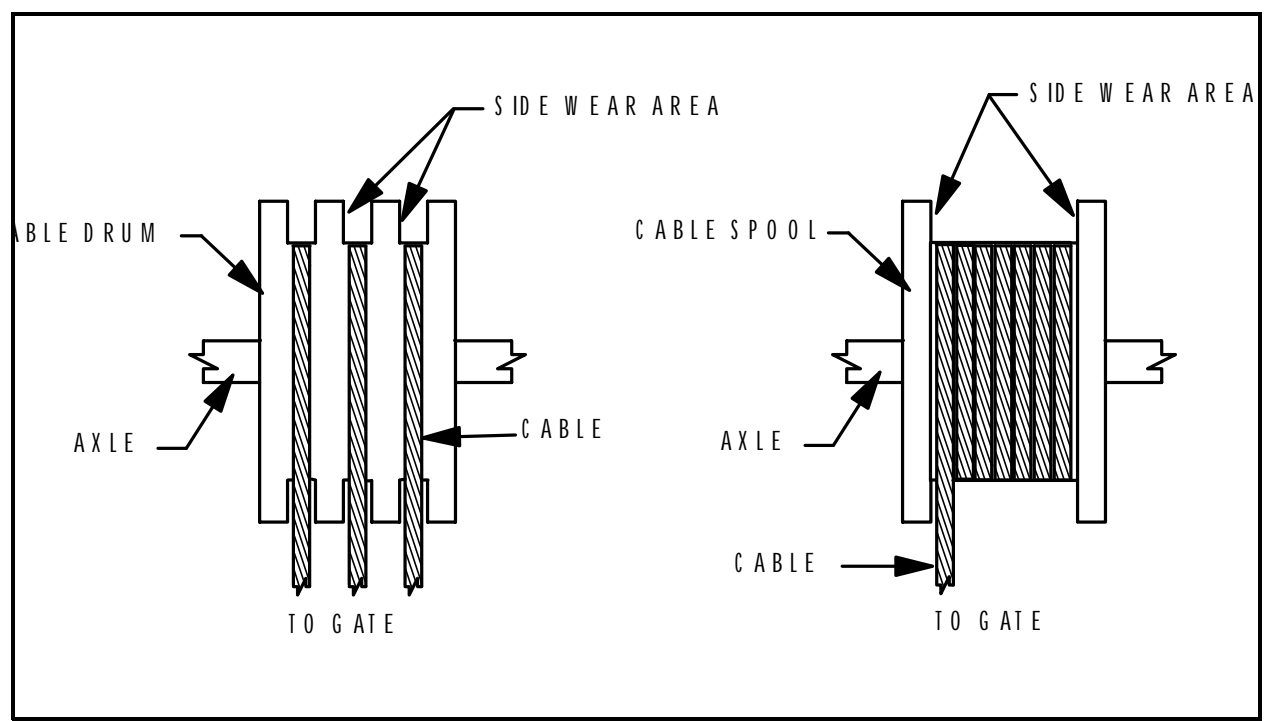

Figure 43. Cable drum wear.

\subsection{Condition Index}

The following section contains the rules for calculating the individual CIs for the cable assembly distresses. Distress descriptions and example illustrations are also provided.

\section{Noise, Jumping, and Vibration}

See noise, jumping, and vibration for the exposed gear assembly (Chapter 4, $\mathrm{p}$ $51)$.

\section{Outer Wire Wear}

Definitions and causes. Wire wear is the reduction in diameter of the cable wires. Wear occurs when the cable moves over drums or through abrasive mediums. 
Measurements and limits. The percentage of wear on the outer wires, $\mathrm{X}$, is recorded. The limiting value for this distress is:

$$
x_{\text {MAX }}=33 \%
$$

(U.S. Army Corps of Engineers, 1987).

Example: The outer wires of a cable were worn an average of $20 \%$. The CI for the cable wear distress is:

$$
C I=100(0.4)^{(20 / 33)}=57
$$

The $\mathrm{CI}$ is rated Marginal.

\section{Reduction in Rope Diameter}

Definition and causes. A reduction in the cable diameter may be attributed to excessive external abrasion, internal or external corrosion, loosening or tightening of rope lay, inner wire breakage, and/or rope stretch.

Measurement and limits. The new diameter of the cable, $\mathrm{X}_{\mathrm{NEW}}$, and the diameter at the minimum cross section, $\mathrm{X}_{\mathrm{WORN}}$, are recorded on the inspection form. The difference between these diameters is:

$$
x=x_{N E W}-x_{\text {WOR N }}
$$

The values for $\mathrm{X}_{\mathrm{MAX}}$ are:

$\begin{array}{ll}\text { Original Diameter of Cable } & \underline{X}_{\operatorname{MAX}} \\ \text { up to } 3 / 4 \text { in. } & 3 / 64 \text { in. } \\ 7 / 8 \text { in. to } 1-1 / 8 \text { in. } & 1 / 16 \text { in. } \\ 1-1 / 4 \text { in. and up } & 3 / 32 \text { in. }\end{array}$

(U.S. Army Corps of Engineers, 1987).

Example: The inspection of a cable assembly revealed significant reduction in diameter of the cable. The new and current diameters were:

$$
x_{N E W}=1 \text { in. }
$$




$$
x_{\text {कО } ⿻ \text { ค }}=31 / 32 \text { in. }
$$

Equation 9.2 gives the difference between these diameters:

$$
x=1 \mathrm{in} .-31 / 32 \mathrm{in} .=1 / 32 \mathrm{in} .
$$

With the original diameter between $7 / 8$ in. and 1-1/8 in., $\mathrm{X}_{\mathrm{MAX}}$ is $1 / 16$ in. The $\mathrm{CI}$ is calculated with Equation 2.1:

$$
C 1=\left[100(0.4)^{(1 / 32) /(1 / 16)}\right]=63
$$

This CI is rated Fair.

\section{Corrosion}

Definition and causes. Corrosion of cables can cause sudden failure with little warning, and as cables often corrode from the inside out, it is important to determine if any internal corrosion is occurring. Corrosion of cables is caused by interaction with the environment and a lack of lubrication.

Measurement and limits. If slight corrosion is evident (e.g., slight discoloring), the CI will be 70. However, if the cable has pitting or severe rusting, the CI will be 40 (Committee of Wire Rope Producers, 1979).

Example: While inspecting the cable near the splash zone in a cable assembly, severe rusting was detected. The $\mathrm{CI}$ for corrosion is:

$$
C 1=40
$$

The CI is rated Marginal.

\section{Bird Cages, Kinks, and Protruding Core}

Definition and causes. A bird cage is a local area of severely unraveled cable (Figure 41). Bird cages form when slack develops in the cable and that slack is suddenly removed. Bird cages can also be formed when the cable is wrapped too tightly around drums. Kinks are permanent distortions caused by loops being drawn too tightly. A protruding core occurs when the center strand protrudes through the outer strands (Figure 42). 
Measurement and limits. The existence of bird cages, kinks, and protruding cores is recorded in the inspection form. If one or any combination of these three distresses occurs, the CI will be 40 (U.S. Army Corps of Engineers, 1987).

Example: A kink was found in a cable assembly during an inspection. The CI for this distress is:

$$
c 1=40
$$

The CI is rated Marginal.

\section{Unlayed Strands}

Definition and causes. A cable is comprised of several uniformly distributed individual strands. Sometimes the strands become displaced along one side of the rope. These displacements can be caused by rubbing around or against an object.

Measurement and limits. The existence of any unlayed strands are recorded in the inspection form. If unlayed strands exist the CI will be 40 .

Example: Several unlayed strands were found during a cable assembly inspection.

The CI for the unlayed strands is:

$$
c 1=40
$$

The rating for this $\mathrm{CI}$ is Marginal.

\section{Wire Breakage}

Definition and causes. This distress deals with the number of broken wires in a length of cable known as a rope lay. Broken wires can be caused by excessive loads, fatigue, and wear.

Measurement and limits. The maximum number of broken wires, $\mathrm{X}$, in all of the strands within any one rope lay are recorded for each cable set. The limiting value of broken wires per rope lay is:

$$
x_{\text {MAX }}=6
$$

(U.S. Army Corps of Engineers, 1987). 
Example: Four broken wires were found in one rope lay of a cable. The CI for broken wires is:

$$
c I=\left[\begin{array}{lllll}
1 & 0 & 0 & (0.4)^{4 / 6}
\end{array}\right]=54
$$

The CI is rated Marginal.

\section{Unequal Tension}

Definition and causes. For a cable operated structure to be operating properly, the cables should have equal tension. For multiple cables, it is important that all the cables be tensioned uniformly. Some cables may be overstressed if the load is not evenly distributed.

Measurement and limits. The number of cables that are relatively untensioned, $\mathrm{X}$, is recorded in the inspection form. The limiting value for untensioned cables is:

$$
x_{\text {MAX }}=1
$$

Example: One cable had a different frequency when struck than the other cables in the set, signaling unequal tension. The CI for unequal tension is:

$$
c I=\left[\begin{array}{llllll}
1 & 0 & 0 & (0.4)^{1 / 1}
\end{array}\right]=40
$$

This CI is rated Marginal.

\section{Drum Wear}

Definition and causes. Drum wear is the reduction of steel in the cable drum through wearing. The cause for this wearing is the misalignment of the cable and drum during operation and wear due to normal use.

Measurement and limits. The existence of drum wear or damage is recorded in the inspection form. If drum wear exists, an estimate of the groove wear is recorded. The groove wear is given in percentage of the cable diameter. If the estimated groove wear is less than 10 percent the $\mathrm{CI}$ is 70 . If the estimated groove 
wear is equal to or greater than 10 percent, the wear is measured. The limiting value for groove wear is:

$$
x_{\text {MAX }}=25 \%
$$

If side wear is evident, the CI must be less than or equal to 70 (Department of the Army Hydroelectric Design Center, North Pacific Division, Army Corps of Engineers, 1993).

Example: Drum wear was evident on a cable assembly. The estimated percentage of groove wear was 20 percent. The wear was then measured with a template and was found to be 15 percent. The $\mathrm{CI}$ for drum wear is:

$$
C_{1}=\left[\begin{array}{lllll}
1 & 0 & 0 & (0.4)^{15 / 25}
\end{array}\right]=58
$$

This CI is rated Fair.

\section{Cable Drum Anchorage Movement/Deterioration}

See anchorage movement/deterioration for the exposed gear assembly (Chapter 4, p 51).

\section{Sheave Wear}

See drum wear for the cable assembly (Chapter 9, p 130).

\section{Sheave Bearing/Bushing Wear}

See bearing/bushing wear for the exposed gear assembly (Chapter 4, p 52).

\section{Sheave Anchorage Movement/Deterioration}

See anchorage movement/deterioration for the exposed gear assembly (Chapter 4, p 51).

\section{Idlers/Rollers Wear}

Definitions and causes. The distress for idlers and rollers is the wear or wobbling of the idlers or rollers. As a groove is worn in the idler or roller, the rate of wear in the cable increases. Wobbling of the idler or roller can cause the cable to 
untrack. Wear and wobbling can be caused by normal use and improper lubrication. Wobbling can also be caused by wear between the idler or roller and the shaft on which it rotates.

Measurements and limits. If the idlers or rollers do not work properly, but are not causing damage to the cable, the $\mathrm{CI}$ is 70 . If damage is occurring to the cable because the idlers or rollers are not working properly, the CI is 40 .

Example: A deep groove was cut in an idler, causing extensive damage to the cable.

The CI for idlers/rollers is:

$$
c_{1}=40
$$

The $\mathrm{CI}$ is rated Marginal.

\section{Gate or Valve Connection Movement}

See end connection movement for the strut arm assembly (Chapter 7, p 97).

\section{Assembly Cl}

The assembly CI will be calculated with Equations 2.2, 2.5, and 2.6 (See Chapter 2, Assembly Distress). The two critical distresses in the cable assembly are the bird cage, kink, or protruding core distress and the wire breakage distress. The CIs from the remaining 13 distresses will be used to calculate the weighted $\mathrm{CI}_{\mathrm{w}}$ (Equation 2.5). The weighting factors for those 13 distresses are in Table 18.

\subsection{Field Test}

The bar charts in Figures 44 and 45 compare the experts' subjective CI from the various field tests to the CI calculated from the rules in Section 9.3 for two cable distresses. Only data from assemblies with observed distresses were plotted. Comparisons between the calculated and experts' average CIs are summarized below.

\section{Noise, Jumping, and Vibration}

The noise, jumping, and vibration distress was not calibrated because noise, jumping, or vibration was not observed in cables. Hence, the calculated CIs were all 100, and the experts' average CIs were 90 or above. The noise, jumping, and 


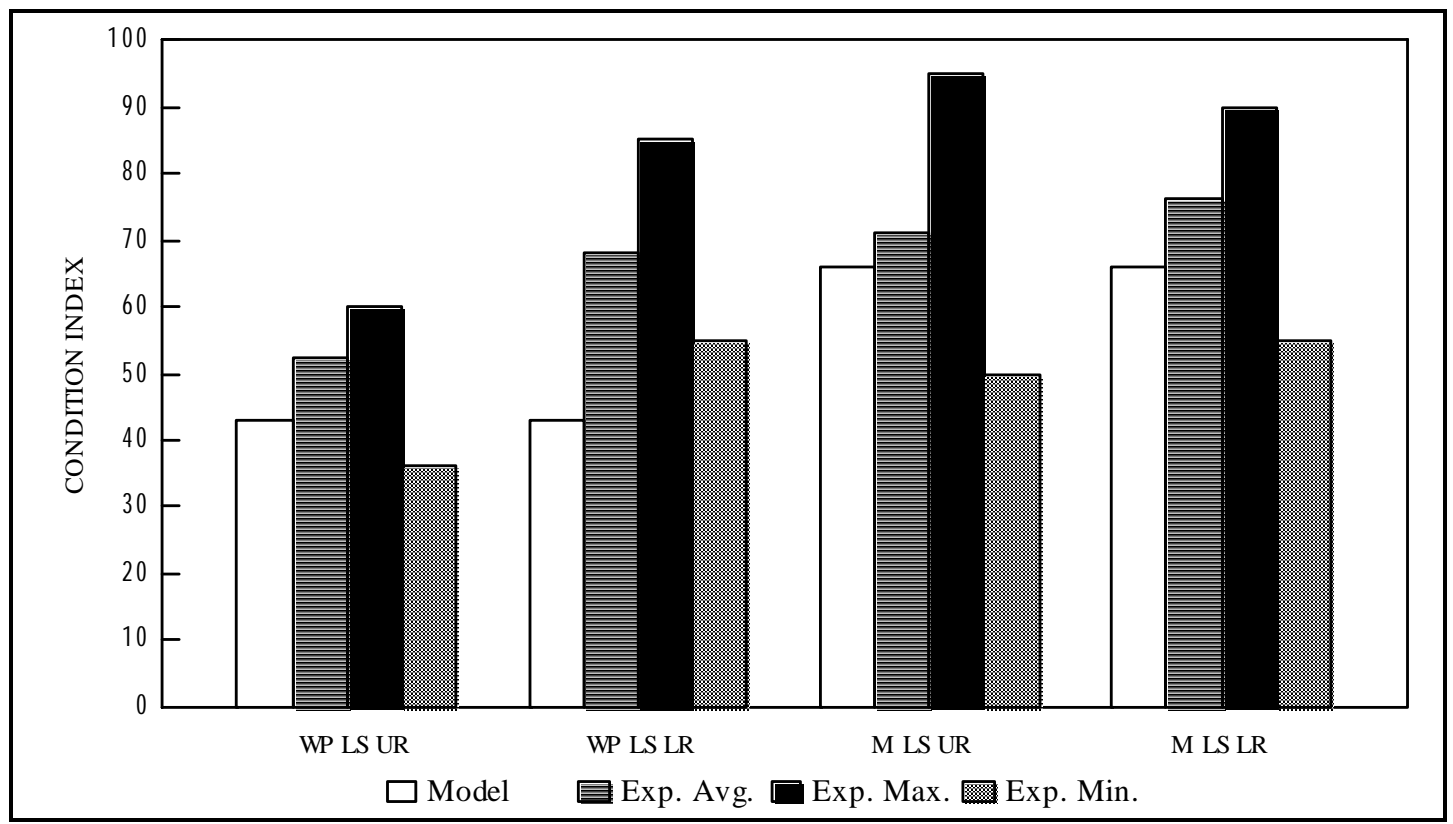

Figure 44. Outer wire wear: cable assembly.

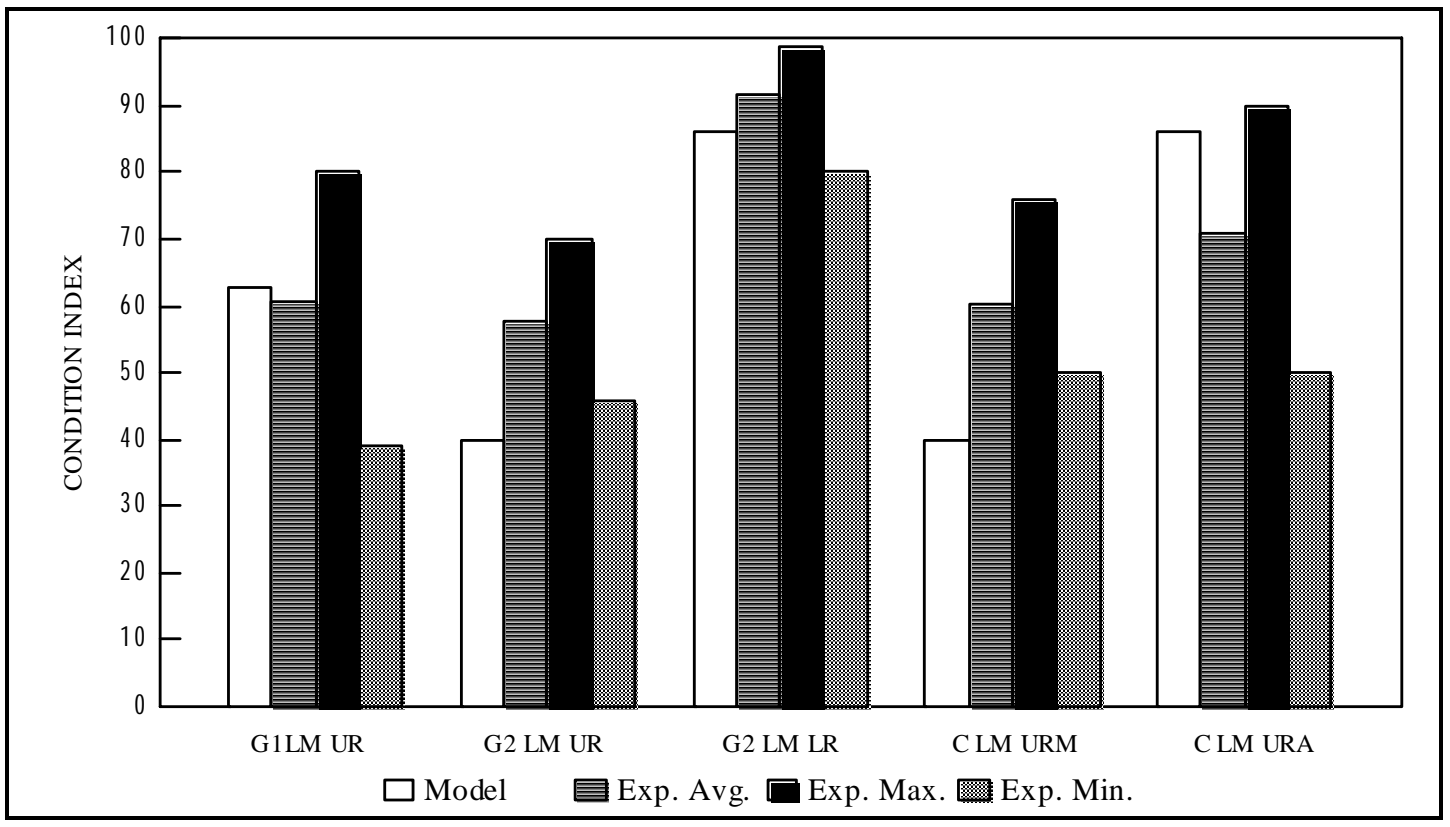

Figure 45. Wire breakage: cable assembly.

vibration distress was calibrated in the enclosed gear assembly, and those calculated CIs closely approximated the experts' averages.

\section{Outer Wire Wear: Figure 44}

The outer wire wear distress was observed in four of the 22 assemblies that were inspected during the field tests. For the remaining 18 assemblies, the calculated CIs were 100, and the experts' average CIs were 90 or above. In the four assemblies for which wire wear was observed (Upper Right Sector Lock Gate W.P. 
Franklin, Lower Right Sector Lock Gate W.P. Franklin, Upper Right Sector Lock Gate Moorehaven, and Lower Right Sector Lock Gate Moorehaven), the assemblies were used to operate sector lock gates. In all four cases, the experts' average CI was higher than the calculated CI; however, in three of those cases, the experts' average CI was within 10 points of the calculated CI. Because the value of $\mathrm{X}_{\mathrm{MAX}}$ was taken from the Safety and Health Requirements Manual (USACE 1987), it will not be adjusted.

\section{Reduction in Rope Diameter}

The reduction in rope diameter was observed in three cable assemblies during the field tests. The measurement technique used to determine the amount of reduction, however, was inaccurate. A new technique is now described in Section 9.2. While this distress cannot be calibrated, the value of $\mathrm{X}_{\mathrm{MAX}}$ was taken from the Safety and Health Requirements Manual (USACE 1987).

\section{Corrosion}

The corrosion distress was not calibrated because corrosion was not observed in cables. Hence, the calculated CIs were all 100, and the experts' average CIs were 90 or above. While this distress cannot be calibrated, the rule for the corrosion of the cable assembly was based on the Safety and Health Requirements Manual (USACE 1987).

\section{Bird Cages, Kinks, and Protruding Core}

The bird cages, kinks, and protruding core distress was not calibrated because the cable assemblies observed did not show this type of damage. Hence, the calculated CIs were all 100, and the experts' average CIs were 90 or above. Although this distress was not calibrated, the experts agree with the Wire Rope Users Manual (Committee of Wire Rope Producers 1979), which states that wire rope should be replaced immediately if any one of these three types of damage exists in the cable. This corresponds well to the rule in Section 9.3 for this distress.

\section{Unlayed Strands}

The unlayed strands distress was not calibrated because no unlayed strands were observed in cables during the field tests. Hence, the calculated CIs were all 100 , and the experts' average CIs were 90 or above. 


\section{Wire Breakage: Figure 45}

Broken wires were observed in five of the 22 cables assemblies inspected during the field trips. The calculated CIs were 100, and the experts' average CIs were 90 or above for all 22 assemblies for which wire breakage was not observed. For the five cable assemblies for which broken wires were observed, the calculated CIs were higher than the experts' average CIs for two cases and were lower on the remaining three cases. The rule in Section 9.3 for wire breakage was based on the Wire Rope Users Manual (Committee of Wire Rope Producers 1979).

\section{Unequal Tension}

The equal tension distress was not calibrated because unequal tension was not observed in cables during the field tests. Hence, the calculated CIs were all 100, and the experts' average CIs were 90 or above.

\section{Drum Wear}

The drum wear distress was not calibrated because drum wear in the cable drums was not observed during the field tests. Hence, the calculated CIs were all 100 and the experts' average CIs were 90 or above. Although the drum wear distress was not calibrated, the current rule is based on discussion with the experts.

\section{Drum Anchorage Movement/Deterioration}

The drum anchorage movement/deterioration distress was not calibrated because no movement or deterioration was detected in any of the drum anchorages. Hence, the calculated CIs were all 100 and the experts' average CIs were 90 or above. The anchorage movement/deterioration distress was calibrated for the exposed gear assemblies (Section 4.4).

\section{Sheave Wear}

The sheave wear distress was observed on two cable assemblies at the W.P. Franklin Lock. The sheave wear distress was not on the inspection form when the distress was observed and, therefore, cannot be calibrated. Although the sheave wear distress was not calibrated, the current rule is based on discussion with the experts. 


\section{Sheave Bearing/Bushing Wear}

The sheave bearing/bushing wear distress was not calibrated because no wear in the sheaves was observed during the field tests. Hence, the calculated CIs were all 100, and the experts' average CIs were 90 or above. The bearing/bushing wear distress was calibrated for the exposed gear assemblies (Section 4.4).

\section{Sheave Anchorage Movement/Deterioration}

The sheave anchorage movement/deterioration distress was not calibrated because no movement or deterioration was detected in any of the sheave anchorages. Hence, the calculated CIs were all 100, and the experts' average CIs were 90 or above. The anchorage movement/deterioration distress was calibrated for the exposed gear assemblies (Section 4.4).

\section{Idler/Roller Wear}

The idler/roller wear distress was observed on two cable assemblies at the W.P. Franklin Lock. The idler/roller distress was added to the inspection form after the first field test but was not observed in succeeding field tests. Therefore, the distress cannot be calibrated. Although the idlers/rollers distress was not calibrated, the current rule is based on discussion with the experts.

\section{Gate or Valve Connection Movement}

The gate or valve connection distress was not calibrated because no relative movement was detected at the gate or valve connections. Hence, the calculated CIs were all 100 and the experts' average CIs were 90 or above.

\section{Assembly Cl: Figure 46}

The assembly CI for the cable assembly was calibrated for four assemblies. For two of the assemblies, the model CIs were significantly lower than the experts' average CIs, and for the other two calibrated assemblies, the model CIs closely approximated the experts' average CIs. In only one case (Upper Right Sector Lock Gate Moorehaven) did the model CI and the experts' average CI fall into a different zone. In all four cases, wire breakage (a critical distress) controlled the assembly CI. 


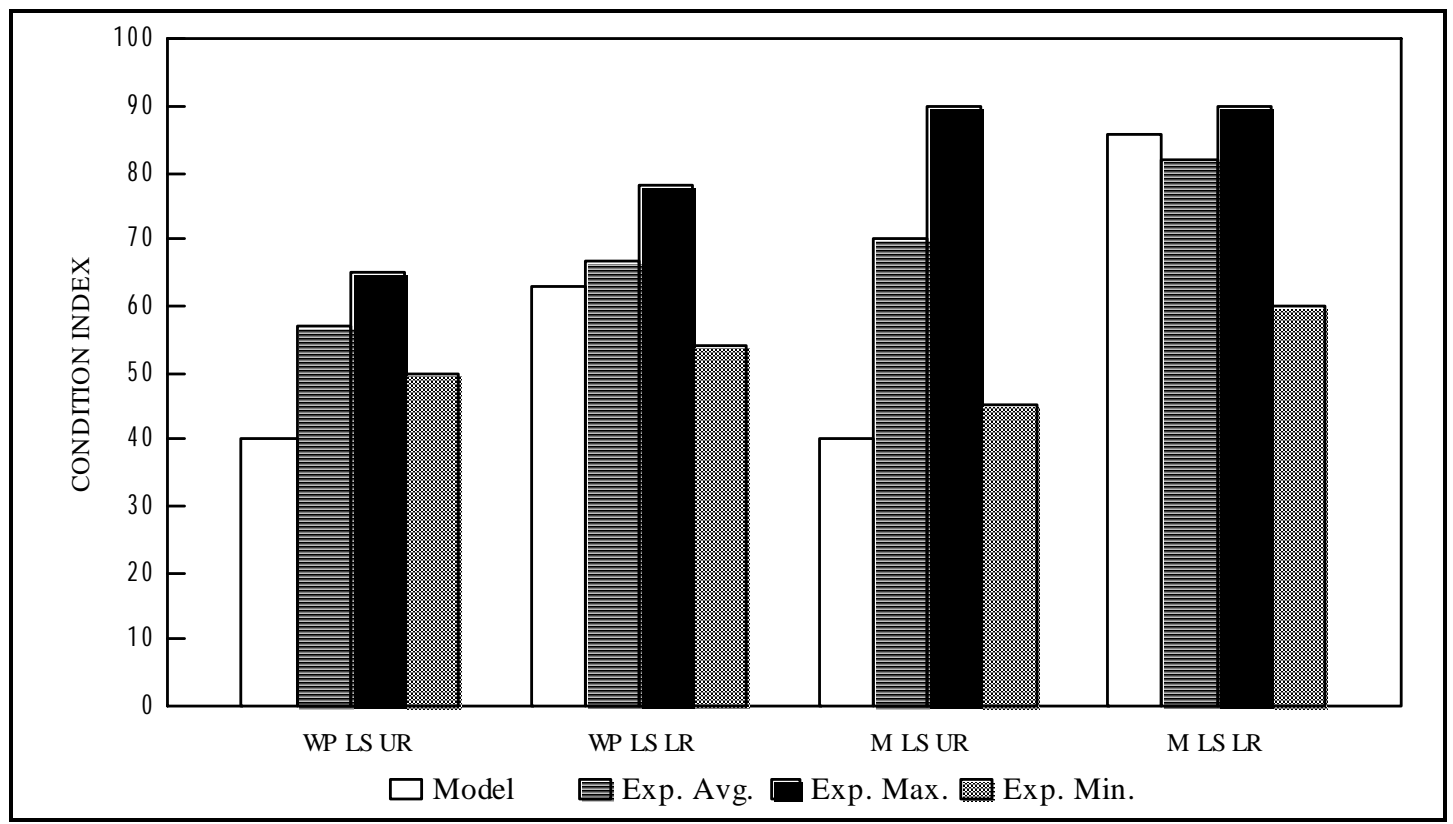

Figure 46. Cable assembly $\mathrm{Cl}$. 


\section{Chain Assembly}

\subsection{Component Identification}

Definitions and sketches for components of the chain assembly are presented in the following paragraphs.

\section{Chain}

A chain is a series of links connected to one another. Chain lifting systems are sometimes used to raise or lower dam or lock structures (Figure 47). The chain gets lifted and wound over a sprocket type device during the operation of the assembly.

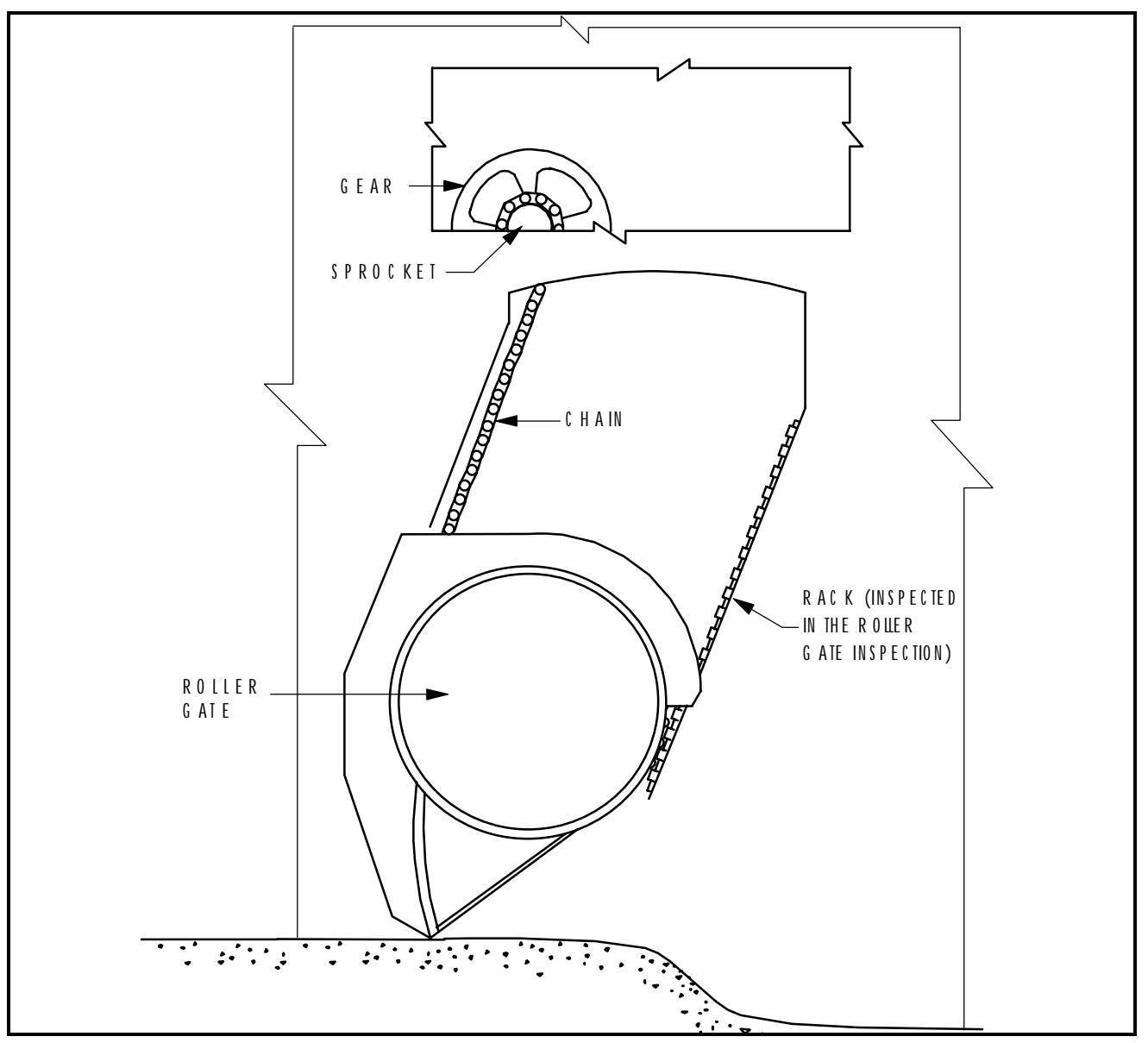

Figure 47. Side view of roller dam gate operating equipment. 


\section{Roller Chain}

A roller chain consists of roller bushings, side plates, and pins (Figure 48).

The roller bushings turn on the pins, thereby reducing the friction between the chain and the sprocket. The rollers fit between the sprocket teeth.

\section{Round Chain}

The links of this chain are oval shaped and permanently fitted into one another (Figure 48).

\section{Sprocket}

The sprocket is the component that retrieves the chain as it rotates. The chain links fit on the sprocket teeth.

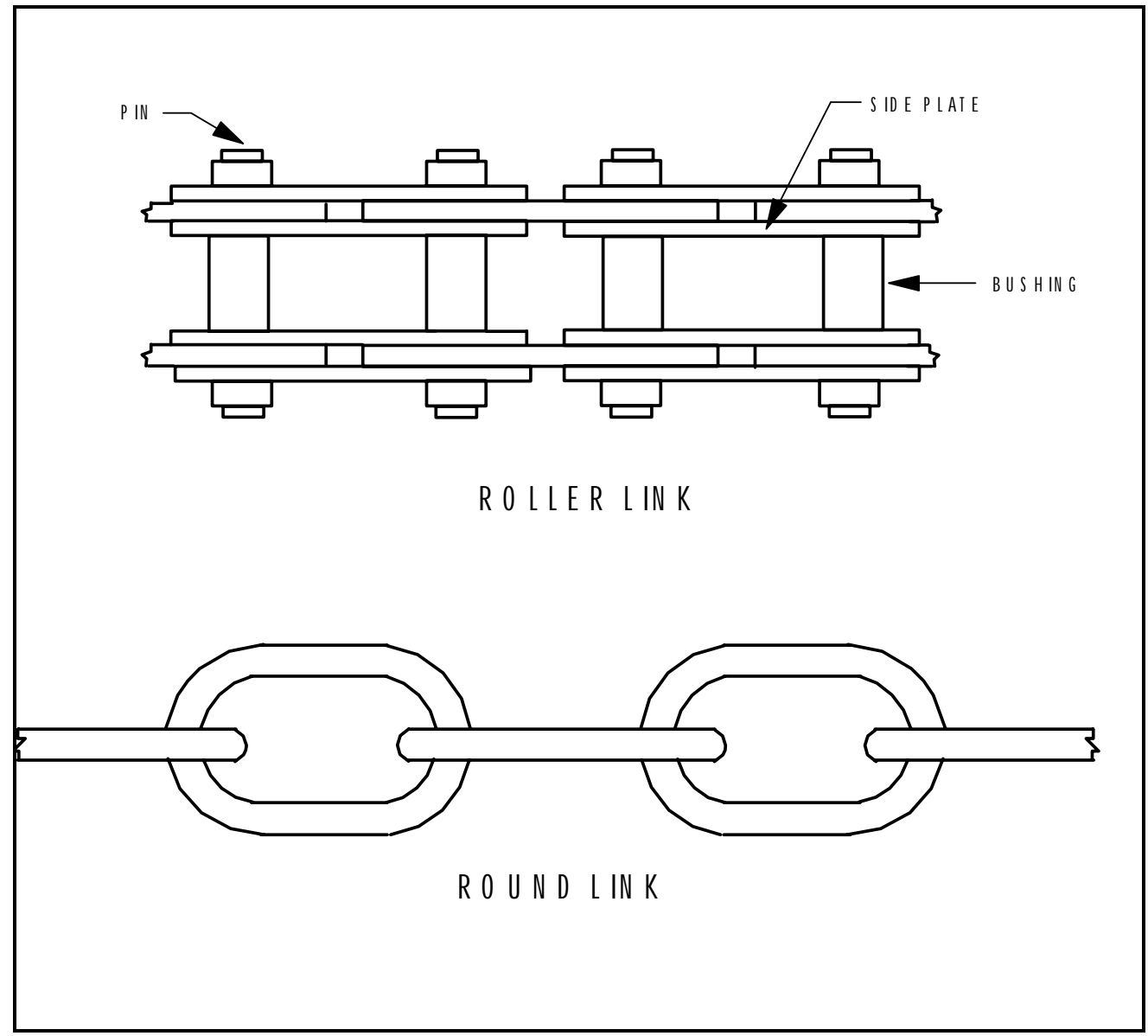

Figure 48. Chain link schematic. 


\subsection{Inspection Form With Comments}

The following pages are Parts 1 and 2 of the field inspection forms for the chain assembly. The side-by-side arrangement of the opposing pages displays specific explanations (right side) adjacent to the entry on the inspection form (left side). 


\section{U.S. ARMY CORPS OF ENGINEERS}

\section{CHAIN INSPECTION PART 1}

P.T.\#:

PROJECT NAME:

DATE:

GATE IDENTIFICATION: (identify the appropriate structure)

Lock Gate
Upper
1. Left Leaf
2. Right Leaf
Lower
1. Left Leaf
2. Right Leaf

Valve

$\begin{array}{lll}\text { Emptying } & \text { 1. Left } & \text { 2. Right } \\ \text { Filling } & \text { 1. Left } & \text { 2. Right }\end{array}$

Dam Gate

Number

CHAIN LINK TYPE (circle the appropriate number):

1) ROLLER

2) ROUND

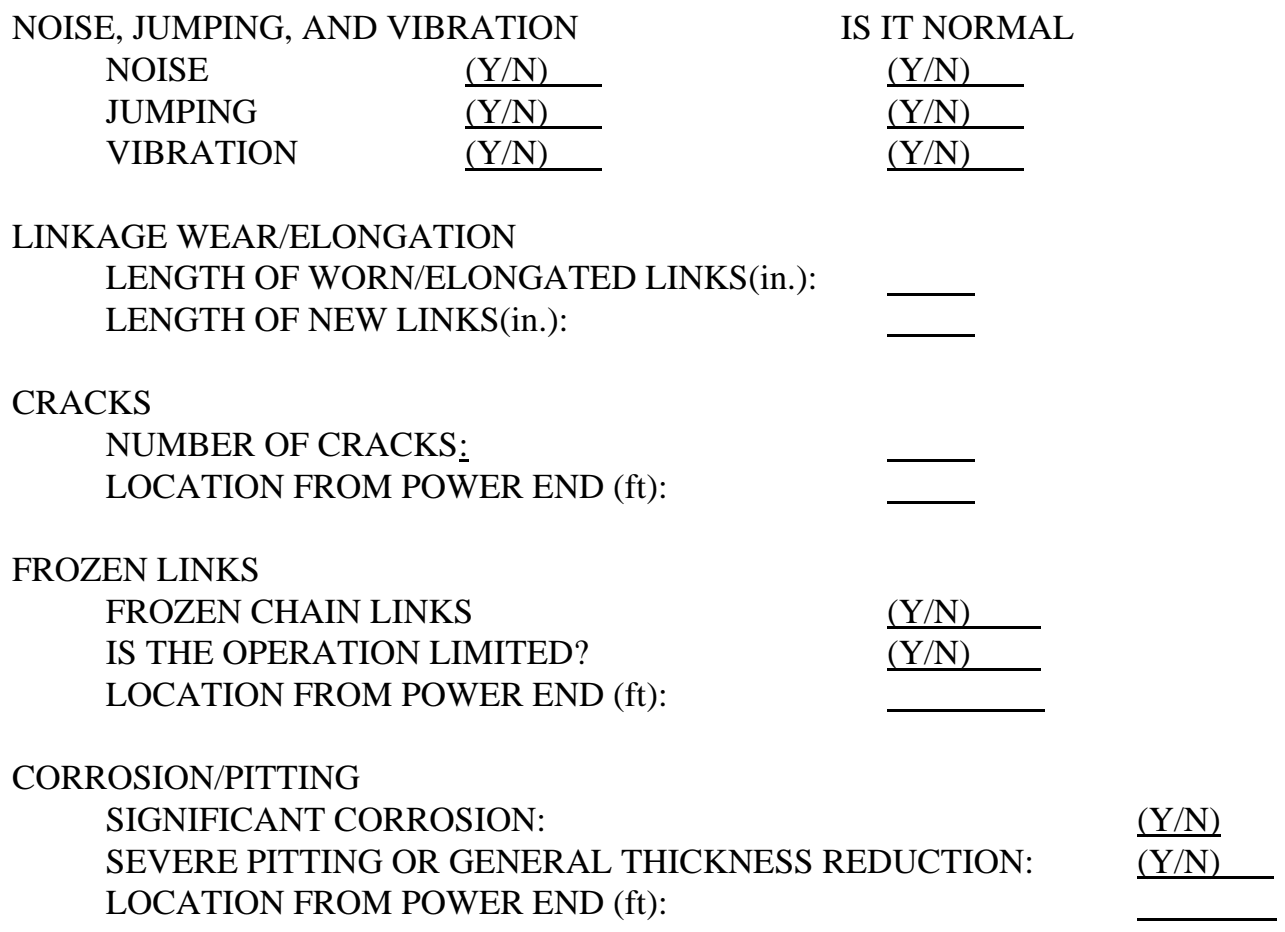
COMMENTS: 
Part 1 Comments: Field data

Enter the PROJECT NAME for this inspection, the DATE of the inspection, and, for the GATE IDENTIFICATION, identify which valve or dam gate is being inspected. Also enter the power transfer number (P.T.\#), which can be found on Page 1 of the inspection form.

Identify whether the chain is a ROLLER or ROUND LINK TYPE.

Observation of the chain assembly during gate or valve movement is a good indicator of problems. Record any indication of NOISE, JUMPING, and/or VIBRATION during operation and then indicate whether this noise, jumping, and/or vibration is NORMAL.

LINKAGE WEAR/ELONGATION of the chain occurs between the links of the chain (Figure 49). Record the LENGTH OF WORN/ELONGATED LINKS. This distance can be measured on a roller link chain by placing a tape measure along the loaded chain and measuring from the center to center of several consecutive link pins (Figure 49). For a round link, measure from end to end of the links while the chain is loaded (Figure 49). To get a more accurate estimate of total wear and elongation, measure 10 to 20 consecutive links and divide the measured distance by the number of links. The worst worn or elongated links will most likely be those that ride on the sprocket most frequently, if the gate operates at a relatively constant elevation. Also record the LENGTH OF NEW LINKS. This distance can be obtained from construction drawings. If construction drawings are not available, measure the distance between links that get little use, and use this distance as an estimate of the distance between new links.

Record the NUMBER OF CRACKS in the chain links. Also record the LOCATION of the cracked links from the power end (Figure 40).

Many times after a structure has been in the same position for some time, the links will lock together and not bend around the sprocket. Record a yes (Y) if the chain will not bend around the sprocket or, in other words, the chain LINKS are FROZEN. If links are frozen, they will often remain bent in the shape of the sprocket after they have been loaded. If there are frozen links, record whether they cause LIMITED OPERATION of the structure. The structure may have to be raised higher than normal to check the probable problem links. Also record the LOCATION of the frozen links from the power end (Figure 40).

The presence of excessive CORROSION on the chain is a potential problem. Record YES if there is SIGNIFICANT CORROSION (more than general scaling). If yes, indicate if there is SEVERE PITTING (1/8 in. pits or greater) in a dense pattern or GENERAL THICKNESS REDUCTION of $10 \%$ or greater in local areas. Also record the LOCATION of the corrosion from the power end (Figure 40). 


\section{CHAIN INSPECTION PART 2}

P.T.\#:

SPROCKET WEAR

WEAR?

$(\mathrm{Y} / \mathrm{N})$

IF YES, ESTIMATE \% REDUCTION OF SPROCKET TOOTH:

IF GREATER THAN 10\%, MEASURED \% REDUCTION OF SPROCKET TOOTH:

SPROCKET ANCHORAGE

MOVEMENT: $\quad(\mathrm{Y} / \mathrm{N})$

CORROSION: $\quad(\mathrm{Y} / \mathrm{N})$

CRACKED CONCR.: $\quad(\mathrm{Y} / \mathrm{N})$

EXPOSED BOLTS: $\quad(\mathrm{Y} / \mathrm{N})$

IF YES (Y), THEN IS THERE

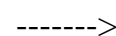

CORROSION:

$\underline{(\mathrm{Y} / \mathrm{N})}$

MISSING OR

BROKEN NUTS: $\quad(\mathrm{Y} / \mathrm{N})$

LOOSE NUTS: $\quad(\mathrm{Y} / \mathrm{N})$

END CONNECTION MOVEMENT

IS THE GATE OR VALVE OBSERVABLE(Y/N)?

IF YES, ESTIMATE MOVEMENT (in.):( 0, 1/8, 1/4, 3/8, 1/2):

COMMENTS: 
Part 2 Comments: Field data

SPROCKET WEAR is wear due to the chain constantly rubbing over the sprocket teeth. Record if there is WEAR of the sprocket teeth. IF YES, ESTIMATE the \% of REDUCTION OF the SPROCKET TOOTH. If the estimated reduction is GREATER THAN $10 \%$, MEASURE the $\%$ of REDUCTION OF the SPROCKET TOOTH. One way to measure the $\%$ of reduction is to measure the width of a sprocket tooth that sees little contact, assume that width as the new sprocket tooth width, and compare that width to the measured width of a worn tooth. The new tooth width can also be obtained from construction drawings.

Record any evidence of MOVEMENT greater than 0.002 in. at the SPROCKET ANCHORAGE as the gate is opened and closed. Evidence of movement can be observed visually or enhanced by placing a dial gage to monitor any movement. Excessive concrete spalling may indicate a displacement occurred at this location at some time. Also, record the presence of any CORROSION (10\% volume loss) of the steel portion or any CRACKED CONCRETE at the interface of the embedment. Small hairline cracks, probably caused by thermal expansion or contraction of the concrete, should be ignored. Indicate if there are any CORRODED (10\% volume loss), MISSING OR BROKEN, or LOOSE nuts at this connection if the BOLTS are EXPOSED.

Record if the GATE OR VALVE CONNECTION IS OBSERVABLE. IF YES, record the MOVEMENT at the END CONNECTION by visually observing any movement as the chain goes from slack to full tension and estimating the movement to the nearest $1 / 8$ in. (Figure 27). To further enhance the visual observation, place a dial gage at this location.

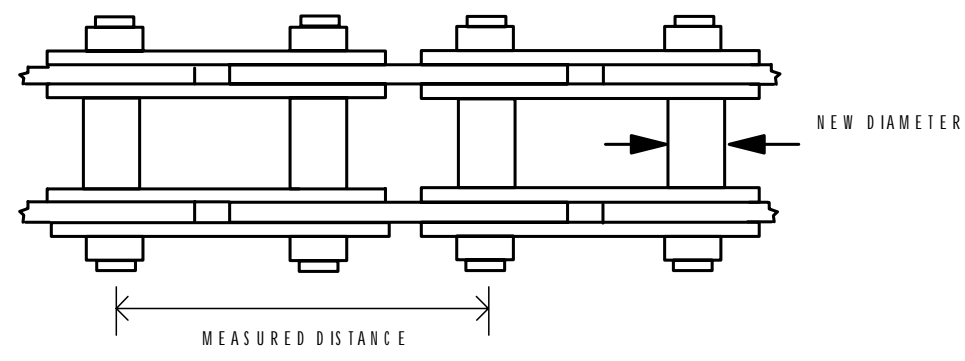

ROLLER LIN K

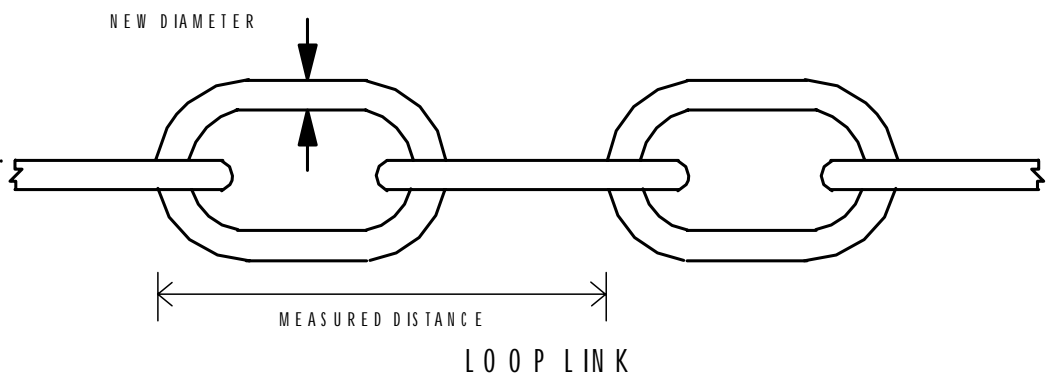

Figure 49. Chain linkage wear. 


\subsection{Condition Index}

The following section contains the rules for calculating the individual CIs for the chain assembly distresses. Distress descriptions and example illustrations are also provided.

\section{Noise, Jumping, and Vibration}

See noise, jumping, and vibration for the exposed gear assembly (Chapter 4, p 51).

\section{Linkage Wear/Elongation}

Definition and cause. Linkage wear/elongation can be caused by the reduction of cross-sectional area of chain links at the point of contact, wear of the connecting pins and rollers, and elongation of the chain links. For roller links, this wear occurs between the pin and the side plate and for round links the wear occurs where the links interconnect (Figure 49). Linkage wear and elongation are caused by normal operation of the chain assembly, through the interaction between the chain links, misalignment of the sprocket, or excessive loading.

Measurement and limits. The evaluation of chain link wear/elongation will be accomplished by comparing the length of a new link to the current chain link length. The difference, $X_{1}$, between the length of the new links, $\mathrm{X}_{\mathrm{NEW}}$, and the measured length, $\mathrm{X}_{\mathrm{WORN}}$, is:

$$
x_{1}=x_{\text {WORN }}-x_{N E W}
$$

The percentage of wear, $\mathrm{X}$, is:

$$
X=\left(X_{1} / X_{N E W}\right)\left(\begin{array}{lll}
1 & 0 & 0
\end{array}\right)
$$

The limiting value for linkage wear/elongation is:

$$
x_{M A X}=10 \%
$$

(U.S. Army Corps of Engineers, 1987). 
Example: In the inspection of a chain assembly, the measured distance between pins of a roller link was:

$$
x_{\text {WORN }}=14.50 \text { in. }
$$

The new distance between pins was:

$$
X_{N E W}=14.00 \mathrm{in} .
$$

Applying Equation 10.1 gives:

$$
x_{1}=(14.50-14.00)=0.50 \mathrm{in} .
$$

The percentage of wear/elongation in the chain is:

$$
x=(0.50 / 14.00)(100)=3.5 \%
$$

The CI for linkage wear/elongation is:

$$
C_{1}=\left[100(0.4)^{3.5 / 10}\right]=73
$$

The CI is rated Good.

\section{Cracks}

See cracks for the exposed gear assembly (Chapter 4, p 54).

\section{Frozen Links}

Definition and causes. The links of a chain are frozen when they will not bend properly around the sprocket or remain bent when loaded. Links may become frozen when the gate is not moved frequently. Frozen links are caused by inadequate lubrication and interaction with the environment (corrosion).

Measurement and limits. If the chain links in a chain set are frozen, it is recorded in the inspection form. The $\mathrm{CI}$ will be 70 if there are frozen links, but the 
equipment is still operational. However, if the structure operation is limited due to the frozen links, the CI will be 40 .

Example: A chain assembly that was not operated often had several frozen links. The operation of the structure was not limited by the frozen links, therefore, the CI for the frozen links distress is:

$$
c 1=70
$$

The CI is rated Good.

\section{Corrosion/Pitting}

See corrosion for the strut arm assembly (Chapter 7, p 101).

\section{Sprocket Wear}

Definition and causes. Sprocket wear is the wear of the sprocket teeth. This wear occurs because of the interaction between the sprocket teeth and the chain links. Normal use and lack of lubrication can cause sprocket wear.

Measurement and limits. Measurement of sprocket wear will be made by estimating the percentage of reduction of original sprocket tooth, $\mathrm{X}$. If the estimated value of reduction is greater than 10 percent, a measured percentage of reduction, $\mathrm{X}$, is found. The limiting value for sprocket wear will be:

$$
x_{M A X}=20 \%
$$

Example: The estimated percentage of reduction for a worn sprocket tooth was:

$$
x=5 \%
$$

The CI for sprocket wear is:

$$
c 1=100(0.4)^{5 / 20}=80
$$

Table 2 describes the CI for sprocket wear as Good. 


\section{Sprocket Anchorage Movement/Deterioration}

See anchorage movement/deterioration for the exposed gear assembly (Chapter 4, p 51).

\section{End Connection Movement}

See end connection movement for the strut arm assembly (Chapter 7, p 97).

\section{Assembly Cl}

The assembly CI will be calculated with Equations 2.2, 2.5, and 2.6 (See Chapter 2, Assembly Distress). The lone critical distress in the chain assembly is the cracks distress. The CIs from the remaining eight distresses will be used to calculate the weighted $\mathrm{CI}_{\mathrm{w}}$ (Equation 2.5). The weighting factors for those eight distresses are in Table 19.

\subsection{Field Test}

The chain assembly was not observed during the first two field tests in the Jacksonville and Louisville Districts; therefore, data to calibrate the rules in Section 10.3 could not be obtained. On the third field trip, the chain assembly was observed and discussion with the experts was helpful in revising the inspection form and rules for the chain assembly. The rules for similar distresses in other assemblies were used as guidelines for the rules in Section 10.3.

\section{Noise, Jumping, and Vibration}

The noise, jumping, and vibration distress was calibrated for the enclosed gear assembly, and those calculated CIs closely approximated the experts' average CIs.

\section{Linkage Wear}

The linkage wear distress could not be calibrated but was tested during the third field test. The technique described in Section 10.2 seemed to work reasonably well. The value of $\mathrm{X}_{\mathrm{MAX}}$ in Section 10.3 was obtained from the Safety and Health Requirements Manual (USACE 1987). 


\section{Cracks}

Although the cracks distress could not be calibrated, the experts felt that cracks in a chain assembly were critical and should be repaired. The rule for the cracks distress in Section 4.3 corresponds well with the collective expert opinion.

\section{Frozen Links}

Although the frozen links distress could not be calibrated, the experts felt that frozen links in a chain assembly were serious and should be repaired. The rules for the frozen links distress in Section 10.3 correspond well with the collective expert opinion.

\section{Corrosion/Pitting}

The corrosion/pitting distress could not be calibrated for the chain assembly. The rule for the corrosion distress was, however, calibrated for the strut arm assembly and the calculated CIs closely approximated the experts' average CIs.

\section{Sprocket Wear}

Although the sprocket wear distress could not be calibrated, the inspection questions and rules were written to closely resemble the questions and rules for cable drum wear that were presented in Chapter 9.

\section{Sprocket Anchorage Movement/Deterioration}

The sprocket anchorage movement/deterioration distress could not be calibrated for the chain assembly. The anchorage movement/deterioration distress was, however, calibrated for the exposed gear assembly (Section 4.4) and the enclosed gear assembly (Section 5.4).

\section{End Connection Movement}

Although the gate connection movement distress could not be calibrated for the chain assembly, the distress was calibrated for the strut arm assembly. The calculated CIs closely approximated the experts' average Cis.

\section{Assembly CI}

Although the combined CI could not be calibrated for the chain assembly, the weighting factors used to calculate the assembly CI (Table 19) were obtained from the experts. 


\section{Hydraulic Cylinder Assembly}

\subsection{Component Identification}

Definitions and sketches for components of a hydraulic cylinder are presented in the following paragraphs.

\section{Hydraulic Cylinder}

Hydraulic cylinders produce the force required to move the gate structure or lift and lower the valve structure. Hydraulic cylinders are often used horizontally in gate structures (Figures 5 and 37). Hydraulic cylinders are also used horizontally in conjunction with the rocker assembly in valve structures (Figure 6). In some cases, the hydraulic cylinders are used vertically directly above a vertical lift valve (i.e., therefore, a rocker arm is not needed).

\section{Packing Plate}

The function of the packing plate is to allow the piston rod to pass through the cylinder end without leakage of hydraulic fluid. The packing plate is at the end of the hydraulic cylinder (Figure 6).

\section{Piston Rod}

The piston rod extends from the hydraulic cylinder and transfers the force from the hydraulic cylinder to the strut (Figure 6).

\section{End Connection}

The end connection is located at the end of the piston rod. Its function is to transfer force from the piston rod to the strut, rack, or rocker (Figure 6).

\section{Anchorage}

The anchorage transfers the load from the hydraulic cylinder to the concrete base (Figure 6). 


\section{Guides}

In some cases, the hydraulic cylinder rod has guides to support the cylinder.

\subsection{Inspection Form With Comments}

The following pages are Parts 1 and 2 of the field inspection forms for the hydraulic cylinder assembly. The side-by-side arrangement of the opposing pages displays specific explanations (right side) adjacent to the entry on the inspection form (left side). 
Intentionally Blank 
U.S. ARMY CORPS OF ENGINEERS

P.T.\#:

\section{HYDRAULIC CYLINDER INSPECTION PART 1}

PROJECT NAME:

DATE:

GATE IDENTIFICATION: (identify the appropriate structure)

Lock Gate

$\begin{array}{lll}\text { Upper } & \text { 1. Left Leaf } & \text { 2. Right Leaf } \\ \text { Lower } & \text { 1. Left Leaf } & \text { 2. Right Leaf }\end{array}$

Valve
Emptying
1. Left
2. Right
Filling
1. Left
3. Right

Dam Gate

Number

NOISE, JUMPING, AND VIBRATION

NOISE

JUMPING

$(\mathrm{Y} / \mathrm{N})$

VIBRATION

$\frac{(\mathrm{Y} / \mathrm{N})}{(\mathrm{Y} / \mathrm{N})}$

IS IT NORMAL

$(\mathrm{Y} / \mathrm{N})$

$(\mathrm{Y} / \mathrm{N})$

$\underline{(\mathrm{Y} / \mathrm{N})}$

ANCHORAGE MOVEMENT/DETERIORATION

MOVEMENT: $\quad(\mathrm{Y} / \mathrm{N})$

CORROSION: $\quad \frac{(\mathrm{Y} / \mathrm{N})}{(\mathrm{Y} / \mathrm{N})}$

CRACKED CONCR.: $\quad(\mathrm{Y} / \mathrm{N})$

EXPOSED BOLTS: $\quad \underline{\underline{(\mathrm{Y} / \mathrm{N})}} \quad---->\quad$ IF YES (Y),

CORROSION: $\underline{(\mathrm{Y} / \mathrm{N})}$

MISSING OR

BROKEN NUTS: $(\mathrm{Y} / \mathrm{N})$

LOOSE NUTS: $(\mathrm{Y} / \mathrm{N})$

END CONNECTION MOVEMENT

(estimate movement (in.): $0,1 / 8,1 / 4,3 / 8,1 / 2$ ):

OPEN CLOSED

CORROSION/PITTING OF ROD

SURFACE CORROSION: $(\mathrm{Y} / \mathrm{N})$

PITTING:

$(\mathrm{Y} / \mathrm{N})$

IF YES, \# OF PITS(per worst foot):

LOCATION:

DAMAGED ROD

PERCENT OF ROD WHICH IS SCORED:

LOCATION:

PEELING OF CHROME: (Y/N)

OTHER SIGNIFICANT DAMAGE:

IF YES, EXPLAIN:

$(\mathrm{Y} / \mathrm{N})$

OIL LEAKAGE

EVIDENCE OF RECENT OIL LEAKAGE: (Y/N)

NUMBER OF OIL DROPS PER STROKE:

DRIFT

DRIFT (in.): 
Part 1 Comments: Field data

Enter the PROJECT NAME on which the inspection will be performed, the DATE of the inspection, and for the GATE IDENTIFICATION, identify whether this is a lock gate, valve, or dam gate. Also enter the power transfer number (P.T.\#), which can be found on Page 1 of the inspection form.

Observation of the hydraulic cylinder assembly during gate or valve movement is a good indicator of problems. Record any indication of NOISE, JUMPING, and/or VIBRATION during operation and then indicate whether this noise, jumping, and/or vibration is NORMAL.

Record any evidence of MOVEMENT greater than 0.002 in. at the ANCHORAGE as the gate or valve is opened and closed. Evidence of movement can be observed visually or enhanced by placing a dial gage to monitor any movement (Figure 50). Excessive concrete spalling may indicate a displacement occurred at this location at some time. Also, record the presence of any CORROSION (10\% volume loss) of the steel portion or any CRACKED CONCRETE at the interface of the embedment. Small hairline cracks, probably caused by thermal expansion or contraction of the concrete, should be ignored. Indicate if there are any CORRODED (10\% volume loss), MISSING OR BROKEN, or LOOSE nuts at this connection if the BOLTS are EXPOSED.

Record any relative MOVEMENT in the END CONNECTION between the rod and the attached component such as the rocker arm (Figure 27), strut, cross head, etc., by visually observing any movement parallel to the cylinder and estimating the movement to the nearest $1 / 8$ in. To further enhance the visual observation, place a dial gage at this location.

Record evidence of any SURFACE CORROSION on the cylinder rod. If corrosion is present, check to see if PITTING of the rod has occurred. If so, record the number of pits in the worst foot along the length of the rod. Also record the LOCATION of the surface corrosion from the connection end.

Wipe the rod clean and observe and record the PERCENTAGE of the cylinder ROD that is SCORED greater than 1/64 in. Scoring is grooving along the length of the cylinder rod. Also record the LOCATION of the scoring from the connection end. If applicable, record the PEELING of CHROME from the surface of the rod. Also, indicate whether any other SIGNIFICANT DAMAGE to the rod (such as nicks, bowing of the rod, etc.) has occurred.

Record any EVIDENCE OF RECENT OIL LEAKAGE. Record the NUMBER OF OIL DROPS that leak from the packing seal interface during one full STROKE (Figure 50). Many times this can be accomplished by placing a sheet of paper below the cylinder end.

Record the amount of DRIFT or movement of the hydraulic rod. When the hydraulic cylinder is used for valve or dam gate operation, the valve or dam gate should be in the open position. When the hydraulic cylinder is used to operate a lock gate, the lock gate should be in the open position. Isolate the cylinder by closing all oil valves and measuring the drift in a 15-min interval with a ruler or a dial gage (Figure 50). 
U.S. ARMY CORPS OF ENGINEERS

P.T.\#:

HYDRAULIC CYLINDER INSPECTION PART 2

DAMAGED GUIDE

ARE ANY GUIDES USED IN THE HYDRAULIC CYLINDER ASSEMBLY? (Y/N)

IF YES,

DOES ASSEMBLY SLIDE SMOOTHLY?:

$(\mathrm{Y} / \mathrm{N})$

ARE GUIDES DAMAGED?:

IF YES, IS THE HYDRAULIC CYLINDER BEING DAMAGED?

$(\mathrm{Y} / \mathrm{N})$

$(\mathrm{Y} / \mathrm{N})$

COMMENTS: 
Part 2 Comments: Field data

Record if ANY GUIDES ARE USED IN THE HYDRAULIC CYLINDER ASSEMBLY. IF YES, record if the GUIDES SLIDE SMOOTHLY. Also record if the GUIDES ARE

DAMAGED. If the guides are damaged, record if THE HYDRAULIC CYLINDER is BEING DAMAGED.

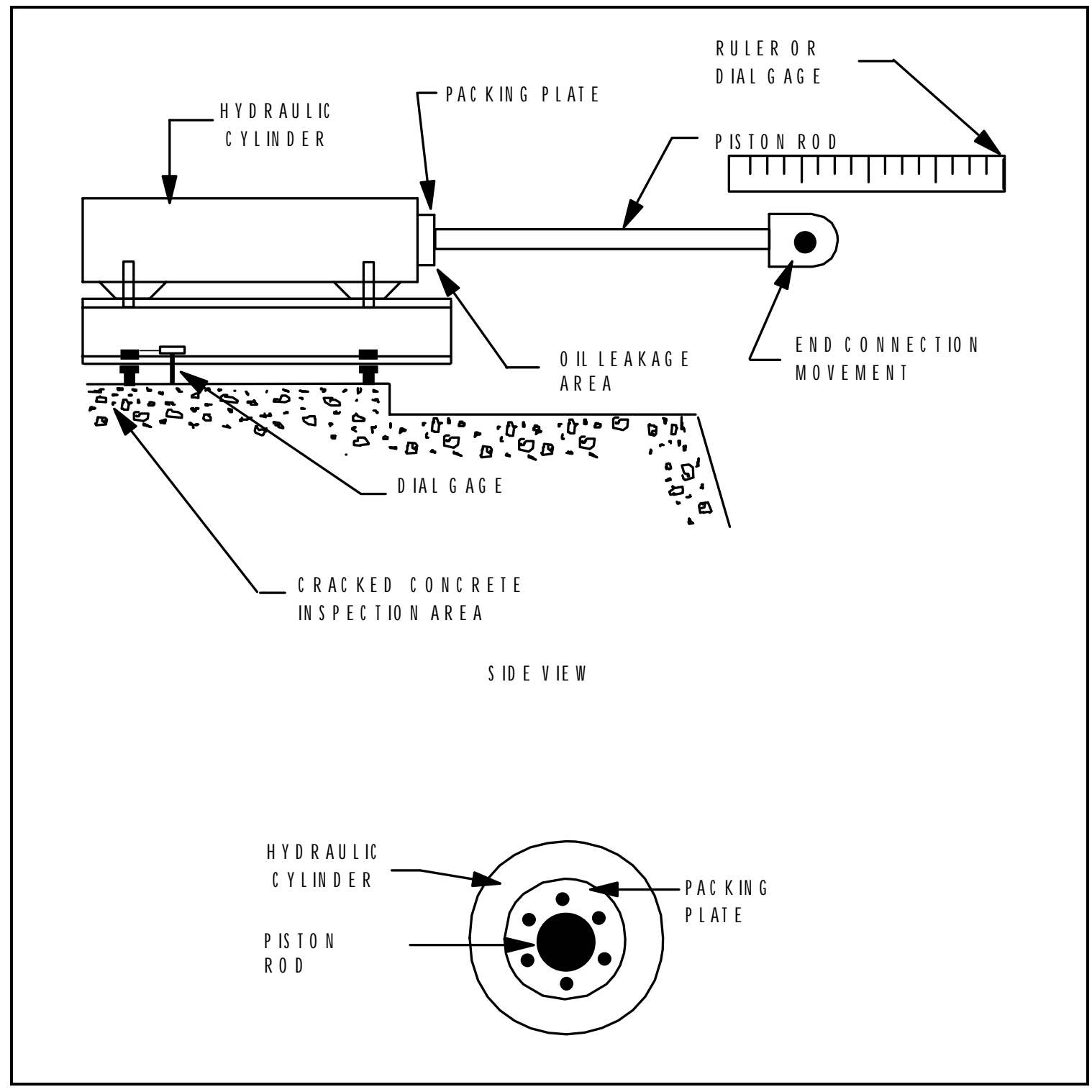

Figure 50. Hydraulic cylinder assembly distress measurements. 


\subsection{Condition Index}

The following section contains the rules for calculating the individual CIs for the hydraulic cylinder assembly distresses. Distress descriptions and example illustrations are also provided.

\section{Noise, Jumping, and Vibration}

See noise, jumping, and vibration for the exposed gear assembly (Chapter 4, p $51)$.

\section{Anchorage Movement/Deterioration}

See anchorage movement/deterioration for the exposed gear assembly (Chapter 4, p 51).

\section{End Connection Movement}

See end connection movement for the strut arm assembly (Chapter 7, p 97).

\section{Surface Corrosion/Pitting of Rod}

Definition and cause. Surface corrosion involves the scaling of steel material on the surface of the cylinder rod due to interaction with the environment. If this interaction continues, pitting will occur. Pitting is the minor loss of steel in localized areas. Surface corrosion and/or pitting on the cylinder rod can be detrimental to the end seals in the hydraulic cylinder.

Measurements and limits. Because any amount of corrosion on a cylinder rod can cause damage to the hydraulic cylinder seals, the CI will be 85 for any evidence of corrosion, including surface corrosion. For the condition of pitting, $\mathrm{X}$ is counted to be the number of pits per worst foot of rod. The limiting number of pits is:

$$
x_{\text {MAX }}=30 \text { pits }
$$

The CI for a rod with any amount of pitting can never be greater than 70 .

Example: Ten pits were found on a cylinder rod during an inspection. The CI based on the number of pits is:

$$
C I=\left[\begin{array}{lllll}
1 & 0 & 0 & (0.4)^{10 / 30}
\end{array}\right]=74
$$


However, the CI can not be greater than 70 if any pits are found; therefore,

$$
C 1=70
$$

The CI is rated Good.

\section{Damaged Rod}

Definition and cause. Scoring of the rod refers to grooving that occurs in the cylinder rod. During normal use, a cylinder rod will wear in a uniform pattern of grooves. The causes for scoring include inadequate lubrication and normal wear during the opening and closing motion. The hydraulic rod is sometimes surfaced with chrome to protect the rod from interaction with the environment. With normal use and exposure to the surrounding environment, the chrome sometimes peels off. Other damage such as nicking of the rod surface or bending of the rod is also possible. This damage could result from misuse of the equipment.

Measurement and limits. The percentage of surface area of the rod that has scoring greater than 1/64 in., X, and the location of these grooves are recorded on the inspection form. Only the percentage of scoring is used in determining the condition of the rod. The limiting value for percentage of scoring is:

$$
x_{\text {MAX }}=100 \%
$$

If there is evidence of chrome peeling off, the CI will be reduced by a factor of 0.70 . If there is other significant damage to the rod such as chips or nicks, the CI will be reduced by a factor of 0.55 .

Example: Scoring greater than 1/64 in. was found on 50 percent of a cylinder rod during an inspection of a hydraulic cylinder assembly. Some of the chrome surface on the rod was peeling off. For the scoring distress:

$$
x=50 \%
$$

Using Equation 2.1 and the value of $\mathrm{X}_{\mathrm{MAX}}$ from Equation 11.2, the CI for scoring is:

$$
c_{1}=\left[\begin{array}{llll}
1 & 0 & 0 & (0.4)^{50 / 100}
\end{array}\right]=63
$$


The CI is further reduced because of peeling of the chrome. The CI for damage of the rod is:

$$
c I=\left(\begin{array}{ll}
6 & 3
\end{array}\right)\left(\begin{array}{lll}
0.7 & 0
\end{array}\right)=44
$$

The CI is rated Marginal.

\section{Oil Drippage}

Definition and cause. Oil drippage can occur at or near the packing plate in the hydraulic cylinder. Excessive cylinder pressure, damage to the rod, or wear of the packing plate from normal use can be the cause of oil drippage.

Measurement and limits. The number of oil drops, $X$, that leak from the packing seal interface are recorded in the inspection form. The limiting value for the number of drops during a full stroke is:

$$
x_{\text {MAX }}=20 \text { drops }
$$

If there is evidence of recent leakage, the CI can be no larger than 85 .

Example: Twelve drops of oil leaked from the packing plate of a hydraulic cylinder. The CI for oil drippage is:

$$
c_{1}=\left[\begin{array}{llll}
1 & 0 & 0 & (0.4)^{12 / 20}
\end{array}\right]=58
$$

The $\mathrm{CI}$ is rated Marginal.

\section{Drift}

Definition and cause. When a structure uses a hydraulic cylinder and all oil valves are closed, little movement of the supported load is expected. Drift distress is the movement of the hydraulic rod with maximum load on the rod. For valve structures with horizontal cylinders, the load is the dead load of the structure when suspended. For sector gear and rack systems (Figure 5), there is normally no dead load is due to the structure, but conditions due to water flow, wind, etc. may create a load condition at the time of the inspection. On a sector gate, the load may be caused by water head or water flow as the gate is opened. 
Measurement and limits. The total amount of drift, $\mathrm{X}$, is the movement recorded in a 15-min interval. The limiting value for drift for a valve structure (loaded) is:

$$
x_{\text {MAX }}=1 \text { in } .
$$

The limiting value for a lock gate structure (nonloaded) is:

$$
x_{\text {MAX }}=1 / 4 \text { in }
$$

The limiting value for a dam gate structure (loaded) is:

$$
x_{M A X}=1 / 16 \text { in } .
$$

Example: The amount of drift found in a hydraulic cylinder used for valve operation was:

$$
x=1.25 \text { in. }
$$

The CI for drift in this hydraulic cylinder is:

$$
\left.c 1=\left[\begin{array}{llll}
1 & 0 & 0 & (0.4
\end{array}\right)^{1.25 / 1}\right]=32
$$

From Table 2, the CI for drift is rated Poor.

\section{Damaged Guides}

Definitions and causes. Cylinder guides can become corroded over time.

Guide anchorages can also deteriorate or become loose. When this occurs, the guide assembly no longer moves smoothly as the hydraulic cylinder is operated.

Corrosion and deterioration of the guides can be caused by interaction with the environment.

Measurement and limits. If the guide does not slide smoothly as the hydraulic cylinder is operated, it is recorded in the inspection form. The CI will be 70 if the guide does not slide smoothly. If there is damage to the guides, the damage is also recorded in the inspection form. The $\mathrm{CI}$ will be 40 if damage can occur to the hydraulic cylinder because of the damaged guides. 
Example: The guide of a hydraulic cylinder jerked as the assembly was being operated. The CI for guides is:

$$
c I=70
$$

The CI is rated Excellent.

\section{Assembly $\mathrm{Cl}$}

The assembly CI will be calculated with Equations 2.5 and 2.6 (see Chapter 2, Assembly Distress). The experts did not consider any of the distresses for the hydraulic cylinder critical; therefore, Equation 2.5 will be used to calculate the assembly CI. The weighting factors for the hydraulic cylinder distresses are in Table 20.

\subsection{Field Test}

The bar charts in Figures 51 to 54 compare the experts' subjective CI from the field tests to the CI calculated from the rules in Section 11.3 for four hydraulic cylinder distresses. Only data from assemblies with observed distresses are plotted. Comparisons between the calculated and experts' CIs are summarized below.

\section{Noise, Jumping, and Vibration}

The noise, jumping, and vibration distress was not calibrated because no noise, jumping, or vibration in hydraulic cylinders was observed. Hence, the calculated CIs were all 100, and the experts' average CIs were 90 or above. The noise, jumping, and vibration distress was calibrated in the enclosed gear assembly, and the calculated CIs closely approximated the experts' averages.

\section{Anchorage Movement/Deterioration: Figure 51}

In only one case (Ortona Vertical Lift Gate \#4) was any anchorage deterioration observed (corrosion of nuts). The calculated CI was 85 . For the other hydraulic cylinder assemblies, no deterioration was recorded by the experts and the calculated CI was 100. 


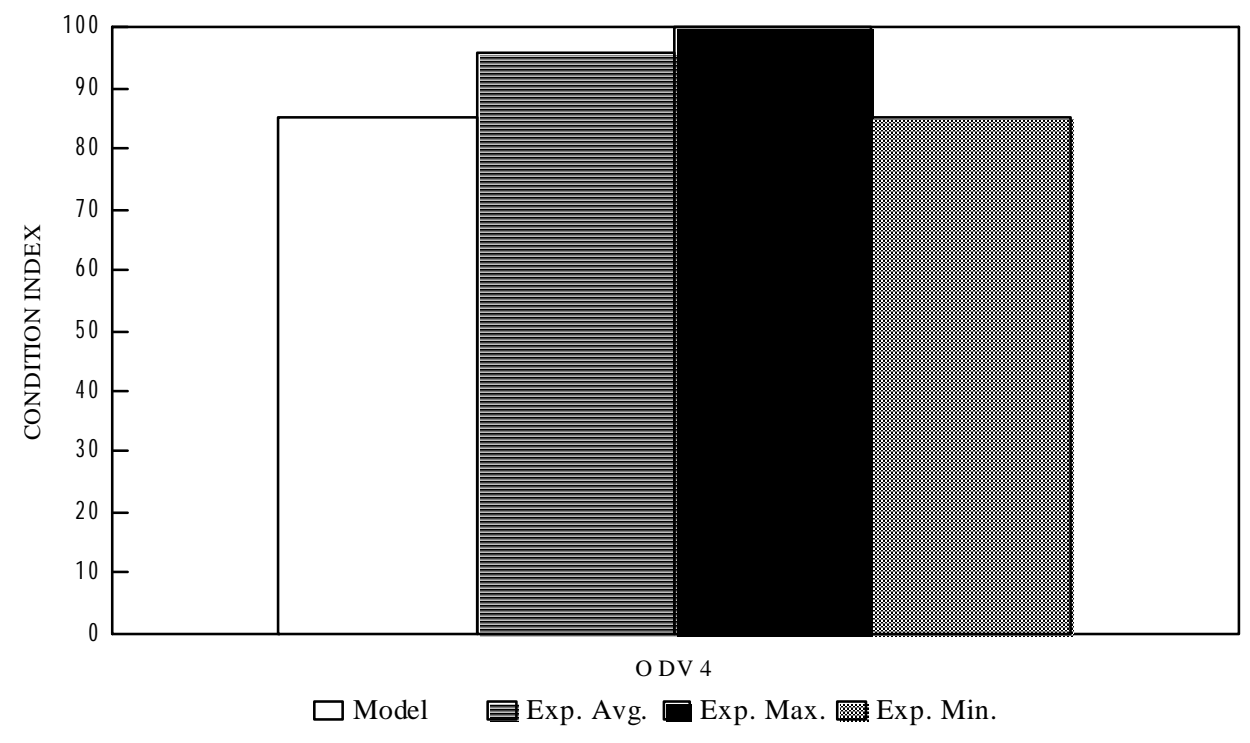

Figure 51. Anchorage movement/deterioration: hydraulic cylinder assembly.

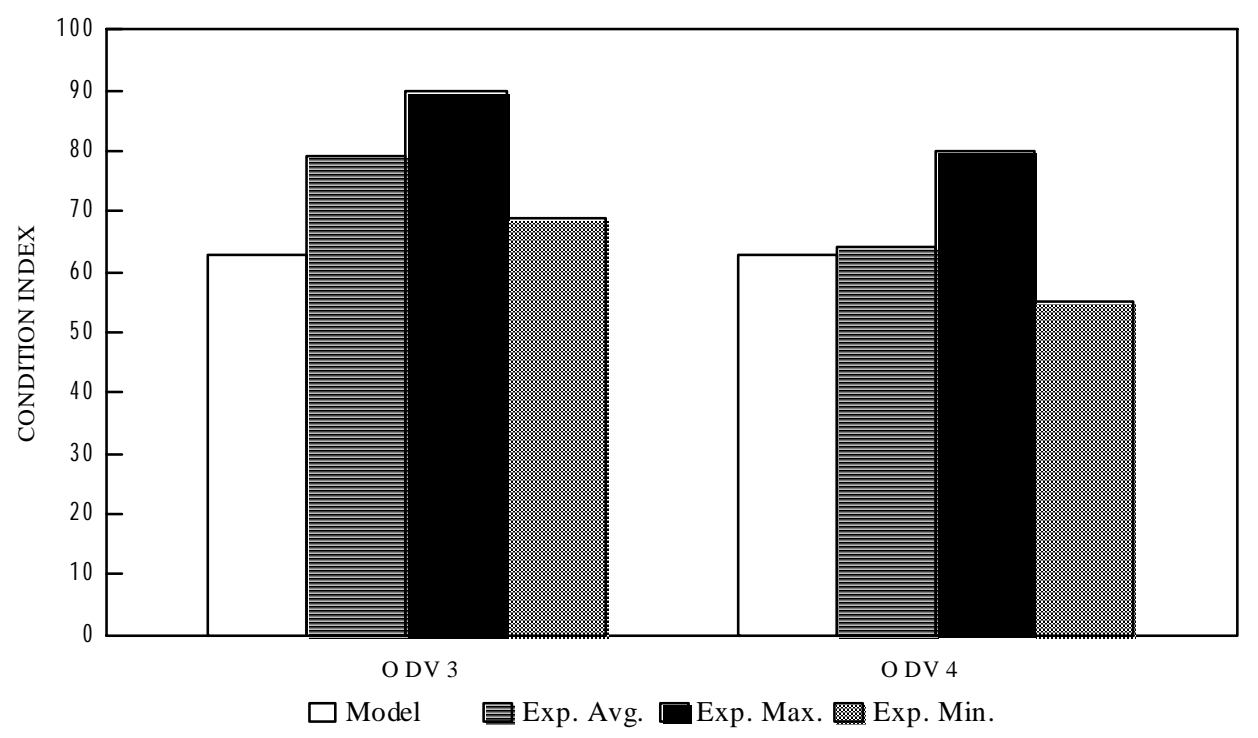

Figure 52. Corrosion/pitting of rod: hydraulic cylinder assembly. 


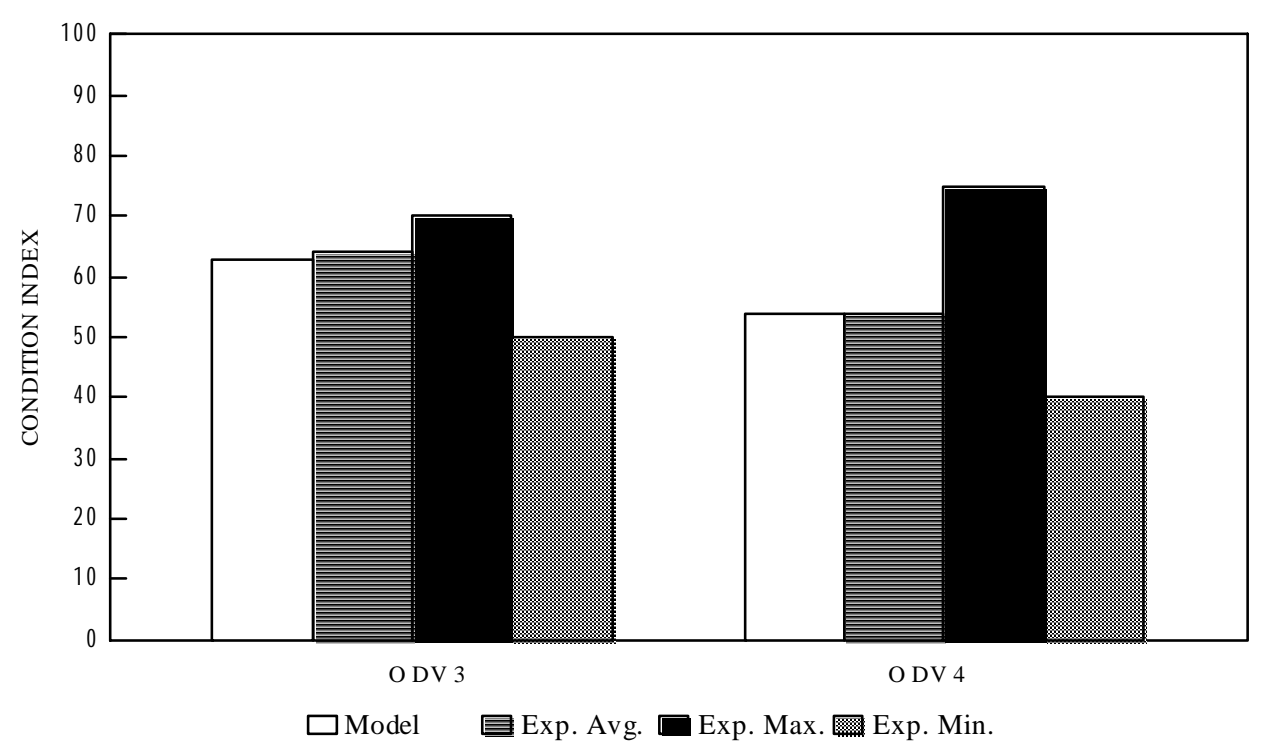

Figure 53. Oil leakage: hydraulic cylinder assembly.

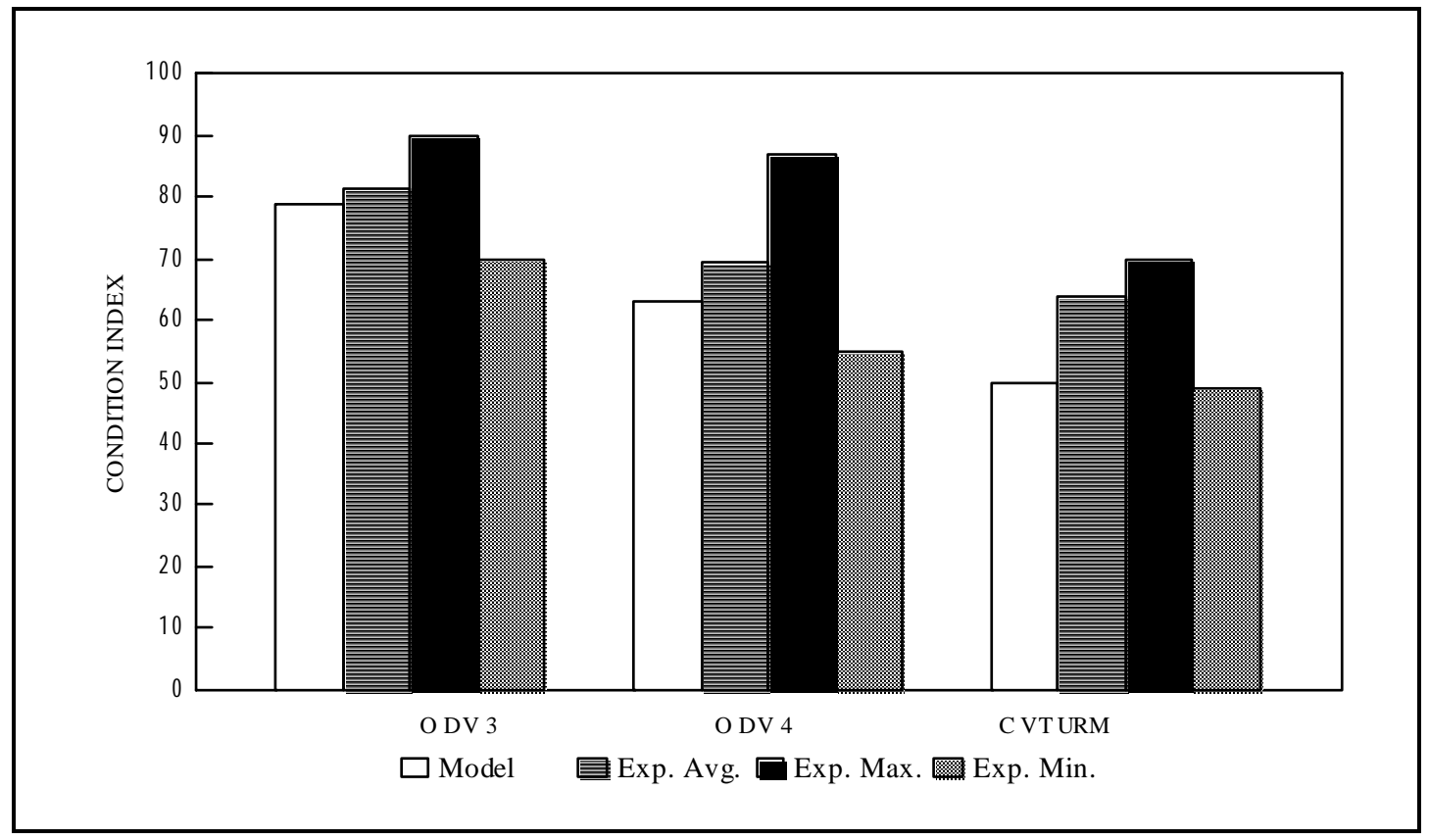

Figure 54. Drift: hydraulic cylinder assembly. 


\section{End Connection Movement}

The end connection movement distress was not calibrated because no movement between the rod and rocker arm or cross heads in hydraulic cylinders was observed. Hence, the calculated CIs were all 100 and the experts' average CIs were 90 or above. The end connection movement distress was calibrated in the strut arm assembly.

\section{Corrosion/Pitting of Rod: Figure 52}

The calculated CI for the corrosion/pitting of the rod closely approximated the expert average. At the two locations where the distress was observed (Vertical Lift Dam Gate \#3 Ortona and Vertical Lift Dam Gate \#4 Ortona), the CI compares very well to the experts' numbers, with a difference of less than 5 points for each.

\section{Damaged Rod}

The damaged rod distress was not calibrated because no damage was observed in the hydraulic cylinders. Hence, the calculated CIs were all 100, and the experts' average CIs were 90 or above.

\section{Oil Leakage: Figure 53}

The calculated CIs for oil leakage varied slightly from the experts' average CIs. On two hydraulic cylinders, oil leakage was evident. On one of these cylinders (Ortona Lift Gate \#4), the experts' average was closely approximated by the calculated CI. On a similar cylinder (Ortona Lift Gate \#3), for which the same number of oil drops per cycle was observed, the calculated CI was the same. The experts' average CI, however, was 16 points higher.

\section{Drift: Figure 54}

The calculated CIs for drift closely approximated the experts' average CI with the exception of one hydraulic cylinder (Filling Valve Cannelton) for which the difference was 17 points.

\section{Assembly $\mathrm{Cl}:$ Figure 55}

The assembly CI for the hydraulic cylinder assembly was calibrated for three assemblies. The model CIs closely approximated the experts' average CIs for all three calibrated assemblies. 


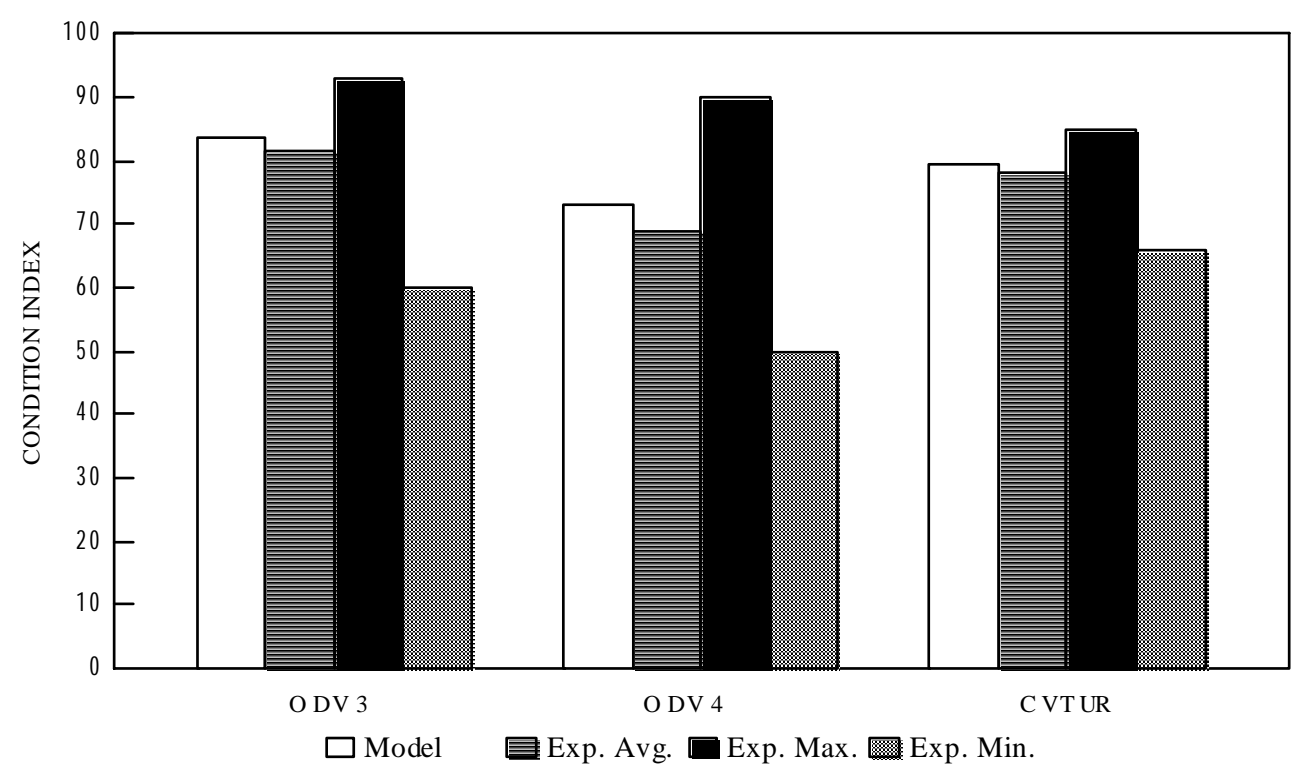

Figure 55. Hydraulic cylinder assembly $\mathrm{Cl}$. 


\section{Coupling Assembly}

\subsection{Component Identification}

Definitions and sketches for components of the coupling assembly are presented in the following paragraphs.

\section{Coupling}

A coupling is a joint between input and output shafts that generally contains meshing teeth to transfer force from one shaft to another (Figure 7). The meshing teeth are enclosed in a hub.

\section{Shaft}

The shaft transfers force from one set of gears to another set of gears or to other equipment such as a cable drum (Figure 7). The input shaft is the shaft on the power end.

Hub

The hub is the casing that contains the meshing teeth of the coupling.

\section{Keyway}

The keyway enables the transmission of torque from a shaft to the shaftsupported element.

\subsection{Inspection Form With Comments}

The following page is the field inspection form page for the coupling assembly. The side-by-side arrangement of the opposing pages displays specific explanations (right side) adjacent to the entry on the inspection form (left side). 
U.S. ARMY CORPS OF ENGINEERS

P.T.\#:

COUPLING INSPECTION

PROJECT NAME:

DATE:

GATE IDENTIFICATION: (identify the appropriate structure)

Lock Gate

Upper 1. Left Leaf 2. Right Leaf

Lower 1. Left Leaf 2. Right Leaf

Valve
Emptying
1. Left
2. Right
1. Left

Filling

2. Right

Dam Gate

Number

NOISE, JUMPING, AND VIBRATION

NOISE

JUMPING

$(\mathrm{Y} / \mathrm{N})$

VIBRATION

$\frac{(\mathrm{Y} / \mathrm{N})}{(\mathrm{Y} / \mathrm{N})}$

IS IT NORMAL

$\frac{(\mathrm{Y} / \mathrm{N})}{(\mathrm{Y} / \mathrm{N})}$

CRACKS

NUMBER OF CRACKS:

CORROSION

SIGNIFICANT CORROSION:

SEVERE PITTING OR GENERAL THICKNESS REDUCTION:

IS THE COUPLING FLEXIBLE(F) OR RIGID(R):

IS THERE RELATIVE MOVEMENT BETWEEN THE INPUT SHAFT AND HUB?

$(\mathrm{Y} / \mathrm{N})$

IF YES, IS THE MOVEMENT EXCESSIVE?

$\underline{(\mathrm{Y} / \mathrm{N})}$

IS THERE RELATIVE MOVEMENT BETWEEN THE OUTPUT SHAFT AND HUB?

$\underline{(\mathrm{Y} / \mathrm{N})}$

IF YES, IS THE MOVEMENT EXCESSIVE?

$\underline{(\mathrm{Y} / \mathrm{N})}$

COMMENTS: 
Comments: Field Data

Enter the PROJECT NAME for this inspection, the DATE of the inspection, and, for the GATE IDENTIFICATION, identify which gate or valve is being inspected. Also enter the power transfer number (P.T.\#), which can be found on Page 1 of the inspection form.

Observation of the coupling during gate or valve movement is a good indicator of problems. Record any indication of NOISE, JUMPING, and/or VIBRATION during operation and then indicate whether this noise, jumping, and/or vibration is NORMAL.

The presence of CRACKS on the coupling is usually not tolerated. Record the NUMBER OF CRACKS found by visual observation of these components.

The presence of excessive CORROSION on the coupling is a potential problem. Record YES if there is SIGNIFICANT CORROSION (more than general scaling). If yes, indicate if there is SEVERE PITTING (1/8 in. pits or greater) in a dense pattern or GENERAL THICKNESS REDUCTION of $10 \%$ or greater in local areas. Carefully observe the keyways (if there are any) for corrosion.

A FLEXIBLE COUPLING is an internal gear (Figure 56). A small amount of lateral movement of the coupling may occur in a flexible type coupling. A RIGID COUPLING is one for which no movement should occur, either in the lateral direction or with respect to the shaft. Rigid couplings are often bolted together.

Observe the shaft and hub when the operating equipment starts and stops. Record if there is any RELATIVE MOVEMENT BETWEEN THE INPUT SHAFT AND the HUB. Also record any RELATIVE MOVEMENT BETWEEN THE OUTPUT SHAFT AND the HUB. If either distress is marked yes, record if THE MOVEMENT IS EXCESSIVE. If the coupling has a keyway, and the key is loose or there is obvious long-term movement, the movement is excessive. 


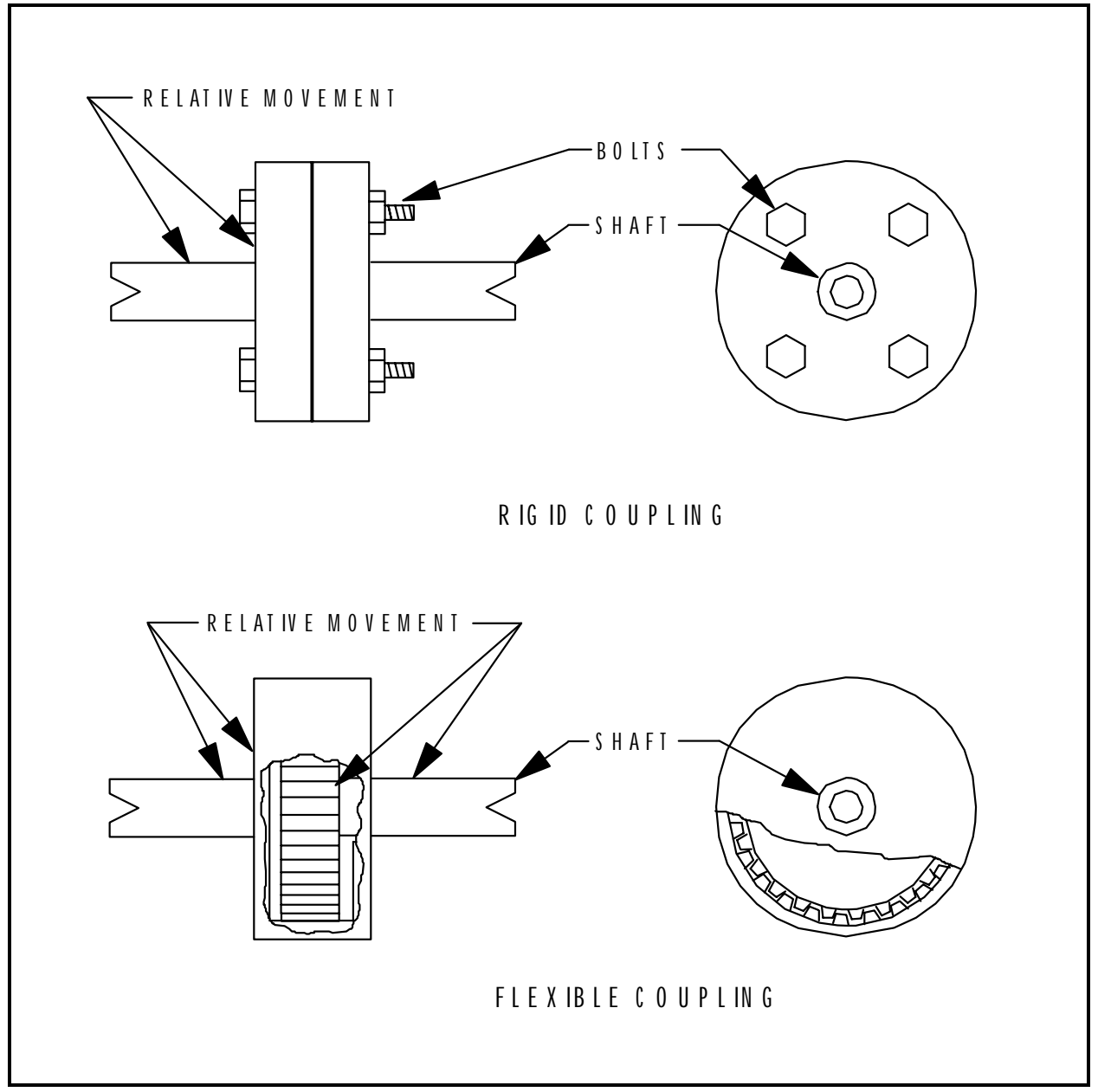

Figure 56. Coupling relative movement measurement.

\subsection{Condition Index}

The following section contains the rules for calculating the individual CIs for the coupling assembly distresses. Distress descriptions and example illustrations are also provided.

\section{Noise, Jumping, and Vibration}

See noise, jumping, and vibration for the exposed gear assembly (Chapter 4, p 51).

\section{Cracks}

See cracks for the exposed gear assembly (Chapter 4, p 54). 


\section{Corrosion}

See corrosion for the strut arm assembly (Chapter 4, p 101).

\section{Input Shaft and Hub Movement}

Definitions and causes. As the coupling becomes worn, relative movement between the input shaft and the hub begins to take place. As this wear becomes worse, the potential for failure becomes greater. Relative movement can be caused by normal use, inadequate lubrication, or corrosion.

Measurements and limits. If relative movement between the input shaft and hub are observed, it is recorded in the inspection form. If relative movement is observed, the CI will be 70. If the movement is excessive, the CI will be 40 . Example: Relative movement between the input shaft and hub was observed on a coupling assembly. The CI for the relative movement between input shaft and hub is:

$$
c 1=70
$$

The CI is rated Good.

\section{Output Shaft and Hub Movement}

See input shaft and hub movement for the coupling assembly (above).

\section{Assembly Cl}

The assembly CI will be calculated with Equations 2.2, 2.5, and 2.6 (See Chapter 2, Assembly Distress). The three critical distresses in the coupling assembly are the cracks distress, the relative movement between the input shaft and hub distress, and the relative movement between the output shaft and the hub distress. The CIs from the remaining two distresses will be used to calculate the weighted $\mathrm{CI}_{\mathrm{w}}$ (Equation 2.5). The weighting factors for those two distresses are in Table 21.

\subsection{Field Test}

The bar chart in Figure 57 compares the experts' only subjective CI from the field tests with the CI calculated from the rules in Section 12.3 for the one 
coupling distress type inspected and rated. Only data from assemblies with observed distresses are plotted. Comparisons between the calculated and experts' CIs are summarized below.

\section{Noise, Jumping, and Vibration}

The noise, jumping, and vibration distress was not calibrated because no noise, jumping, or vibration in couplings was detected. Hence, the calculated CIs were all 100, and the experts' average CIs were 90 or above. The noise, jumping, and vibration distress was calibrated in the enclosed gear assembly and those calculated CIs closely approximated the experts' average CIs.

\section{Cracks}

The cracks distress was not calibrated because no cracks were observed in the couplings. Hence, the calculated CIs were all 100, and the experts' average CIs were 90 or above. Although this distress was not calibrated, the experts felt that cracks in the coupling were critical and should be repaired, which corresponds well to Section 4.3.

\section{Corrosion}

The corrosion distress was not calibrated because corrosion was not observed in couplings. Hence, the calculated CIs were all 100, and the experts' average CIs were 90 or above. The corrosion distress was calibrated in the strut

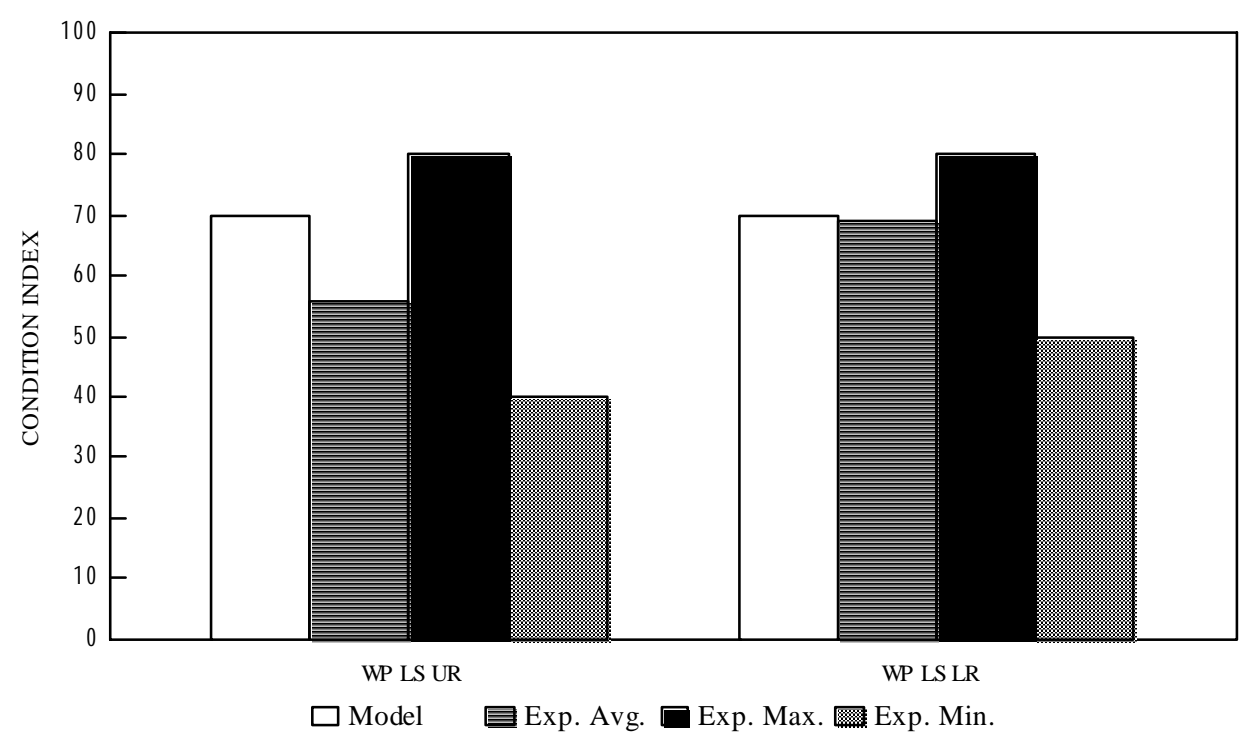

Figure 57. Input shaft and hub movement: coupling assembly. 
assembly, and the calculated CIs closely approximated the experts' average CIs.

\section{Input Shaft and Hub Movement: Figure 57}

Figure 57 shows CI ratings for relative movement between input shaft and hub distress for two sector lock gate operating equipment assemblies, both located at W.P. Franklin. Relative movement was observed in couplings between the reduction gear box shaft and the cable drum shaft. The experts' average $\mathrm{CI}$ for the coupling on the Upper Right Lock Gate is lower than the calculated CI. For the coupling on the Lower Right Lock Gate, the relative movement was less noticeable than on the Upper Right Lock Gate; hence, the experts' average CI was higher, and matched the calculated CI more closely.

\section{Output Shaft and Hub Movement}

The relative movement between output shaft and hub distress was not calibrated because no relative movement between the output shaft and hub in couplings was detected. Hence, the calculated CIs were all 100, and the experts' average CIs were 90 or above. The relative movement between input shaft and hub was calibrated (Section 12.4).

\section{Assembly Cl}

The coupling assembly was not one of the assemblies on the inspection form during the field test at the Jacksonville District; therefore, the experts did not subjectively rate the coupling assembly $\mathrm{CI}$ for the two cases where relative movement was observed. Although the combined CI could not be calibrated for the coupling assembly, the weighting factors used to calculate the assembly CI were obtained from the experts (Table 21). 


\section{Summary and Recommendations}

The inspection and rating procedures described in the previous chapters were kept as simple as possible. Most of the inspection procedures require simple tools such as a tape measure, a dial gage, a ruler, a caliper, or a pry bar. In all cases, the inspection procedure can be accomplished with little interference to normal lock and dam operations.

An inspection form, written to accommodate the inspection procedure, was completed in two sections. On the first, historical information, maintenance history, and current operating characteristics are recorded. Field measurements found during the inspection procedure are recorded in the second section.

After field measurements are obtained, computer software will be written to generate the CI for each of the individual distresses and for each assembly. The $\mathrm{CI}$ is a number between 0 and 100 that quantifies the current condition of the assembly. The CIs generated with the software are used to determine when maintenance or rehabilitation is required. The rules used for the computation of the CIs were developed with the help of Army Corps of Engineers experts.

CIs are calculated for the individual distresses associated with each assembly. The distress CIs are used to calculate the assembly CIs using the minimum of a weighted average or the individual CI of a distress considered critical to the structural stability of the assembly.

Field tests were conducted at 16 lock and dam facilities during three trips. Revisions to the inspection and rating procedures and to the inspection forms were completed following each of the field tests. 


\section{References}

Committee of Wire Rope Producers. 1979. Wire Rope Users Manual, American Iron and Steel Institute, Washington D.C. 20036

Department of the Army Hydroelectric Design Center, North Pacific Division, Army Corps of Engineers. 1993. Condition Rating Procedures/Condition Indicator for Hydropower Equipment, Army Corps of Engineers, Portland, Oregon.

Greimann, L., and J. Stecker, December 1990. Maintenance and Repair of Steel Sheet Pile Structures, Technical Report REMR-OM-9/ADA2231916. U.S. Army Corps of Engineers, Washington, D.C.

Greimann, L., J. Stecker, and K. Rens, December 1990. Management System for Miter Lock Gates, Technical Report REMR-OM-08/ADA231469. U.S. Army Corps of Engineers, Washington, D.C.

Greimann, L., J. Stecker, and K. Rens, September 1993. Condition Rating Procedures for Sector Gates, Technical Report REMR-OM-13/ADA279299, U.S. Army Corps of Engineers, Washington, D. C.

Greimann, L., J. Stecker, and J. Veenstra, March 1994. Condition Rating Procedures for Tainter and Butterfly Valves, Technical Report REMR-OM-14/ADA279326, U.S. Army Corps of Engineers, Washington, D.C.

Greimann, L., J. Stecker, and M. Nop, September 1995. Condition Rating Procedures for Tainter Dam and Lock Gates, Technical Report REMR-OM-17/ADA303294, U.S. Army Corps of Engineers, Washington, D.C.

Shigley, J., and C. Mischke, 1989. Mechanical Engineering Design, Fifth Edition, McGraw-Hill Inc., New York, NY.

U.S. Army Corps of Engineers. 1987. Safety and Health Requirements Manual, Engineer Manual 385-1-1. U.S. Army Corps of Engineers, Washington, D.C.

Wilson, C., and J. Sadler, 1993. Kinematics and Dynamics of Machinery, Second Edition, Harper Collins College Publishers, New York, NY. 


\section{Appendix A Bushing Wear Jacking Procedure}

\section{Introduction}

The procedure and calculations described in this appendix can be used to further evaluate the bushing wear in large horizontal gears if tipping is evident. When applying the following technique, care must be taken not to apply too much force to the gear. Overloading the gear during the jacking procedure could cause serious damage to the bushing system. This procedure should never be performed on gears with bearings, as damage may occur.

\section{Procedure}

Place three dial gages to measure the vertical displacement in the gear (Figure A1). Place one dial gage at the center of the gear. The remaining two dial gages should be placed an approximately equal distance, $\mathrm{X}_{1}$ and $\mathrm{X}_{2}$, from the center of the gear and as close to 180 degrees from each other as possible (Figure A1). To prevent errors in readings, place all dial gage plungers in the same direction. Record the initial dial readings for all dial gages. Place a jack near one of the dial gages and begin jacking. Precaution should be taken while jacking the gear to ensure overloading does not occur. Record the dial gage readings after jacking (Figure A2). Next, release the jack and again take the dial gage readings. Place the jack 180 degrees from the initial position (near the other dial gage) and again jack and record the dial gage readings (Figure A3). Release the jack and record the dial gage readings. 


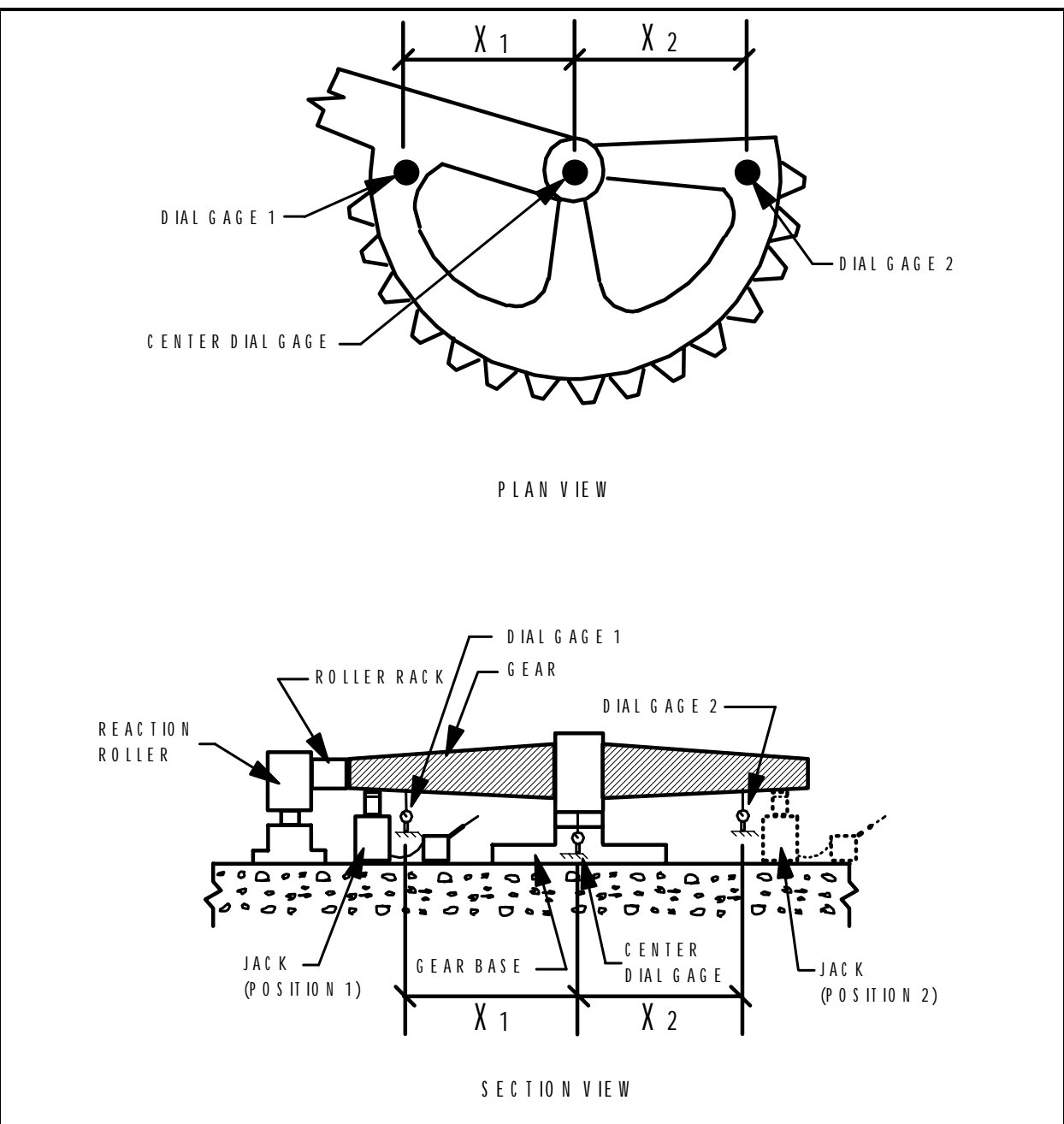

Figure A1. Bushing wear measurement.

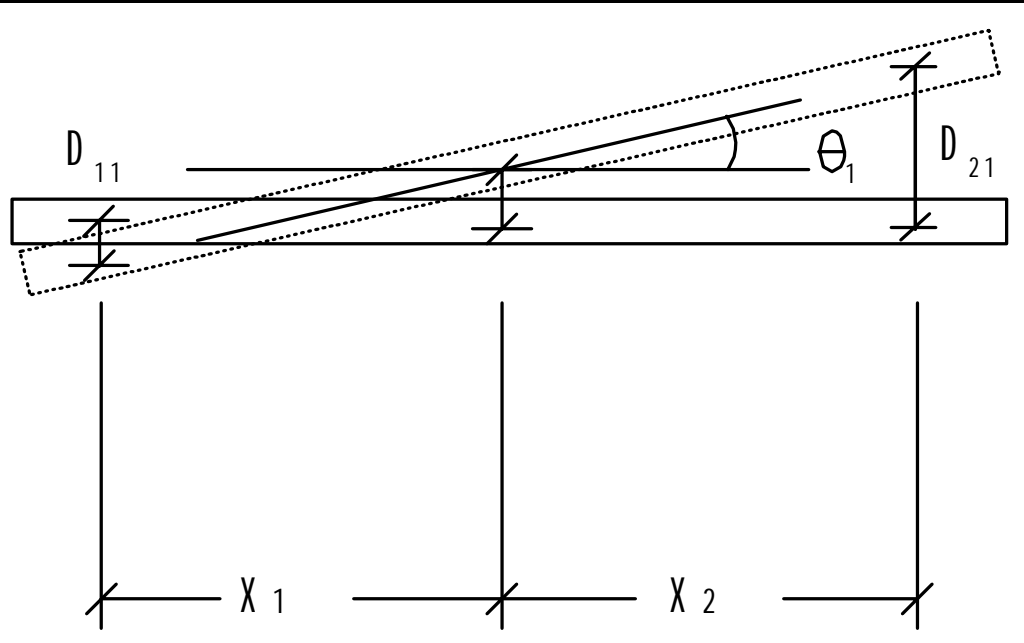

Figure A2. Vertical displacements when jacked on Side 1. 


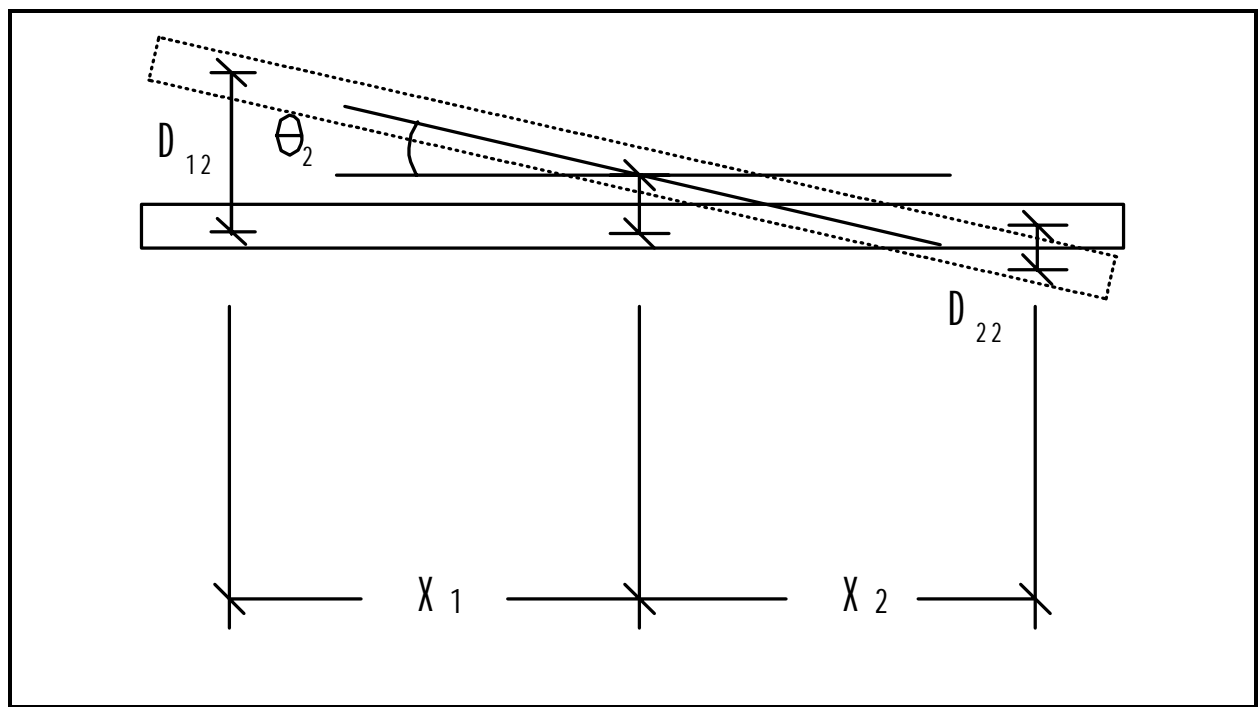

Figure A3. Vertical displacements when jacked on Side 2.

\section{Calculations}

If no bowing occurs in the gear, the total angle of rotation of the gear during the procedure, $\theta$, is found by calculating $\theta_{1}$ (the angle caused by jacking at position 1) and $\theta_{2}$ (the angle caused by jacking at position 2):

$$
\theta=\theta_{1}+\theta_{2}
$$

The following equation can be used to calculate $\theta_{1}$ :

$$
\theta_{1}=\left(D_{11}-D_{21}\right) /\left(X_{1}+X_{2}\right)
$$

where $D_{11}$ is the difference in dial gage 1 readings between the initial gear position and the gear position after the being jacked at position 1 ,

$$
D_{11}=\text { Gage } 1 \text { reading (initial) - Gage } 1 \text { reading (jacked at 1) }
$$

where $D_{21}$ is the difference in dial gage 2 readings between the initial gear position and the gear position after the being jacked at position 1 ,

$$
\mathrm{D}_{21}=\text { Gage } 2 \text { reading (initial) - Gage } 2 \text { reading (jacked at 1) }
$$

Similarly, for $\theta_{2}$

$$
\theta_{2}=\left(D_{12}-D_{22}\right) /\left(X_{1}+X_{2}\right)
$$


where $D_{12}$ is the difference in dial gage 1 readings between the initial gear position and the gear position after the being jacked at position 2 ,

$$
D_{12}=\text { Gage } 1 \text { reading (initial) - Gage } 1 \text { reading (jacked at 2) }
$$

where $\mathrm{D}_{22}$ is the difference in dial gage 2 readings between the initial gear position and the gear position after the being jacked at position 2 ,

$$
D_{22}=\text { Gage } 2 \text { reading (initial) - Gage } 2 \text { reading (jacked at 2) }
$$

Assuming that there is no bowing of the gear, the calculated displacement at the center of the gear, $\mathrm{D}_{\text {CenterCalculated }}$, should be equal to the average of the displacements of the dial gages located 180 degrees from each other, $D_{1}$ and $D_{2}$ :

$$
\mathrm{D}_{\text {CenterCalculated }}=\left(\mathrm{D}_{1}+\mathrm{D}_{2}\right) / 2
$$

If, however, bowing of the gear does occur, $\mathrm{D}_{\text {CenterCalculated }}$ will not be equal to the measured displacement at the center, $\mathrm{D}_{\text {CenterMeasured }}$ (Figure A4). To prevent bowing, which introduces stresses into the gear, the jacking should not continue if $\mathrm{D}_{\text {CenterMeasured }}$ varies significantly from $\mathrm{D}_{\text {CenterCalculated. If bowing has occurred, too }}$ much force is being applied to the gear during the jacking procedure.

\section{Limits}

The limiting value for vertical displacement of an exposed gear that rotates on a bushing is 1/16 in. per foot of gear radius. This corresponds to an angle of rotation of 0.0026 radians or 0.15 degrees.

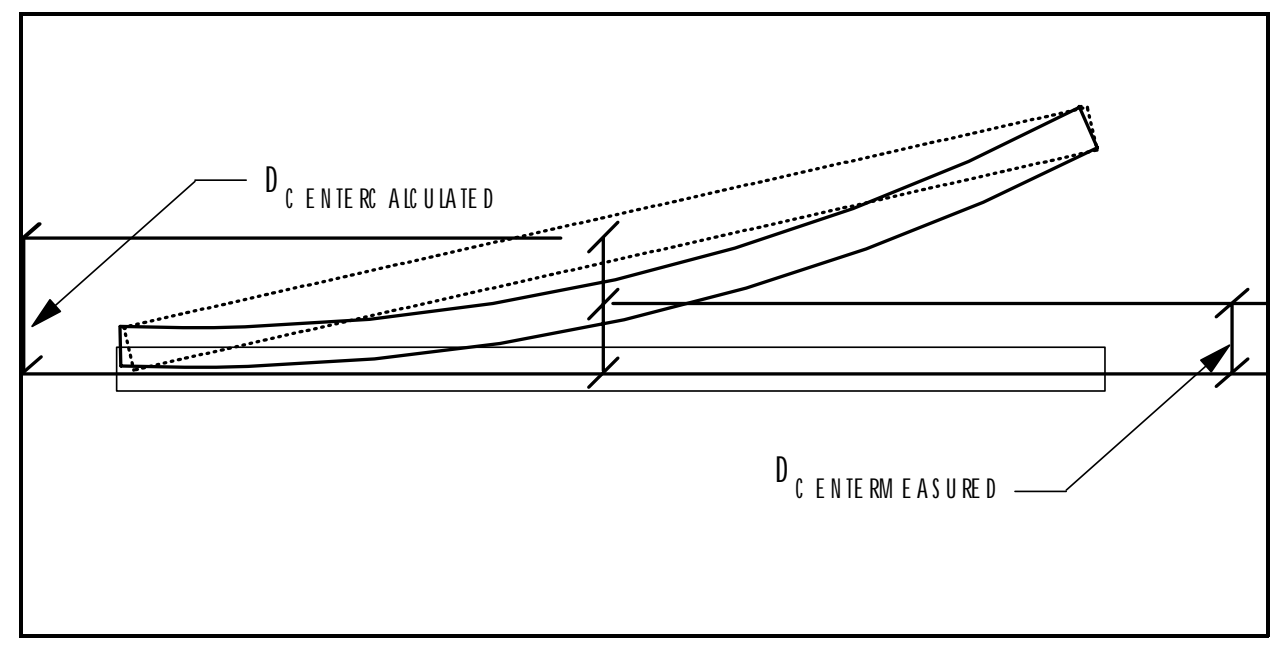

Figure A4. Displaced shape of gear (bowed and unbowed). 


\section{Appendix B \\ Gear Tooth Wear Measuring Procedures}

\section{Introduction}

If the estimated percentage of tooth thickness reduction from the new tooth thickness is 10 percent or greater, the tooth should be measured to get a more precise estimate of tooth wear. This appendix explains tooth thickness measurement techniques.

\section{Gear and Rack Tooth Identification}

To inspect and rate gear and rack tooth wear, familiarity with the nomenclature used in describing gear and rack teeth is necessary; definitions for the various tooth relationships are presented in the following paragraphs and shown in Figure B1.

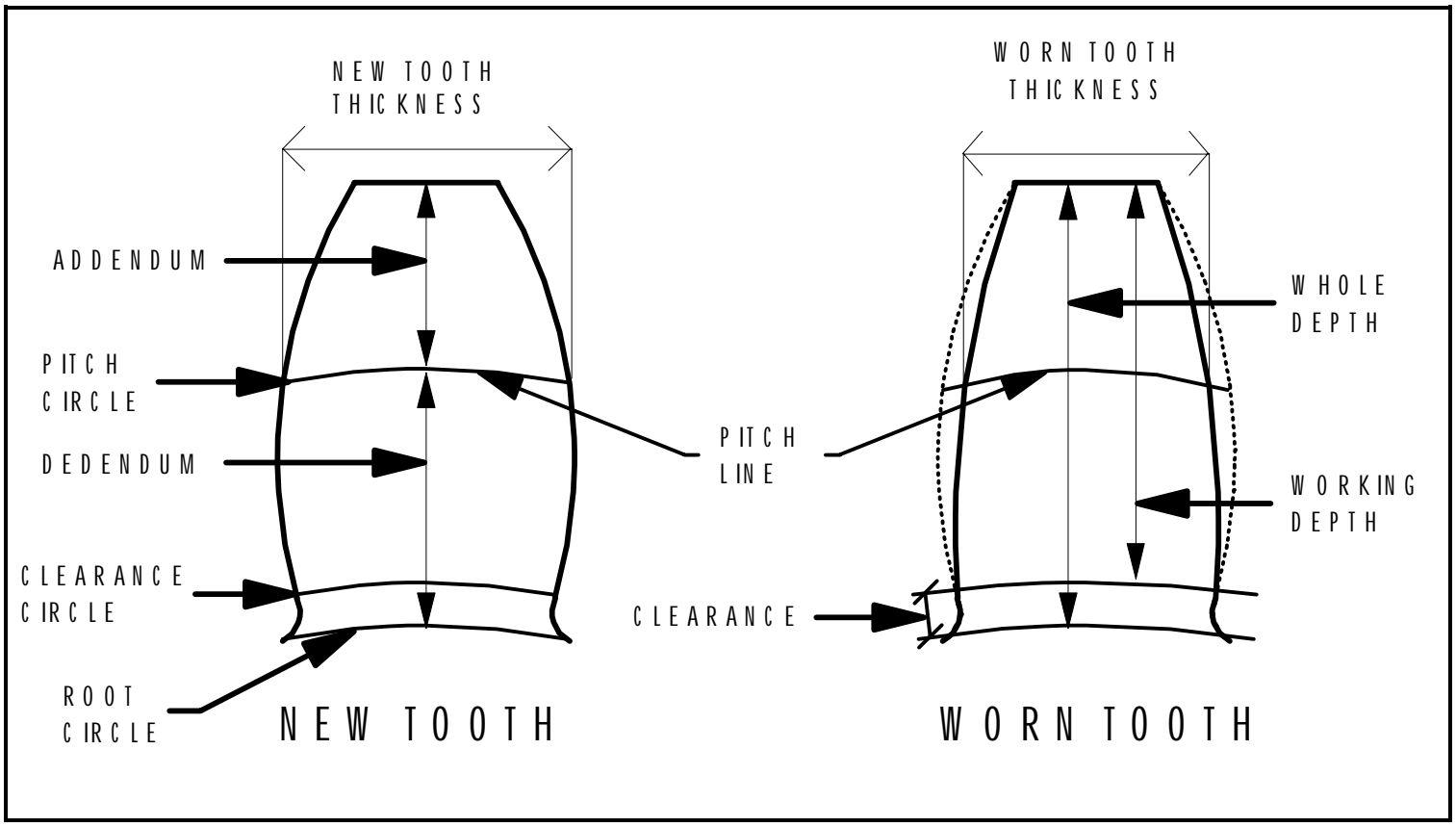

Figure B1. Gear tooth dimensions and wear measurement. 


\section{Addendum}

The radial distance from the pitch line to the top of the gear.

\section{Dedendum}

The radial distance from the pitch line to the root circle.

\section{Clearance}

The radial distance from the clearance circle to the root circle.

Whole Depth

The radial distance between the root circle and the top of the gear.

\section{Tooth Thickness}

The width of the tooth at the pitch line.

\section{Working Depth}

The radial distance from the top of the gear to the clearance circle.

\section{Diametral Pitch (DP)}

The number of teeth of a gear divided by the diameter of the pitch circle in inches.

\section{Circular Pitch (CP)}

The arc distance measured along the pitch circle from a point on one tooth to the corresponding point on the adjacent tooth of the gear. The following equation relates the diametral and circular pitch: $\pi=(\mathrm{CP})(\mathrm{DP})$.

\section{Root Circle}

The circle drawn through the bottom of the gear tooth. 


\section{Clearance Circle}

The largest circle centered at the gear center, which is not penetrated by the teeth of the mating gear.

\section{Pitch Circle}

The circle on a gear that corresponds to the center of the working depth.

Table B1 shows the relationship between the DP and the addendum, the dedendum, the clearance, the whole depth, and the tooth thickness for six commonly used standard gear profile systems.

\section{Procedure 1}

Begin by finding the tooth pitch line. In some cases, the pitch line is scribed on the tooth during the manufacturing process. If the pitch line can be seen, place a caliper on the top of the tooth with a spacer placed between the caliper and the top of the tooth (Figure B2). The caliper points should be on the pitch line, one on each side of the tooth. With the caliper now at the correct depth, slide the caliper along the length of the tooth. Find the location of the tooth where the tooth thickness at the pitch line is the smallest. Record this measurement. If the pitch line is not scribed on the tooth, calculate the addendum of the tooth by use of the construction drawings and Table B1. As shown on Figure B1, the addendum is the distance from the top of the tooth to the pitch line. Use the addendum to calculate the required spacer thickness. With the spacer in place, follow the same procedure as described

Table B1. Gear tooth relationships.

\begin{tabular}{|l|l|l|l|l|l|}
\hline \multicolumn{1}{|c|}{ System } & Addendum & Dedendum & Clearance & $\begin{array}{c}\text { Whole } \\
\text { Depth }\end{array}$ & $\begin{array}{c}\text { Tooth } \\
\text { Thickness }\end{array}$ \\
\hline $\begin{array}{l}141 / 2 \text { full-depth } \\
\text { involute }\end{array}$ & $1 / \mathrm{DP}$ & $1.157 / \mathrm{DP}$ & $0.157 / \mathrm{DP}$ & $2.157 / \mathrm{DP}$ & $1.571 / \mathrm{DP}$ \\
\hline $14 \mathrm{1} / 2$ composite & $1 / \mathrm{DP}$ & $1.157 / \mathrm{DP}$ & $0.157 / \mathrm{DP}$ & $2.157 / \mathrm{DP}$ & $1.571 / \mathrm{DP}$ \\
\hline $\begin{array}{l}20 \text { full-depth } \\
\text { involute (coarse } \\
\text { pitch) }\end{array}$ & $1 / \mathrm{DP}$ & $1.25 / \mathrm{DP}$ & $0.25 / \mathrm{DP}$ & $2.25 / \mathrm{DP}$ & $1.571 / \mathrm{DP}$ \\
\hline $\begin{array}{l}20 \text { full-depth } \\
\text { involute (fine pitch) }\end{array}$ & $1 / \mathrm{DP}$ & $\begin{array}{l}1.2 / \mathrm{DP}+ \\
0.002 \text { in }\end{array}$ & $\begin{array}{l}0.2 / \mathrm{DP}+ \\
0.002 \text { in }\end{array}$ & $\begin{array}{l}2.2 / \mathrm{DP}+ \\
0.002 \text { in }\end{array}$ & $1.571 / \mathrm{DP}$ \\
\hline $\begin{array}{l}20 \text { stub-tooth } \\
\text { involute }\end{array}$ & $0.8 / \mathrm{DP}$ & $1 / \mathrm{DP}$ & $0.2 / \mathrm{DP}$ & $1.8 / \mathrm{DP}$ & $1.571 / \mathrm{DP}$ \\
\hline $\begin{array}{l}25 \text { full-depth } \\
\text { involute }\end{array}$ & $1 / \mathrm{DP}$ & $1.25 / \mathrm{DP}$ & $0.25 / \mathrm{DP}$ & $2.25 / \mathrm{DP}$ & $1.571 / \mathrm{DP}$ \\
\hline
\end{tabular}




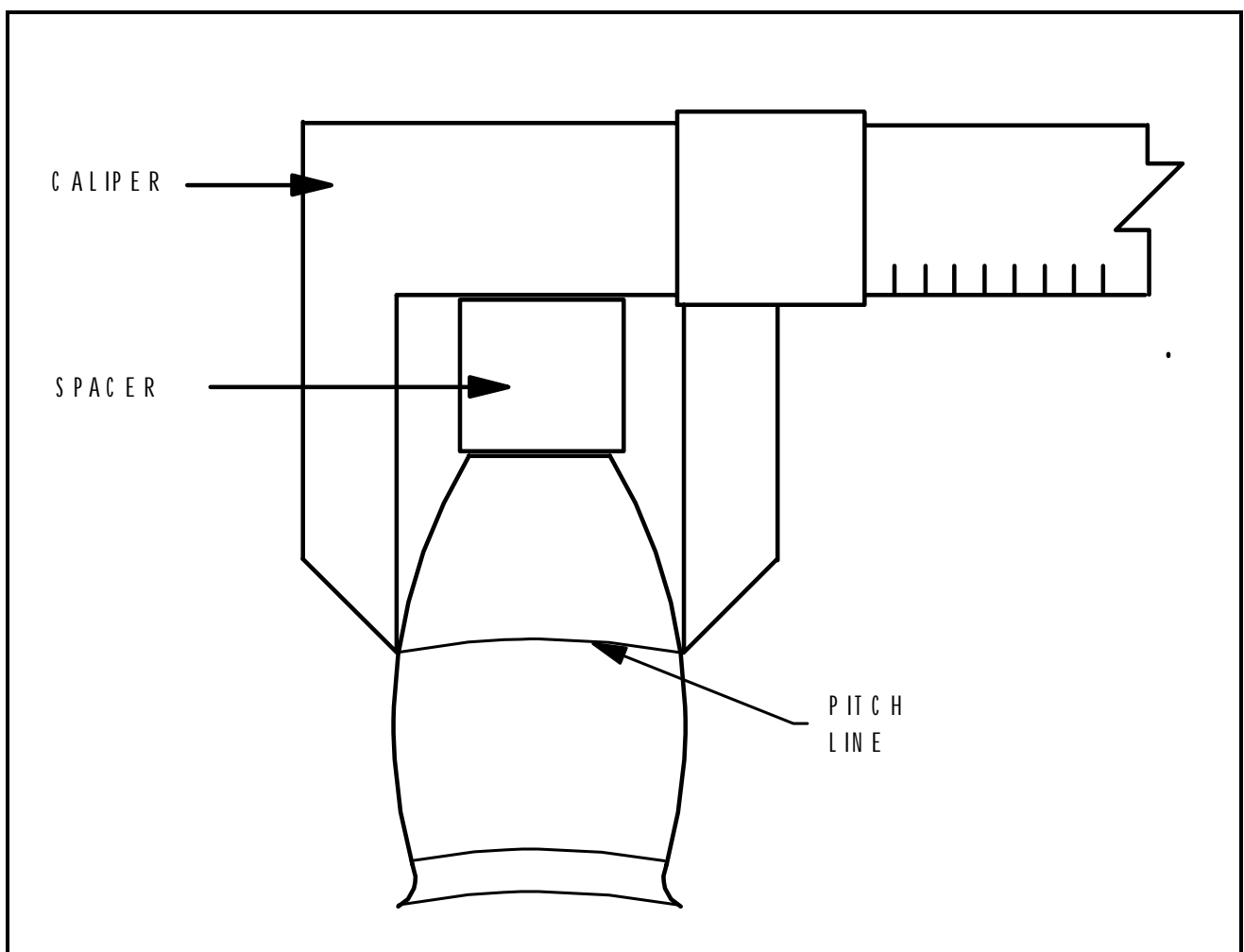

Figure B2. Gear tooth wear measurement: Procedure 1.

above. Next, calculate the new tooth thickness. The new tooth thickness can be calculated from the DP, which can be found in construction drawings, and Table B1. In some cases, the CP may be listed in the construction drawings instead of the DP. The relationship between the $\mathrm{CP}$ and the DP can be found in the gear tooth definitions.

\section{Procedure 2}

If gear tooth templates are available during the inspection, place the template between gear teeth. With the use of feeler gages, measure the gap between the template and the gear tooth at the pitch line. If the pitch line is not scribed on the tooth, locate the pitch line by calculation of the addendum as described in Procedure 1.

\section{Calculations}

If the estimated reduction of tooth thickness is 10 percent or greater, the measured thickness reduction should be entered in Part 2 of the inspection form for the Exposed Gear Assembly and the Rack Assembly. The percentage of tooth 
thickness loss can be calculated using the following equation if Procedure 1 was used.

$$
\% \text { thickness reduction }=1-(\text { Worn thickness }) /(\text { New thickness })
$$

If Procedure 2 was used, the following equation will calculate the percentage of tooth thickness loss.

$\%$ thickness reduction $=($ Measured Gap $) /($ New Thickness $)$

\section{Examples}

\section{Calculation of the Addendum(Location of the Pitch Line)}

The pitch line of a tooth can be found by calculating the addendum of the tooth using Table B1. The distance from the top of the tooth to the pitch line is the addendum. A 20-degree involute stub tooth gear with a diametral pitch of 0.75/in. was inspected. The addendum of the tooth is:

$$
\text { addendum }=(0.8) /(.75 / \text { in. })=1.067 \mathrm{in} \text {. }
$$

The distance from the top of this tooth to the pitch line is equal to $1.067 \mathrm{in}$.

\section{Calculation of New Tooth Thickness}

The construction drawings of a gear that is being inspected show $\mathrm{P}=1.5 / \mathrm{in}$. From the last column of Table B1, the tooth thickness for the gear is:

$$
\text { tooth thickness }=(1.5708) /(1.5 / \text { in. })=1.0472 \text { in. }
$$

\section{Relationship Between CP and DP}

Construction drawings show $\mathrm{CP}=3.1416$ for an exposed reduction gear. The corresponding DP is:

$$
D P=(\pi) /(3.1416)=1
$$

Note: For helical and herringbone (double helical) gears, the same relationships apply (Shigley and Mischke 1989). Helical and herringbone gears are generally coarse pitched; therefore, if this information is not given, assume it is coarse pitched. 
If the pressure angle is not given, the standard helical gear has the same relationships as the 20-degree, coarse pitch gear shown in Table B1. 